\title{
Summaries of FY 92 Geosciences Research
}

\section{December 1992}

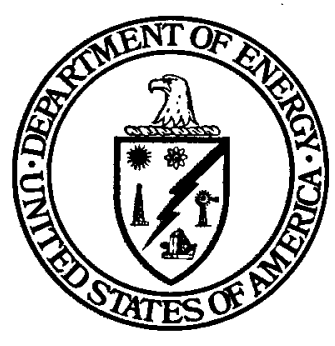

\section{U.S. Department of Energy}

Office of Energy Research

Division of Engineering \& Geosciences

Washington, D.C. 20585

\section{MASTER}




\section{DISCLAIMER}

This report was prepared as an account of work sponsored by an agency of the United States Government. Neither the United States Government nor any agency Thereof, nor any of their employees, makes any warranty, express or implied, or assumes any legal liability or responsibility for the accuracy, completeness, or usefulness of any information, apparatus, product, or process disclosed, or represents that its use would not infringe privately owned rights. Reference herein to any specific commercial product, process, or service by trade name, trademark, manufacturer, or otherwise does not necessarily constitute or imply its endorsement, recommendation, or favoring by the United States Government or any agency thereof. The views and opinions of authors expressed herein do not necessarily state or reflect those of the United States Government or any agency thereof. 


\section{DISCLAIMER}

Portions of this document may be illegible in electronic image products. Images are produced from the best available original document. 
Hins 


\section{CONTENTS}

FOREWORD $\ldots \ldots \ldots \ldots \ldots \ldots \ldots \ldots \ldots \ldots \ldots \ldots \ldots \ldots \ldots \ldots \ldots \ldots$

\section{THE GEOSCIENCES RESEARCH PROGRAM IN THE OFFICE}

OF BASIC ENERGY SCIENCES $\ldots \ldots \ldots \ldots \ldots \ldots \ldots \ldots \ldots$ xiv

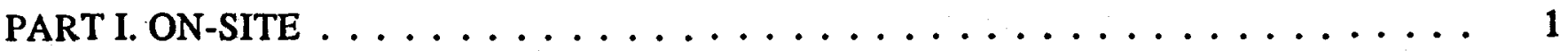

ARGONNE NATIONAL LABORATORY $\ldots \ldots \ldots \ldots \ldots \ldots$

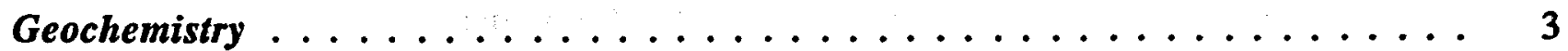

A. Hydrothermal System Evolution $\ldots \ldots \ldots \ldots \ldots \ldots \ldots \ldots \ldots \ldots \ldots$

B. Isotopic Organic Geochemistry . . . . . . . . . . . . . 4

C. Mineral-Fluid Interactions . . . . . . . . . . . . . . 4

BROOKHAVEN NATIONAL LABORATORY $\ldots \ldots \ldots \ldots \ldots$

Geophysics and Earth Dynamics .................... 5

A. Three-Dimensional Imaging of Drill Core Samples Using Synchrotron

Computed Microtomography . . . . . . . . . . . . . . 5

Geochemistry ........................ 5

A. Geochemistry of Organic Sulfur in Marine Sediments ........... 5

IDAHO NATIONAL ENGINEERING LABORATORY . . . . . . . . . . . 7

Energy Resource Recognition, Evaluation, and Utilization . . . . . . . . . . 7

A. Volcanic Stratigraphy of New Idaho National Engineering $\quad \ldots \ldots \ldots \ldots \ldots \ldots \ldots \ldots$

LAWRENCE BERKELEY LABORATORY $\ldots \ldots \ldots \ldots \ldots \ldots \ldots \ldots$

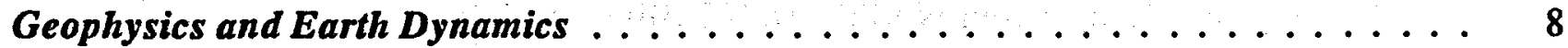

A. High-Resolution Imaging of Electrical Conductivity . . . . . . . . . 8

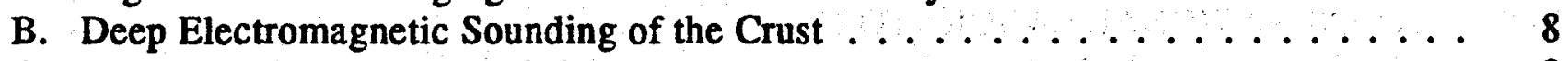

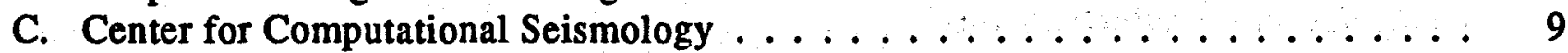

D. Microcrack Growth in Rock . . . . . . . . . . . . . . . . . . . 9

E. Process Definition in Fractured Hydrocarbon Reservoirs . . . . . . . . . . 10

F. Coupled Thermal-Hydraulic-Mechanical Processes in $\quad \ldots \ldots \ldots \ldots \ldots \ldots \ldots \ldots$

G. Advanced Research Concepts . . . . . . . . . . . . . . . 11

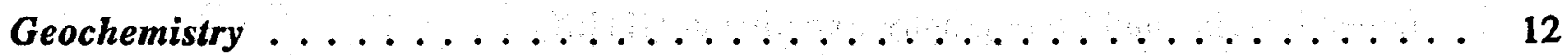

A. Thermodynamics of High-Temperature Brines . . . . . . . . . . . 12

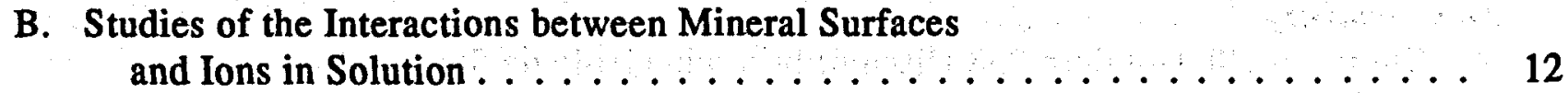

C. Chemical Transport in Natural Systems . . . . . . . . . . . . . 13

D. Center for Isotope Geochemistry . . . . . . . . . . . . . . . . . 13 
Energy Resource Recognition, Evaluation, and Utilization . . . . . . . . . . . . . 14

A. Hydrothermal Chemistry ..................... 14

B. Geophysical Measurements Facility . . . . . . . . . . . . . 15

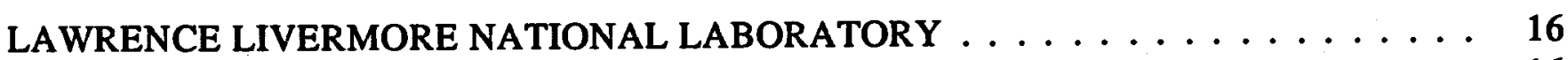

Geophysics and Earth Dynamics . . . . . . . . . . . . . . . 16

A. Rheology of Partially Molten Crustal Rocks . . . . . . . . . . . . . . . 16

B. Electrical Conductivity, Temperature, and Radiative Transport in the Earth . . . . 16

C. Seismic Transmission Imaging . . . . . . . . . . . . . . . . . 17

D. Modification of Fracture Transport Properties of Rocks by

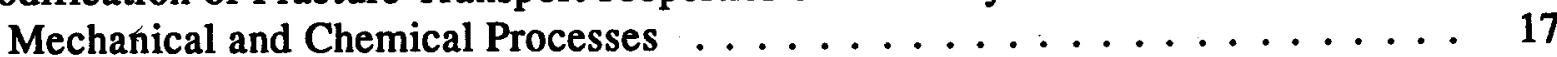

E. Quantitative Image Analysis to Determine Rock Properties . . . . . . . . . . . . . 18

F. Nonlinear Sources for Seismic Imaging-Rock Properties . . . . . . . . . . . 18

G. Poroelasticity of Rock . . . . . . . . . . . . . . . . . . . 19

H. Oxygen and Cation Diffusion in Oxide Minerals . . . . . . . . . . . . . . 19

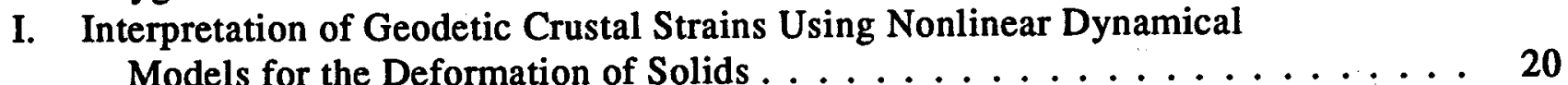

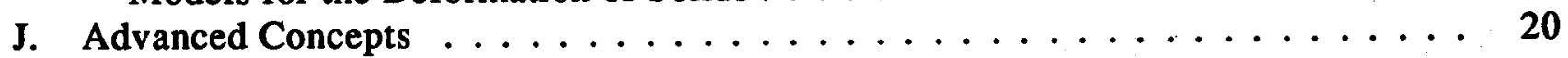

Geochemistry ............................ 21

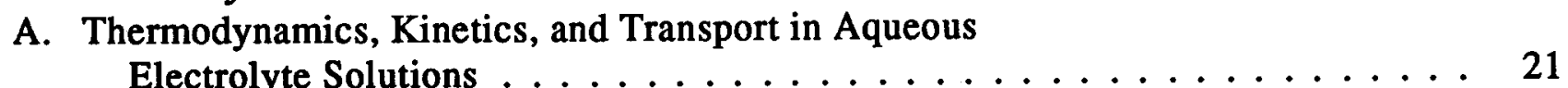

B. Compositional Kinetic Model of Petroleum Formation . . . . . . . . . . . . 21

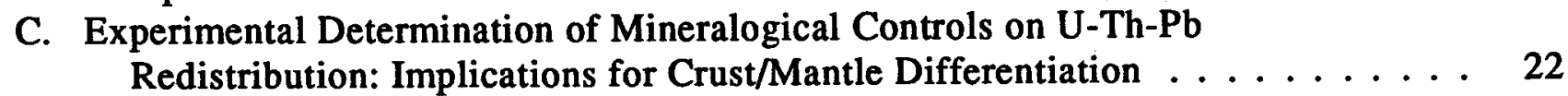

Energy Resource Recognition, Evaluation, and Utilization . . . . . . . . . . 22

A. Katmai Resistivity Studies . . . . . . . . . . . . . . . . . . 22

B. New Approaches to Underground Imaging . . . . . . . . . . . . . 23

C. Investigation of Active Processes in Long Valley Caldera Using the Magma

Energy Deep Exploration Well Phase II Drilling Activities . . . . . . . . . . . 24

LOS ALAMOS NATIONAL LABORATORY $\ldots \ldots \ldots \ldots \ldots \ldots \ldots \ldots$

Geophysics and Earth Dynamics . . . . . . . . . . . . . . . . 25

A. Electrical Conductivity, Temperature, and Radiative Transport

in the Earth . . . . . . . . . . . . . . . . . . 25

B. Nonlinear Generation of Acoustic Beams . . . . . . . . . . . . . . 25

C. Nonlinear Sources for Seismic Imaging . . . . . . . . . . . . . . . 26

D. Imaging of Reservoirs and Fracture Systems Using Microearthquakes

Induced by Hydraulic Injections . . . . . . . . . . . . . . . . . 26

E. Jemez Imaging and Tomography Experiment (JITEX) . . . . . . . . . . . . 27

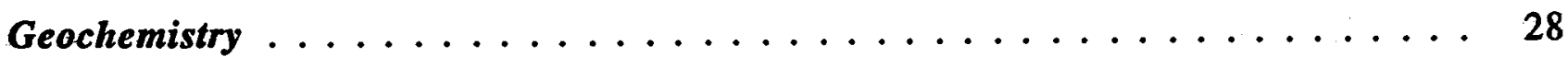

A. Thorium-230-Uranium-238 Disequilibrium in Geologic Systems

Using Solid Source Mass Spectrometry . . . . . . . . . . . . . 
B. Thermodynamic Properties of Aqueous Solutions at High

Temperatures and Pressures . . . . . . . . . . . . . . 28

C. Dynamics of Rock Varnish Formation

D. Geochemistry of Technetium . . . . . . . . . . . . . . . . 29

E. Rock-Water Interactions and Element Migration . . . . . . . . . . 30

F. A Search for Evidence of Large Comet or Asteroid Impacts

at Extinction Boundaries . . . . . . . . . . . . . . 31

G. Direct Speciation of Metal Ions by Optical Spectroscopies . . . . . . . . 31

Energy Resource Recognition, Evaluation, and Utilization . . . . . . . . . . . 32

A. Core Hold VC-2B: Scientific Drilling to Investigate Caldera Processes,

Hydrothermal Dynamics, and Mineralization, Sulphur Springs

Geothermal System, Valles Caldera Magma-Hydrothermal System,

New Mexico . . . . . . . . . . . . . . . . . . . 32

B. Hydrogeochemistry of Nevada Oil Field Waters and Brines . . . . . . . . 32

C. Operation of a Sample Management System for the Continental

Scientific Drilling Program .................... 33

D. Intracaldera Processes Creede Caldera, San Juan

Volcanic Field, Colorado . . . . . . . . . . . . . . . . 33

Solar-Terrestrial Interactions . . . . . . . . . . . . . . 33

A. Energy Transport in Space Plasma . . . . . . . . . . . . . . . 34

B. The Solar Wind-Magnetospheric Interaction $\ldots \ldots \ldots \ldots \ldots \ldots \ldots \ldots$

C. Energetic Particle Acceleration . . . . . . . . . . . . . . . . . 34

D. Radiation from Space and Astrophysical Plasmas ............. 35

E. Advanced Concepts ....................... 35

OAK RIDGE NATIONAL LABORATORY $\ldots \ldots \ldots \ldots \ldots \ldots \ldots \ldots \ldots \ldots$

Geophysics and Earth Dynamics . . . . . . . . . . . . . . . . 37

A. Coupled Acoustic Seismic Imaging and Geochemical Studies of

Magmatic Processes ..................... 37

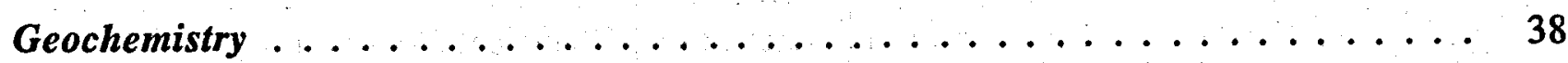

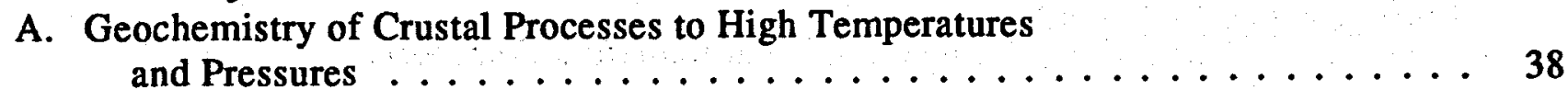

B. Crustal Stability of Hydrocarbons and C-O-H-N Fluids . . . . . . . . . . 40

C. Fundamental Research in the Geochemistry of Geothermal Systems . . . . . . . 42

D. Stable Isotope Systematics During Burial Diagenesis in the

Alberta Basin: an Ion Microprobe Study ... . . . . . . . . . . . . 43

E. Advanced Concepts ........................ 43

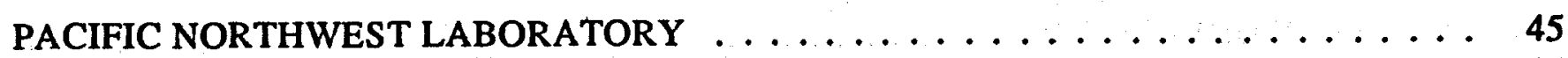

Energy Resource Recognition, Evaluation, and Utilization .......... 45

A. Remote Sensing: Geoscience Data Analysis and Integration . . . . . . . . . 45

B. Remote Geologic Analysis ... . . . . . . . . . . . . . . 46 
Solar-Terrestrial Interactions . . . . . . . . . . . . . . . . . 46

A. Department of Energy Aeronomy/Insolation Studies . . . . . . . . . . . . 47

SANDIA NATIONAL LABORATORIES . . . . . . . . . . . . . . . . . 49

Geophysics and Earth Dynamics . . . . . . . . . . . . . . . . . 49

A. Acoustic Emissions and Damage in Geomaterials . . . . . . . . . . . . . . 49

B. Transport Properties of Fractures . . . . . . . . . . . . . . . . . . . 49

C. Reservoir Characterization: Reef-Type Reservoir . . . . . . . . . . . . . 50

D. Advanced Concepts ....................... 50

E. Thirty-Third U.S. Rock Mechanics Symposium . . . . . . . . . . . . . 51

Geochemistry ........................ 52

A. Magmatic Volatiles ....................... 52

B. Cation Diffusion Rates in Selected Silicate Minerals . . . . . . . . . . . . . 52

C. Isotopic and Mineralogical Indicators of Infiltration and Vertical

Fluid Movement in Unsaturated Zones of Semiarid Terrain . . . . . . . . . 53

D. Mineral Hydrolysis Kinetics $\ldots \ldots \ldots \ldots \ldots \ldots \ldots \ldots$

Energy Resource Recognition, Evaluation, and Utilization . . . . . . . . . . 54

A. Geoscience Research Drilling Office (GRDO) . . . . . . . . . . . . . 54

B. Seismicity Induced by Hydrocarbon Production . . . . . . . . . . . . . 54

C. Investigation of Active in Long Valley Caldera Using the Magma

Energy Deep Exploration Well Phase Drilling Activities . . . . . . . . . . 55

PART II. OFF-SITE $\ldots \ldots \ldots \ldots \ldots \ldots \ldots \ldots \ldots \ldots \ldots \ldots \ldots$

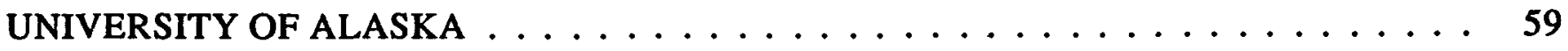

Katmai Scientific Drilling Project . . . . . . . . . . . . . . . . . . . 59

A Theoretical and Simulation Study of Magnetic Reconnection

Processes in the Magnetosphere . . . . . . . . . . . . 60

AMERICAN MUSEUM OF NATURAL HISTORY . . . . . . . . . . . . . . . 61

The Role of Carbon and Temperature in Determining Electrical Conductivity

of Basins, Crust, and Mantle . . . . . . . . . . . . . . 61

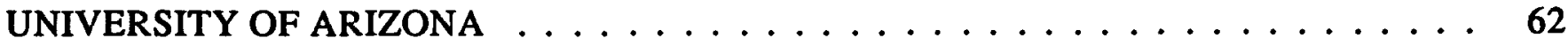

Electrochemical Determination of the Gibbs Free Energies of

Rock-Forming Minerals . . . . . . . . . . . . . . . . 62

Solar Variability Observed Through Changes in Solar Figure

and Diameter . . . . . . . . . . . . . . . . . 63

ARIZONA STATE UNIVERSITY . . . . . . . . . . . . . . . . . . 64

Organic/Inorganic Interactions of Nitrogen in Oil Fields

Part I. Geochemistry . . . . . . . . . . . . . . . . 
BROWN UNIVERSITY . . . . . . . . . . . . . . . . . . . 65

Grain Boundary Transport and Related Processes in Natural

Fine-Grained Aggregates $\ldots \ldots \ldots \ldots \ldots \ldots \ldots \ldots$

CALIFORNIA INSTITUTE OF TECHNOLOGY . . . . . . . . . . . . . 66

Infrared Spectroscopy and Hydrogen Isotope Geochemistry of Hydrous

Silicate Glasses . . . . . . . . . . . . . . . . . . . . . 66

Isotope Tracer Studies of Diffusion in Silicates and of Geological Transport

Processes Using Actinide Elements . . . . . . . . . . . . . 67

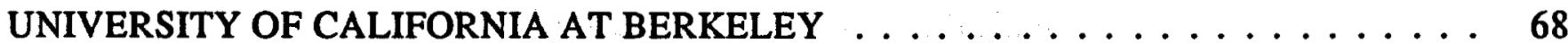

Experimental Measurement of Thermal Conductivity in Silicate Liquids . . . . . . . 68

Advective-Diffusive/Dispersive Transport of Chemically Reacting Species

in Hydrothermal Systems . . . . . . . . . . . . . . . . . . 69

Multi-station Magnetotellurics . . . . . . . . . . . . . . . . . . . 70

Isotopic Studies of Noble Gases in Terrestrial Samples and

Natural Nucleosynthesis . . . . . . . . . . . . . . . . . . . 71

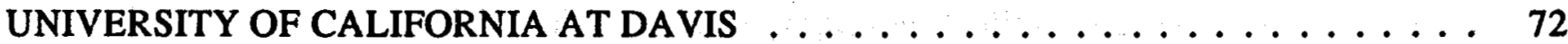

Energetics of Silicate Melts from Thermal Diffusion Studies . . . . . . . . . . 72

A New Method for Determining Thermodynamic Properties of Carbonate

Solid-Solution Minerals . . . . . . . . . . . . . . . . 73

UNIVERSITY OF CALIFORNIA AT LOS ANGELES $\ldots \ldots \ldots \ldots \ldots \ldots \ldots \ldots$

K-feldspar Thermochronology . . . . . . . . . . . . . . . . . 74

Oxygen and Cation Diffusion in Oxide Minerals . . . . . . . . . . 75

UNIVERSITY OF CALIFORNIA AT SAN DIEGO $\ldots \ldots \ldots \ldots \ldots \ldots \ldots$

Deuterium/Hydrogen Ratios and Scanning Electron Microscopy Imaging

of Fossil Organic Matter from California's Monterey Formation . . . . . . . . . 76

UNIVERSITY OF CALIFORNIA AT SANTA BARBARA . . . . . . . . . . . 77

Physical Modeling of Sedimentary Basins, Magna Mechanics, and

Molecular Dynamics of Aqueous Solutions . . . . . . . . . . . . 77

THE UNIVERSITY OF CHICAGO $\ldots \ldots \ldots \ldots \ldots \ldots \ldots \ldots \ldots \ldots \ldots \ldots \ldots \ldots$

Development of Synchrotron X-Ray Microspectroscopic Techniques

and Application to Problems in Low-Temperature Geochemistry . . . . . . . . . 78

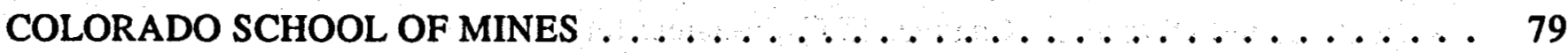

Computational Methods for Improving the Resolution of Subsurface

Seismic Images . . . . . . . . . . . . . . . . . .

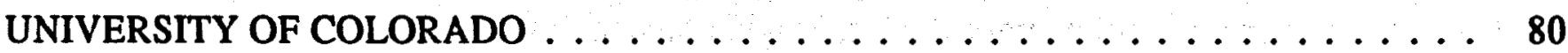

Crystal Chemistry of Hydroxyl and Water in Silicate Minerals . . . . . . . . . 80 
Seismic Absorption in Fluid-Filled Porous Rocks as a Function of

Seismic Frequencies, Pressure, and Temperature . . . . . . . . . . .

COLUMBIA UNIVERSITY

82

Seismology and Tectonics of the Eastern Aleutian Arc . . . . . . . . . . . . 82

Energetics of Silicate Melts from Thermal Diffusion Studies . . . . . . . . . 83

UNIVERSITY OF DELAWARE

Development of an Experimental Data Base and Theories For Prediction

of Thermodynamic Properties of Aqueous Electrolytes and

Nonelectrolytes of Geochemical Significance at Supercritical

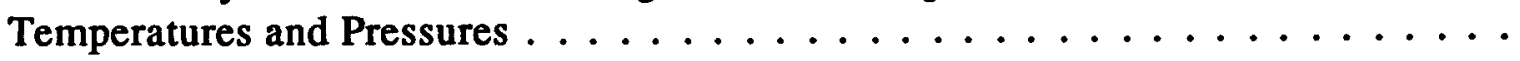

INDIANA UNIVERSITY . . . . . . . . . . . . . . . . . . . . . 85

Mechanochemical Self-Organization and Nonlinear Dynamics in

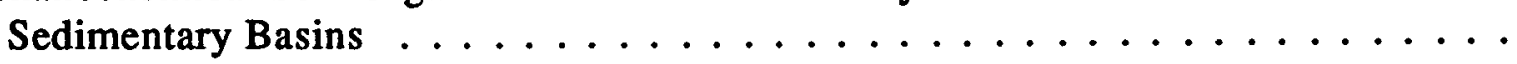

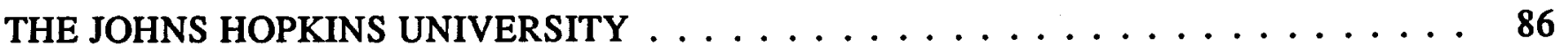

High-Resolution Transmission Electron Microscopy/Analytical Electron

Microscopy and Scanning Electron Microscopy Study of

Fluid-Rock Interactions: Interaction of Copper-, Silver-,

Selenium-, Chromium-, and Cadmium-Bearing Solutions with

Geological Materials at Near Surface Conditions, with an

Emphasis on Phyllosilicates .....................

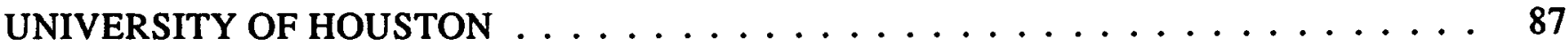

Cross Hole Geotomography in a Partially Depleted Reservoir . . . . . . . . . . . . . 87

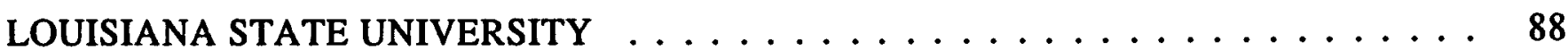

Organic/Inorganic Interactions of Nitrogen in Oil Fields

Part II.Mineralogy and Microbiology ... . . . . . . . . . . . . 88

MASSACHUSETTS INSTITUTE OF TECHNOLOGY . . . . . . . . . . . . . . . 89

In Situ Permeability Determination Using Borehole and Seismic

Logging Data . . . . . . . . . . . . . . . . . . . . . . . . . 89

Reservoir Characterization by Cross Hole Seismic Imaging . . . . . . . . . . . . 90

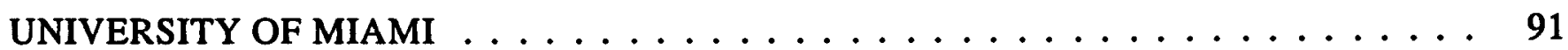

Testing the Correlation Between Sequence Stratigraphy, Seismic

Reflectors, and Diagenetic Changes in Carbonates: Implications

for the Distribution of Porosity and Permeability . . . . . . . . . . . . . . 91

UNIVERSITY OF MINNESOTA . . . . . . . . . . . . . . . . . . . . . 92

Physical Modeling of Sedimentary Basins, Magma Mechanics, and

Molecular Dynamics of Aqueous Solutions . . . . . . . . . . . . . . 
NATIONAL ACADEMY OF SCIENCES NATIONAL RESEARCH COUNCIL . . . . . . 93

Basic Energy Science Studies . . . . . . . . . . . . . . . . . . 93

UNIVERSITY OF NEW MEXICO . . . . . . . . . . . . . . . . . . . . . 96

Impact Deposits at the Manson Impact Structure: Diagenesis and

Postimpact Thermal History . . . . . . . . . . . . . . . . . . 96

Chemical Transport Through Continental Crust . . . . . . . . . . . . . 97

UNIVERSITY OF NEVADA, RENO . . . . . . . . . . . . . . . . . . 98

Drilling of Washoe Lake, Nevada, for Paleoclimate Studies . . . . . . . . . . . 98

CITY UNIVERSITY OF NEW YORK QUEENS COLLEGE . . . . . . . . . . . . . . . 99

Evaporites as a Source for Oil . . . . . . . . . . . . . . . . . . . . 99

STATE UNIVERSITY OF NEW YORK (SUNY) AT STONY BROOK . . . . . . . . . 100

Geochemistry and Origin of Regional Dolomites . . . . . . . . . . . . 100

Three-Dimensional Imaging of Drill Core Samples Using

Synchrotron-Computed Microtomography . . . . . . . . . . . . . . . 101

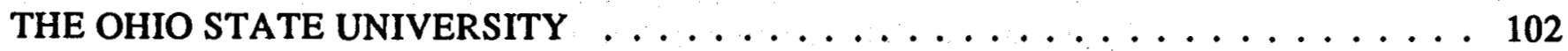

Investigation of Ultrasonic Wave Interactions With Fluid-Saturated

Porous Rocks . . . . . . . . . . . . . . . . . . . . . . . . . . 102

Construction of a Calibrated Sea-Level Curve: Mid-Cretaceous Through

Mid-Tertiary . . . . . . . . . . . . . . . . . . . 103

UNIVERSITY OF OKLAHOMA . . . . . . . . . . . . . . . . . . . . . . . . 104

A Study of Hydrocarbon Migration Events: Development and Application

of New Methods for Constraining the Time of Migration and

an Assessment of Rock-Fluid Interactions . . . . . . . . . . . . . . . . 104

A Study of the Source Materials, Depositional Environments,

Mechanisms of Generation, and Migration of Oils in the

Anadarko and Cherokee Basins . . . . . . . . . . . . . . . . . . . 105

OREGON STATE UNIVERSITY $\ldots \ldots \ldots \ldots \ldots \ldots \ldots \ldots \ldots \ldots \ldots \ldots$

Multi-station Magnetotellurics . . . . . . . . . . . . . . . . . . . 106

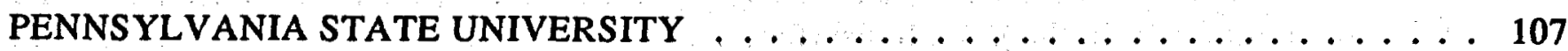

Cretaceous Shallow Drilling in the U.S. Western Interior:

Core Research . . . . . . . . . . . . . . . . . . . . . . 107

PRINCETON UNIVERSITY . . . . . . . . . . . . . . . . . . . 108

Thermodynamics of Minerals Stable Near the Earth's Surface . . . . . . . . . . . 108

The Effects of Natural and Induced Defects on Noble-Gas Transport

in Silicates: a Study of Argon Using Laser, X-Ray, and

Electron Microprobes. . . . . . . . . . . . . . . . . . . . . . . . . . . . 109 
PURDUE UNIVERSITY

Hyperfiltration-Induced Fractionation of Lithium Isotopes in

Geologic Systems . . . . . . . . . . . . . . . . . . . . . 110

RICE UNIVERSITY . . . . . . . . . . . . . . . . . . . . . . . . . 111

Transition Metal Catalysis in the Generation of Petroleum and

Natural Gas

SAN DIEGO STATE UNIVERSITY . . . . . . . . . . . . . . . . . . . . . . . . . 112

Eleventh Workshop on Electromagnetic Induction in the Earth . . . . . . . . 112

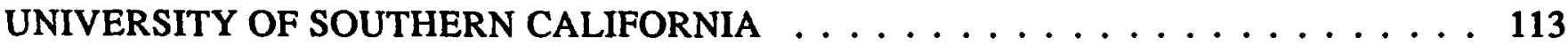

Continental Scientific Drilling Program: The Seismology of

Continental Thermal Regimes . . . . . . . . . . . . . . . . . 113

UNIVERSITY OF SOUTH FLORIDA . . . . . . . . . . . . . . . . . . . . . . 114

Clay Mineral Diagenesis in the Monterey Formation . . . . . . . . . . . . . . . 114

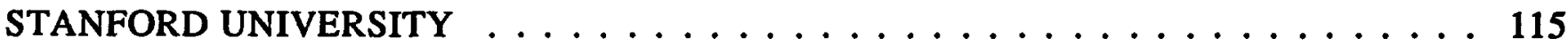

Fluid Flow, Element Migration, and Petrotectonic Evolution of the Early

Mesozoic Central Klamath Island Arc, Northwesternmost California . . . . . . . . 115

Porous Reservoir Rocks with Fluids: Acoustic and Reservoir and

Transport Properties . . . . . . . . . . . . . . . . . 116

Models of Natural Fracture Connectivity: Implications

for Reservoir Permeability . . . . . . . . . . . . . . . . . . . . . . 117

Seismicity Induced By Hydrocarbon Production . . . . . . . . . . . . . . . . 118

TEXAS A\&M UNIVERSITY . . . . . . . . . . . . . . . . . . . . . . . . . . . . 119

Mechanical Properties and Modeling of Seal-Forming Lithologies . . . . . . . . . . 119

THE UNIVERSITY OF TEXAS AT AUSTIN $\ldots \ldots \ldots \ldots \ldots \ldots \ldots$

The Role of Mud Rocks in Burial Diagenesis . . . . . . . . . . . . . . . . . . . 120

Energy Flux and Hydrogeology of Thermal Anomalies in the Gulf of

Mexico Sedimentary Basin-South Texas Example . . . . . . . . . . . . 121

UNIVERSITY OF TULSA . . . . . . . . . . . . . . . . . . . . . . 122

Stability of Natural Gas in the Deep Subsurface . . . . . . . . . . . . . . . . . . 122

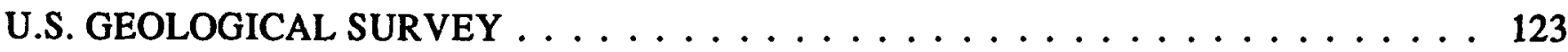

Cretaceous Shallow Drilling in the U.S. Western Interior . . . . . . . . . . . . . 123

UNIVERSITY OF UTAH RESEARCH INSTITUTE . . . . . . . . . . . . . . . . . . . 124

Participation in the Creede Scientific Project as On-Site

Principal Investigator $\ldots \ldots \ldots \ldots \ldots \ldots . \ldots \ldots \ldots$ 
Investigation of High-Temperature, Igneous-Related Hydraulic

Fracturing as a Reservoir Control in the Blackburn and

Grant Canyon Oil Fields, Nevada . . . . . . . . . . . . . . . . . . . . . . 125

Tensor, Controlled-Source Audiomagnetotelluric Survey Over the Sulphur

Springs Thermal Area, Valles Caldera (including Phase 2-Analysis

of the Tensor Controlled-Source Audiomagnetotelluric Method in an

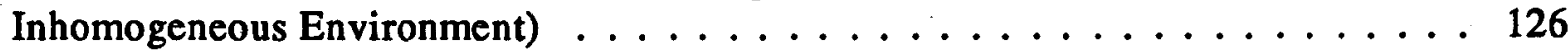

VIRGINIA POLYTECHNIC INSTITUTE AND STATE UNIVERSITY . . . . . . . . . . . 127

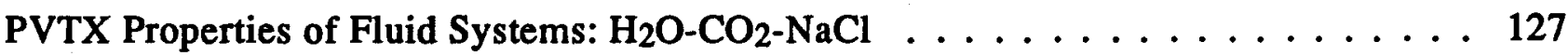

Zircons and Fluids: An Experimental Investigation with Applications

for Radioactive Waste Storage . . . . . . . . . . . . . . . . . . 128

UNIVERSITY OF WASHINGTON . . . . . . . . . . . . . . . . . . . 129

Two- and Three-Dimensional Magnetotelluric Inversion . . . . . . . . . . . . 129

WASHINGTON STATE UNIVERSITY . . . . . . . . . . . . . . . . . . . . . 130

Origin of Flood-Basalt Volcanism on the Columbia Plateau: an

Integrated Approach Using Geology, Geophysics, and Petrology . . . . . . . . 130

WASHINGTON STATE UNIVERSITY TRI-CITIES . . . . . . . . . . . . . . . 131

Transport in Porous and Fractured Media of the Creede Formation . . . . . . . . . 131

WASHINGTON UNIVERSITY . . . . . . . . . . . . . . . . . . . . . . 132

Development of an Experimental Data Base and Theories for Prediction of

Thermodynamic Properties of Aqueous Electrolytes and Nonelectrolytes

of Geochemical Significance at Supercritical Temperatures and Pressures . . . . . . 132

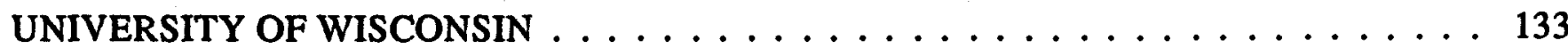

Poroelasticity of Rock . . . . . . . . . . . . . . . . . 133

WOODS HOLE OCEANOGRAPHIC INSTITUTION . . . . . . . . . . . . . . . . . . 134

Geochemical Incorporation of Sulfur Into Organic Matter: Role of Sulfur in the

Formation and Diagenesis of Macromolecular Organic Matter in Sediments . . . 134

Organic Geochemistry of Outer Continental Margins and Deep-

Water Sediments ... . . . . . . . . . . . . . . . . . . . 135

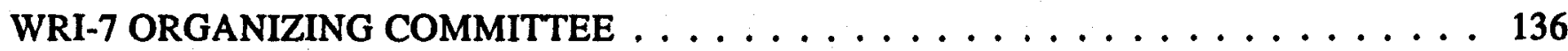

Seventh International Symposium on Water-Rock Interaction . . . . . . . . . . 136

YALE UNIVERSITY . . . . . . . . . . . . . . . . . . . . . . . 137

Reactive Fluid Flow and Applications to Diagenesis, Mineral Deposits,

and Crustal Rocks . . . . . . . . . . . . . . . . . 137

GEOSCIENCE RESEARCH HISTORICAL SUMMARY $\ldots \ldots \ldots \ldots \ldots \ldots \ldots$ 
TOPICAL INDEX $\ldots \ldots \ldots \ldots \ldots \ldots \ldots \ldots \ldots \ldots \ldots$

INDEX OF TECHNICAL CONTRIBUTORS . . . . . . . . . . . . . . . . . . 146 


\section{FOREWORD}

The Department of Energy supports research in the geosciences in order to provide a sound foundation of fundamental knowledge in those areas of the geosciences that are germane to the Department of Energy's many missions. The Division of Engineering and Geosciences, part of the Office of Basic Energy Sciences of the Office of Energy Research, supports the Geosciences Research Program. The participants in this program include Department of Energy laboratories, academic institutions, and other governmental agencies. These activities are formalized by a contract or grant between the Department of Energy and the organization performing the work, providing funds for salaries, equipment, research materials, and overhead.

The summaries in this document, prepared by the investigators, describe the scope of the individual programs. The Geosciences Research Program includes research in geophysics, geochemistry, resource evaluation, solar-terrestrial interactions and their subdivisions including Earth dynamics, properties of Earth materials, rock mechanics, underground imaging, rock-fluid interactions, continental scientific drilling, geochemical transport, solar/atmospheric physics, and modeling, with emphasis on the interdisciplinary areas. All such research is related either directly or indirectly to the Department of Energy's long-range technological needs. 


\section{THE GEOSCIENCES RESEARCH PROGRAM IN THE OFFICE OF B ASIC ENERGY SCIENCES}

The Geosciences Research Program is directed by the Department of Energy's (DOE's) Office of Energy Research (OER) through its Office of Basic Energy Sciences (OBES). Activities in the Geosciences Research Program are directed towards the long-term fundamental knowledge base necessary to provide for energy technologies of the future.

Future energy technologies and their individual roles in satisfying the nation's energy needs are uncertain in their particulars. It is clear, however, that these future energy technologies will involve consumption of energy and mineral resources and generation of technological wastes. The Earth is a source for these energy and mineral resources and is also the host for the wastes generated by technological enterprise. Viable energy technologies for the future must contribute to a national energy enterprize that is efficient, economical, and environmentally sound.

The Geosciences Research Program emphasizes research leading to fundamental knowledge of the processes that transport, modify, concentrate, and emplace (1) the energy and mineral resources of the Earth and (2) the energy byproducts of man. The Geosciences Research Program is divided into five broad categories:

- Geophysics and Earth Dynamics;

- Geochemistry;

- Energy Resource: Recognition, Evaluation, and Utilization;

- Hydrogeology and Exogeochemistry; and

- Solar-Terrestrial Interactions.

The following outline of current research in these categories is intended to be illustrative and evolves with time and progress in these fields. Individual research projects supported by this program at DOE laboratories, national laboratories, academic institutions, research centers, and other federal agencies typically have components in more than one of the categories or subcategories listed. Also, it is common for research activities to involve a high level of collaboration between investigators at different institutions.

\section{GEOPHYSICS AND EARTH DYNAMICS}

A. Large-Scale Earth Dynamics. Research on the physics of lithospheric dynamics such as plate motion, mountain building, basin development, and regional scale uplift/subsidence and its concomitant effects.

B. Evolution of Geologic Structures. Research on the physical controls and physical effects of the dynamic evolution of geologic structures (e.g., folds, faults, basins, volcanoes) on a local or regional scale. 
C. Properties of Earth Materials. Research on physical properties of rocks and minerals determined in the laboratory or in the field (in situ), by direct or indirect techniques, and applicable on the spatial and temporal scales of geologic processes.

D. Rock Mechanics, Fracture, and Fluid Flow. Research on the response of rock and rock units to induced stress and the role of fluid flow as a cause and/or effect.

E. Underground Imaging. Research to characterize the layering, mineralogy, lithology, geometry, fracture density, porosity, fluid content, and composition of the lithosphere using geophysical methods.

\section{GEOCHEMISTRY}

A. Thermochemical Properties of Geologic Materials. Research on the thermodynamic and chemical properties of geologic materials and their kinetic/dynamic interactions.

B. Rock-Fluid Interactions. Research on the chemical and mechanical consequences of rock-fluid interactions and the mass and energy transport controls of such interactions.

C. Organic Geochemistry. Research on naturally occurring carbonaceous and biologically derived substances of geologic and energy importance.

D. Geochemical Transport. Research (both experimental and theoretical) on the geochemical separation, transport, and concentration of materials in the Earth's crust induced by the spatial and temporal dynamics of lithospheric processes leading to a predictive capability.

\section{ENERGY RESOURCE RECOGNITION, EVALUATION, AND UTILIZATION}

A. Resource Definition and Utilization. Research to develop new and advanced bases for the physicochemical dynamics needed for improved energy and energy-related resource exploration, definition, and use.

B. Reservoir Dynamics and Modeling. Research on the physicochemical dynamics of geothermal and hydrocarbon reservoirs in their natural and perturbed (by production, injection, or reinjection) states.

C. Properties and Dynamics of Magma. Research on the origin, migration, emplacement, and crystallization of natural silicate liquids and their heat energy.

D. Continental Scientific Drilling. Research on the scientific objectives of the OBES Geosciences Research Program using advanced technologies in shallow, intermediate, and deep drilling for Earth observation facilities. Scientific research and advanced drilling technologies development are coordinated by an Interagency Coordinating Group (DOE, the U.S. Geological Survey, and the National Science Foundation) under the aegis of the Interagency Accord on Continental Scientific Drilling. 


\section{HYDROGEOLOGY AND EXOGEOCHEMISTRY}

A. Fluid Transport Dynamics and Modeling. Research on the chemical transport and energy/mechanical consequences of fluid interactions and transport, leading to a predictive capability.

B. Thermochemical Properties of Energy Materials. Research on the thermodynamic and chemical properties of materials and their kinetic/dynamic interactions in fluid/rock systems.

C. Perturbations of Fluid Flow. Research on the physicochemical dynamics and chemical transport of fluid/rock systems in response to mechanical and energy perturbations, leading to a predictive capability.

\section{SOLAR-TERRESTRIAL INTERACTIONS}

A. Magnetospheric Physics. Research on the fundamental interactions of the solar wind with the terrestrial magnetic field and the Earth's magnetosphere as a model magnetohydrodynamic generator and associated plasma physics research.

B. Upper Atmosphere Chemistry and Physics. Research on thermal, compositional, and electrical phenomena in the upper atmosphere and the interactions induced by solar radiation.

C. Solar Radiation and Solar Physics. Research on the structure and dynamics of the sun and the characteristic interactions of solar radiation with the Earth, including the effects of solar radiation on the climate. 
PART I ON-SITE 

CONTRACTOR:

CONTRACT:

CATEGORY:

PERSON IN CHARGE:
ARGONNE NATIONAL LABORATORY

Argonne, Illinois 60439
109 ENG 38

Geochemistry

N. C. Sturchio

A. Hydrothermal System Evolution (N. C. Sturchio [708-252-3986; FAX 708-252-6476; E-mail Sturchio@cmt.anl.gov], G.B.Arehart, B.D.Holt, and C.H. Lewis)

The objective of this program is to achieve a better understanding of rock-water interactions and geochemical transport in shallow portions of the Earth's crust. Active hydrothermal systems are being examined to determine the sources of fluids and solutes, the mechanisms and rates of geochemical transport processes, and the relation of hydrothermal systems to larger-scale tectonomagmatic and climatic processes, through field-based studies involving detailed chemical and isotopic analyses. Emphasis is given to applications of actinide-series (uranium and thorium) disequilibria and stable isotopes (H, He, B, C, O, S, and $\mathrm{Sr}$ ) to understand hydrothermal processes. Chemical equilibrium and mass transfer calculations are used to interpret phase equilibria and element redistribution. Such work is of basic importance to a wide variety of energy-related concerns involving mass transport in rock-water systems. Progress during the past year is summarized in the following paragraphs.

Oxygen and carbon isotope ratios were measured for travertines of known age (determined previously by uranium-series methods) from the northern Yellowstone area. These data were examined for evidence of temporal variation that could be interpreted in terms of changes in the oxygen isotopic composition of meteoric recharge waters. Results indicate that extensive oxygen isotopic exchange with meteoric water at low temperature may have altered the primary oxygen isotopic composition in the calcitic travertines, possibly during conversion from aragonite to calcite. Therefore, oxygen isotope ratios in calcitic travertines are not reliable indicators of past meteoric water compositions. However, the 22,000-year old aragonitic travertines that formed during an early phase of Pinedale deglaciation have oxygen and carbon isotope ratios indistinguishable from modern aragonitic travertines at Mammoth Hot Springs.

The evolution of geothermal systems in the northern Kenya Rift Valley was investigated (in collaboration with P. N. Dunkley and M. Smith of the British Geological Survey). Uranium-series age determinations of hot-spring siliceous sinters and chalcedonic silica veins from Quatemary alkaline volcanoes of the inner trough were performed. Periods of hot-spring activity during the past 400,000 years are correlated with high paleolake levels within the rift valley. This indicates that climatic changes modulate the availability of recharge water to a deep, long-lived heat source(s).

Radium isotope activities are being measured in a number of saline groundwaters and brines from oilfields in the Illinois Basin and eastern Kansas. Preliminary data show a good correlation between aquifer rock type and $[\mathrm{Ra} / \mathrm{Ba}]$ and $\left({ }^{228} \mathrm{Ra} /{ }^{226} \mathrm{Ra}\right)$ values in fluids. Also observed is a correlation between $[\mathrm{Ra} / \mathrm{Ba}$ ] and salinity. Models incorporating chemical (sorption, ion exchange, and solubility) and nuclear (alpha-recoil) processes are being developed to interpret the analytical data. 


\section{B. Isotopic Organic Geochemistry (N. C. Sturchio [708-252-3986; FAX 708-252-6476; E-mail Sturchio@cmt.anl.gov],A.J.Bakel, and B.D.Holt)}

The objective of this program is to contribute to a better understanding of the origin and history of petroleum in sedimentary basins. Fundamental questions addressed by this work include: the relation between oil composition and source rock type; the nature of chemical changes that occur within organic matter during diagenesis and catagenesis; the effects of maturation, migration, mixing, and biodegradation on oil composition; and the validity of oil-source rock and oil-oil correlations. The results of this work have significant applications in hydrocarbon resource exploration and production. The principal approach employed in this program is gas chromatography/isotope ratio mass spectrometry (GC/IRMS) for compoundspecific analysis of carbon isotope ratios in complex organic mixtures. Suites of well-characterized petroleum samples, obtained from collaborating scientists, are being analyzed. Separation of various compound fractions by standard methods are sometimes required prior to GC/IRMS analysis for optimal results.

Progress during the past year has been made in analytical techniques and in several collaborative research efforts. A study of three oil families present in the Illinois B asin (collaboration with J. B. Risatti,
Illinois State Geological Survey) showed that oils generated from Ordovician source rocks have patterns of ${ }^{13} \mathrm{C} /{ }^{12} \mathrm{C}$ ratios of $n$-alkanes distinct from those of oils generated from source rocks of different ages. This study demonstrated the potential utility of the carbon isotopic compositions of $n$-alkanes as a correlation tool. Another study is under way to determine whether compound-specific isotopic analysis can differentiate oils from different reservoirs within a single oil field. If so, this could have important applications in oil production.

The carbon isotopic compositions of $\mathbf{n}$-alkanes separated from a number of Gulf Coast oils of differing maturity were measured (in collaboration with A. James and L. Wenger of Exxon Production Research) and were found to vary systematically as a function of maturity. A method has been established for determining ${ }^{13} \mathrm{C} /{ }^{12} \mathrm{C}$ ratios of most compounds present in whole oils from $\mathrm{C}_{4}$ to $\mathrm{C}_{19}$. A number of Gulf Coast oils also are being studied by this method. The results obtained thus far indicate that different compound classes have different ranges of ${ }^{13} \mathrm{C} /{ }^{12} \mathrm{C}$ ratios. The complex isotopic relationships observed between compound classes are being interpreted in terms of possible reaction mechanisms.

\section{Mineral-Fluid Interactions (N. C. Sturchio [708-252-3986; FAX 708-252-6476; E-mail Sturchio@cmt.anl.gov],R.P.Chiarello,and R.A.Wogelius)}

The purpose of this program is to advance the basic understanding of mineral-fluid interactions and transport phenomena in rock-water systems through fundamental studies of atomic-scale reaction mechanisms and kinetics in controlled experimental systems. A crucial problem is to establish the relation between atomic-scale processes and the macroscopic behavior of geochemical systems. Current models of the behavior of natural rock-water systems involve numerous simplifications, approximations, and assumptions that cannot be verified or corrected without detailed knowledge of the operant mechanisms at the atomic scale.

The principal approach employed in this research is to observe oriented single-crystal mineral surfaces in situ during controlled reaction with fluids in a transparent flow-through reaction cell, using $X$-ray scattering and $X$-ray absorption spectroscopic techniques with high-brilliance synchrotron radiation. Experiments are being performed on common rock-forming minerals (feldspar, olivine, muscovite, and calcite) under conditions representative of near-surface environments. Types of reactions being investigated include adsorption, hydrolysis, and oxidation-reduction.

Progress during the past year involved design, assembly, and testing of a flow-through reaction cell for synchrotron experiments, examination of the effects of different surface preparation techniques on surface quality, and a set of pilot experiments at the National Synchrotron Light Source. 
CONTRACTOR:

CONTRACT:

CATEGORY:

PERSONS IN CHARGE:
BROOKH AVEN NATIONAL LABORATORY

Associated Universities, Inc.

Upton, Long Island, New York 11973

DE-AC02-76CH00016

Geophysics and Earth Dynamics

K. W. Jones

A. Three-Dimensional Imaging of Drill Core Samples Using Synchrotron Computed

Microtomography (K.W. Jones [516-282-4588; FAX 516-282-7905; E-mail

JONES@BNLX26.NSLS.BNL.GOV], P. Spanne, and W. B. Lindquist)

Knowledge of the pore structure of rocks is of fundamental importance in understanding fluid flow in geological structures. The pore structure can be studied in a unique way using high-intensity $\mathrm{X}$ rays from a synchrotron $X$-ray source.

The synchrotron makes feasible the use of high-resolution-computed microtomography for nondestructive measurements of the structure of different types of drill core samples. The work is carried out using bending magnet radiation from the National Synchrotron Light Source for measurements below X-ray energies of 40-50 keV. A superconducting wiggler source is used for large samples that require higher $\mathrm{X}$-ray energies. The spatial resolution of the measurement can be adjusted to fit the objectives of a specific experiment. The best resolution obtained to date is about $2 \mu \mathrm{m}$. Measurements have been $m$ ade on a number of large rocks that clearly show the inhomogeneities, pores, and cracks present. The system can be used to produce images of a crack structure in three dimensions. Analysis of the data uses the distribution of measured attenuation coefficients and two-point correlation structure to determine porosity and other information relevant to the rock structure.

\section{CATEGORY: $\quad$ Geochemistry}

\section{PERSON IN CHARGE: $\quad$ A. Vairavamurthy and B. Manowitz}

A. Geochemistry of Organic Sulfur in Marine Sediments (A. Vairavamurthy [516-282-5337; FAX 516-282-5526] and B. Manowitz [516-282-2458; FAX 516-282-5526])

Sulfur is believed to be intimately involved in preserving organic matter in sediments, in converting this organic matter to petroleum, and in controlling the timing of petroleum generation from a source rock. The fundamental issue in this matter is the mechanism of sulfur incorporation into organic matter, which is still not well understood. The objectives of this program are to elucidate the geochemical mechanisms of organic sulfur formation in sediments, to examine the influence of sulfur incorporation in the preservation of sedimentary organic matter, and to identify useful organic sulfur biomarker compounds formed through reactions of nucleophilic sulfur with biogenic organic molecules and to follow up their transformation during early diagenesis. The 
approach involves field studies, laboratory experiments, and application of unique analytical techniques including synchrotron-radiation-based $X$-ray absorption/fluorescence spectroscopy for characterization and determination of sulfur species.

Presently, a major effort is aimed at understanding the role of polysulfides in sedimentary organic sulfur formation during early diagenesis. Our recent laboratory studies suggest that a significant fraction of inorganic polysulfides is bound to the particulate phase of sediments and can react with carbon-carbon unsaturated bonds in organic matter, thereby attaching them to the particulate phase through polysulfide linkages. The ongoing studies of sedimentary sulfur species from an organic-rich coastal site (Great South Bay and Long Island) and from a salt marsh (Flax Pond and Stony Brook) indicate that in fact the dominant fraction of hydrophilic thiols (e.g., 3-mercaptopropionic acid) is present in binding with the particulate phase of sediments. This mechanism may play an important role in the preservation of organic matter in anoxic sediments. $X$-ray absorption near-edge structure (XANES) analysis reveals that organic sulfonic acids constitute a major fraction in organic extracts of sediments from Great South Bay. These are remarkable results because sulfonic acids have not been found as major constituents in any previous study. Laboratory studies are being pursued to understand the origin of this class of compounds in sediments.

We have continued to improve the methodology for determining sulfur species in sediments and petroleum samples using XANES spectroscopy. XANES spectroscopy was used to study air oxidation of aqueous sulfide under conditions typical of marine sediments. Thiosulfate was detected as the predominant product of sulfide oxidation with sulfite and sulfate amounting to $<5 \%$ of the product sulfur. Added $\mathrm{Ni}^{2+}$ caused significant formation of polysulfides in addition to accelerating the oxidation rate to the maximum. XANES spectrum of thiosulfate reveals that the two different sulfur atoms in thiosulfate are in +5 and -1 oxidation states, contrary to the currently accepted view that they exist in +6 and -2 states. This new finding helps to explain how thiosulfate can serve as a fermentation substrate in disproportionation, which is an important pathway in anoxic energy metabolism. Significant advances have also been made in developing a new hand-held sediment corer for obtaining a relatively large amount of sample (about $50 \mathrm{~g}$ ), at 1-cm-deep intervals in sediment cores, and for stabilizing thiols (without undergoing oxidation) in pore water samples when they have to be stored for several days prior to analysis. 
CONTRACTOR:

CONTRACT:

CATEGORY:

PERSON IN CHARGE:
IDAHO NATIONAL ENGINEERING LA BORATORY

Idaho Falls, Idaho 83415

DE-AC07-761DO1570

Energy Resource Recognition, Evaluation, and Utilization

\section{A. Volcanic Stratigraphy of New Idaho National Engineering Laboratory Corehole WO-2 (W. R. Hackett [208-526-6963; FAX 208-526-0875])}

Five thousand feet $(1.5 \mathrm{~km})$ of continuous rock core have been recovered recently from corehole WO-2 at the Idaho National Engineering Laboratory, on the Eastern Snake River Plain (ESRP). The ESRP is a large bimodal igneous province that developed in the wake of the Yellowstone mantle plume. The basal $1,250 \mathrm{ft}(385 \mathrm{~m})$ of WO-2 core are composed of Neogene rhyolites, the first stratigraphically complete section of silicic volcanics yet continuously cored from this igneous province. The rhyolites are predominately ash-flow tuffs, erupted from inferred but now buried calderas.

Core lithology, geochronometry, and bulk-rock chemistry allow correlation with outflow ignimbrites and distal tephra-fall deposits from the surrounding terrain, leading to improved knowledge of early silicic-volcanic processes and caldera formation on the ESRP. The information in turn leads to an improved understanding of the interaction of the mobile continental lithosphere with the underlying Yellowstone mantle plume. 
CONTRACTOR:

CONTRACT:

CATEGORY:

PERSON IN CHARGE:
LAW RENCE BER KELEY LABORATORY

University of California

Berkeley, Califomia 94720
DE-AC03-76SF00098

Geophysics and Earth Dynamics

T. V. McEvilly

A. High-Resolution Imaging of Electrical Conductivity (H. F. Morrison [510-642-3804; FAX 510-642-3805], K. H. Lee [510-486-7468; FAX 510-486-5686; E-mail kiha@csem.lbl.gov], and A. Becker)

The goal of our research is to develop methods for mapping or imaging the electrical conductivity in the earth using low-frequency electromagnetic fields. In spite of the great progress in developing numerical solutions and interpretational methods, however, many fundamental questions relating to resolution, range of exploration, required bandwidth in frequency, and optimum spatial coverage remain to be answered. In addition, practical techniques must be developed to present accurate maps or images of the conductivity to the geoscientists or field engineers.

Research has been focused on continued development of the q-domain direct-imaging technique and improved resolution through use of iterative Born inversion algorithms using frequency-domain data. The q-domain study has been very successful, and the results are shown in a paper by Lee and Xie. The Born inversion approach is important because data are available at present only in the frequency domain. In particular, we have been developing the iterative Born inversion technique for imaging conductivity structures of axial symmetry. An overview in experimental design for electromagnetic imaging largely based on the Born analysis is presented in a paper by Morrison.

\section{B. Deep Electromagnetic Sounding of the Crust (H. F. Morrison [510-624-3804; FAX 510-642-3805], N. E. Goldstein, and K. H. Lee)}

The three main methods of mapping the electrical conductivity of the Earth's crustgeomagnetic depth sounding, magnetotellurics, and controlled source-may be considered as subsets of a generalized electromagnetic induction problem. While exact numerical solutions are still beyond reach for realistic geologic models for some of these methods, it has been instructive to analyze approximate solutions arrived at by linearizing the formulation using the Born or Rytov approximation. Because all the methods involve measurements at many points on the surface, it has also been instructive to analyze the field solutions in spatial wave number space and to borrow some of the methodology of wave equation imaging or tomography to describe resolution of the methods. It has been found, by direct analogy with seismic tomography, that the reconstruction of the conductivity distribution depends on the wave number coverage provided by the source and receiver; the multiple-source, controlled-source methods provide inherently greater information than the single or low wave number natural field methods. Within all the methods is a progression in information content from purely inductive methods to those that also depend on electric fields that are sensitive to conductivity discontinuities. The formalism of the approximate solution clearly shows the role of near surface inhomogeneities and explains the role of spatial filtering in reducing their effects. 
It has also been found by comparison with exact solutions and generalized least squares inversion schemes that the Bom approximation and inversions resolve the geometry of the conductivity distribution remarkably well.

\section{Center for Computational Seismology (CCS) (T. V. McEvilly 1510-486-7347; FAX 510-486-5686; E-mail tvmcevilly@lbl.gov] and E.L.Majer [510-486-6709; FAX 510-486-5686; E-mail elmajer@lbl.gov])}

CCS provides a core research facility for many Basic Energy Sciences (BES) programs as well as other Department of Energy (DOE), government, and private industry cooperative research ventures. A wide variety of state-of-the-art software and hardware is being developed and maintained to support high-level research. During the last year research has focused on subsurface imaging using active and passive sources at scales ranging from meters to whole-Earth dimensions.

A Solbourne 902 compute engine, augmented with a Solbourne 602 file server, gives approximately $65 \mathrm{Mips}$ of processing power at 12 Mflops for the dual processor machine. Disk capacity is about 20 Gbytes, serving about 60 routine users. More than 100 CCS scientific publications and theses have been produced. A list of these reports is available from E. L. Majer by E-mail (elm@ccs.lbl.gov).

CCS has continued support in several different areas of seismology: the processing and interpretation of vertical seismic profiling (VSP) data for fault delineation and fracture detection, CALCRUST, tomographic imaging, the analysis of natural source data for whole-Earth imaging and detailed fault imaging, and several projects for the DOE nuclear waste program.

Some examples of CCS's role in seismic research are:

1. analysis of seismic data for Continental Scientific Drilling Program and thermal regimes programs as well as other BES projects at Lawrence
Berkeley Laboratory and other national laboratories (BES);

2. development of seismic exploration and monitoring techniques for the geothermal industry (DOE geothermal and private industry);

3. fracture detection research using VSP/ tomographic techniques (DOE geothermal, waste isolation, and private industry); and

4. data processing for CALCRUST, a consortium of four universities using seismic reflection methods for intermediate and deep crustal structural analysis (National Science Foundation and private industry).

Present emphasis stresses vector wave propagation, including scattering and attenuation, in three-dimensionally heterogeneous anisotropic media. Applications range across DOE programs, from environmental remediation to fossil/ geothermal reservoir characterization, radioactive waste repositories, and crustal dynamics. Major efforts are directed to tomographic imaging methods, at scales of meters (cross-hole surveys), kilometers (crustal structure), and global dimensions (whole-Earth travel-time inversions). In addition, seismic reflection studies benefit from the large body of processing software at CCS, and research based on reflection profiling ranges from shallow soil-contaminant mapping to crustal structure investigations. Recently, attention has been directed to the development of effective methods for visualization of subsurface structure in three dimensions.

\section{Microcrack Growth in Rock (L. R. Myer [510-486-6456; FAX 510-486-5686; E-mail myer@lbl.gov] and N.G.W.Cook)}

The purpose of this study is to develop a fundamental understanding of the growth of microcracks in brittle rock under compressive stress conditions. The results have broad applicability to any problems requiring knowledge of the effects of discontinuities on the mechanical properties of rock masses.

Previous theoretical work resulted in new crack models that were used to simulate the stress-strain behavior of brittle rock under triaxial compression. 
Additional numerical studies have been carried out to investigate crack interaction in failing brittle rock.

In the next phase of the program, porous rocks were studied to evaluate the extent to which the same failure mechanisms were operative. An experimental study aimed at obtaining quantitative data on microcrack growth under triaxial loading conditions was completed. As part of this study, a Wood's metal casting technique was developed to preserve microstructures as they exist under load.

To study microstructure under more complex compressive stress regimes, hollow cylinder and indentation tests were performed, again using the Wood's metal casting technique. Results have shown that extensile cracking is an important failure mechanism at the grain scale even under compressive stress conditions, which ultimately result in macroscopic shear features. The principal effect of confining stress is to produce a negative component of the mode I stress intensity factor that inhibits extension of the longest cracks, allowing shorter cracks to nucleate and grow as differential compressive stress increases. Crack interaction leads ultimately to formation of shear bands. In porous rocks compaction constitutes a significant proportion of deformation under confining stress and occurs as a result of comminution of grains and subsequent rotation and displacement of fragments.

Micromechanical models based on continuum analyses have proved to be appropriate for crystalline rock. However, in porous rock neither the effects of the stochastic grain distribution nor the processes of compaction are amenable to continuum approximation. Current work is therefore directed at application of discontinuum models to modeling failure of porous rock. The initial stage of this work involves development of a method to permit failure of individual elements in a discontinuum model.

E. Process Definition in Fractured Hydrocarbon Reservoirs (L. R. Myer [510-486-6456; FAX 510-486-5686; E-mailmyer@lbl.gov],N.G.W.Cook, J.C.S.Long, E.L.Majer, T.V.McEvilly, and $H . F$. Morrison)

This program addresses the problems associated with detecting and determining the physical properties of fracture systems and relating these measurements to fluid transport in fractured hydrocarbon reservoirs. An integrated interdisciplinary approach has been adopted involving laboratory studies of basic physical processes and properties of fractures, development of complementary seismic and electromagnetic methods for imaging of fractures and heterogeneities, numerical studies of flow in fracture networks of heterogeneous geometry, and hardware development for seismic imaging.

In the areas of fracture detection by geophysical methods, several goals have been accomplished. Complementary tomographic techniques have been developed for imaging of fractures using seismic and electromagnetic energy. A seismic diffraction tomography program has been developed and successfully applied to a data set from a small-scale in situ test. An electromagnetic diffusion tomography algorithm has also been developed with application to detection of planar fractures illuminated by a dipolar magnetic field.

In an activity complementing the seismic diffraction tomography development, a new approach to modeling wave propagation through fractured media is being studied. In this approach each fracture is represented by a zero-thickness interface with varying rheological properties. The theory has been successfully used to model results of laboratory tests on natural fractures under difference stresses and under dry and saturated conditions. Subsequently, the theory was successfully used to model compressional wave data from a cross-hole experiment in fractured basalt. Other laboratory measurements in support of the seismic theoretical studies have shown that the chemical interactions at the solid-liquid interface in a saturated fracture strongly affect, along with liquid viscosity and film thickness, the transmission of shear waves across the fracture. Seismic measurements on an anisotropic schistose rock have shown that commonly used first-order scattering theories can be used to model shear wave velocity birefringence in such rocks but do not provide an adequate model for attenuation.

In the study of methods for integrating geophysical data into hydrologic methods, conditioned inverse methods were applied in modeling hydrologic tests in a granitic rock mass. In this study major conductive elements were identified 
using geophysics, and then simulated annealing was used in modeling the hydrologic behavior.

Fundamental laboratory studies of fluid flow in single natural fractures revealed significant deviations from the parallel-plate model for fractures in which the change in aperture between the plates is taken to be equivalent to the mechanical deformation of the fracture. The volumetric change in fracture void space and change in contact area must also be taken into account.

Finally, work in hardware development for fracture characterization has centered on completion of a downhole swept-frequency resonant shear wave source. Redesign of electronics for stabilization was completed, and design of a feedback system for sweep control was begun.

\section{F. Coupled Thermal-Hydraulic-Mechanical Processes in Petroleum Reservoirs (C.-F. Tsang [510-486-5782; FAX 510-486-5686; E-mail chinfu@lbl.gov] and J. Noorishad)}

Various aspects of petroleum reservoir engineering, such as isothermal and nonisothermal hydraulic fracturing and permeability variations near injection and production wells, involve coupled thermal-hydraulic-mechanical processes. The computer code ROCMAS was developed to address these coupled phenomena. The aim of this project has been to improve the numerical solution approach used in the code and to enhance its modeling capability. The former aim has been achieved by implementation of an incremental loading scheme, a Newton-Raphson linearization scheme, dynamic storage allocation, an efficient equation solver, and a weighted predictor-corrector time integration method. For the equation solver, a realistic joint model has replaced the old ideal elastic-plastic model. Preliminary work for the development of various material constitutive models has been done.
Partial and full verifications of all the changes pertinent to hydraulic and mechanical and to coupled hydromechanical aspects have been achieved. Results of these efforts have appeared in the International Journal of Rock Mechanics and Mining Sciences. A companion paper, in the same joumal, reports achievement of a first-time field experimental verification of the ROCMAS code in an injection test of fractures intercepted in a well.

Integration of the thermal analysis capability, in the revised hydromechanical version of the ROCMAS code, has been another focus of recent research in the project. Efforts to remedy the poor performance of the finite-element method in dealing with convection-dominated, sharp-front transport problems have led to the development of a corrective procedure. These findings have been published in Water Resources Research.

\section{G. Advanced Research Concepts (T.V.McEvilly [510-486-7347; FAX 510-486-5686; E-mail mcevilly@lbl.gov])}

A modest program of theoretical and field studies was supported by Basic Energy Sciences Advanced Research Concepts funds at Lawrence Berkeley Laboratory, in very close collaboration with Paul Johnson (Los Alamos National Laboratory) and Brian Bonner (Lawrence Livermore National Laboratory), who reported the original laboratory-scale results, and it is intended to be complementary to their continued research on the phenomenon of nonlinear seismic wave propagation. We brought to the collaboration the established capabilities at Lawrence Berkeley Laboratory for research on the fundamentals of elastic wave propagation in rock and for state-of-the-art field methods in seismology, including novel systems for data acquisition and advanced computational resources for processing and analysis. The theoretical basis for nonlinear effects in elastic wave propagation has been well developed. Experimental confirmation and important applications abound in the field of acoustics, including underwater sound. Recent laboratory work of $P$. Johnson and colleagues suggests nonlinear propagation in rock at the centimeter scale. Attempts to observe nonlinear effects in data from our 100-m-to-km scale reflection profiles and special vertical seismic profiling surveys supported in this exploratory research were unsuccessful in demonstrating nonlinear effects along the propagation paths of the waves, although high harmonic generation occurred at the sources (coupled vibrator-ground systems). Other attempts to find evidence at the $10-\mathrm{km}$ scale in our 
high-resolution microearthquake data also failed to produce definitive proof. Direct estimation of third-order terms from high-quality laboratory measurements of velocities in rocks under various loading conditions produced values consistent with other studies, and these values in turn predict large nonlinear effects for intersecting-beam experiments at field-scale wavelengths. An outcome of this study has been a multi-laboratory proposal to investigate systematically the theoretical and experimental aspects of nonlinear elastic wave generation and propagation.

\section{CATEGORY: Geochemistry}

PERSON IN CHARGE: T. T. McEvilly

\section{A. Thermodynamics of High-Temperature Brines (K. S. Pitzer [510-486-5456; FAX 510-642-8369; E-mail kspitzer@lbl.gov])}

This project covers theoretical and experimental studies concerning the thermodynamic properties of aqueous electrolytes and other systems at high temperatures. The components important in natural waters and other geochemical fluids are emphasized. The resulting data are important in understanding various geological processes, in exploiting geothermal and other natural resources, and in fission-product waste disposal. Moreover, this information has a wide range of applicability, since similar solutions arise in many industrial processes and in high-pressure steam power plants.

The experimental program involves measuring heats of mixing or dilution of solutions at temperatures extending above $350^{\circ} \mathrm{C}$ and pressures to $1 \mathrm{kbar}$. The data base for the principal components of natural waters has now become adequate for the prediction of mineral solubilities up to $300^{\circ} \mathrm{C}$ in brines, containing $\mathrm{Na}^{+}, \mathrm{K}^{+}, \mathrm{Mg}^{2+}, \mathrm{Ca}^{2+}, \mathrm{Cl}^{-}, \mathrm{OH}^{-}$,
$\mathrm{SO}_{4}^{2-}$, and $\mathrm{H}_{2} \mathrm{O}$. Once the parameters are established for binary and common-ion ternary systems, no further parameters are needed for more complex brines, and calculations are truly predictive.

The recent theoretical program included a comprehensive model for both saturated liquid $\mathrm{NaCl}-\mathrm{KCl}-\mathrm{H}_{2} \mathrm{O}$ and solid $\mathrm{NaCl}-\mathrm{KCl}$ over a very wide range of $\mathrm{T}$ and $\mathrm{P}$ and the full range of composition. Also, an empirical equation of $\mathrm{CO}_{2}-\mathrm{H}_{2} \mathrm{O}$ was developed in connection with new volumetric measurements made at Virginia Polytechnic Institute for the range $400-700^{\circ} \mathrm{C}$ and $2-6$ kbars. Current research is directed to a new general equation of state for $\mathrm{CO}_{2}$ for the much broader range $218-1600 \mathrm{~K}$ and $0-40$ kbars. This equation will then be generalized to the binary $\mathrm{H}_{2} \mathrm{O}-\mathrm{CO}_{2}$ in a manner consistent with the statistical mechanics of multicomponent systems and connecting with an accurate equation of state for pure $\mathrm{H}_{2} \mathrm{O}$.

\section{B. Studies of the Interactions between Mineral Surfaces and Ions in Solution (D. L. Perry [510-486-4819; FAX 510-486-5799])}

This task encompasses fundamental studies to determine the basic surface chemistry of common minerals (both synthetic and natural) and the chemical reactions of metal ions with the mineral surfaces. The research encompasses (1) basic spectroscopy of natural minerals and their synthetic counterparts, (2) spectroscopic studies of metal ions that have been adsorbed onto the mineral surfaces, (3) syntheses and spectroscopy of model compounds that form in metal ion-mineral reactions, and
(4) spectroscopy of organic compounds that have been chemisorbed onto minerals.

$\mathrm{X}$-ray photoelectron and Auger spectroscopic techniques have been used to study the surfaces and their reactions with metal ions in solution. These reactions, conducted at temperatures between 25 and $100^{\circ} \mathrm{C}$ to vary the kinetics and the extent of the reactions, are shown to vary greatly from the analogous reactions in which the reacting substrates have been oxidized. The clean mineral surfaces that have undergone reaction are observed to be much 
less heterogeneous than the comparable reactions involving the oxidized surfaces.

One sulfide system that has been studied is that of the oxidation of europium monosulfide, EuS, using Mossbauer-151 spectroscopy and comparing the results with those of compounds that could possibly form during its oxidation. This metal-species sulfide offers a unique opportunity to look at several oxidation-reduction processes that may come into play in geochemical systems. First, there is the europium(II) $\rightarrow$ europium(III) oxidation. Second, there is the oxidation route of the sulfide. A detailed knowledge of these oxidation-reduction processes may also shed some light on the role of europium in its concentration of such geologic materials as plagioclase, in which europium is incorporated to a greater degree than other rare earths when it is reduced to the europium(II) state.

The data show that the oxidation of europium(II) sulfide is neither rapid nor facile. Neither is the oxidation a nontrivial, straightforward process. Both the chemical products formed during the oxidation and the mechanisms of the reactions were found to be exceedingly complex, with competing reaction processes occurring. Also, the conditions of the oxidation seem to have an exceedingly strong effect on the final chemical state of the europium sulfide surface.

It is clear from these experimental data that surfaces involved in air interface reactions as described here cannot be satisfactorily described as simple homogeneous surfaces available for dissolution or other subsequent reactions. Rather, the solid/air interface reaction processes involving these surfaces can only be modeled as processes that must include a multiplicity of reactions involving chemical species such as europium sulfide oxidation products. These (and related) reaction systems of metal ions will be studied further with respect to the reaction products, mechanisms, and kinetics. The experimental work described here with traditional $\mathrm{X}$-ray photoelectron, Auger, and other types of spectroscopy is preparatory to studying these geochemical systems with the Advanced Light Source at Lawrence Berkeley Laboratory. Additionally, parallel research in these chemical systems of geologic materials is being continued using synchrotron radiation.

\section{Chemical Transport in Natural Systems (C. L. Carnahan 1510-486-6770; FAX 510-486-5686; E-mail clcarnahan@csa.lbl.gov])}

This research involves theoretical and numerical studies of processes affecting the movement of chemically reactive solutes in groundwater flow systems. These studies are relevant to the understanding and quantitative description of energy-related phenomena such as the chemical evolution of fluids in deep sedimentary basins and the subsurface migration of toxic and radioactive wastes.

The theoretical studies focus on the development of conceptual and mathematical models describing solute transport and chemical equilibria in groundwater. The models consist of coupled, nonlinear, partial differential, and algebraic equations; the equations are "solved" by a series of computer programs, of which the most recent is designated THCVP.
THCVP simulates migration of solutes with feedback from chemical reactions to fluid flow. In particular. THCVP simulates changes of permeability (and, thus, fluid flow) caused by precipitation or dissolution of reactive solids. The THCVP program is a useful tool for predicting mobilization (or immobilization) of chemicals as well as permeability changes in the subsurface produced by injection of reactive chemicals through boreholes or by mixing of waters having different chemical compositions. The effects of varying temperature on chemical reactions can be included in simulations with THCVP; this feature extends simulation capabilities to subsurface regimes influenced by variable temperature fields.

\section{Center for Isotope Geochemistry (D.J. DePaolo [510-486-4975; FAX 510-486-5686])}

The Center research combines high-precision measurements of isotopic ratios in natural materials with mathematical models to understand the spatial and time scales of geochemical processes of interest 
for energy management. Current efforts are concentrated on $\mathrm{Sr}, \mathrm{Ca}, \mathrm{O}, \mathrm{C}, \mathrm{He}, \mathrm{Ne}, \mathrm{Ar}$, and $\mathrm{Nd}$ isotopic ratios and on problems of mass transport in fluid-rock systems, interpretation of past global climatic change, stratigraphy and structure of sedimentary basins, and crustal magmatic and tectonic processes.

Isotopic ratios can be useful indicators of subsurface hydrological parameters such as fluid residence times, fluid-rock reaction rates, and solute retardation factors and processes. A mathematical basis for the application of isotopic measurements of fluids and rocks to the field-scale parameterization of hydrological systems is a major effort of the Center. This approach is supplemented by systematic measurements of relatively simple natural systems and by the development of improved sampling and measuring techniques to enhance information retur. Emphasis in development is on microsampling of geological materials; on high-precision measurement of the small amounts of recovered material; and on rapid, automated low-blank chemical separation of trace elements.
Isotopic measurements of natural waters and minerals precipitated from such waters are an important source of information on past earth climatic and hydrological conditions. Such information is critical for all types of waste management and is important baseline data for evaluating models of atmospheric processes. Our approach is to use mathematical models to understand how secondary processes affect proxy climate indicators and to use the models to design measurement programs aimed at obtaining more reliable records. Our studies use continental groundwater and river water records as well as estuarine and marine records.

Other efforts of the Center are aimed at geochemical techniques for dating and correlation of sedimentary and volcanic rocks and for understanding the time scales and mechanisms of crustal processes such as extensional faulting, mountain building, and volcanism. These efforts are aimed at improving geological characterization for regulatory purposes and at improving subsurface characterization of sedimentary reservoirs.
CATEGORY:

PERSON IN CHARGE:
Energy Resource Recognition, Evaluation, and Utilization

\author{
T. V.McEvilly
}

\section{A. Hydrothermal Chemistry (H. A. Wollenberg [510-486-5344; FAX 510-486-5686])}

The evolution and circulation of hydrothermal systems associated with magmatic bodies in the upper crust are subjects central to understanding the thermal regimes of the continents and their related resources. In this regard, emphasis of this task is the study of rock-fluid interactions associated with calderas. Alteration mineralogy and isotope ratios in rock matrix and fracture linings are combined with chemistries and isotope ratios of downhole fluid samples and springs and with mineralogy of drill core and cuttings to determine the extent of rock-water interaction. Oxygen, hydrogen, carbon, and strontium isotope ratios are used to trace the paths of hydrothermal fluids from precipitation in recharge areas, through the hydrothermal systems, to surface manifestations. Alteration mineral assemblages are used to reconstruct thermal regimes associated with earlier hydrothermal circulation. At
Long Valley, California, isotope ratios in drill cores and surface outcrops, as well as in hydrothermal fluids and mixed meteoric-hydrothermal waters from surface springs, indicate (1) contact of hydrothermal fluids with basement rocks, (2) upward flow of the fluids in the caldera's west moat, and (3) their subsequent eastward movement in caldera fill. Hydrothermal systems of the Valles and Long Valley calderas also provide settings to investigate mineral associations and mobility of uranium and thorium at elevated temperatures under conditions analogous to those expected in tuffaceous rock encompassing a high-level radioactive waste repository. Opportunities are being explored with the geothermal industry to collaborate in deep drilling that would investigate the upflow zone of the Long Valley caldera's hydrothermal system. Collaboration continues with colleagues at the Los 
Alamos National Laboratory and the U.S. Geological Survey, exemplified by a collection of papers published in a recent issue of the Journal of Volcanology and Geothermal Research.

B. Geophysical Measurements Facility (T. V. McEvilly 1510-486-7347; FAX 510-486-5686; E-mail mcevilly@lbl.gov] and H.F.Morrison)

The Geophysical Measurements Facility (GMF) at Lawrence Berkeley Laboratory operates to facilitate the use of the large complement of field systems and equipment by researchers needing the particular measurements for their projects. The GMF support is used to maintain systems in field-ready condition and to instruct users in safe and technically proper equipment operation. Support comes from specific research projects for upgrading hardware and software, for fabricating new or modifying existing equipment, and for assistance in field deployments and operations. Examples during this reporting period are (1) operation and maintenance of microearthquake networks in use at The Geysers, Coso, and Parkfield; (2) operation and maintenance of the logging trucks and Vibroseis units used in several projects; (3) deployment of the downhole fluid sampler at The Geysers vapor-dominated geothermal field; (4) hydrological and geophysical field studies at the Kesterson and Stillwater study areas; (5) cross-well electromagnetic experiments at the Richmond aquifer test facility on salinity plume detection; (6) cross-seismic tomography for fracture mapping at the Yucca Mountain facility; and (7) technical advice on field techniques and advanced instrumentation in use at electromagnetic/OTD Integrated Demo sites. The GMF provides a test and development environment for the in-field seismic tomographic imaging system; operation of the aquifer test facility at the Richmond field station; cross-hole tomography at the Lawrence Livermore National Laboratory dynamic stripping remediation exercise; field and technical support for the ten-company/DOE research in Texas on crosshole electromagnetic imaging; and assistance through equipment loans to various labs, universities, and federal agencies needing modern field capabilities in geophysical measurements. GMF is a small but critical element in the Lawrence Berkeley Laboratory geoscience research effort. 
CONTRACTOR:

CONTRACT:

CATEGORY:

PERSON IN CHARGE:

\section{LAW RENCE LIVERMORE NATIONAL LABORATORY University of California \\ Livermore, California 94550}

W-6405-ENG-48

Geophysics and Earth Dynamics

\section{A. Rheology of Partially Molten Crustal Rocks (F. J. Ryerson [510-422-6170]; FAX 510-422-1002; E-mail ryerson@s91.es.llnl.gov] and M. L. Beeman [510-422-7108])}

To describe the rates and efficiencies of crustal deformation processes, data from both experimental studies of rock deformation and pressuretemperature studies within crustal deformation zones are required. In this project we are (1) developing the equipment and techniques required to measure the plastic deformation of crustal lithologies under pressure-temperature conditions of crustal deformation and (2) investigating the petrologic, thermal, and tectonic history of a shear zone in southern China that is associated with the Indo-Asian collision. Current experimental work is concentrated on quartz \pm melt and microcline-melt aggregates. Aggregates have been produced both through chemical precipitation techniques and by air pulverization of macroscopic starting $m$ aterials. The melt composition currently used is an alkali silicate, but attempts are under way to use melts of granitic composition produced by air-pulverizing obsidian. We have obtained differential stresses as low as 100 MPa in melt-free quartzite samples. Additionally, we have demonstrated a transition from semi-brittle to fully ductile behavior in these samples between 0 and approximately 5 vol\% melt.

The field-oriented portion of this project has been undertaken in collaboration with Mark Harrison and colleagues at the University of California, Los Angeles. We are investigating the tectonic history of the Red River shear zone in southern China with a combination of thermochronological and petrologic techniques in order to recover the pressuretemperature history of the region. This region has been proposed as a ductile strike-slip shear zone along which Indo-China extruded to the east as a result of the Indo-Asian collision. We find that left-lateral, strike-slip, ductile deformation ceased in the vicinity of our sampling sites between 24 and 20 $\mathrm{Ma}$ and that the mylonitic gneisses in the shear zone were subsequently obliquely unroofed because of later brittle normal faulting activated along the earlier ductile shear zone.

B. Electrical Conductivity, Temperature, and Radiative Transport in the Earth (A. G. Duba [510-422-7306; FAX 510-423-1057; E-mail @s61.es.llnl.gov;] and T. J. Shankland, Los Alamos National Laboratory [E-mail SHANKLAND@ESSDP1])

Both electrical and optical research efforts help determine temperature distributions in the crust and upper mantle. Electrical conductivity and thermoelectric effect in the mantle minerals olivine and pyroxene are being measured as a function of temperature, orientation, oxygen fugacity, $\mathrm{fO}_{2}$, and iron content. Ordinarily inference of upper mantle temperatures from electrical data is accomplished by inserting electrical conductivity (s) measured in the field into the s-T relationship. The intent of this work is to comprehend in detail the electrical conduction mechanisms in mantle-forming minerals so that mechanical, seismic, and electrical properties of the earth's mantle may be understood to the point of predicting their values. A source of uncertainty derives from a compositional discrepancy: we have 
the most accurate and reproducible conductivities for mantle olivine by itself, but upper mantle rocks have other mineral phases, principally pyroxene, that lower the bulk $\mathrm{Mg} / \mathrm{Si}$ stoichiometry from that of olivine. We have investigated the effect of buffered silica, $\mathrm{MgO}$, and $\mathrm{FeO}$ activities on conductivity of single olivine crystals by dusting samples with a layer of powdered pyroxene or magnesiowustite, that acts as a silica reservoir. There is a measurable change, a decrease of $\log s$ by 0.1 to $0.2 \log _{10}$ units. Theoretical calculations of point defects support the conclusion that pyroxene or oxide activity produces minimal effect by confirming the small change in majority carriers. These calculations are based on the mass-action equations governing equilibrium thermodynamic concentrations of point defects and on further constraints such as bulk charge neutrality and lattice site conservation. The major implication of this result is that the defect concentrations of the dominant charge carrier responsible for conduction in olivine in this temperature regime seem not to be grossly affected by the presence of pyroxene. Thus, we believe that the minor effect of pyroxene can be treated as a perturbation when calculating temperature-depth relationships (electrogeotherms) for the mantle from olivine conductivity data. With this m ajor uncertainty diminished we are much more confident about using single crystal data from mantle-derived crystals to calculate conductivities, and mantle temperatures inferred from these conductivities are on a much firmer basis.

\section{Seismic Transmission Imaging (G.Zandt [510-423-6835; E-mail zandt@s25.es.llnl.gov])}

The emphasis in this project is on using seismic transmission imaging (STI) as a tool to study the continental crust. STI uses direct (or diving) waves to "illuminate" a target volume. The primary goal is to investigate enhancements to imaging methods to achieve higher resolution and apply them to regions of complex crustal structure such as magmatic and volcanic areas where the reflection technique works poorly. Enhanced images are not the final results; emphasis is also placed on interpretation of the results to improve understanding of geological processes in the continental lithosphere. In the last year, progress was made in three areas: (1) completion of lecture notes on nonlinear inversion and tomography, (2) a local earthquake traveltime tomography study of the Cape Mendocino
Triple Junction area resulting in a velocity model and relocated hypocenters that clearly-define the subducting Gorda Plate beneath the western edge of North America and suggest a thickened crust above the southward dipping portion of the Gorda Plate, and (3) a study of the lithosphere structure in the Death Valley region using a variety of seismic imaging techniques. The crustal structure in Death Valley is similar to other parts of the Basin and Range; however, the upper mantle is distinctly different (containing a very low velocity zone $\sim 3.7 \mathrm{~km} / \mathrm{s}$ ). The results suggest that processes in the upper mantle are largely responsible for the isostatic response to extreme extension, with some crustal intrusion accommodating some of the crustal "thinning."

\section{Modification of Fracture Transport Properties of Rocks by Mechanical and Chemical Processes (W.B.Durham [510-422-7046; FAX 510-423-1057; E-mail durham@s38.es.llnl.gov] and B.P. Bonner)}

It is widely accepted that the movement of fluid through the crust is controlled, not by the bulk permeability of the medium, but by the network of joints (fractures) that pervade the medium. The goal of this project is to understand the physics of fluid flow in individual fractures and to better constrain models of flow in fracture networks. We emphasize a laboratory approach, with the aim of providing the large body of data that will be necessary for general validation of models of fracture hydrology.
Topography of the individual surfaces on a coarse as well as microscopic scale are characterized using a profilometer having extremely high positional accuracy in the plane of the fracture. Fracture aperture and fracture permeability are measured as a function of confining pressure (as high as $160 \mathrm{MPa}$ ). We can also vary other relevant parameters: fractures slightly offset from their mated positions, the effects of various kinds of wear (e.g., sandblasting, abrasion), and the effect of grain size 
by using different rock types. Eventually we hope to extend the study to observation of chemical changes occurring on the fracture surfaces that result from reactive flow. Each of these changes is reflected in different spectral characteristics of the rough and irregular aperture formed by two facing rock halves. A premise of the work is that joint permeability depends on the complex shape of the aperture and not, for instance, on a single parameter such as an average aperture and that most joints can be characterized spectrally by a small number of parameters in predictive, analytical models (none of which exist yet) of fluid flow. Correlations between changes in spectral properties and changes in fracture behavior can then be evaluated for causal relationships within the context of emerging models.

E. Quantitative Image Analysis to Determine Rock Properties (J. G. Berryman [5]0-423-2905; FAX 510-422-1002; E-mail berryman1@llnl.gov] and S. C. Blair [510-422-6467; FAX 510-423-1057; E-mailblair@s55.es.llnl.gov])

The objective of this project is to use advanced image processing and analysis techniques to characterize the physical and mechanical properties of rocks. During this year our work (in collaboration with Professor Neville G.W. Cook at the University of Califormia at Berkeley) has focused on the study of relative permeability of sandstones and extension of our analysis to include the mechanical properties of rocks.

In the study of relative permeability, we investigated two-phase flow in Berea sandstone in which the permeability of the sample was controlled by the nonwetting fluid contained in large, well-connected pores. We developed analytical expressions that incorporate the percolation thresholds for the various fluid phases and developed a simple but rigorous analytical expression relating the surface area of fluid/fluid interfaces to other surface areas considered in multiphase flow. Our estimate of the overall permeability of the sample was within a factor of two of the measured permeability.
Our goal in the mechanical study is to develop a general methodology that can predict the mechanical behavior of rocks and other heterogeneous $m$ aterials in the brittle field based on properties of their microstructure. Rock fracture is known to be sensitive to disorder over many scales, and image processing is being used to characterize the various types of disorder observed. The mechanical properties of rocks are greatly influenced by cracks and fractures that nucleate at the grain scale. Our initial efforts are focused on investigating the effect of strength disorder on the process of fracture.

We have developed a "nearest neighbor" model in which the breaking rule for the elements was based on fracture mechanics and the stress redistribution near broken elements followed nearest neighbor rules (the model allows incorporation of disorder, heterogeneity, and complex geometries found in nature and is compatible with percolation theory). In this model we used initial crack distributions observed in images of rock microstructure and produced strain-hardening behavior and promising results for clustering of cracked elements.

F. Nonlinear Sources for Seismic Imaging-Rock Properties (B. P. Bonner [510-422-7080; FAX 510-423-1057], joint research with T. J. Shankland [505-667-4907] and P. A. Johnson, Los Alamos National Laboratory, and R. J. O'Connell, Harvard University)

This research is directed at developing a low-frequency, directed source by nonlinear elastic wave mixing of two primary frequency waves. Directed sources would be ideal for probing rock masses using seismic tomography. A narrow, low-frequency beam would improve examination of acoustic interfaces underground. Possible applications might include locating discontinuities associated with hydrocarbon reservoirs, burn fronts caused by in situ processing, boundaries of ore bodies, and fluids migrating near waste repositories. A necessary first step to optimize the low-frequency source is characterizing rocks to understand the effects of parameters such as pressure, excitation amplitude, porosity, and fluid saturation on the efficiency of nonlinear-wave generation. Earlier measurements demonstrated that strong nonlinear effects occur for Berea sandstone. 
We have used our low-frequency torsional oscillator to characterize these nonlinear phenomena in detail in order to determine the mechanism responsible for the observations. Measurements of amplitude-dependent attenuation and waveform distortion were made simultaneously with this apparatus as a function of strain amplitude. Both predicted phenomena were observed to be much larger than those observed for metal and intact ceramics. Theoretical analysis suggests that partial slip along open, intemal microfractures causes the compliance to become strain dependent and is therefore capable of producing the observed nonlinear wave propagation effects. Environmental effects that change the nature of partial slip, such as pore fluid content and the normal stress across the microfracture, will effect the nonlinear response because of partial slip. Manipulating these variables will provide an opportunity for optimizing source performance in situ.

\section{G. Poroelasticity of Rock (B. P. Bonner [510-422-7080; FAX 510-423-1057])}

Geologic processes and geophysical interpretations that involve significant coupling between deformation and fluid flow are at the interface between rock mechanics, seismology, and geohydrology. Characterization of quasi-static fluid pressure response to stress is fundamental to hydrogeologic understanding of porous and fractured rock masses and hence to efficient use of hydrocarbon reservoirs and to safe disposition of nuclear and hazardous waste. The dynamic response to stress (elastic wave velocity and attenuation) is dependent on the permeability, porosity, and saturation of the rock mass. Theoretical and empirical models that connect field observation to rock and fluid properties provide the basis for seismic exploration for oil and gas and for seismic characterization of the near surface for environmental restoration and waste remediation. The approach we have taken is comprehensive and includes both experimental and theoretical components and is a collaborative effort with H. Wang of the University of Wisconsin. To establish the controls of permeability on the parameters within the equations that govern fluid flow, measurements must be made over frequencies that range from static to ultrasonic. An ultra-low frequency, low-amplitude torsional oscillator has been used to measure modulus and attenuation for
Berea sandstone to determine the frequency dependence of the acoustic parameters through comparison with ultrasonic measurements being made at Wisconsin. The program takes advantage of the joint capabilities of the laboratories at Wisconsin and Lawrence Livermore National Laboratory to span over eight decades in stress wave frequency range. An automated apparatus was constructed at Lawrence Livermore National Laboratory to study the slow compressional mode (the low-frequency limit of the acoustic slow wave is diffusive flow) and was used to show that clay content controls flow at high as well as low frequencies. New theoretical developments include (1) a generalization of Gassman's relation for predicting moduli of saturated porous media to the more realistic case of two frame constituents, thus providing the first rigorous explanation for the observed effective stress rules for mixtures of sand and clay; (2) computation of new constraints on the laws of effective pressure for transport properties; and (3) further calculations of effective stress rules for transport properties that allow cracks and imperfect bonding between the two solid constituents. Further collaborative work with Wang is aimed at including coupled fluid/elastic effects in double porosity models under development at Lawrence Livermore National Laboratory.

\section{H. Oxygen and Cation Diffusion in Oxide Minerals (F.J.Ryerson [510-422-6170; FAX}

510-422-1002; E-mail Ryerson@s91.es.llnl.gov]) and K. D. McKeegan,University of California at Los Angeles, Department of Earth and Space Sciences, Los Angeles, CA 90024 [310-825-3580; FAX 310-825-2779; E-mail kdm@argon.ess.ucla.edu])

This project concerns the experimental determination of diffusion coefficients, under a variety of environmental conditions, for minerals of importance to contemporary petrologic problems. The results of these investigations support efforts to constrain the physical properties of minerals as a 
function of chemical environment, such as the variation in plastic deformation rate as a function of the oxygen fugacity $\left(\mathrm{fO}_{2}\right)$, by determining relationships between point defect chemistry and diffusive transport. Other applications of the data involve thermochronometry of crustal rocks and meteoritic materials. Work is proceeding in the following areas: (1) the role of $\mathrm{fO}_{2}$ and silica activity on the diffusion of oxygen in olivine; (2) the role of $\mathrm{fO}_{2}$ and silica activity on the diffusion of silicon in olivine; (3) determination of activation volumes for oxygen, silicon, and magnesium diffusion in olivine; (4) oxygen diffusion in diopside, spinel, hibonite, and melilite solid solutions; and (5) lead diffusion in monazite to calibrate a "prograde thermochronometer" to better understand crustal thermal histories.
In the initial year of funding, data have been obtained for oxygen diffusion in anorthite and in melilite. The results have been applied to refining our models of oxygen isotopic exchange with nebular gas during crystallization of calciumaluminum-rich inclusions in carbonaceous meteorites. Analytical procedures for the measurement of lead diffusion in monazite have been developed at Lawrence Livermore National Laboratory using their CAMECA ims $3 f$ ion microprobe. Ion microscope imaging has revealed that lead-rich regions, likely included during synthesis, complicate diffusion measurement. Nonetheless, a gradient has been measured by depth-profiling of a sample annealed at $1000^{\circ} \mathrm{C}$ indicating that both this material and this approach may be used to determine lead diffusion.

I. Interpretation of Geodetic Crustal Strains Using Nonlinear Dynamical Models for the Deformation of Solids (J. B. Rundle [510-294-5236; FAX 510-422-1002; E-mail rundle@s37.es.llnl.gov])

A variety of critical energy facilities face significant natural hazards from several kinds of tectonic instabilities, notably, earthquakes, volcanic eruptions, and landslides. The most promising approach to understanding these instabilities is to analyze, using appropriate dynamical models, crustal strains using a variety of land- and space-based field geodetic data including geodolite, Global Positioning System, very long baseline interferometry, precise leveling, and so forth. Recent progress in numerical simulations of faults, fracture systems, and landslides has been made by developing nonlinear dynamical models of these complex systems. The idea is to simulate systems in the computer because the spacial and temporal scales of the natural system prohibit observations of many important variables. One goal in particular is to understand the physics of how earthquakes nucleate and grow so that the initial stages of the nucleation process can be identified in the crustal strain data. Models are based on cellular automaton techniques, field theories using Langevin dynamics, and on the nearest neighbor Burridge Knopoff model for earthquakes. Analysis of results employs ideas borrowed from studies of scaling theories, including critical phenomena, nucleation in thermal and magnetic systems, and percolation problems. Simulations are being carried out on a variety of machines ranging from desktop workstations to high performance, massively parallel supercomputers.

\section{J. Advanced Concepts (F. J. Ryerson 1510-422-6170; FAX 510-422-1002; E-mail}

Ryerson@s91.es.llnl.gov])

This project provides support to encourage the development of new ideas and research directions in the earth sciences. New topics are selected each year based on scientific merit and relationship to the mission and interests of the Earth Sciences Department. Typically, the research is oriented toward developing capabilities that will be needed by Laboratory programs in the future. Seed money is also provided to assess the feasibility of a given research direction to scope out experimental or computational requirements. This year we have supported exploratory studies in the application of atomic force m icroscopy (AFM) to the investigation of mineral dissolution and precipitation kinetics. The objective of the current work is to begin development of a prototype cell allowing AFM measurements to be made under geologically important conditions, that is, moderate temperature and pressure. 
Developments in the past year have permitted AFM to observe crystal growth and dissolution of geologic and industrial materials at the atomic scale in a flowing cell, permitting characterization of the growth processes in detail. This capability will allow determination of dissolution mechanisms and rates of dissolution and growth for important rock-forming minerals.

\section{CATEGORY:}

PERSON IN CHARGE:
Geochemistry

F. J. Ryerson

A. Thermodynamics, Kinetics, and Transport in Aqueous Electrolyte Solutions (J. A. Rard [510-422-6872; FAX 510-422-0208] and D. G. Miller [510-422-8074; FAX 510-422-6363; E-mail dmiller@llnl.gov])

The goal of this project is to measure precisely the thermodynamic and transport properties of aqueous electrolyte solutions over the entire composition range, including systems relevant to geochemical brines, diagenetic processes, radioactive waste isolation, and environmental pollutants. To accomplish this goal, osmotic and activity coefficients (isopiestic method), Fickian diffusion coefficients (Rayleigh and Gouy interferometry), densities (pycnometry), and solubilities (isopiestic method) are being measured for various electrolytes and their mixtures at $25^{\circ} \mathrm{C}$. New methods for the extraction of accurate diffusion coefficients from the interference patterns, and for estimating diffusion and activity coefficients for mixtures, are being developed.

This year, isopiestic measurements were performed for aqueous mixtures of $\mathrm{NaCl}+\mathrm{SrCl}_{2}$ over the water activity range $0.9716 \leq \mathrm{a}_{\mathrm{w}} \leq \mathbf{0 . 8 7 1 2}$. These values supplement earlier experimental results for the range $0.8668 \leq a_{w} \leq 0.6579$, which extend to the solubility limit. We also extended the equations for analyzing experimental diffusion data to the four-component Gouy case, and a program embodying our procedure for extracting diffusion coefficients from four-component Gouy data was completed in collaboration with colleagues at Texas Christian University and the University of Naples. The procedure was successfully applied to the first optical data collected on a four-component system.

The Gosting diffusiometer was moved to Texas Christian University and, with our assistance, has been reassembled, recalibrated, and is now in full working order.

\section{B. Compositional Kinetic Model of Petroleum Formation (A. K. Burnham [510-422-7304; FAX 510-422-3118], R. L. Braun, J. J. Sweeney, J. G. Reynolds, and L. H. Hair)}

The objective of this project is to derive and verify quantitative chemical kinetic models of petroleum generation and expulsion from its source rock. Parallel tasks in oil generation kinetics, oil-cracking kinetics, phase-equilibrium calculations, geochemical analysis, and geological modeling help achieve that objective. The results of this work are largely incorporated into a flexible computer model, PMOD, which simulates oil and gas generation and destruction, rock compaction, and fluid expulsion. The ultimate goal of this work is to reduce the cost of petroleum exploration and production by improving the reliability of integrated basin analysis, a modeling technique that incorporates many aspects of geology, geophysics, geochemistry, and hydrology to determine when and where oil is generated, migrates, and accumulates.

To determine reaction kinetics for individual hydrocarbon and heteroatom products, a pyrolysis study using triple-quadruple mass spectrometry was completed for seven source rocks. Information regarding individual products is important to help establish the origin of activation energy distributions, to understand variations of gas/oil 
ratios during maturation, and to define the source terms for components that are involved in important secondary reactions. A simpler pyrolysis-mass spectrometric method for obtaining similar information was also investigated. A Pyromat-II programmed micro-pyrolysis instrument was interfaced to a VG Micromass residual gas analyzer. This inexpensive analyzer has the capability of providing high-quality gas evolution data. Results from analyzing this data agree well with those from pyrolysis-TQMS and pyrolysis-FTIR. The gas evolution profiles show excellent promise as a diagnostic of kerogen type.

Rock compaction is an important driving force for primary expulsion of fluid products from the source rock. A new rock compaction algorithm was developed for PMOD to more accurately simulate the decrease in porosity as a function of overburden pressure and pore pressure. Porosity increase was also permitted in the model, when dictated by the effective-pressure compaction law, to the extent that new porosity is created by the conversion of solid material to fluid products. The latter concept is consistent with the hypothesis that kerogen is mainly load bearing, not pore filling. It is possible that primary expulsion of fluid products is limited by their sorption on minerals and on remaining solid organic matter. An experimental study of the absorption of various solvents on kerogen as a function of temperature and pressure was initiated.

\section{Experimental Determination of Mineralogical Controls on U-Th-Pb Redistribution: Implications for Crust/Mantle Differentiation (H. F. Shaw [510-423-4645; FAX 510-423-1057; E-mail shaw4@llnl.gov] and F.J.Ryerson [510-422-6170; FAX 510-422-1002;E-mail ryerson@s91.es.llnl.gov])}

Along with the formation of the earth's core, the differentiation of the crust and mantle represents the major chemical fractionation process occurring on the earth. The nature of this process and its variability throughout earth history have been scrutinized through the application of a wide variety of trace element and isotopic analyses of crustal- and mantle-derived samples. Complete use of such data requires a quantitative understanding of the fractionation of the elements of interest between melts and residual solid assemblages - the relevant mineral-melt partition coefficients must be known. Mineral-melt partition coefficients for $U$, Th, and $\mathrm{Pb}$ are largely unknown as functions of pressure, temperature, $\mathrm{fO}_{2}$ and composition for anatexis in both mafic and felsic systems, yet these elements control the evolution of the lead isotopic system and the uranium-series disequilibrium geochronology and are also important heat-producing elements. This projects concentrates on the experimental determination of mineral-melt and mineral-vapor partitioning for $\mathrm{U}, \mathrm{Th}$, and $\mathrm{Pb}$ in such systems. Clinopyroxene-melt partitioning is the current major focus. Experiments are under way to determine the partition coefficients for clinopyroxene-basalt and clinopyroxene-tonalite pairs as functions of pressure, temperature, $\mathrm{fO}_{2}$, and variations in melt composition. In addition to $\mathrm{U}, \mathrm{Th}$, and $\mathrm{Pb}$, the partitioning of cerium and niobium will also be studied to yield information regarding the genesis of complementary cerium and niobium anomalies in the crust and mantle.
CATEGORY:

PERSON IN CHARGE:
Energy Resource Recognition, Evaluation, and Utilization

\author{
F.J. Ryerson
}

\section{A. Katmai Resistivity Studies (P.W. Kasameyer 1510-422-6487; FAX 510-422-4918; E-mail Kasameyer@llnl.govor kasameyer@s69es.llnl gov] and M.Wilt)}

As part of the Continental Scientific Drilling Program, we participated in the geophysical expeditions to study the Novarupta area in the Valley of Ten Thousand Smokes, Alaska. The purpose of 
this work was to delineate subsurface electrical conductivity structures caused by groundwater depth variations, regions of intense alteration, and geologic structures. The most interesting results came from the induction soundings. All soundings were interpreted to determine three-layer structures, and these structures were assembled into a threedimensional model.

From this model, we make the following conclusions. (1) Very high near-surface resistivities $(>2000 \mathrm{ohm}-\mathrm{m}$ ) were observed at all stations except those collected directly on areas of intense alteration. This resistive layer is presumed to represent the dry air-fall layers, varies in thickness from 25 to $125 \mathrm{~m}$, and is draped over a relatively smooth, more-conductive base. (2) The base of the near-surface layer is a relatively smooth, westward dipping surface, with a local high under the Turtle. This could represent the water table or a change in lithology of the erupted material. (3) The geoelectrical section is underlain by a conductive "basement" that coincides with the outcropping Nak-Nak sedimentary rocks to the north. The top of the basement dips about 10 degrees to the south, and its appearance is suggested beneath the Turtle. The basement is not seen within about $500 \mathrm{~m}$ of Novarupta. These observations suggest that the basement is the pre-eruption surface and that it was reamed out to a diameter of hundreds of meters during the eruption. (4) Many complexities are seen between the near-surface resistive layer and the conductive basement. These will be studied in the future. In addition, we collected a 2- to 3-km-long dipole survey line across a series of grabens suspected to be the northwestern boundary of the caldera. We found almost no structural change at the outermost graben but detected significant changes at the inner one. Careful modeling of this data is required before we can draw conclusions about the caldera boundary.

B. New Approaches to Underground Imaging (J. G. Berryman [510-423-2905; FAX 510-422-1002; E-mail berryman1@llnl.gov] and W.D.Daily [510-422-8623; FAX 510-422-3013])

One focus of this project is towards the continuing development of a new imaging method called Electrical Impedance (or Resistance) Tomography (EIT/ERT) into a practical tool for cross hole imaging. EIT/ERT uses low-frequency current input and voltage output to estimate impedance/resistivity distributions in the earth. This approach has the advantage that signal attenuation is significantly lower than that in high-frequency electromagnetic tomography (developed earlier at Lawrence Livermore National Laboratory); the disadvantage is that new, more sophisticated reconstruction methods must be developed to analyze the data because the location of the electrical field lines depends on the resistivity distribution to be determined. Codes for analyzing threedimensional EIT data and displaying the reconstructions have been written and are under evaluation.

Work has also been completed on surface survey data; that is, current was injected, and voltage differences measured only on the surface of the earth. A field demonstration has shown that EIT can remotely detect and locate a leak in a lined hazardous waste storage pond. Numerical simulations have shown that EIT is also capable of imaging many types of underground targets of geophysical interest from cross-borehole measurements.

The other major focus of this project is to make seismic tomography more reliable in the sense that quantitative checks are available to determine how well resolved the various image elements may be. One approach that has commonly been used to analyze the results of tomographic reconstructions is the resolution matrices for the model and for the data. Berryman has recently shown that both model and data resolution matrices can be constructed during the course of the iterative algorithms commonly used for large tomographic reconstructions. In principle, these ideas may also be carried over to other iterative reconstruction codes, including those for EIT/ERT. 


\section{Investigation of Active Processes in Long Valley Caldera Using the Magma Energy Deep Exploration Well Phase II Drilling Activities (J. B. Rundle [510-294-5236; FAX 510-422-1002; E-mail rundle@s37.es.llnl.gov], joint research with W.R. Wawersik [505-844-4342; FAX 505-844-7354], D. J. Holcomb, and L. M. Teufel, Sandia National Laboratories)}

Geodetic and seismic data collected in Long Valley from 1975 to the present define a pattem of uplift and strain that has been explained by geophysical models involving dike injection and magma intrusion at depths as shallow as $5 \mathrm{~km}$ beneath the caldera floor. A program of in situ stress measurements in the Long Valley Deep Exploratory well has been designed to test the validity of the geophysical models for the location, size, shape, and depth of active magma chambers. Moreover, the comparison of core-based and downhole stress measurements will help to evaluate the validity of far less expensive core-based methods for determining stress directions and magnitudes. Data on in situ stress have been obtained in the Office of Basic
Energy Sciences-funded core hole following Phase II drilling, between 2363 and $2378 \mathrm{~m}$ in basement rock, using core-based and acoustic televiewer methods. Acoustic emission signatures in biaxially loaded subcores using the Kaiser effect method suggest that the maximum in situ principal stress within basement is horizontal and north-south oriented. Preparations for hydrofracture measurements of stress, to be obtained within the core hole during August 1992 are under way. Numerical modeling studies have been initiated to place earlier calculations of stresses induced by injected $\mathrm{m}$ agma within the context of the stress field produced by the regional tectonic structure. 
CONTRACTOR:

CONTRACT:

CATEGORY:

PERSON IN CHARGE:
LOS ALAMOS NATIONAL LABORATORY

University of California

Los Alamos, New Mexico 87545

W-7405-ENG-36

Geophysics and Earth Dynamics

M. Fehler

A. Electrical Conductivity, Temperature, and Radiative Transport in the Earth (T. J. Shankland [505-667-4907; FAX 505-665-2971; E-mail SHANKLAND@ESSDP2:LANL.GOV] and

L. M. Hirsch, joint research with A. G. Duba, Lawrence Livermore National Laboratory)

Both electrical and optical research efforts help determine temperature distributions in the crust and upper mantle. Electrical conductivity and thermoelectric effect in the mantle minerals olivine and pyroxene are being measured as a function of temperature, orientation, oxygen fugacity $\left(\mathrm{fO}_{2}\right)$, and iron content. Ordinarily, inference of upper mantle temperatures from electrical data is accomplished by inserting electrical conductivity(s) measured in the field into the sT relationship. The intent of this work is to comprehend in detail the electrical conduction mechanisms in mantle-forming minerals so that mechanical, seismic, and electrical properties of the earth's mantle may be understood to the point of predicting their values. We have taken a large step toward this goal by publishing a second standard olivine electrical conductivity curve versus $\mathrm{fO}_{2}$. This
sT relationship incorporates much of our previous work on identifying charge carriers, quantifying effects of chemical buffering using both measurements and theory of defects, demonstrating and explaining the role of iron/magnesium ratios, and identifying contributions from grain boundaries. Oxygen fugacity derives from high-temperature single crystal conductivities and intermediate temperature measurements of dunite. Because it incorporates spatial averaging over the three axes of this orthorhombic crystal, it is appropriate for upper mantle rocks having random crystallographic orientations. We believe that $\mathrm{fO}_{2}$ comprises the best olivine data for the temperature range of 700 to $1500^{\circ} \mathrm{C}$. When used to obtain upper mantle temperatures, it should supply the best upper bounds on "electrogeotherms" yet available.

B. Nonlinear Generation of Acoustic Beams (P. A. Johnson 1505-667-8936; FAX 505-667-8487; E-mail JOHNSON@SEISMOS.LANL.GOVJ,T.J. Shankland, and J.N. Albright)

Our intention in this work is to take advantage of the strong nonlinear elasticity that exists in rocks to examine a new class of phenomena such as spectral band shifts and crack-induced contributions to the equation of state. Another objective is to develop a theory describing effects of crack density, fluid content, and anisotropy on nonlinear interactions with the intent of optimizing conditions for testing the nonlinear source. Materials studied include the crystalline rocks basalt and granite as well as the model reservoir rock Berea sandstone.
The focus is along several lines of research including field, theoretical, and laboratory studies. In cooperation with a geophysical exploration firm and Lawrence Berkeley Laboratory, field experiments employing Vibroseiss sources showed that a simple spectrum of two primary frequencies can lead to a rich spectrum as elastic wave fields interact nonlinearly. Fourier transforms of the spectra display (1) harmonics of the primaries, (2) sum and difference frequencies, and (3) cross-terms of these frequencies with themselves and the primaries. The significance of these results 
is the possible use of this spectral richness in geophysical interpretation.

In further work, the one-dimensional wave equation for an isotropic, homogeneous, elastic solid was derived from the energy density correct to fifth order in the strain using Green's function technique. Sum and difference frequency generation and the dependence of the amplitudes of these frequency terms on initial amplitudes and distance were then studied. The alteration in the spectrum with distance is a significant outcome from this exercise. Laboratory experiments match the theoretical results well. Other theoretical work that will eventually relate crack density to nonlinear coefficients was also begun. The method is a self-consistent approach based on the method employed by Budiansky and O'Connell. An effective media approach is also being considered.

Finally, nonlinear resonance experiments show dramatic nonlinearity in aluminum and sandstone from which we hope to obtain nonlinear elastic moduli as a function of strain amplitude $(\mathrm{dM} / \mathrm{dA}$, where $M$ is a modulus and $A$ is strain amplitude); the moduli will be used in our model studies.

\section{Nonlinear Sources for Seismic Imaging (T. J. Shankland [505-667-4907; FAX 505-665-297I; E-mail SHANKLAND@ESSDP1] and P. A. Johnson, joint research with B. Bonner, Lawrence Livermore National Laboratory, and R.J. O'Connell, Harvard)}

The objective of this work is to study the feasibility of producing a collimated, low-frequency wave source by nonlinear wave mixing of two high-frequency signals. A second objective is to study the transition from linear to nonlinear elasticity using high precision ultrasonics and low-frequency attenuation observations in rock as a means of optimizing the wave-mixing phenomenon. A third objective is to develop processing methods by which to use the nonlinearly created waves.

Extensive experiments with what is now called the frequency domain travel time response method have been conducted. This phase interference method for measuring travel times shows separate arrivals as individual spikes along the time axis, enabling precise determination of travel time for each separate ray path. The spikes at different arrival times can be regarded as the response to an impulse traveling along each different path. Suggested patents of the method for use with nonlinear, directional sources have been submitted to the Los Alamos patent group.
Studies of amplitude-modulated signals by use of a torsional oscillator to show directly that energy can be pumped from high to low frequencies were ongoing. These experiments are a key complement to the ultrasonic experiments because they show that the nonlinear effects are also strong in the seismic frequency band. Experiments with aluminum samples having nearly linear response are being used to measure system contributions to the observed intermodulation effects to isolate effects intrinsic to the rock. In addition, it was shown that "selfdemodulation" by the rock mass may provide another, potentially more efficient, means of generating low-frequency beams.

Finally, ultrasonic low-frequency collimated source studies were aimed at separating out source intermodulation distortion (creating an electronic difference frequency signal) from the difference frequency signal created in the rock. The problem has been solved by use of a sensitive, optical detector placed at the source.

\section{Imaging of Reservoirs and Fracture Systems Using Microearthquakes Induced by Hydraulic Injections (M. Fehler [505-667-1925; FAX 505-667-8487; E-mail fehler@seismo5.lanl.gov] and L. House)}

Although hydraulic fracturing is commonly used to improve the performance of both oil and gas and geothermal reservoirs, the effects of the fracturing are often only poorly known. Active seismic methods such as vertical seismic profiling can be used to probe the fracture system, but they are expensive and provide information mainly near the wells used. Microearthquakes induced by the fracturing are located throughout the fractured volume and are considerably more energetic sources of seismic waves, particularly shear waves, than the sources used by the active seismic methods. Because the 
presence of fluid paths in rock affects shear (S) waves more than compressional $(\mathrm{P})$ waves, $S$ waves are a particularly sensitive way to probe fracture systems created by hydraulic fracturing. Thus, data from induced microearthquakes can provide a much more detailed view of the structure of the fractured rock volume than any other data.

Arrival times of both the $P$ and $S$ seismic waves provide information about seismic velocities in the fractured rock as well as about the microearthquake locations. These arrival times can be inverted to simultaneously relocate the microearthquakes and obtain a three-dimensional image of the seismic velocity of the fractured rock. The velocity image, often termed a "tomogram," from one hydraulic fracture experiment has provided a more comprehensive view of the effects of the fracturing than has been heretofore available. Those portions of the tomograms with seismic velocities lower than the intact rock velocities should correspond to rock volumes that have a significant proportion of fluid-filled fractures. To corroborate some of the results found in the tomograms, a method to simultaneously find locations of earthquakes in a tight cluster and find the ratio of $P$ to $S$ wave velocities in the region containing the cluster has been developed. This method allows more reliable determinations of the relative locations of the microearthquakes in the cluster. In addition to arrival times, the waveforms from the induced microearthquakes can contain detailed information about some parts of the rock structure in and near the fractured volume. Of particular interest are the portions of the waveforms after the direct $P$ and $S$ arrivals (termed the coda). Distinct arrivals in the coda result from prominent scatterers. In an otherwise fairly uniform rock, newly created fluid-filled fractures will provide some of the most prominent scatterers in the vicinity of the fractured rock volume. Locating these scatterers and characterizing the change in their reflectivity during the hydraulic fracturing process may also locate some of the best fluid paths in the fractured volume. These analysis methods have the potential for defining the internal structure of hydraulically fractured rock with considerably greater detail than was previously available.

\section{E. Jemez Imaging and Tomography Experiment (JITEX) (M. Fehler [505-667-1925; FAX 505-667-8487; E-mailFEHLER@SEISMO5.LANL.GOV] and W.S.Baldridge)}

The objective of this study is to construct a model of the crust and upper mantle beneath the Valles Caldera that incorporates data from as many geophysical and geological disciplines as possible. A majority of the effort will involve collecting and interpreting seismic data to be used in imaging the subsurface structure beneath the caldera. Models for the geometry of the caldera structure and fill, geometry and internal structure of the composite pluton underlying the caldera, and the structure and composition of the middle to lower crust beneath the pluton will be tested. This work will lead to a new fundamental understanding of the origin, evolution, and modem thermal regime of a major intraplate magmatic system.

The Jemez volcanic field and Valles caldera are important targets for a major geophysical field experiment because (1) the caldera is the world-known textbook example of an ash-flow center and type site for recognition of magmatic resurgence; (2) the sites are geologically young, relatively simple structurally, and relatively small-thus manageable for detailed imaging experiments; (3) especially clearly defined are the major structural elements such as the topographic caldera wall, resurgent dome and keystone graben, and structural boundary (ring fault as reflected by an arcuate collar of postcollapse lava domes); and (4) abundant geologic and geophysical framework data are available, including substantial "ground-truth" drillhole data.

The major effort at this time is in setting up logistics for a reflection-refraction line to be conducted in the fall of 1992. This line will include 300 seismic stations spread over a line $170 \mathrm{~km}$ long. Six shots will be fired to the stations. The station spacing in the caldera will average $300 \mathrm{~m}$, and spacing will extend to $1200 \mathrm{~m}$ at the edges of the line. Part of the planning for this experiment includes modeling the waveforms that might be expected to be recorded using models based on previous geophysical and geological studies in the region. 


\section{CATEGORY: $\quad$ Geochemistry}

\section{PERSON IN CHARGE: $\quad$ D. Janecky}

\section{A. Thorium-230-Uranium-238 Disequilibrium in Geologic Systems Using Solid Source Mass Spectrometry \\ (M. T. Murrell [505-667-4299; FAX 505-665-4955; E-mail 099691@INCDP3. LANL.GOV], D. A. Pickett, S. J. Goldstein, B. M. Tissue, B. L. Fearey, and A. M. Volpe)}

Uranium-series disequilibrium techniques are well established and valuable tools in geochronology and geochemistry. Such measurements have typically been made by decay counting; however, there is significant interest in the development and application of mass spectrometric techniques for uranium-series measurements. The goal of this work is to provide an improved capability for Quaternary dating which can be used to address basic questions in geochemistry and geology as well as having practical applications to geologic hazard risk assessment and paleoclimate studies.

Initial efforts at Los Alamos National Laboratory emphasized the development of mass spectrometric techniques for as many of the long-lived members of the uranium-series as possible. With this goal substantially met, current focus is on refining these methods for analyses of smaller samples (resonance ionization mass spectrometry for thorium and protactinium) and in using these new capabilities to probe the recent evolution of magmatic systems. This work has demonstrated that magma fractionation, magma chamber residence, and transport of crystal-melts before eruption can occur over geologically short periods. These techniques have also been used to determine the formation rates of oceanic crust at mid-ocean ridges. In addition, to better understand the mechanisms that can produce uranium-series disequilibrium in nature, experiments were performed to define the partitioning of uranium-series members between fluids. Initial work has been with carbonate and silicate fluids and has demonstrated fractionation among elements that are extremely incompatible.

\section{B. Thermodynamic Properties of Aqueous Solutions at High Temperatures and Pressures (P. S. Z. Rogers [505-667-1765; FAX 505-665-3403; E-mail 084120@INCDP3. LANL.GOV])}

Knowledge of the thermodynamic properties of electrolyte solutions at high temperatures is important in studies of geothermal systems, hydrothermal alteration processes, and elemental transport in deep brines such as those that are being encountered in the Continental Scientific Drilling Program. Properties to at least $500 \mathrm{~K}$ for carbonates, hydroxy species, and organic complexes are needed to model cementation, mineral diagenesis, and element transport in sedimentary basin evolution. The purpose of this investigation is to determine, through calorimetric measurements, the thermodynamic properties of geochemically important ionic species in aqueous solutions over a wide range of composition and temperature. Where appropriate, we are combining thermodynamic measurements and modeling with other Basic Energy
Sciences projects in rock-water interaction and spectroscopy of aqueous fluids to provide a broad approach for solving geochemical problems. We are continuing collaboration with Oak Ridge National Laboratory to combine their enthalpy and our heat capacity measurements in a single model parameterization. In this manner, we are able to provide the most complete description possible for the thermodynamic properties of aqueous electrolytes to high temperatures and pressures.

Measurements of heat capacities in the sodium carbonate/bicarbonate system have been completed to $523 \mathrm{~K}$ at 7 to $40 \mathrm{MPa}$, and to $573 \mathrm{~K}$ at $40 \mathrm{MPa}$. The thermodynamic properties of the $\mathrm{H}_{2} \mathrm{CO}_{3}$ $\mathrm{CO}_{2}$ (gas)- $\mathrm{H}_{2} \mathrm{O}$ system are of major importance in models of hydrothermal mineralization because of the influence that loss of $\mathrm{CO}_{2}$, through boiling, has 
on the $\mathrm{pH}$ of hydrothermal fluids. Properties to at least $500 \mathrm{~K}$ for carbonates are especially needed to model cementation, m ineral diagenesis, and element transport in sedimentary basin evolution. Experimentally, the properties of this system are more easily obtained through heat capacity measurements of sodium carbonate, sodium bicarbonate, and dissolved $\mathrm{CO}_{2}$, with sodium chloride added to vary the total ionic strength in the dissolved gas studies. The $\mathrm{Na}_{2} \mathrm{CO}_{3}-\mathrm{NaHCO}_{3}-\mathrm{H}_{2} \mathrm{O}$ experiments are the first step in studying this complex system. Collaborative efforts with Mike Simonson (Oak Ridge National Laboratory) and Colin Downes (DSRI, New Zealand) are planned to complete the necessary data base for this system.

\section{Dynamics of Rock Varnish Formation (R. Raymond, Jr. [505-667-4580; FAX 505-665-3285; E-mail 085602@ESSDP2.LANL.GOV],S.L.Reneau,D.L.Bish, and G. D. Guthrie, Jr.)}

Rock varnish is a microns-thick coating, composed primarily of manganese and iron oxides and clay minerals, that is ubiquitous on exposed rock surfaces in arid and semi-arid regions. Rock varnish contains distinct micro-stratigraphic layers that record environmental changes during the period of varnish formation, and these layers have potential to provide an improved understanding of paleoenvironmental changes in desert regions. However, the effects that relationships between varnish mineralogies, varnish elemental contents, vamish diagenesis, and the mechanism of varnish formation have on elemental and mineralogic attributes used in paleoclimatic studies are not yet understood.

We are using a combination of optical microscopy, electron microanalysis, $X$-ray diffraction, $X$-ray fluorescence, and chemical analysis to evaluate the mineralogic and elemental composition of rock varnish as a function of local geology, geochemical environments, and varnish source environments. The main objective of this research is to isolate the major environmental variables responsible for variations in rock varnish chemistry and morphology. Supplemental objectives are: (1) to use rock varnish micro-stratigraphy to understand the nature of environmental changes in different parts of the southwest deserts; (2) to use variations in rock vamish $m$ icro-stratigraphy to $m$ ap out the extent of specific environmental changes, such as changes in rainfall patterns associated with changes in regional atmospheric patterns; and (3) to document the climatic conditions present at the time of formations of major landscape features.

The proposed research has the potential to expand knowledge of the paleoenvironmental history of deserts and thus allow a better understanding of possible environmental changes associated with global climatic changes. Such knowledge will make it possible to decipher more accurately the timing of erosional, depositional, and tectonic events for semi-arid and arid regions not only in the southwestem United States but in other strategic regions of the world. Understanding of such timing will be of significant value to enhanced resolution of young mantle/crust interactions, improved seismic risk evaluations, and improved characterization of sites for nuclear power plants and toxic and nuclear waste disposal.

\section{Geochemistry of Technetium (N. C. Schroeder [505-667-0967; FAX 505-665-4955; E-mail 098491@INCDP3.LANL.GOV], David Morgan [Transylvania University, Lexington, KY, 40508, USA], D. J. Rokop, J. T. Fabryka-Martin, and D. B. Curtis)}

The methodology for evaluating risks associated with the storage of wastes in underground repositories requires an understanding of the physicochemical processes that are likely to impact the wastes and the consequences of those interactions with respect to the effectiveness of the repository. The objective is to minimize the risk to populations thousands of years in the future. Because of the spatial and temporal scales involved, there is no experiment that constitutes "proof" of the accuracy of the risk assessments. Instead of the more familiar scientific concept of designing an experiment to test a hypothesis, the validity of the predictions used in these assessments is done by ensuring that the conceptual basis for predictive models is consistent with fundamental physical and 
chemical principles; that such processes have occurred on a relevant time and space scale and in appropriate chemical and physical environments; and that the computer codes are adequately descriptive of the consequences of these processes.

These practical needs have placed new demands on the level of understanding of natural processes. The development of geologic repositories for the long-term storage of high-level radioactive wastes has such a need for understanding processes. In the simplest of terms, the processes of interest in such repositories are those that influence the ability of engineered materials to retain the wastes, the movement of fluids in the underground, and the ability of moving fluids to transport hazardous waste constituents. In the long term, these constituents in radioactive waste are the long-lived actinides and fission products produced in nuclear fuel. We are characterizing the retention and mobility of ${ }^{99} \mathrm{Tc}$ in a variety of natural environments to evaluate the consequences of geochemical/hydrologic processes on the retention and transport of this long-lived fission product.

For about 20 years the Cambric experiment has measured the migration of radionuclides from the site of an underground nuclear test. Ten years after the 1965 test, a re-entry well was drilled into the remnant of the explosion cavity to obtain core and water samples. Pumping water from a satellite well $91 \mathrm{~m}$ from the cavity subsequently induced an artificial gradient that has allowed soluble radionuclides to migrate from the cavity. Los Alamos National Laboratory has participated in this experiment for its entire duration and made the samples available to us for studying ${ }^{99} \mathrm{Tc}$ retention and migration in an alluvial aquifer.

Only $0.01 \%$ of the ${ }^{99} \mathrm{Tc}$ in the source appears to be available to the mobile fluid phase. This is in contrast to tritium, which is essentially entirely available for transport. Technetium- 99 is measurable in the water of the satellite well, at concentrations considerably below limits established for public drinking water, indicating that the available technetium has migrated through $90 \mathrm{~m}$ of tuffaceous alluvium.

The results demonstrate that the vitrified rock in the test cavity has been effective in retaining ${ }^{99} \mathrm{Tc}$ on a time scale of tens of years. However, the migration properties indicate that the small proportion of the fission product that is available to the fluid phase is transported unimpeded by chemical interactions with the solid materials in the intervening media.

\section{E. Rock-Water Interactions and Element Migration (D. R. Janecky [505-665-0253; FAX \\ 505-665-4955; E-mail 098106@incdp3.lanl.gov], R.W. Charles [505-667-4985; FAX \\ 505-665-4955;E-mail081948@incdp3.lanl.gov],J.Musgrave,P.R. Dixon, and W.P.Myers)}

The emphasis of this project is integration of studies of chemical interactions between rocks and fluids in hydrothermal systems applicable to environments of general interest for the discovery and recovery of energy, whether geothermal or fossil. Present efforts include laboratory experiments, computational modeling, field studies, and application of unique analytical facilities.

The major focus at this time is characterizing processes in geothermal systems in volcanic terrains and sedimented basins. Samples from Valles Caldera drill core are being analyzed to determine element redistribution on bulk to microscopic scales. Nuclear microprobe analyses of individual minerals in selected samples is providing unique insights into which major minerals contain minor and trace elements ( $<1$ weight $\%$ concentrations) and how different assemblages of minerals change the distribution of these elements. Our high-temperature down-hole fluid sampler is being used to collect solutions that can be compared to the analytical results and phase equilibria calculations. Experimental systems are being applied to saline brine reactions and water-rock reaction processes at conditions near critical phenomena. Saline brine experiments are providing a high-quality data set to test and enhance computational models and characterization of reaction path processes analogous to natural systems. Development is ongoing of analytical and experimental approaches to use solutions spiked with ${ }^{29} \mathrm{Si}$ or ${ }^{30} \mathrm{Si}$ to quantify dissolution and precipitation processes for systems close to equilibrium. The results of these experiments and models are also compared to other 
well studied geothermal systems. Other modeling efforts involve developing approaches and methodology to explicitly integrate sensitivity analysis and spatial/temporal heterogeneity into large geochemical models and data bases.

\section{F. A Search for Evidence of Large Comet or Asteroid Impacts at Extinction Boundaries (M. Attrep,Jr. [505-667-0088; FAX 505-665-4955; E-mail 0908804@INCDP3.LANL.GOV])}

Objectives of this investigation are to identify the signatures in the geological record of large-body impacts and/or massive volcanism in relation to the known extinction boundaries in the fossil record, to investigate trace-element migration of the chemical element, to investigate the environmental consequences of these large impacts, and to advance the field of chemostratigraphy. Instrumental neutron activation analysis is used to measure the elemental abundance form ore than 40 elements (major, m inor, and trace), and radiochemical analysis is used to determine the more rare platinum group elements. The 93-Ma late Cenomanian extinction event of marine animals was studied at 29 sites around the world. Sc, Ti, V, Cr, Mn, Co, Ni, Ir, Pt, and $\mathrm{Au}$ showed excess. The excess of the siderophiles hint of a possible large-body impact(s) for the source; however, no physical evidence (microspherules or shocked mineral grains) coincides with the elemental signals. The terrestrial-like signature may be a result of intense sea floor spreading activity or increased circulation of deep, metal-rich water associated with the large late Cenomanian event. Several new Cretaceous-Tertiary boundary sites have been located in the western interior of the United States and at a site in Brazil that may aid in the resolution of the single versus multiple impact controversy. Pre-Cambrian-Cambrian kerogens from Russia show high iridium and gold values indicating biological and/or organic chemical processes involved. The Alamo Breccia (Devonian) in Nevada show elevated iridium (139 ppb) that hints to a possible extra-terrestrial origin for cause.

\section{G. Direct Speciation of Metal Ions by Optical Spectroscopies (C. D. Tait [505-667-3965; FAX 505-665-3403; E-mail 103104@INCDP3.LANL.GOVJ and D.R.Janecky)}

To understand the effects of organic complexation in low-to-moderate temperature systems involving secondary ore formation, rock weathering, and oil field production techniques, we are using UV/Vis absorption, laser Raman scattering, and synchronously scanned luminescence spectroscopies to investigate $\mathrm{Pd}(\mathrm{II}), \mathrm{Al}(\mathrm{III})$, and Fe(III) temperature-dependent speciation. We have also been adapting the synchronously scanned luminescence technique to a petrographic microscope to study fluid inclusions from oil field samples. This latter work should enable us to determine oil maturation and migration pathways in samples such as the Austin Chalk.

Organics such as carboxylic acids have been found to be better coordinators to cations than initially anticipated. This is especially true for platinum group elements (PGEs) such as
palladium(II), in which even simple acetate can compete with chloride as a complexant at room and elevated temperatures (to at least $90^{\circ} \mathrm{C}$ ). Consequently, while remobilization of PGEs has been controversial, our laboratory evidence supports the possible role of several complexants that would solubilize palladium.

Weathering of aluminosilicate rocks by organics is facilitated by strong aluminum complexation by organics such as oxalic acid. Although the temperature-dependent equilibrium constant for aluminum-oxalate increases with increased temperature, care must be taken before extrapolating to real systems such as sedimentary basins. To apply spectroscopic laboratory results to these real systems, we are investigating competition with other cations such as iron, which may compete for the organics at higher temperatures. 
CATEGORY:

Energy Resource Recognition, Evaluation, and Utilization

PERSON IN CHARGE: $\quad$ G. Heiken

A. Core Hole VC-2B: Scientific Drilling to Investigate Caldera Processes, Hydrothermal Dynamics, and Mineralization, Sulphur Springs Geothermal System, Valles Caldera Magma-Hydrothermal System, New Mexico (J. N. Gardner [505-667-1799; FAX 505-665-3285, E-mail GARDNER@ESSXRF.LANL.GOV] and F.E. Goff, joint research with

J. B. Hulen, University of Utah Research Institute)

Research core hole VC-2B is located in the Sulphur Springs subsystem of the Valles caldera hydrothermal system. The last flow test of VC-2B ( $1762 \mathrm{~m}$ depth, $295^{\circ} \mathrm{C}$ bottom hole temperature) was conducted in May 1992. Currently, the casing of the hole is perforated at five horizons ranging in depth from 640 to $1480 \mathrm{~m}$ and in temperature from 195 to $280^{\circ} \mathrm{C}$. Fluids produced during the test appear to originate mainly from the upper three horizons in Tertiary sandstone and Quaternary caldera-fill tuffs. Several suites of fluid and gas samples were collected from miniature weber separators and from the weirbox during the test. Samples will be analyzed for their chemical and isotopic composition by the
VC-2B science team. The objectives of these tests are to determine the characteristics of the main producing horizons of the hole.

Plugging and abandonment of VC-2B should be complete by late July 1992 . A bridge plug will be set at about $620 \mathrm{~m}$, and a combination of cement and muds will fill the hole. The wellhead will be removed and the site restored according to the wishes of the landowner.

A special issue of the Journal of Volcanology and Geothermal Research has been arranged to combine all unpublished research stemming from VC-2A and VC-2B core holes.

\section{B. Hydrogeochemistry of Nevada Oil Field Waters and Brines (F. Goff [505-667-8060; FAX} 505-665-3285; E-mail@ESSXRF.LANL.GOV])

The object of this project is to characterize the chemical and isotopic composition of waters and brines associated with several unique oil fields in Railroad and Pine Valleys, Nevada. Two of the fields (Blackburn and Grand Canyon/Bacon Flat) produce petroleum from active hydrothermal environments reported to be as hot as $170^{\circ} \mathrm{C}$. The tectonic settings of the oil fields are typical Basin and Range grabens. Elsewhere in Nevada, gold deposits of hydrothermal origin are mined from sedimentary rocks known to have some hydrocarbons.

At this writing, we have examined waters from five oil fields and have found that each field contains waters of unique chemical and isotopic composition.
Application of chemical geothermometers indicates that these waters have equilibrated at temperatures $\leq 150^{\circ} \mathrm{C}$. Modeling of tritium data using a well-mixed reservoir code suggests the mean residence time of waters in the reservoirs is $\leq 2000$ year. Stable isotope data $(\delta \mathrm{D} / \delta 180)$ indicate that water recharge to reservoirs occurs locally. The $\delta 13 \mathrm{C}-\mathrm{HCO} 3$ values of most fluids indicate carbon sources from marine limestones and dolomites. This project has just begun, thus many more wells are being considered for sampling, and fluid data will be augmented with chemical and isotopic data of gases and reservoir rocks. 


\section{Operation of a Sample Management System for the Continental Scientific Drilling Program (S.J. Goff [505-667-7200; FAX 505-665-3285; E-mail 102063@ESSDPI.LANL.GOV] and R. Dayvault, UNC, Grand Junction)}

Rigorous and effective sample management is a key part of a Continental Scientific Drilling Program (CSDP). Curatorial policy guidelines and procedures for sample curation have been formulated for the Department of Energy, Office of Basic Energy Sciences drilling efforts. Los Alamos National
Laboratory, in cooperation with UNC Geotech, Grand Junction Operations continue to provide sample management of current and proposed CSDP core holes. We are also looking at the potential for other uses within the Department of Energy for the Grand Junction facility.

\section{Intracaldera Processes Creede Caldera, San Juan Volcanic Field, Colorado (G. Heiken [505-667-8477; FAX 505-665-3285; E-mail HEIKEN@ESSLAB.LANL.GOV] and D. Krier)}

In an earlier study of the Creede Formation, based on surface outcrops and shallow mining company coreholes, Heiken and Krier concluded that the process of caldera structural resurgence was rapid and that caldera lakes were developed in an annulus located between the resurgent dome and caldera wall. Our approach to evaluating the timing of caldera resurgence is to study the provenance of clastic rocks throughout the Creede Formation. We are looking for the first appearance within these sediments of welded Snowshoe Mountain Tuff, the caldera-fill deposit that makes up the Creede resurgent dome. We will also use tuffs within the Creede Formation to date this first appearance of materials from the resurgent dome. A careful study of interbedded travertine layers may also be used as an indicator of structural resurgence; at the surface, some travertine fissure ridges occur along the "hinge line" at the base of the resurgent dome.

We are also characterizing all ash beds within the Creede Formation and are comparing them petrologically and chemically with the intracaldera Fisher quartz latite lavas, which at the surface are interbedded with the Creede Formation. Highresolution $40 \mathrm{Ar} / 39 \mathrm{Ar}$ geochronology of the tuffs will be performed by M. Lanphere of the U.S. Geological Survey. The petrologic data are being compared with the caldera-forming Snowshoe Mountain Tuff and provide information on the evolution of the Snowshoe Mountain magma body. These results will be integrated into a larger picture of both igneous and structural processes occurring after caldera collapse. We are also working with T. McCormick (University of Colorado) on the diagenesis of tuffs and tuffaceous sandstones, with the purpose of evaluating fluid-glass interactions within the Creede moat.

At this time, we have received our core samples; they are being divided, and thin sections are being prepared. We hope to have initial petrologic data on the sandstones and tuffs by midwinter.
CATEGORY:

Solar-Terrestrial Interactions

PERSON IN CHARGE:

\section{S. Peter Gary}

The objective of this program is to carry out theoretical and experimental research on the plasma physics of the solar wind and the Earth's magnetosphere and ionosphere. Because the solar wind and magnetospheric plasmas are the media through which solar-generated disturbances propagate and in which solar wind convection energy is stored and subsequently released to the auroral ionosphere, these studies help us understand the coupling of solar variations to the near-Earth environment. This research supports the Department of Energy's missions in fusion energy research and space-based defense activities, as well as its ongoing solar-terrestrial research program. 


\section{A. Energy Transport in Space Plasma (S. P. Gary [505-667-3807; FAX 505-665-3332; E-mail GARY@ESSDPI.LANL.GOV])}

The long-term goal of this research is to understand the flow of plasma energy in the near-Earth space environment from a small-scale point of view. We use particle distribution functions observed by Los Alamos National Laboratory plasma instruments on scientific satellites as well as computer simulations developed at Los Alamos National Laboratory to carry out fundamental studies of plasma instabilities and associated transport in and near the solar wind, the Earth's bow shock, and the terrestrial magnetosphere.

Our most important accomplishment of 1991 has been our development of a theoretical basis for the experimental identification of low-frequency plasma instabilities in space. Through the use of what we call "transport ratios," dimensionless combinations of fluctuating field and plasma quantities, we can calculate several distinguishing quantities for each instability that may arise in a particular space plasma. Then, if experimental frequency spectra do not permit the observer to distinguish among several possible unstable modes, our criteria can be used to provide clear, if not unambiguous, identification of the instability. The first test of this theory concerns differentiating the mirror and ion cyclotron anisotropy instabilities in the Earth's magnetosheath; we are presently working with both computer simulations and spacecraft data to determine whether our theory is relevant and useful.

\section{B. The Solar Wind-Magnetospheric Interaction (J. Birn [505-667-9232; FAX 505-665-3332; E-mail BIRN@ESSDP1.LANL.GOV] and E.W.Hones, Jr. [505-667-4727])}

The goal of this research is to further the understanding of the Earth's magnetosphere, coupled to the fast-flowing solar wind plasma on the one hand and to the ionosphere on the other. The focus is primarily the study of its large-scale structure and dynamics using theory, numerical modeling, and correlative studies of data from multiple sites within and near the magnetosphere (including the Earth itself as well as scientific satellites).

Our most important achievements in 1991 were made in two areas. The quasi-steady theory of large-scale plasma structures was further advanced. Using standard integration techniques, a broad general class of two- and three-dimensional self-consistent solutions can now be derived that include the effects of fast plasma flow along the magnetic field lines and its compressibility.
Potential applications include the structure of the near and distant magnetotail; plasmoid propagation within the tail; the magnetopause (i.e., the boundary between the magnetosphere and the solar wind plasma) with imbedded structures such as waves or magnetic "flux ropes"; and other current sheet structures in laboratory, space, or astrophysical plasmas. The three-dimensional simulations of magnetotail dynamics have been extended to study effects of internal dynamic processes (which result in plasma heating, consistent with observations, but in no significant change in overall stability) and the expected consequences of the tail instabilities near the Earth. We found that the field-aligned currents, which are generated through the tail instability and provide the coupling with the ionosphere, match very well the observed currents near the Earth.

\section{Energetic Particle Acceleration (G. D. Reeves [505-665-3877; FAX 505-665-3332; E-mail REEVES@ESSDP1.LANL.GOVJ)}

The goal of this research is to develop a better understanding of the Earth's energetic particle environment near geosynchronous orbit. We have been analyzing data from a series of geosynchronous spacecraft that carry Los Alamos National Laboratory energetic particle detectors. The energies measured range from tens of kiloelectron volts to hundreds of $m$ illion electron volts. The lower end of this range lies somewhat above the thermal plasma energies and is therefore sensitive to local acceleration processes such as magnetospheric substorms. The higher end of the energy range is in 
the realm of cosmic rays and is therefore well suited to the study of energetic particles that can penetrate the Earth's magnetic field such as galactic cosmic rays and particles produced in solar flares.

We have been investigating both types of processes. The year 1989 was one of the most active on record for solar flares that produce electrons and protons with energies greater than $10 \mathrm{MeV}$. We have analyzed the effect of these events at geosynchronous orbit in terms of their temporal variability, their magnitude, integrated flux, and spectral characteristics. We have also analyzed a large solar flare event in April and May 1990, which produced dramatic effects at the Earth. The flare produced a shock in the solar wind that drove the magnetopause well inside the geosynchronous orbit and simultaneously injected trapped energetic particles to altitudes as low as 2 Earth radii forming a new and long-lived radiation belt with particle energies of many million electron volts.

We have also advanced our research on magnetospheric substorm acceleration. We refined our computer model that calculates the drift trajectories of trapped particles using realistic magnetic field models, and we have investigated the dependence of the model on important parameters such as the energy and pitch angle of the particles and the characteristics of the magnetic field. The major accomplishment of 1991 in this area was the application of this model to several joint studies that use other data sets. These studies allow us to investigate the relationship of the injection of energetic particles to other substorm processes such as the appearance of the aurora in the ionosphere and the formation of a magnetic reconnection region in the Earth's magnetic tail.

\section{Radiation from Space and Astrophysical Plasmas (G. R. Gisler [505-667-1375; FAX 505-665-3332;E-mailGISLER@ESSDP1.LANL.GOVJ)}

The goal of this research is to understand how relativistic charged particles originate in both astrophysical and solar system plasmas and how these energetic particles couple with background thermal plasma and electromagnetic radiation. Our most important accomplishment of 1991 came from the study of second-order Fermi acceleration of electrons in "swarms" of randomly moving magnetic inhomogeneities. These swarms are characterized by a Maxwellian velocity distribution, and correspond in real life to a distribution of Alfven waves in the interplanetary medium, or to a distribution of magnetized clouds in the interstellar medium of our galaxy. The electrons are assumed to arise from the background thermal population, so they are also characterized by a Maxwellian distribution. By doing test particle simulations of a variety of configurations, tens of thousands of electrons for each configuration of $m$ agnetic inhomogeneities, we found that power-law tails to high energies are produced only when the swarm thermal speed is low compared to the thermal speed of the particle population. For high swarm thermal speeds, bulk heating is produced without much boosting of electrons into a suprathermal tail. When power-law tails are produced, the differential energy spectral index lies between -1 and -2 . Most of the strongly boosted electrons are found to have initial energies well below the peak of the initial electron Maxwellian. This suggests that the boosting occurs mainly when individual particles of low energy are caught in multi-mirror collapsing traps and escape only after gaining large amounts of energy.

\section{E. Advanced Concepts (C. Myers [505-667-3466; FAX 505-667-3494] and R. W. Charles [505-667-4958;FAX 505-665-4955;E-mail 08194@INCDP1.LANL.GOV])}

Three projects are under way in 1992:

1. Admission as a voting member to DOSSEC.

2. Dating of young surfaces using cosmogenic helium (J. Poths)
This project explores the possibility of determining surface exposure ages using cosmogenic noble gases. Cosmic rays penetrate to a few meters depth in the Earth's surface, producing among other cosmogenic nuclides, ${ }^{3} \mathrm{He}$ and ${ }^{21} \mathrm{Ne}$. The buildup of these stable noble gases allows the "age" of a surface to be estimated. This technique 
should become an important age-dating technique for the Quaternary. We are comparing this technique with older techniques such as potassium-argon (done by others). Initial results for lavas from the Potrillo (southem New Mexico) and the Cima (California) volcanic fields indicate that the technique is reproducible at young ages and can readily distinguish between the ages of flows that geochemistry and potassium-argon dating suggest were erupted simultaneously.

\section{Volcanic Gas and Tritium Studies (F. Goff)}

Collection and analysis of gases and steam condensates from Mount St. Helens (Washington),
Pu'u Oo' (Kilauea, Hawaii), and Pacaya (Guatemala) volcanoes have been undertaken to determine the contribution of magmatic volatiles to the shallow (but new) geothermal system at Mount St. Helens and to attempt to characterize the tritium content of magmatic water at all these volcanoes. The latter objective stems from the hypothesis of S. Jones (Brigham Young University) that cold nuclear fusion in the earth should cause anomalous tritium to be emitted from the volcanoes. Mount St. Helens and Pu'u Oo' samples contain about 3 tritium units, well above 0 tritium units predicted by conventional wisdom. A suite of samples collected from Pacaya is undergoing analysis. Galaris (Columbia) will be sampled next. 
CONTRACTOR:

CONTRACT:

CATEGORY:

PERSON IN CHARGE:
OAK RIDGE NATIONAL LABORATORY

Martin Marietta Energy Systems, Inc.

Oak Ridge, Tennessee 37831

DE-AC05-840R21400

Geophysics and Earth Dynamics

R. T. Williams

A. Coupled Acoustic Seismic Imaging and Geochemical Studies of Magmatic Processes $(R . T$.
Williams [615-974-2366; FAX 615-974-2368;E-mail rick@geophysics.esd.ornl.gov], M. T. Naney, A.J. Witten, and G. K. Jacobs)

Tests of in situ vitrification (ISV) technology for stabilizing old waste also provide a unique opportunity to conduct research in seismic imaging and geochemistry. The test at Oak Ridge National Laboratory (ORNL) in 1991 was extensively instrumented with thermocouples (73 type-K, 12 type-C, and 2 type-S), optical pyrometers (6), pressure transducers (3), and heat flux sensors (6) within and around the melt. Volatiles and particulates emanating from the surface of the melt were sampled every $2 \mathrm{~h}$ using particle and reactive base-treated filters. Seismic data were collected along profiles using three-component geophones on the surface and in wells on either side of the melt and hydrophones in water-filled wells. DC electrical resistivity data were collected using vertical electrode arrays installed in six wells surrounding the melt. Ground-penetrating radar data were collected along a profile over the melt at the end of the test after all metal equipment had been removed from the site. Core drilling was conducted to determine the shape of the melt and to obtain samples for physical properties and petrologic studies.

A major objective of this research was to obtain complementary petrologic and geophysical data, both to determine melt properties and to study their use in methods for imaging natural lava lakes, magma chambers, and plutons. The advantages of using an ISV are: (1) it is large enough to use field-scale geophysical instrumentation but small enough to permit many aspects of a controlled and monitored laboratory experiment; (2) the chemical composition and physical properties of the pre- and post-melt materials can be well characterized; (3) the spatial and temporal history of the system during melting and crystallization can be monitored; and (4) gaseous and particle emissions from the ISV melts can be sampled and analyzed using standard methods developed for volcanic gases. The melt boundaries and some features of its interior have been imaged using the three-component seismic data. Other continuing work includes: comparison of the physical, thermal, and petrologic evolution of the melt to models of magmatic processes; elucidation of mechanisms controlling the release of volatile elements; and tomography based on the dc resistivity (in collaboration with Brian Spies of SchlumbergerDoll Research), hydrophone, and ground-penetrating radar data. 
CATEGORY:

PERSON IN CHARGE:
Geochemistry

R. E. Mesmer

\section{A. Geochemistry of Crustal Processes to High Temperatures and Pressures (D. J. Wesolowski [615-574-6903; FAX 615-574-4961], J. G. Blencoe [615-574-7041; FAX 615-574-4961; E-mail jblencoe@blencoe.chem.ornl.gov], and D.R.Cole [615-574-5473; FAX 615-574-4961; E-mail me@cole.chem.ornl.gov],with J.L.S. Bell and D.A.Palmer)}

This program provides fundamental geochemical information on fluid-rock interactions in the Earth's crust pertinent to magma/hydrothermal and hydrocarbon energy resources, large-scale fluid circulation, and remedial waste cleanup activities. Aqueous systems are investigated with a wide array of hydrothermal facilities that permit studies of metal complexation, mineral solubilities, acid and base dissociation, ion activity coefficients, and reaction kinetics. Studies of stable O, H, C, S isotope partitioning between minerals and fluids in experimental and natural systems help delineate the mechanisms and rates of fluid-rock reactions, fluid fluxes, and paleotemperatures. Silicate phase equilibria, crystallization kinetics, element partitioning, and melt/volatile interactions are studied under controlled redox conditions. Theoretical and empirical modeling complements the experimental approach by extending the results to experimentally inaccessible pressuretemperature-composition regions and by establishing the critical relationship between experimental and complex natural systems.

\section{Hydrothermal Geochemistry}

One of the most intriguing questions associated with aqueous and hydrocarbon fluid circulation in both sedimentary basins and geothermal systems is how aluminum is transported in brines to permit secondary porosity development, mineral alteration, and porosity occlusion via aluminosilicate dissolution and precipitation (feldspars, micas, clays, etc.). The most abundant potential organic complexing ligand encountered in sedimentary basin brines and some geothermal systems (e.g., Guaymas Basin) is acetate, a product of thermal degradation of buried organic matter.

To determine the importance of acetate in aluminum transport, an extensive series of potentiometric titrations of acetate buffers with aluminum chloride solutions was conducted using a high-temperature hydrogen-electrode concentration cell. The formation constants for $\mathrm{AlAc}^{2+}$ and $\mathrm{AlAc}_{2}^{+}$ were determined at temperatures of 25 to $125^{\circ} \mathrm{C}$ in 0.1 to 5.0 molal $\mathrm{NaCl}$ brines. Modeling of these results demonstrates that $\mathrm{AlAc}^{2+}$ may be the dominant aluminum species in solution in acetate-bearing sedimentary basin brines in the oil window.

Other organic acids reported in basinal brines include formate, malonate, and oxalate. The latter two are known to form extremely stable bidentate complexes with a variety of multiply charged cations, including aluminum, iron, calcium, and magnesium, at room temperature. In the past year, the dissociation constants of formic acid (25 to $\left.200^{\circ} \mathrm{C}\right)$ and malonic acid $\left(0\right.$ to $100^{\circ} \mathrm{C}$, collaboration with R. M. Kettler of the University of Nebraska) were determined in 0.1 to 5.0 molal $\mathrm{NaCl}$ brines by potentiometry. Quantitative studies of metal complexation by these acids can now begin.

Because the thermal stabilities of organic acids are important in assessing their role in metal transport, a series of studies has been initiated in which the decomposition of formic and oxalic acids is conducted in the high-temperature potentiometric cell. Instantaneous rates of decomposition have been determined mathematically from the derivatives of functions of the organic acid concentration vs time. In this way, the thermal stabilities of formic acid, 
formate, oxalic acid, bioxalate, and oxalate have been independently determined in the 150 to $250^{\circ} \mathrm{C}$ range.

A major study of the solubilities of calcite and dolomite was also completed in the 30 to $300^{\circ} \mathrm{C}$ range and 300 to 1300 bars in low-salinity $\mathrm{H}_{2} \mathrm{O}-\mathrm{CO}_{2}$ solutions. Both calcite and dolomite exhibit retrograde solubility with increasing temperature and prograde solubility with increasing pressure. The equilibrium constants for both calcite and dolomite can be simply modeled as a function of temperature and the density of the solvent water, with dolomite being less soluble than calcite by approximately $0.5 \mathrm{log}$ units at equivalent conditions. Extrapolation of the $\log \mathrm{K}$ values for calcite to low temperature and pressure demonstrates quantitative agreement with the best available literature data. The effect of increasing pressure on the solubility of these minerals is significant, in that burial and uplift as well as lithostatic to hydrostatic pressure changes may exert a major influence on secondary porosity development in carbonate source rocks and reservoirs.

\section{Stable Isotope Systematics of Fluid-Rock Interactions}

Many hydrothermal systems exhibit varying degrees of fluid-rock oxygen isotope disequilibrium for the bulk rock. A detailed comparison of data from a variety of active geothermal and paleohydrothermal systems indicates that the degree of equilibration of the bulk fluid and rock is related to the temperature and salinity of the system, with higher temperatures and salinities promoting more rapid approach to isotopic equilibrium. This relationship is entirely consistent with calculations based on experimental studies completed in this laboratory and elsewhere and carried out for a simple closed system model that estimates the fraction of isotope exchange between rock and fluid as a function of temperature, rock type, salinity of the fluid, grain size, fluid/rock ratio, and the rate of isotope exchange.

Fluid composition plays a major role in determining the degree of isotopic equilibration in short-lived natural systems. Furthermore, the fact that many silicate-fluid exchange reactions are relatively fast compared to geologic time scales suggests that observed variations in the degree of isotopic exchange may have resulted from periodic, local self-sealing of the fracture network throughout the time of hydrothermal activity in a given system. This observation may explain, in part, the apparent discrepancy often reported between "field rates" of fluid rock reactions estimated from natural systems and "laboratory rates" of similar reactions studied in controlled experiments.

Stable isotope systematics can also be effectively employed in studies of Earth-surface processes in which insight is gained as to paleoclimatic conditions via rock-atmosphere-ground water interactions. Pedogenic carbonates in well-preserved paleosols in late Pleistocene alluvial fan deposits in southcentral New Mexico have elevated ${ }^{13} \mathrm{C} /{ }^{12} \mathrm{C}$ ratios relative to paleosols in overlying Holocene fans. The change from heavier to lighter carbon isotope ratios occurs rather abruptly at 9,900 years ago. The higher ${ }^{13} \mathrm{C}$ values in the late Pleistocene appear to reflect abundant $\mathrm{C}_{4}$ grasses, which would have inhibited erosion in the upland areas, with a shift toward desertscrub (a $10 w{ }^{13} \mathrm{C}$ plant assemblage) in the Holocene. Pollen analyses of paleosols support this interpretation. The ${ }^{18} \mathrm{O} /{ }^{16} \mathrm{O}$ ratios in the carbonates are similar for Holocene and late Pleistocene paleosols, reflecting a mean annual temperature of roughly $13.8^{\circ} \mathrm{C}$, which apparently did not change significantly over the last 40,000 years in this region. It is known that high atmospheric $\mathrm{CO}_{2}$ contents adversely effect $\mathrm{C}_{4}$ plant metabolism. These observations, coupled with polar ice core $\mathrm{CO}_{2}$ data, suggest that a combination of reduced rainfall and increased atmospheric $\mathrm{CO}_{2}$ contributed to the demise of $\mathrm{C}_{4}$ vegetation in the southwestern United States.

Studies of this system are being conducted in collaboration with G. H. Mack, T. H. Giordano, W. C. Schaal, and C. Monger of New Mexico State University. Isotopic studies of the erosional source rocks of these alluvial fans-the Organ Cauldron and subvolcanic batholith, an early Oligocene volcanic sequence-are being conducted in collaboration with M. McCurry of Idaho State University and L. Farmer of the University of Colorado. 


\section{Thermodynamics of Rock-Forming Crystalline Solutions and Silicate Melts}

Because plagioclase feldspar is the most abundant mineral in continental crustal igneous rocks and because water is the primary fluxing agent in igneous processes, the albite-water system is an excellent analog for modeling the behavior of granitic magmas. New, thermodynamically rigorous models have been developed for this system that employ a two-parameter Margules or a threeparameter Redlich-Kister formulation. These models accurately describe all thermodynamic properties and phase equilibria in the albite-water system in the range of 700 to $1200^{\circ} \mathrm{C}$ and 1 to $8 \mathrm{kbars}$. Calculated activity-composition relations are similar to those predicted by equations based on PVT data (but the model does not require such data, which are exceedingly difficult to obtain), excess enthalpies are in substantial agreement with data obtained from calorimetry, and calculated phase relations are fully compatible with the best available experimental data. Activities of melt species were calculated using a standard state in which the activity of molecular water in the melt is numerically equal to the activity of total water in the melt.

A major modeling effort, in collaboration with C. V. Guidotti of the University of Maine and F. P. Sassi of the Universita di Padova, Italy, has also been focused on the solvus relations and thermodynamic mixing properties of paragonite-muscovite crystalline solutions. These micas are abundant in many shallow to intermediate depth crustal metamorphic rocks and continental granites and play an important role in magma generation and crystallization in the crust. X-ray diffraction data on natural $2 \mathrm{M}_{1}$ paragonites and muscovites have been evaluated, and accurate unit cell dimensions have been determined. Derived equations for molar volume indicate that excess molar volume is positive for sodium-bearing muscovites but is either zero or slightly negative for potassium-bearing paragonites.

Solvus data obtained by Blencoe (1974) for synthetic, binary paragonite-muscovite micas have been reanalyzed to delineate the solvus and to develop a new thermodynamic model. The data indicate that at pressures between 2 and 8 kilobars and temperatures above $400^{\circ} \mathrm{C}$, mutual paragonitemuscovite crystalline solution increases with increasing pressure, which helps to explain why most sodium-rich muscovites are found in high-pressure metamorphic rocks. This result further indicates that paragonite-muscovite micas are highly compressible, which is a new and unexpected finding. A polybaric, polythermal excess free-energy equation was developed from these data, which provides calculated paragonite-muscovite solvi for 1 bar to $10 \mathrm{kbars}$ and temperatures $>400^{\circ} \mathrm{C}$. Numerical geothermometers based on solvus data for natural paragonite-muscovite pairs were also developed.

\section{B. Crustal Stability of Hydrocarbons and C-O-H-N Fluids (J. G. Blencoe 1615-574-7041; FAX 615-574-4961; E-mail jblencoe@blencoe.chem.ornl.gov],with J.L.S. Bell, D. B. Joyce and J. C. Seitz)}

The objective of this project is to determine the thermodynamic and kinetic properties of carbonaceous fluids over ranges of pressure, temperature, and composition encountered in the Earth's crust. Such fluids play a dominant role in the transport of energy and material in the crust, and are themselves energy resources, in the form of biogenic and abiogenic natural gas and other hydrocarbon fluids. The pressure-volume-temperature (PVT) relationships of $\mathrm{C}-\mathrm{O}-\mathrm{H}-\mathrm{N}$ fluids and mixtures are evaluated to $500^{\circ} \mathrm{C}$ and $4 \mathrm{kbars}$ to derive all other thermodynamic properties. The equilibrium activity/composition relationships of $\mathrm{C}-\mathrm{O}-\mathrm{H}-\mathrm{N}$ fluids up to $8 \mathrm{kbars}$ and $1100^{\circ} \mathrm{C}$ are determined by employing novel experimental techniques. The thermal stability of organic compounds such as acetic acid are studied to identify unconventional biological inputs to $\mathrm{C}-\mathrm{O}-\mathrm{H}-\mathrm{N}$ fluids encountered in natural gas reservoirs. 


\section{PVT Properties of C-O-H-N Gases}

A unique high PT vibrating tube densimeter designed and constructed at ORNL has been used to obtain PVT data on binary and ternary mixtures in the system $\mathrm{CO}_{2}-\mathrm{CH}_{4}-\mathrm{N}_{2}$ at 50,100 , and $200^{\circ} \mathrm{C}$ and at pressures of $100,200,400,600,800$, and 1000 bars, encompassing the complete compositional range in this system, which is representative of natural gas reservoirs. Conservative estimates of accuracy are $P, \pm 2.0$ bar; $T, \pm 0.2^{\circ} \mathrm{C}$; and $\mathrm{V}, \pm 0.2 \%$. Preliminary modeling of the results indicates that temary molecular interaction parameters are small and that most of the binary data are well described by two-parameter Margules-type formulations.

At the higher temperatures and pressures, the deviation from ideal mixing of the pure end members for these gases are often less than 3\% of the total volume. However, at lower pressures and temperatures $\left(<200^{\circ} \mathrm{C}\right)$, mixtures containing $\mathrm{CO}_{2}$ exhibit remarkably large excess volumes. For instance, an $80 \% \mathrm{CO}_{2}, 20 \% \mathrm{~N}_{2}$ mixture at $50^{\circ} \mathrm{C}$ has an excess volume greater than $+20 \%$ of total volume at 100 bars and less than $-10 \%$ at 600 bars. $\mathrm{CO}_{2}-\mathrm{CH}_{4}$ and $\mathrm{CO}_{2}-\mathrm{CH}_{4}-\mathrm{N}_{2}$ mixtures also exhibit large and widely varying excess properties at these conditions.
Such large deviations from ideal mixing exert a profound influence on derived thermodynamic properties of the components, such as activity. Moreover, such information is critical in reservoir engineering and the transmission of natural gas through pipelines.

A detailed comparison of various published equations of state for pure gases and mixtures in the $\mathrm{CO}_{2}-\mathrm{CH}_{4}-\mathrm{N}_{2}$ system with the newly obtained data reveals that none of the currently available models adequately represents the actual behavior of these gases at all temperatures and pressures studied. Most of the equations break down near the critical point of $\mathrm{CO}_{2}$ for mixtures containing this gas in any significant proportions. Furthermore, it is clear that the major source of error in most of the available formulations is in the numerical description of the PVT properties of the pure end members. Of the equations of state investigated, DDMIX, the mixture property program available from the National Institute of Standards and Technology (Ely, 1988), is uniformly superior. However, most geoscientists and petroleum engineers are currently using some form of a modified Redlich-Kwong equation of state.

\section{Activity-Composition Relationships of $C-O-H-N$ Gases}

Experimental studies of $\mathrm{CO}_{2}-\mathrm{H}_{2} \mathrm{O}$ mixtures are now under way, employing an internally heated pressure vessel specifically designed for hydrogen service and capable of precise redox control. Silver oxalate and water are loaded into $\mathrm{Pd}_{75} \mathrm{Ag}_{25}$ capsules with $\mathrm{Ni} / \mathrm{NiO}$ or $\mathrm{Co} / \mathrm{CoO}$ to control oxygen fugacity. Hydrogen pressure is controlled with a separate $\mathrm{Pd}_{75} \mathrm{Ag}_{25}$ membrane, and the activity of water is computed from the reaction $\mathrm{H}_{2} \mathrm{O}=\mathrm{H}_{2}+1 / 2 \mathrm{O}_{2}$. The composition of the quenched capsules and the Gibbs-Duhem equation is then used to determine the activity-composition relationships of the mixtures. Measurements have been completed at $50^{\circ}$ intervals from 400 to $650^{\circ} \mathrm{C}$ at 500 bars total pressure, with successful reversals at all conditions studied. The results demonstrate large positive deviations from ideal mixing at the lower temperatures for $\mathrm{CO}_{2}$-rich mixtures, with the system approaching ideal mixing at $650^{\circ} \mathrm{C}$.

Development of an equation of state for $\mathrm{CO}_{2}-\mathrm{H}_{2} \mathrm{O}$ mixtures is also proceeding, the new model incorporating experimental solvus relations, measured mixing enthalpies and volumes, and the activity-composition results described above. Margules, Van Laar, and Quasichemical models are being empirically fitted to these data. Preliminary results demonstrate that combining the derivative properties, enthalpy, and volume with phase equilibrium data and the activity-composition data previously described offers a much more powerful and reliable avenue to a quantitative and thermodynamically rigorous equation of state for this system than has been available in the past. 
The kinetics of thermal decarboxylation of aqueous solutions of acetic acid and sodium acetate were evaluated at 335 and $355^{\circ} \mathrm{C}$ in the presence of various potentially catalytic surfaces. Such high temperatures were needed to observe the decomposition in a practical time scale. The results were then extrapolated down to the more geologically relevant conditions of 100 to $200^{\circ} \mathrm{C}$. Quartz, calcite, and pyrite were found to have minor catalytic effects; whereas calcium- and iron-bearing montmorillonite, hematite, and magnetite exerted a profound effect on rates of decomposition. The dependence of the rate on the surface area of pyrite per unit volume of solution was also studied. The results show that the decarboxylation of acetic acid is surface-catalyzed, with the cleavage of the carbon-carbon bond occurring while the acetate molecule is adsorbed. Entropies and enthalpies of activation for all catalytic substrates indicate the existence of a common rate-determining step.
In the absence of an effective catalyst, acetic acid survives indefinitely ( $>5$ billion years) at $100^{\circ} \mathrm{C}$. Iron-bearing phases such as magnetite and iron-montmorillonite rapidly catalyze the decarboxylation to $\mathrm{CH}_{4}$ and $\mathrm{CO}_{2}$, while minerals such as hematite induce an oxidative decomposition to $\mathrm{CO}_{2}$ and/or complex polycondensates. The half-life of acetic acid in the presence of calcium-montmorillonite is approxi- mately 410 years at $100^{\circ} \mathrm{C}$. Thus, it is clear that both the host lithology and the production rate of acetic acid from thermal degradation of more complex organic material are significant in controlling the concentration of this carboxylic acid at any given time in a basinal brine. Furthermore, circulating brines containing acetate may encounter lithologies that could rapidly induce decomposition to produce $\mathrm{CH}_{4}, \mathrm{CO}_{2}$, or complex polycondensates.

\section{Fundamental Research in the Geochemistry of Geothermal Systems (D. J. Wesolowski [615-574-6903; FAX 615-574-4961] and D. R. Cole [615-574-5473; FAX 615-574-4961; E-mail me@cole.chem.ornl.gov],with J.Horita)}

The goal of this research is to provide quantitative experimental data and theoretical models for fluid/rock interaction processes that bear a direct application in the discovery and exploitation of active geothermal systems. Simple analogs are studied to develop useful generalizations of the behavior of more complex systems in which $\mathrm{Na}-\mathrm{K}-\mathrm{Mg}-\mathrm{Ca}-\mathrm{Cl}-\mathrm{SO}_{4}-\mathrm{HCO}_{3}$ brines react with mineral assemblages in the system $\mathrm{Na}-\mathrm{K}-\mathrm{Ca}-\mathrm{Mg}-\mathrm{Fe}-$ $\mathrm{Al}-\mathrm{Si}-\mathrm{S}-\mathrm{O}-\mathrm{C}-\mathrm{H}$ at elevated temperatures and pressures.

\section{Geochemistry of Aluminum in Natural Waters}

Brine chemistry and the development and occlusion of porosity in most geothermal systems are highly dependent on the stability of aluminosilicate minerals in the rock matrix, such as feldspars, micas, and clays. An exact description of the distribution of the species $\mathrm{Al}^{3+}$ and $\mathrm{Al}(\mathrm{OH})_{\mathrm{y}}^{3-y}(\mathrm{y}=1$ to 4$)$ is required to predict the solubilities of these phases in natural waters. During the last year, a detailed study was completed on the hydrolysis of $\mathrm{Al}^{3+}$ in $\mathrm{NaCl}$ brines using a unique, high-temperature potentiometric cell. The equilibrium quotients for the reaction $\mathrm{Al}^{3+}$ $+\mathrm{H}_{2} \mathrm{O}=\mathrm{Al}(\mathrm{OH})^{2+}+\mathrm{H}^{+}$were obtained at 25-degree intervals from 25 to $125^{\circ} \mathrm{C}$ in 0.1 to 5.0 molal $\mathrm{NaCl}$ solutions. Because of the exceedingly low solubility of most aluminum minerals, these two species will dominate the transport of aluminum in acidic brines to at least $150^{\circ} \mathrm{C}$. A quantitative model for this reaction as a function of temperature and ionic strength has been developed.

These results, combined with previous studies completed in this project and the aluminum acetate complexation study described in Part A of this section, provided the means to interpret the extensive gibbsite- $\mathrm{Al}(\mathrm{OH})_{3} \mathrm{cr}$-solubility data in near- 
neutral pH solutions reported in previous years. The formation constant for the reaction $\mathrm{Al}(\mathrm{OH})^{2+}+$ $\mathrm{H}_{2} \mathrm{O}=\mathrm{Al}(\mathrm{OH})_{2}^{+}+\mathrm{H}^{+}$has been modeled to $200^{\circ} \mathrm{C}$ using these results and critically evaluated literature data.

\section{Oxygen and Hydrogen Isotope Systematics in Brines}

Studies of the distribution of stable oxygen and hydrogen isotopes in geothermal waters and m ineral assemblages provide quantitative information on reservoir temperatures, fluid sources and fluxes, and the extent of subsurface processes such as steam separation. However, the effect of dissolved ions on the partitioning of these isotopes between brines, steam, and minerals, although known to be significant, has largely been ignored because of uncertainty in the magnitude of the effect at high temperature. During the past year, measurements of the effect of pure salts in the system $\mathrm{Na}-\mathrm{K}-\mathrm{Ca}-\mathrm{Mg}-\mathrm{Cl}-\mathrm{SO}_{4}$ on the water liquid-vapor partitioning of hydrogen and oxygen isotopes have been completed for 0.5 to 6.0 molal salt solutions in the range 50 to $100^{\circ} \mathrm{C}$. The effect of 1.0 to $5.0 \mathrm{molal}$ $\mathrm{NaCl}$ has been determined to $200^{\circ} \mathrm{C}$.

Sodium and potassium salts have little or no effect on the partitioning of oxygen isotopes at temperatures up to $200^{\circ} \mathrm{C}$. On the other hand, calcium and $m$ agnesium salts of chloride and sulfate exhibit large salt effects, to the extent that isotopic studies of systems involving brines containing less than 1 molal of these cations must take into account the salinity effect in the derivation of temperatures and water/rock ratios.

All the salts studied exert significant effects on the partitioning of hydrogen isotopes between brines and vapor. Chloride salts affect the partitioning by 1 to 2 per mil per molal chloride, with only minor effects related to the nature of the cation. Sulfate salts exhibit a smaller salt effect, indicating that the doubly charged anion is not more strongly hydrated than the singly charged chloride ion. Both oxygen and hydrogen isotope salt effects are linear with the molality of the dissolved salt. For chloride salts, the hydrogen isotope salt effect decreases with increasing temperature to about $100^{\circ} \mathrm{C}$ and remains constant at approximately 1 per mil per molal chloride in the 100 to $200^{\circ} \mathrm{C}$ range.

D. Stable Isotope Systematics During Burial Diagenesis in the Alberta Basin: an Ion Microprobe Study (D.R. Cole [615-574-5473; FAX 615-574-4961;E-mail me@cole.chem.ornl.gov],with L. R. Riciputi, and W.H. Christie)

In this project, the micron-scale spatial resolution, elemental and isotopic imaging, and quantitative trace element and isotope ratio analytical capabilities of a state-of-the-art Cameca $4 f$ ion microprobe are being developed and used in a study of the fluid/rock interactions associated with burial and hydrocarbon generation in carbonates and clastics of the Alberta Deep Basin. A detailed study has been initiated on the trace element distributions in primary and diagenetic calcites and dolomites of the Nisku Formation, an important petroleum host rock in the Alberta Basin. Distributions of iron and manganese indicate changes in redox conditions during early diagenesis and later fluid-flow events. Barium, $\mathrm{B}, \mathrm{Na}, \mathrm{Mg}, \mathrm{Si}$, and $\mathrm{Al}$ changes with time suggest significant changes in fluid source coincident with dolomitization of the calcite reefs, a process leading to increased permeability. In general, the chemical variability on a fine scale revealed by the ion probe indicates that the chemical composition of the diagenetic carbonates responds to a complex interplay between primary composition; changes in chemistry, temperature, and flux of fluids through time; and the variable chemistry of small, rock-dominated microenvironments.

Sulfur isotope ratios (precision of 0.5 per mil) have been measured in a variety of pyrite grains, some as small as $40 \mu \mathrm{m}$, from both the Nisku and the sour gas province located farther southwest in the Alberta B asin. Very large variations in the ratios (up to 40 per mil) appear to reflect differences in sources of reduced sulfur-either thermogenic or bacteriologic reduction of seawater sulfate-or variations in the fluid flow dynamics of the system, either open or closed. Considerable progress was also made during this period on the development of oxygen isotope ratio measurement techniques. Precisions of 1 per mil have been obtained on 
magnetite standards with spatial resolution on the order of $10 \mu \mathrm{m}$. Because the remnant magnetism of diagenetic magnetites can be used to date late diagenetic events, coupling such observations with oxygen isotope and trace element analyses offers the opportunity to develop a time-temperature-fluid source history of the Alberta Basin and other hydrocarbon-bearing systems.

\section{E. Advanced Concepts (D. R. Cole [615-574-5473; FAX 615-574-4961; E-mail me@cole.chem.ornl.gov] and D.J.Wesolowski [615-574-6903; FAX 615-574-4961])}

This project explores topics in the geosciences that offer the opportunity to open new frontiers of scientific inquiry or methodology. These goals are often achieved by developing unique laboratory facilities, techniques and theoretical models. The benefits of this exploratory research impact many areas related to the domestic energy supplies.

Design and construction of a new high pressure-temperature, flowing emf cell was completed this year. The new cell will enable the measurement of $\mathrm{pH}$ in aqueous solutions to at least $400^{\circ} \mathrm{C}$ and $1 \mathrm{kbar}$, an accomplishment never before achieved. This capability will enable the study of the hydrogen ion activity in supercritical brines such as those encountered in magma/geothermal systems and will permit measurements of the pressure dependence of protolytic aqueous reactions relevant to deep sedimentary basin settings.

Geologic applications of the Cameca $4 f$ ion microprobe are being developed. A new method for the quantitative analysis of rare earth elements in a variety of silicate structures, involving the use of doubly charged ions of odd mass isotopes, was demonstrated that is four times faster than current methods, with sensitivities of 5 to $50 \mathrm{ppb}$. Energy offset techniques have also been developed that allow linear calibration curves to be generated for $B$, $\mathrm{Na}, \mathrm{Al}, \mathrm{Ca}, \mathrm{Mg}, \mathrm{Mn}, \mathrm{Fe}, \mathrm{Sr}$, and $\mathrm{Ba}$ in carbonates, with detection limits of $<1 \mathrm{ppm}$ and precisions of approximately $10 \%$ on spot sizes of 15 to $30 \mu \mathrm{m}$. Elemental imaging using the probe has been expanded to enable trace element imaging of fields up to $500 \times 500 \mu \mathrm{m}$ with resolution of about $10 \mu \mathrm{m}$.

A collaboration with the Advanced Inorganic Materials Group continues to explore novel methods of materials synthesis using geochemical experimental techniques. Attempts to synthesize covalently bonded carbon-nitride compounds, expected to have a hardness similar to diamond, demonstrate that extremely high pressures are required. However, potential precursor materials with short-range, trigonal, layered structures were formed at $700^{\circ} \mathrm{C}$ and $2.25 \mathrm{kbars}$.

A collaboration was initiated with $L$. A. Odom of Florida State University to investigate the potential use of paramagnetic defect centers in natural quartz as a geochronometer. Such defect centers are stabilized in quartz as a result of gamma irradiation from natural unstable isotopes (uranium, thorium, etc.) as well as cosmic rays. Extremely high dose rates available at the High Flux Isotope Reactor at ORNL are needed to test hypotheses regarding the annealing rates of defect centers and also to help distinguish between centers resulting solely from radiation damage and those associated with trace impurities, such as aluminum and iron, in the quartz matrix. 
CONTRACTOR:

CONTRACT:

CATEGORY:

PERSON IN CHARGE:
PACIFIC NORTH WEST LABORATORY

Battelle Memorial Institute

Richland, Washington 99352

DE-AC06-76RLO 1830

Energy Resource Recognition, Evaluation, and Utilization

E. W. Kleckner

A. Remote Sensing: Geoscience Data Analysis and Integration (H. P. Foote [509-376-8418] and G. E. Wukelic)

This research emphasizes the development of advanced interactive techniques for processing, analyzing, and displaying combinations of remote sensing and geosciences data. Both data types are becoming more abundant and more relevant to DOE's responsibilities in resource discovery, energy development, environmental restoration, global environmental change, and national security. Previously developed techniques have been effectively applied in a variety of earth science, environmental, and national security programs. Large multidimensional geophysical and geologic data sets are now becoming commonplace. Examples include three-dimensional seismic reflection data, computer tomography, and output from three-dimensional simulation models. These data sets may contain from $10^{6}$ to $10^{8}$ data values, and thus are of the same order of size as multispectral satellite data sets. The 1989 California Loma Prieta earthquake and aftershock history is a good example of this type of data set, which consists of several thousand hypocenter locations with time of occurrence and magnitude. We have used a workstation, coupled to a video disk system, to record a computer-generated moving display of this data set. The video display allows a viewer to assimilate quickly the principal spatial and temporal features of the aftershock history. The video sequence may be recorded for later review, comparison, or distribution to other investigators.
We have produced computer-simulated flyovers by combining digital topographic data with satellite imagery and digitized geologic maps. These video sequences have been produced for the Valles Caldera, New Mexico; Yucca Mountain, Nevada; and Nevada nuclear test sites. We are currently investigating a new approach to visualization and interaction with large data sets. Computer hardware is now fast enough to create what is frequently called a virtual environment. In a virtual environment the "view through a window" approach to visualization currently in use is taken to the next step. The user, in effect, steps through the viewing window and can interact with the data set in a synthetic threedimensional space. The illusion is created by tracking the position and orientation of the viewer, and generating a display to match. The advantage of this approach is the ability to interact in a more natural way with a three-dimensional data set. We are evaluating several possible applications of virtual environments to geophysical data sets. The initial problem is matching a potential application to the current hardware constraints. One promising approach is an environment that would support analysis of three-dimensional seismic hypocenters and associated faults and surface features. We have begun evaluation of display requirements on a Stardent graphics for this application. We are also investigating six degree-of-freedom space trackers and stereo viewing options. 
B. Remote Geologic Analysis (M. G. Foley [509-376-8635; FAX 509-376-5368; Internet mg_foley@pnl.gov],P.G.Heasler, and K.A.Hoover)

We have developed an automated geomorphic pattern-recognition method for identifying buried geologic structures manifested in erosional topography. Using only a digital elevation model (DEM), we can identify linear segments of valley bottoms and fit planes to those segments that are coplanar. Our algorithms find all points in the DEM that are lower in elevation than their neighbors, string these low points together into continuous valley bottoms, and fit vectors to colinear segments of the valleys. The analysis then compares valley-segment vectors to find those that are coplanar and calculates the locations and orientations of the resulting planes. Statistical clustering of the planes allows us to spatially locate zones of anomalously high density for comparison with mapped geologic features. Implicit in this approach is the assumption that segments of erosional valleys lying along approximately planar faults or fracture zones are coplanar. Coplanar analysis detects planar correlations in any three-dimensional orientation, from vertical to horizontal; however, because they are not expected to control the erosional development of drainages, we do not look for shallowly dipping planes. We analyzed the Yucca Flat area of the Nevada Test Site to test our approach in an area where subsurface geology and geologic structures are relatively well known. The coplanar pattem-recognition analysis identified 26,473 individual planes in a $30-\mathrm{m}$ resolution DEM for a 33- $\times$ 42-km area. In the 21 most significant clusters of planes, we compared the surface traces with the following: topographic features, mapped geology and geologic structures, fractures activated during nuclear tests, litho-stratigraphic isopach and structural contour maps, gravity anomaly plots, a plot of basin-fill thickness modelled on gravity anomalies, and a magnetic anomaly map of the northern part of Yucca Flat. We found strong correlations between plane clusters, segments of surficial faults, and apparent structures in the subsurface. The automated analysis apparently detects associations of subparallel fractures in the upper few kilometers of the Earth's crust that we infer are upward-diverging fault or fracture splays reflecting faults or folds at greater depth. This inference suggests our approach could be useful for identifying fracture systems that control the migration of fluids (e.g., natural gas, hydrothermal fluids, contaminated groundwater) in low-permeability rocks. The capability to detect fracture zones and infer the nature of the underlying structure would also be applicable to seismic hazard analysis, especially to predict earthquakes that may be generated by faults having little or no mapped surface expression.

\section{CATEGORY:}

\section{PERSON IN CHARGE:}

Solar-Terrestrial Interactions

E. W. Kleckner
The Earth's upper atmosphere and magnetosphere are strongly coupled and are constantly undergoing dynamic changes as a result of solar activity and the energy that is delivered to the earth in the form of the solar wind. This energy is transfered to the magnetospheric plasma through a variety of processes, where it is stored in the form of electric and magnetic fields and energetic particles. Ultimately, much of this energy is released into the upper atmosphere impulsively, in the form of auroral and magnetic storms, or more passively through heating and convection of the atmospheric components. The consequences of this energy influx are felt on Earth by its influence on communications, radar, and power grid systems, as well as the upper atmosphere where this influx can be a major factor in ionization, thermal structure, and dynamic behavior of the gases. This program is centered on aeronomy and space physics in the upper atmosphere, while in the lower atmosphere it is concerned with the processes of radiative transfer. Specifically, the aeronomy program is concerned with processes at the boundaries between the plasmasphere-magnetosphere and the ionosphere- 
stratosphere regions. While significant advances have been made in our understanding of these regions during the past two decades, there are still outstanding questions as to energy coupling mechanisms at the interfaces. Our understanding of the physics of these zones is particularly important when attempting to arrive at definitive solarterrestrial cause and effect relationships. A multiyear data base of direct and diffuse multi-spectral solar radiation measurements forms a baseline for much of the insolation research program. Our research has two goals: to measure the spectral characteristics of scattered and direct sunlight under various atmospheric conditions, and to create models of the effects of clouds and trace species in the troposphere and lower stratosphere on incoming solar radiation. These natural or human-made trace species include aerosols and gases.

\section{A. Department of Energy Aeronomy/Insolation Studies (E. W. Kleckner [509-376-8425; FAX 509-376-5368; Internet ew_kleckner@pnl.gov],D.W.Slater, and N.R. Larson)}

One consequence associated with energy storage within the magnetosphere is the transfer of energy from highly energetic ions to thermal electrons within near-Earth space, and ultimately into the upper atmosphere where ambient electron temperatures can reach several degrees. The resulting excitation of atomic oxygen leads to photon emissions that, in turn, are useful markers for this energy influx. An extensive parametric study was undertaken with researchers from the University of Michigan to characterize the conditions within the Earth's upper atmosphere and possible coupling mechanisms to the magnetosphere that could best explain the seasonal and solar cycle variations of electron temperature enhancements as monitored indirectly by the Pacific Northwest Laboratory (PNL) photometer chain. This has led to an explanation of the variability of emission intensities and occurrences that was tested against results of a statistical study of these variations using the PNL data. The required reduction of the magnetospheric energy source to power these features is postulated as being caused by compositional changes of the high-energy magnetospheric plasma. Studies of in situ measurements of these compositional changes and the resulting effects on energy coupling into the upper atmosphere are currently well under way. With the increasing pace of technology development, we have designed and constructed fully automated charge coupled device (CCD) imagers to enhance, and soon replace, the PNL photometer network in monitoring telltale optical emissions from the upper atmosphere. Software development for the Macintosh control computer has been upgraded and is integrated into an image analysis package; this will allow remote control and viewing of images if direct user control is desired. Likewise, programming of the EPROM on the controller circuit board that is responsible for carrying out many of the actions demanded by the Macintosh, as well as self-diagnostics and safety features, has been completed and tested. We are now entering the field test phase of operations. The intensified version of our original CCD imager has been converted from a UNIX operating system to a Macintosh control system to offer uniformity of operations between systems. The eruption of Mount Pinatubo in the Philippines in June of 1991 resulted in the most significant aerosol pertubation to the stratosphere since early in this century. Basic Energy Sciences Geosciences instruments developed by PNL measured an $11 \%$ decrease in solar radiation available to the northern United States in the mid-visible region of the spectrum for the regional mid-April maximum perturbation. Aerosol particle growth, dominated by sulfuric acid, was observed to be m uch more significant than that resulting from $\mathrm{El}$ Chichon volcano in 1983 . As a result, we are estimating that the decay of Pinatubo aerosols from the 1991 eruption will require a minimum of 2 years. This is long enough to cause a temporary net cooling of the Earth's surface, provided that other agents of atmospheric change remain constant. We are engaged in a cooperative research effort on the effects of cloud occlusions of the sun on energy cycling within solar heat engines. The study requires high time resolution direct solar beam measurements obtainable with a rotating shadowband radiometer (RSR). The magnitudes and time spans of solar beam occlusions are quantified to determine their influence on a $25 \mathrm{~kW}$ Stirling engine system. While many occlusion events are typically seen during a day, the number that lead to a break in operation of the engine are only about $4 \%$ during the spring to 
autumn months. Analysis of winter data is not yet completed. By modeling the energy response of the engine to the observed direct beam data, it will be possible to assess the solar energy potential of m any sites simply by operating an inexpensive RSR on location. 
CONTRACTOR:

CONTRACT:

CATEGORY:

PERSON IN CHARGE:
SANDIA NATIONAL LABORATORIES

Albuquerque, New Mexico 87185

DE-AC04-76DP00789

Geophysics and Earth Dynamics

M. C. Walck

A. Acoustic Emissions and Damage in Geomaterials (D. J. Holcomb [505-844-2157; FAX 505-844-7354])

A fundamental parameter in many geophysical and geotechnical problems is the state of stress in the rock mass of interest. The standard techniques for determining in situ stress have limitations such as cost, limited depth range or reliance on unproven models. A method that promises to circumvent many of these difficulties has been developed as a result of research on damage and acoustic emissions in rock. Using a phenomenon known as the Kaiser effect, which acts as a marker indicating the stress a sample has experienced, the theory shows how to use core samples to determine the complete stress tensor. The advantages of the method are (1) no expensive downhole testing is required, (2) depth limitations are removed, (3) no model of the material properties is required, and (4) the complete stress tensor is determined, both magnitude and orientation. The theory has been applied to core recovered from the Long Valley Magma Energy borehole.

Lectures on the theory were given at a seminar series devoted to discussing possible contributions of acoustic emission techniques to petroleum production, sponsored by Shell Research at The Hague, Netherlands. The possibility of determining the complete stress tensor from core-based measurements has economic implications. Maintaining stable boreholes depends on a knowledge of the state of stress at depth. Enhanced oil recovery techniques, such as water flooding and hydraulic fracturing, depend on knowing the orientation of the stress field.

The first field experience with the new theory was at the Long Valley m agma energy site. Oriented core was retrieved from a depth of $7000 \mathrm{ft}$ and tested to determine the in situ stress. Theory predicts that by applying extensional loading (two of the principal stresses equal and the third constant), the orientation and magnitude of the stress field from which the core was retrieved can be found. Testing to determine orientation has been completed and clearly shows an effect resembling the predicted results. Independent verification will require completion of hydraulic fracturing measurements in the summer of 1992.

\section{B. Transport Properties of Fractures (S. R. Brown [505-844-0774; FAX 505-844-7354])}

Fluid flow in fractured rocks is of primary importance to oil recovery; this research focuses on the physics of transport of fluid and electric current through fractures in rock and the scale dependence of related properties. This work should prove useful to many energy programs involving fractured rock, including fractured oil/gas reservoirs, geothermal reservoirs, and waste isolation and remediation sites. The transport of fluid and conduction of electricity along a single fracture have been studied previously by numerical simulation and theories of random resistor networks. These results show that the transport properties of rough-walled fractures deviate significantly from the commonly used parallel-plate model of a fracture. Laboratory experiments are being done to test these results. Four specimens of natural rock joints and one control specimen with grit-blasted surfaces have been prepared for use in these laboratory experiments. A new sample fixture along with two fluid flow meters 
have been built to allow both the electrical conductivity and the fluid permeability to be measured simultaneously as a function of fracture aperture. The experiments will be completed by the end of FY 1992.

One-in.-diam core samples from 23 natural rock joints have been collected for a study of the roughness and degree of mismatch of fracture surfaces. The resulting data have led to the development of a simple mathematical model of a rough-walled fracture, which contains only three free parameters. This model can be used to generate realistic computer models of rough fractures for use in the study of various physical properties including the fluid permeability, elastic stiffnesses, and the frictional shear strength.

A study of potential applications of electrokinetic measurements to the description of the permeability distribution and the fluid velocity fields in fractured and other porous media has been completed. Preliminary experiments have shown that measurable electric currents are generated by water flowing through packings of sand. More detailed laboratory bench-top experiments of flow in sandstone slabs with heterogeneous permeability and porosity distributions have been done. The principal observations are: (1) the electric potential generated changes sign as the fluid velocity direction reverses, (2) the magnitude of the electric potential agrees qualitatively with that of the the fluid velocity, and (3) the electric potential is strongly affected by fluid permeability barriers and other sample heterogeneities. Further work is in progress to understand the physics of the process and the effect of natural heterogeneities in the geometry of the porous medium.

\section{Reservoir Characterization: Reef-Type Reservoir (G. J. Elbring [505-844-4904; FAX 505-844-7354] with R. M. Turpening, MIT)}

Better characterization of oil and gas reservoirs can be accomplished through the use of combined compressional (P) and vertically polarized shear (SV) wave data sets. In conjunction with Roger Turpening of MIT, a reef-type reservoir will be imaged with directly generated crosshole data sets of each of the above wave types. Downhole P-wave sources are commercially available, and Sandia National Laboratories are providing the shear-wave source technology.

Cross hole SV wave data were collected at the site between boreholes spaced $600 \mathrm{~m}$ apart. Processing of these data revealed clear SV arrivals. Velocities from these arrivals will be compared to shear-wave velocities determined from vertical seismic profiling data to examine anisotopy of the formations.

\section{Advanced Concepts}

\section{Lattice Gas Automata (LGA) (H. W. Stockman [505-844-0975; FAX 505-844-7354])}

LGA can be used to calculate flow and transport of solutes, colloids, and immiscible liquids through fractured and porous media. Recently, the Sandia LGA codes were completely rewritten to provide greater flexibility and speed and to allow more complicated boundary conditions. A single code can
Problems were encountered in loss of source strength at greater depths, and changes in the source design are under way to remedy this. Cross hole P-wave data were also collected by MIT and are being interpreted.

A process was developed for applying a time-varying filter to the source reference trace to remove harmonics and flatten the frequency spectrum. This improves the waveform of the crosscorrelated data and increases the accuracy of time picks and velocity determinations.

The integrated crosshole $P$ and SV data sets should provide not only better spatial resolution as compared to surface seismic methods but will also provide greater information on the properties of the reservoir itself. 
automaton. LGA codes must use temporal and spatial averaging to produce useful flow and transport data; in most LGA codes, the averaging process greatly slows the calculation and becomes the rate-limiting step. Therefore, the averaging algorithms have been designed to be extremely efficient, so they add comparatively little overhead to the simulations.

Applications of the LGA codes are quite varied. With the oscillatory pressure gradient, effects of "barometric pumping" on fission gas and radon transport in dual-porosity, fractured media can be modeled (Nilson, JGR v96 \#B 13, pp. 21,933-21,948,
1991). This phenomenon causes radically increased gaseous transport above underground nuclear test sites and may contribute to high radon levels of homes in the western United States. Other applications involve more basic research. Two examples are modeling the effects of temperaturedependent viscosity on the patterns of convection in magma chambers and modeling the extrusion of viscosity-zoned magmas through pipes and layered sills (in cooperation with $C$. $R$. Carrigan of Lawrence Livermore National Laboratory).

\section{Boundary Conditions for the Earth's Crust (L. W. Teufel [505-844-8680; FAX 505-844-7354])}

The petroleum industry is, and has been for decades, changing the state stress over large volumes of the lithosphere by reducing the pore pressure in hydrocarbon reservoirs. As pore pressure is reduced, the effective stresses in the reservoir will increase, but at different rates, depending upon the boundary conditions on the reservoir and the poroelastic deformation behavior of reservoir rock and bounding formations. Previously, as part of a cooperative Department of Energy research program with Phillips Petroleum Company, the effect of pore pressure drawdown on the minimum horizontal in situ stress in the Ekofisk Field (a chalk hydrocarbon-reservoir in the North Sea) was determined from shut-in pressure data of hydraulic fractures. These stress data were used to characterize the boundary condition of the reservoir. The reservoir followed a stress path, $K$ (defined as the change in effective horizontal stress/change in effective overburden stress from initial reservoir conditions) of about $\mathbf{0 . 2}$. This stress path is not a constant total-stress boundary condition, where an incremental increase in effective overburden stress is matched by an identical increase in effective horizontal stress (i.e., shear stress remains constant with decreasing pore pressure, and $\mathrm{K}$ equals 1 ). The
$K$ value measured in the reservoir is also much smaller than the $\mathrm{K}$ value of about 0.4 to 0.6 measured in uniaxial strain tests of reservoir chalk, which represent a fixed-displacement boundary condition.

Using hydraulic fracture stress data obtained from Amoco Norway, a stress path during pore pressure drawdown has been constructed for the Valhall Field, a chalk hydrocarbon-reservoir near the Ekofisk Field. The reservoir stress path $\mathrm{K}$ is 0.16 , which is nearly the same as measured in Ekofisk. The in situ stress data from these two reservoirs suggest a third possible boundary condition, constant effective horizontal stress. For the Ekofisk and Valhall reservoirs, the increase in shear stress with increasing mean stress lies between the stress path predicted by uniaxial strain and constant effectivehorizontal-stress boundary conditions.

Stress data taken during the pore pressure history of other reservoirs will provide additional information about the appropriate boundary conditions for the lithosphere. We are now in the process of contacting several petroleum companies to determine the possibility of obtaining hydraulic fracture data during the production life of reservoirs in different geologic and tectonic environments.

\section{E. Thirty-Third U.S. Rock Mechanics Symposium (Wolfgang R. Wawersik 1505-844-4342; FAX 505-844-7354])}

The 33rd U.S. Symposium on Rock Mechanics took place June $7-10,1992$, in Santa Fe, New Mexico. The conference was sponsored jointly by the U.S. National Committee for Rock Mechanics, the Department of Energy Office of Basic Energy
Sciences, and the Intermational Society for Rock Mechanics. The Santa Fe Rock Mechanics meeting was hosted by four national laboratories (Lawrence Berkeley, Lawrence Livermore, Los Alamos, and Sandia) with participation of over 40 session and 
workshop developers from academia, industry, and government including the U.S. Bureau of Mines and the U.S. Geological Survey.

The program of the 33rd U.S. Rock Mechanics Symposium combined 16 technical sessions with related workshops and 2 short courses. The technical sessions were selected to optimize exchanges of geoscience elements in civil engineering, engineering geophysics, engineering mechanics, hydrology, mining engineering, petroleum engineering, physics, and tectonophysics. The technical sessions also served subtopics in underground excavation, underground storage, mine design, reservoir management, and fault mechanics. Four workshops were Coal Mine Pillar Design, Modeling of Fractured Reservoirs, Geotechnical Design Methodology, and Induced Seismicity. Two short courses disseminated ideas concerning the use of fractals in the geosciences and geostatistics in rock mass characterization. Major findings were published in hard-bound proceedings containing over 100 technical contributions selected from over 275 abstracts. Proceedings of the Mine Pillar Design and Induced Seismicity workshops were distributed in separate proceedings. Major ideas related to fractured reservoirs, geotechnical design methodology, and fracture evolution in rock masses were presented in keynote papers.

The symposium was attended by over 400 scientists and engineers with exceptionally strong representation by industry and by the geoscience/ tectonophysics community. The symposium also supported the attendance of approximately 60 students in the geosciences and geotechnical engineering.

\section{CATEGORY: Geochemistry}

PERSON IN CHARGE: $\quad$ M. C. Walck

\section{A. Magmatic Volatiles (H.R. Westrich [505-844-7354; FAX 505-844-7354])}

The magmatic volatiles project is in its final year of support. Results from this project were intended to enhance our knowledge of the volatile contents of shallow magmatic systems and their degassing behavior during volcanic eruptions. This year, electron and ion microprobe analytical techniques have been employed to measure the $\mathrm{H}_{2} \mathrm{O}$, chlorine, and sulfur contents of both trapped glass inclusions and matrix glasses from the June 15, 1991, Mount Pinatubo eruption. Comparison of pre- and post-eruptive dissolved volatile contents of tephra samples yields an estimate of the volatiles released during the climatic June 15 eruption. The petrologic method was found to grossly underestimate sulfur degassing when compared to TOMS satellite $\mathrm{SO}_{2}$ measurements $(20 \mathrm{Mt})$. Examination of glass inclusion textures in common phenocryst hosts have suggested that a separate vapor phase coexisted with the Pinatubo dacite prior to eruption; that is, void volumes suggest that they represent primary vapor bubbles. Thermodynamic calculations show that the sulfur was present as $\mathrm{SO}_{2}$ in the water-rich vapor phase. Minimum estimates of $\mathrm{H}_{2} \mathrm{O}$ and chlorine released during this eruption were 240 and $4.5 \mathrm{Mt}$, respectively. Similarly derived, water-rich gases may be a common source of the excess sulfur frequently reported for explosive volcanism.

\section{B. Cation Diffusion Rates in Selected Silicate Minerals (R. T. Cygan [505-844-7216; FAX 505-844-7354], with H. R. Westrich and C. S. Schwandt)}

The occurrence of disequilibrium behavior in geological materials is often attributed to the limited diffusion of chemical species through a silicate mineral. Evaluation and modeling of geochemical processes related to nuclear waste, energy, and materials problems will require the accurate determination of cation diffusion data in a variety of silicate minerals. In an effort to evaluate the relatively slow diffusion of $\mathrm{Mg}^{2+}, \mathrm{Mn}^{2+}$, and $\mathrm{Ca}^{2+}$ in phases such as garnet (where diffusion rates are on 
the order of $10^{-21}$ to $10^{-18} \mathrm{~m}^{2} / \mathrm{sec}$ in the temperature range of 700 to $1000^{\circ} \mathrm{C}$ ), we have developed a new technique for the preparation of diffusion couples using thin film deposition. Polished surfaces of natural pyrope and grossular garnets have been subjected to electron beam and resistive evaporation of $\mathrm{MgO}$ under ultrahigh vacuum conditions. Profilometry and scanning electron microscopy analysis suggest the oxide thickness on the gamet substrate is on the order of 1000 to $2000 \AA$. This layer provides a source of $\mathrm{Mg}^{2+}$ for diffusion into the garnet. Initial experiments have used the natural abundance of the magnesium isotopes; however, to evaluate the self-diffusion coefficient, we will use an enriched ${ }^{25} \mathrm{MgO}$ source. Diffusion anneals performed at $900^{\circ} \mathrm{C}$ with a fixed oxygen fugacity of $10^{-12}$ for $40 \mathrm{~h}$ provide clean homogeneous surfaces for ion microprobe analysis; there is no evidence of a disrupted interface. Depth profiles obtained using a Cameca $4 f$ ion microprobe are reproducible and clearly define the oxide-gamet interface. Diffusional penetration depths for $\mathrm{Mg}^{2+}$ are on the order of $0.3 \mu \mathrm{m}$.

\section{Isotopic and Mineralogical Indicators of Infiltration and Vertical Fluid Movement in Unsaturated Zones of Semiarid Terrain (S. J. Lambert [505-844-7876; FAX 505-844-7354])}

The objective of this project is to determine how the depth, volume, rate of infiltration, and groundwater travel-time between surface and subsurface are governed by the seasonal distribution of rainstorms and storm intensity. In the part of the project dealing with direct observations of infiltration in the unsaturated zone, 14 dripwater-sampling stations have been established in Carlsbad Caverns, located in the northern Chihuahuan Desert of southeastern New Mexico. Dripwaters at each station are monitored monthly for drip rate and isotopic composition. The ${ }^{18} \mathrm{O} /{ }^{16} \mathrm{O}$ and deuterium/hydrogen ratios in cavern dripwaters (compared to those of rainwaters collected at the surface) will serve as natural environmental tracers for infiltration of stormwaters. The infiltration rates and isotopic compositions at various locations and depths are compared with intensities and isotopic compositions of rainstorms. From this comparison, the magnitudes, durations, and time delays of recharge pulses relative to surficial events can then be inferred. To date, 6 months of baseline data have been collected. Variations in drip rates have been observed at 11 localities. Subsurface mixing of recharge waters has yielded an isotopically homogeneous groundwater regime over $3 \mathrm{~km}^{2}$, although statistically significant isotopic variations in recharge waters have been observed at one sampling locality. Three sites in desert areas have been identified for possible examination of secondary soil minerals as proxy records of shallow infiltration.

\section{Mineral Hydrolysis Kinetics (H. R. Westrich [505-844-9092; FAX 505-844-7354]}

and R. T. Cygan)

Funding for the mineral hydrolysis project began in February 1992 in order to measure the dissolution kinetics of orthosilicate minerals and to incorporate these data in molecular dynamics computer simulations of the solid-liquid interface. A suite of orthosilicate minerals has been assembled, either at one atmosphere or obtained commercially as natural minerals for dissolution measurements. This suite includes both alkaline-earth ( $\mathrm{Be}, \mathrm{Mg}$, and $\mathrm{Ca}$ ) and transition metal endmembers (Mn, Fe, Co, and $\mathrm{Ni}$ ). Both pH-stat and batch techniques have been used for dissolution m easurements after extensive sample preparation and characterization. Measurements have suggested that dissolution rates of compositionally distinct orthosilicate minerals scale similarly to rates of water exchange around the corresponding dissolved, divalent cation. Minerals that contain alkaline-earth cations dissolve at rates that correlate with ionic size, whereas minerals containing first-row transition metals dissolve at rates that vary with the number of cation d-electrons. Both types of behavior are controlled by the character of the short-range bonds between the divalent cation and the neighboring oxygen atoms. 
Thus, silicate mineral dissolution mechanisms may be linked to ligand exchange of dissolved metals. Synthesis and collection of inosilicate minerals ("pyroxenes") have begun for dissolution measurements of the chain silicates.

\section{CATEGORY:}

PERSON IN CHARGE:

\section{Energy Resource Recognition, Evaluation, and Utilization}

A. Geoscience Research Drilling Office (GRDO) (P. Lysne [505-844-8885; FAX 505-844-3952], with A. Sattler, D. Blankenship, and R. Jacobson)

GRDO supports research scientists who require drilling and other field operations to investigate processes in the Earth's crust. This support can include drilling and logging equipment, consultation regarding permitting issues, and the development of cost schedules. Support usually starts at the conceptual phase of a program and continues through abandonment. GRDO maintains a strong tie to the Department of Energy/Geothermal Division and to the Ocean Drilling Program (ODP). GRDO also is involved with industry operations regarding the development of geothermal resources. GRDO can serve as a contact for wells of opportunity.

1. Katmai Drilling Project. GRDO is responsible for implementing the drilling and drilling-related aspects of the Katmai Program. This work includes establishing the base camp and the helicopter support services and providing the necessary state and federal permits. GRDO recently published a revised edition of the Operations Plan, and this plan forms the basis for the draft environmental impact statement that is being generated by the National Park Service. Some specialty drilling and logging equipment is being designed to support the operation.

2. Fluid Sampler Program. Conventional fluid samplers leak when withdrawn from a hot hole. This effect is caused by a contraction of the sampled fluid causing a pressure decrease below hydrostatic within the sampling vessel. A program has been initiated to correct this deficiency. The tool will feature an on-board computer that provides a measurement of the sampled state as well as pressure and temperate states within the borehole. This program is a cooperative effort with the ODP, which is responsible for providing the uphole geochemical analysis equipment.

3. $O D P$. GRDO maintains contact with the ODP through participation in the ODP's Downhole Measurements Panel and through discussion with ODP engineering staff. ODP coring technologies and equipment were used in the coring phase of the Long Valley Exploratory Well.

\section{B. Seismicity Induced by Hydrocarbon Production (D. F. McTigue [505-844-0450; FAX 505-844-4523], with P. Segall, Stanford University)}

Seismicity that correlates with extraction of hydrocarbons is observed at numerous localities throughout the world, posing a potential safety hazard, as well as a threat to production. The goal of this research program is to gain a fundamental understanding of this type of induced seismicity. The phenomenon is somewhat unexpected because fluid extraction causes a decrease in pore pressure and a corresponding increase in the magnitude of the effective confining stress, which stabilizes rock against frictional failure. A possible mechanism for the phenomenon has been identified in the elastic coupling of contracting reservoir rocks with their surroundings; the model is generally consistent with the locations and focal mechanisms of observed events. The current research program involves reduction and analysis of independently obtained field data, development of analytical and numerical models for the poroelastic stresses generated by fluid 
extraction, and comparison of the observations and simulations.

Earthquake locations, static and dynamic rock properties, and historical records for gas-production, reservoir-pressure, and surface leveling for a producing field at Lacq, France, have been obtained through collaboration with J. R. Grasso (University of Grenoble). The Green's function for the response to a change in pore pressure in an axisymmetric layer embedded in a half-space has been determined. This solution has been used to evaluate the stresses induced by the reservoir pressure draw-down at Lacq. The model checks reasonably well against measured surface subsidence, and against general areas of stress concentration, as indicated by earthquake hypocenter locations.

Numerical simulations are needed to account for more realistic geometries and for heterogeneous material properties. A benchmark study comparing finite-element calculations to the analytical results for a homogeneous elastic domain has been completed and shows excellent agreement; the cross-check provides confidence in the implementation of both the analytical and numerical solution schemes. Heterogeneous models are being developed to examine the localization of the pumping-induced stresses by materials of greater elastic modulus. The models account for mechanical stratigraphy based on seismic profiles, well logs, and properties measured on cores. It is anticipated that numerical simulations will show that consideration of variable rock properties removes some of the mismatch between observed quantities and predictions based on the homogeneous model.

\section{Investigation of Activity in Long Valley Caldera Using the Magma Energy Deep Exploration Well Phase II Drilling Activities (J. B. Rundle [510-294-5235; FAX 510-422-1002; E-mail rundle@s37.es.llnl.gov], joint research withW.R. Wawersik [505-844-4342; FAX 505-844-7354], and D. J. Holcomb and L. M. Teufel, Sandia National Laboratories)}

Geodetic and seismic data collected in Long Valley from 1975 to the present define a pattern of uplift and strain that has been explained by geophysical models involving dike injection and magma intrusion at depths as shallow as $5 \mathrm{~km}$ beneath the caldera floor. A program of in situ stress has been obtained in the Office of Basic Energy Sciences-funded corehole following Phase II drilling, between 2363 and $2379 \mathrm{~m}$ in basement rock, using core-based and acoustic televiewer methods. Acoustic emission signatures in biaxially loaded subcores using the Kaiser effect m ethod suggest that the maximum in situ principal stress within basement is horizontal and north-south oriented. Preparations for hydrofracture measurements of stress to be obtained during August 1992 within the corehole are under way. Numerical modeling studies have been initiated to place earlier calculations of stresses induced by injected magma within the context of the stress field produced by the regional tectonic structure. 



\section{PART II}

OFF-SITE 

GRANTEE:

GRANT:

TITLE:

PERSONS IN CHARGE:
UNIVERSITY OF ALASKA

Geophysical Institute

Fairbanks, Alaska 99775-0800

\section{DE-FG06-92ER14232}

Katmai Scientific Drilling Project

J. C. Eichelberger and S. E. Swanson

(907-474-5530; FAX 907-474-7290)

The Katmai Project is part of the national Continental Scientific Drilling Program, which seeks to understand fundamental processes of crustal evolution through three-dimensional investigation of the continental crust. The 1912 eruption near Mt. Katmai on the Alaska Peninsula was the outstanding volcanic event of this century in the United States, and indeed in the world. The eruption is ideally suited to investigation of explosive volcanism because it is relatively simple, both in terms of geologic setting and chronology of the event itself. Objectives of the project are to improve models for explosive enuptions, to determine the source and mechanisms of metals transport in fumaroles of the 1912 ignimbrite, and to establish the rates and mechanisms of ongoing cooling of the system. The project was selected for implementation based upon peer- and panel-reviews by DOE, National Science Foundation, and the U.S. Geological Survey (USGS) and a panel review (as to suitability of the site) by the National Academy of Sciences. The approximately 40 scientists involved in the project come from numerous universities, the USGS, and several DOE laboratories. About half of this group was active during the surface phase of the project. The main surface effort took place in 1989-90, when a coordinated suite of geophysical surveys defined a 2-km-diameter vent for the eruption buried beneath its own ejecta at the head of the Valley of Ten Thousand Smokes. This work also provided evidence of a huge magma body still present beneath the region. The project plan calls for drilling into the 1912 vent over a 2-year period beginning in 1994. Two holes will prove a complete cross section of the vent and sample its still-cooling feeder to a depth of $1.2 \mathrm{~km}$. An environmental impact statement is currently being written under the management of the Alaska Region Office of the National Park Service (NPS).

Tasks under this grant are coordination of the project and a surface-based investigation of the degassing and mixing behavior of the 1912 magmas. The former effort consists primarily of representing the project during the National Environmental Policy Act (NEPA)-mandated process. NEPA documents were reviewed for technical accuracy and completeness during their preparation. Presentations were made at formal public hearings in Anchorage and King Salmon, and on-site guidance was provided during data collection to evaluate environmental impact issues. The second task uses the exceptional suite of variably quenched 1912 magmatic material to investigate the timing and processes of volatile release and magma mixing. The suite encompasses rapidly quenched air-fall pumice, variably welded pyroclastic vent fill rapidly quenched during ejection in late explosion, and Novarupta lava ranging from glassy to fully devitrified. The vent-fill ejecta also provides the best indication of what will be encountered in drilling and a chemical baseline by which post-emplacement mass transport can be assessed. Investigation of the occurrence and distribution of the vent-fill ejecta was conducted during the summer of 1992, and analysis is under way.

Following completion of the NEPA Process, NPS is scheduled to issue a record of decision in 1993. If the drilling is approved, it will provide an unprecedented view of the processes and structures that give rise to explosive eruptions as well as new insights into processes of ore formation and hydrothermal circulation. 
GRANTEE:

PERSONS IN CHARGE:
GRANT:

TITLE:
UNIVERSITY OF ALASKA

Geophysical Institute

Fairbanks, Alaska 99775-0800
DE-FG06-86ER 13530

A Theoretical and Simulation Study of Magnetic Reconnection Processes in the Magnetosphere

L. C. Lee and S.-I. Akasofu (907-474-7410;

FAX 907-474-7290; E-mail fred::Iclee [Span] or

fflcl@alaska [Bitnet])
Magnetic reconnections take place at the Earth's magnetopause as well as in the magnetotail. The magnetopause is the interface between the solar wind and the magnetosphere where the transport of particle, momentum, and energy takes place. The magnetic reconnection provides an efficient process for the conversion of magnetic energy to particle energy and also changes the topology of magnetic field configuration in the magnetosphere. Reconnection in the magnetotail is believed to be responsible for the geomagnetic substorm. In the past year we have obtained several new results, which include (1) the field-line topology of magnetic flux ropes associated with three-dimensional (3-D) reconnection processes, (2) properties of magnetic reconnection with large separatrix angle, (3) structure of the dayside reconnection layer in dissipative magnetohydrodynamic (MHD) and hybrid models, and (4) the \$beta\$ dependence of the collisionless tearing instability at the dayside magnetopause.

At the dayside magnetopause, magnetic flux ropes can form as a result of multiple $X$-line reconnection. Our 3-D MHD simulation shows that for an appropriate extent and location of two neighbouring $X$-lines, a simple magnetic topology can be expected, in which the major amount of magnetic flux of the rope is connected at each end to only one side of the current sheet. For a sufficient relative shift of the $X$-lines, magnetic flux may enter a flux rope from the magnetosphere and exit into the magnetosphere, leading to the formation of magnetic flux ropes that contain a considerable amount of magnetosheath plasma on closed magnetospheric field lines. This process may provide a possible explanation for the formation of fossil flux transfer events in the magnetosphere and the formation of the low-latitude boundary layer.

We have studied the magnetic reconnection with large magnetic separatrix angles. When the normal magnetic field on the inflow boundary is large, steady-state reconnection with large magnetic separatrix angles are obtained. Field-aligned plasma jets are observed when the normal magnetic field and magnetic Reynolds number are large. It is found that each plasma jet consists of two parts: a slow-mode shock and a fast-mode compressional structure. The acceleration of plasma by the slow shock and the deceleration by the fast shock lead to the formation of the narrow plasma jet observed in the simulation.

We have also used the hybrid code as well as MHD code to study the structure of reconnection layer at the Earth's dayside magnetopause. In the MHD simulations, it is found that steady intermediate shock, time-dependent intermediate shock (TDIS), slow shock, expansion wave, or contact discontinuity can be formed as a result of magnetic reconnection. However, in the hybrid simulations it is found that the TDIS evolves quickly to a steady rotational discontinuity and that the contact discontinuity does not appear in the reconnection layer. From this study, one may conclude that the rotational discontinuity would be observed more often at the magnetopause than the intermediate shock. 
GRANTEE:

GRANT:

TITLE:

PERSON IN CHARGE:
AMERICAN MUSEUM OF NATURAL HISTORY

Department of Mineral Sciences

New York, NY 10024

DE-FG02-92ER14265

The Role of Carbon and Temperature in Determining Electrical Conductivity of Basins, Crust, and Mantle

E. A. Mathez (212-769-5379; FAX 212-769-5339)
This is a collaborative project with A. G. Duba (Lawrence Livermore National Laboratory) and T. J. Shankland (Los Alamos National Laboratory) to investigate the effect of carbon in rocks on electrical conductivity. The great sensitivity of conductivity to small concentrations of fluids, ores, and carbons and to temperature make electromagnetic methods a unique probe of the Earth. For the most part, conductivity profiles have been interpreted without consideration of the effects of carbon because carbon contents of crystalline and some sedimentary rocks are small. However, in the few rocks in which its distribution has been studied in detail, carbon has been found to be present along microfractures and mineral grain boundaries. This raises the possibility that carbonaceous compounds form interconnected networks over megascopic regions and thus exert a dominant influence on bulk-rock conductivity, even in rocks in which concentrations are small.
The initial work will include (1) the determination of conductivity across individual carbon-bearing microfractures and its relationship to film thickness; (2) the mapping of the distribution of carbons in rocks over regions of several centimeters; (3) and the determination of electrical conductivities of the same samples for which carbon distribution has been investigated. The initial investigations will focus on certain mantle peridotites for which analytical data on the carbonaceous compounds already exist and certain exposed crustal rocks thought to be responsible for deep crustal conductivity anomalies. The data collected at one atmosphere and room temperature will provide the basis to derive a relationship describing conductivity of carbon-bearing rocks at conditions relevant to basins, crust, and mantle. 
GRANTEE:

GRANT:

TITLE:

PERSON IN CHARGE:
UNIVERSITY OF ARIZONA

Department of Geological Sciences

Gould-Simpson Bldg.

Tucson, Arizona 85721

Electrochemical Determination of the Gibbs Free Energies of Rock-Forming Minerals

Lawrence M. Anovitz (602-621-4618; FAX 602-621-2672;

E-mail Anovitz@arizrvax)

This project involves measurement of thermodynamic data for rock-forming minerals using an electrochemical approach. Gibbs energies will be measured directly for oxide buffers and the joins diopside-hedenbergite and enstatite-ferrosilite using redox equilibria and solid-state electrolytes. Measurement of these data as a function of temperature will strongly constrain both the standard state Gibbs free energies and entropies of these phases. The $\mathrm{Fe} / \mathrm{Mg}$ ordering state of the orthopyroxenes being measured will also be examined as a function of composition and temperature in order to further constrain our understanding of the effects of submicroscopic properties that the activity-composition relations of this join. The relative accuracy of electrochemical measurements and the fact that this technique is the only one currently available that directly measures the Gibbs energy of a phase as a function of temperature makes data obtained in this manner ideal for many types of geochemical calculations. These phases occur in a wide variety of igneous and metamorphic rocks, and high quality thermodynamic data for them are essential to understanding the conditions under which these rock types form.

Work this year has concentrated on completion and initial tests of the equipment, synthesis of pyroxenes, and a reevaluation of mixing properties on the join diopside-enstatite, necessary if the binary data collected in these experiments are to be combined into a ternary model for $\mathrm{Ca}-\mathrm{Fe}-\mathrm{Mg}$ pyroxenes. Orthopyroxene glasses have been synthesized across the enstatite-ferrosilite join, although, as expected, high-iron glasses crystallize olivine and quartz. Crucibles pressed from 5 mil molybdenum foil have proven an inexpensive alternative to platinum for making reduced iron glasses in a gas-mixing furnace. As with graphite, however, small amounts of molybdenum metal are occasionally found in the glass. The amount varies from run to run, and we are exploring methods to minimize this contamination. The glasses formed in these runs commonly form pyroxene quench crystals. These materials have been crystallized into orthopyroxenes in a piston-cylinder apparatus, although additional runs are needed to homogenize the resulting pyroxenes. Reduced-iron glasses have been made along the diopside-hedenbergite join, and work on both syntheses is ongoing. The equipment is currently undergoing initial test runs using oxide buffer assemblages. Early runs yielded a redesign of the vacuum system, which has fewer leaks and is easier to assemble and test.

Reexamination of the diopside-enstatite join was necessary because currently available models for this join predict that end-member diopside is metastable with regard to a subcalcic diopside and wollastonite. A model in which this is no longer the case has been completed which suggests that activity-composition relations for ordered intermediate phases such as diopside are strongly model dependent. A manuscript describing this work is in submission. Direct measurements of the activities of such materials are needed in order to constrain possible models. Cobalt-diopside appears an ideal candidate for this test using the electrochemical technique. 
GRANTEE:

GRANT:

TITLE:

PERSON IN CHARGE:
UNIVERSITY OF ARIZONA

Department of Physics

Tucson, Arizona 85721

DE-FG02-89ER 13670

Solar Variability Observed Through Changes in Solar Figure and Diameter

H. A. Hill (602-621-6782; FAX 602-621-4721;

E-mail hhill@sclera.physics.arizona.edu)
The program objective is to use measurements of solar shape, diameter, and limb-darkening function as an indirect diagnostic of temporal changes in solar luminosity. These observations complement space measurements of total irradiance because they can potentially reveal fundamental changes in global photospheric structure by discriminating against effects of solar active regions that affect full disk radiometer measurements. Solar structure changes indicated by these observations may be more relevant to long-term climate change than variability associated with solar cycle phenomena. Solar limb intensity profiles are analyzed according to the Finite Fourier Transform Definition of the solar edge in order to obtain differential radius measurements that characterize the solar limb- darkening function. Time series of observations now include data from 40 days in 1991 and 16 days in 1992.
Results obtained during solar cycle 21 indicate that from 1973 to 1983 the globally averaged differential radius increased significantly, which may be important for understanding the decrease in total irradiance measured by satellite and rocket radiometers that is not explained by solar cycle phenomena. Since 1983 a small but significant decrease in differential radius values has been observed. This suggests a slight increase in the photospheric temperature gradient consistent with measured changes in equivalent widths of Fraunhofer lines. The observed behavior of solar limb darkening shows that the contribution of the quiet photosphere to solar luminosity is not strongly connected to solar cycle activity and hence may be the more important component of long-term climate variability. 
GRANTEE:

GRANT:

TITLE:

PERSON IN CHARGE:
ARIZONA STATE UNIVERSITY

Department of Geology

Tempe, Arizona 85287-1404

DE-FG02-9IER 14218

Organic/Inorganic Interactions of Nitrogen in Oil Fields

Part I. Geochemistry

L. B. Williams (602-965-0829; FAX 602-965-8102;

E-mail ATLBW(@ASUACAD.Bitnet)
The study of nitrogen diagenesis in clastic sequences associated with hydrocarbon occurrences is intended to aid in predicting favorable areas of petroleum exploration and recovery by establishing a better understanding of the interaction of organic maturation products with authigenic minerals. A detailed investigation of the geochemistry of nitrogen in oil fields is being conducted in order to test the model that nitrogen is generated from hydrocarbons during thermal maturation and is incorporated into authigenic clay minerals in the sediments through which the oil and brines migrate. Nitrogen, incorporated in diagenetic clays as ammonium $\left(\mathrm{NH}_{4}^{+}\right)$, is "fixed" and therefore records a geochemical event that may not be reflected in the fluid chemistry at a later time. Anomalous fixed- $\mathrm{NH}_{4}$ concentrations are known to occur in producing intervals of hydrocarbon reservoirs. Therefore, a correlation of fixed- $\mathrm{NH}_{4}$ anomalies across an oil field could be used to indicate pathways of hydrocarbon migration into the trap and may point to isolated compartments of by-passed oil.

Fordoche Field, a 4-km-deep multi-reservoir oil field in the Louisiana Gulf Coast Basin, is the focus of this research. This field is typical of Gulf Coast oil fields, with basin stratigraphy and structure representative of the majority of known hydrocarbon accumulations. The results of this investigation should therefore be applicable to many other oil fields. The approach is to chemically characterize all components of the hydrocarbon environment that could have an influence on $\mathrm{NH}_{4}$-fixation. Quantitative and isotopic analyses of nitrogen compounds in the oil, kerogen, and minerals are being conducted. Concurrent mineralogical and microbial investigations of the field are being conducted in Part II of this research by collaborators at Louisiana State University. Similar data will be collected from an oil field updip from Fordoche Field, where migration distances are thought to be greater, yet the oil source is the same. Comparison of these data sets could provide information on the effects of migration on nitrogen chemistry. The results from this collaborative research will provide a large data base for examining the effects of local and regional scale migration on nitrogen speciation and isotopic fractionation during diagenesis. This knowledge will allow evaluation of the usefulness of fixed- $\mathrm{NH}_{4}$ anomalies in the recovery of hydrocarbons. 
GRANTEE:

GRANT:

TITLE:

PERSONS IN CHARGE:
BROWN UNIVERSITY

Department of Geological Sciences

Providence, Rhode Island 02912

\section{DE-FG02-90ER14144}

Grain Boundary Transport and Related Processes in Natural Fine-Grained Aggregates

R. A. Yund and J. R. Farver (401-863-1931;

FAX 401-863-2058; E-mail ray@gech031.geo.brown.edu)
The objective of this study concerns the direct measure of diffusional transport rates in rocks and how the rates vary with mineralogy and microstructure, as well as temperature and pressure. The results provide much needed data on the nature of grain boundaries in rocks and the rate of transport of chemical components through rocks. Applications of these data include evaluating the retentiveness of different geological medium for the isolation and confinement of nuclear and chemical waste, modeling the migration of hydrocarbons through different rock types to refine exploration and development strategies for more efficient oil and natural gas recovery, and determining fluid/rock interactions and thermal histories of hydrothermal systems.

We have developed a technique for experimentally determining diffusional transport rates in fine-grained, monomineralic aggregates using the ion microprobe (SIMS) and have used this to study natural quartz aggregates. In addition, we have demonstrated the important effect of fluid composition on the equilibrium microstructure, and on the nature and rate of diffusional transport, in quartz aggregates. Samples texturally equilibrated with $6 \mathrm{M} \mathrm{NaCl}$ have dihedral angles (q) that are less than $60^{\circ}$, which indicates that the fluid forms an interconnected network along the three grain edge channels, while samples texturally equilibrated with pure $\mathrm{CO}_{2}$ yield $\mathrm{q}>60^{\circ}$, which indicates that the fluid forms isolated pores at three grain junctions. The effective diffusion rate (bulk diffusivity) of oxygen in the aggregates is four to five orders of magnitude greater in samples with an interconnected fluid because of transport by ionic diffusion through the static fluid, which is much faster than true grain boundary diffusion.

Our current research focuses on the determination and comparison of the nature and rates of diffusional transport of oxygen and select geologically and environmentally important cations in natural and hot-pressed monomineralic aggregates of feldspar and calcite, and bi-mineralic aggregates of feldspar + quartz. Samples are texturally equilibrated with fluids common to natural environments, and the diffusivities are correlated with the nature of the grain boundaries and sample microstructure, which are characterized by transmission and scanning electron microscopy. 
GRANTEE:

GRANT:

TITLE:
CALIFORNIA INSTITUTE OF TECHNOLOGY

Division of Geological and Planetary Sciences

Pasadena, California 91125

Infrared Spectroscopy and H ydrogen Isotope Geochemistry of Hydrous Silicate Glasses

PERSONS IN CHARGE:

S. Epstein (818-356-6100) and E. Stolper (818-356-6504;

FAX 818-568-0935; E-mail ems@expet.gps.caltech.edu)

The focus of this project is the combined application of infrared spectroscopy and stable isotope geochemistry to the study of hydrogen- and oxygen-bearing species dissolved in silicate melts and glasses. The partitioning of hydrogen isotopes $(D$ and $H$ ) between water vapor and rhyolitic silicate melt and glass was measured at temperatures of 550 to $850^{\circ} \mathrm{C}$ and pressures up to 2000 bars. The solubility of water in rhyolitic melts and the speciation of water (i.e., the proportions of dissolved water molecules and hydroxyl groups) in such melts have also been measured, with careful attention to the temperature dependence of speciation and the kinetics of interconversions between species. These results make it possible to use hydrogen isotope data to model the degassing of high-level silicic magmatic centers of the sort being considered as geothermal resources and are critical to understanding the behavior of hydrogen isotopes during igneous and hydrothermal processes. These results also could be valuable in applications of glass technology to development of nuclear waste disposal strategies.

Diffusive transport of water and carbon dioxide in silicate liquids and glasses plays an important role in many phenomena of interest in the geological and materials sciences. For example, the rate of water and carbon dioxide diffusion in silicate liquids controls the growth of bubbles in ascending magmas, and influences the degree to which magmas can degas on ascent and the availability of compressed vapor in bubbles to power explosive volcanic eruptions. Hydration and dehydration of silicate glasses in geological and man-made environments are also limited by water diffusion and relate to issues such as the chemical stability of glasses, the mechanical strength of glass fibers, the kinetics of $\mathrm{SiO}_{2}$ film growth on silicon substrates, water-rock reaction leading to ore deposition, and obsidian hydration dating of young volcanic rocks. Work during the current grant period has shown that in volcanic glasses, the diffusivity of water molecules is much greater than that of hydroxyl groups and the diffusivity of carbon dioxide molecules is greater than that of carbonate groups. The uniqueness of our approach stems from our ability to measure the concentration profiles of these separate species, which allows the problem to be treated in terms of distinct diffusing, reacting species. These results have been used as a basis for understanding the "self diffusion" of oxygen in silicate minerals and glasses. The theory needed to understand the connection between the diffusivity of water and oxygen has been developed and used to show that diffusion of molecular water or carbon dioxide in nominally anhydrous minerals and melts are the likely controls on measured self-diffusion coefticients of oxygen.

Study of stable isotope partitioning between vapor and silicates was extended during the current grant period to the fractionation of oxygen isotopes between $\mathrm{CO}_{2}$ vapor and silicate minerals and glasses. Fractionation factors were measured by equilibrating small amounts of vapor with large amounts of silicate, followed by mass spectrometric analysis of the vapor. The success of the technique is related to the role of $\mathrm{CO}_{2}$ molecules, which diffuse rapidly through the silicate, as carriers for exchangeable oxygen atoms. 
GRANTEE:
GRANT:

TITLE:
CALIFORNIA INSTITUTE OF TECHNOLOGY

Division of Geological and Planetary Sciences

Pasadena, CA 91125
DE-FG03-88ER 13851

Isotope Tracer Studies of Diffusion in Silicates and of

Geological Transport Processes Using Actinide Elements
We have measured magnesium self-diffusion in spinel and coexisting melt, at bulk chemical equilibrium, using an isotopic tracer. The diffusion coefficients were calculated from the measured isotope profiles using a model that includes the complementary diffusion of ${ }^{24} \mathrm{Mg},{ }^{25} \mathrm{Mg}$, and ${ }^{26} \mathrm{Mg}$ in both phases with the constraint that the magnesium content of each phase is constant. The diffusion appears to be much slower than previous estimates because earlier measurements probably included grain boundary transport. These results were applied to plagioclase-olivine inclusions in carbonaceous meteorites, which show variable magnesium isotope fractionation effects. To preserve isotopic heterogeneity, these inclusions must have initially cooled faster than 50 to $250^{\circ} \mathrm{C} / \mathrm{h}$. The magnesium diffusion experiments use an isotope exchange technique for phases in chemical equilibrium. This allows the precise and simultaneous determination of diffusion coefficients in both phases. This type of experiment has broad application for many elements, including silicon and oxygen, and other mineral systems. Diffusion coefficients for coexisting elements can be obtained in a single experiment. The measurement of slow diffusion rates can be determined from a coupled experiment with a phase where diffusion is faster. Diffusion coefficients of the order of $10^{-14} \mathrm{~cm}^{2} / \mathrm{s}$ are now readily measurable.

We have pursued the study of resonance ionization mass spectrometry (RIMS) for elements that are hard to ionize by conventional techniques or whose analysis is seriously compromised by isobaric interferences. Emphasis has been placed on establishing the extent to which isotope selective effects in resonance ionization can be minimized so that this technique becomes more widely applicable.
We have investigated laser-induced isotope selectivity in the resonance ionization of osmium and titanium. A single-color, one-photon resonant ionization scheme was used for several different transitions to produce osmium photoions. Isotope selectivity is strongly dependent on laser power and wavelength, even when the bandwidth of the laser radiation is much larger than the optical isotope shift. Variations in the ${ }^{190} \mathrm{Os} /{ }^{188} \mathrm{Os}$ ratio of $\approx 20 \%$ for a detuning of $0.8 \mathrm{~cm}^{-1}$ were observed on a transition with a small oscillator strength. Large even-odd isotope selectivity with a $13 \%$ depletion of ${ }^{189}$ Os was observed on a $\Delta \mathrm{J}=+1$ transition, at low laser intensity. For $\Delta \mathrm{J}=-1$ and 0 transitions, the isotope selectivity was reduced by polarization scrambling and for strongly saturating conditions. Employing the wavelength dependence of even-even isotope selectivity as an internal wavelength standard permits accurate and reproducible wavelength adjustment of the laser radiation. This provides control of laser-induced isotope selectivity for single-color ionization, and yields, in the saturation regime, for $\Delta J=+1$, a precision of better than $0.4 \%$. For titanium, a pronounced wavelength dependence of even mass isotope ratios is caused by large nuclear volume effects near the magic neutron number 28 $\left({ }^{50} \mathrm{Ti}\right)$. Optical isotopic shifts of 0.06 to $0.21 \mathrm{~cm}^{-1}$ between ${ }^{50} \mathrm{Ti}$ and ${ }^{46} \mathrm{Ti}$ were measured on several resonance transitions. Isotopic selectivity in the resonance ionization process for ratios of odd to even mass isotopes was examined for several transitions as a function of the laser polarization state and intensity. The results for titanium agree with those for osmium and indicate that by a careful choice of resonance transitions and laser operating conditions, isotope ratios free of laser-induced biases can be measured with RIMS. 
GRANTEE:

GRANT:

TITLE:

PERSON IN CHARGE:

\section{UNIVERSITY OF CALIFORNIA AT BERKELEY \\ Department of Geology and Geophysics \\ Berkeley, CA 94720}

DE-FG03-9IER 14200

Experimental Measurement of Thermal Conductivity in Silicate Liquids

I. S. E. Carmichael (510-642-2577; FAX 510-643-9980)
To measure accurately the conduction of heat in a sample, it is necessary to minimize and quantify heat transport by convection and radiation. The experimental technique generally acknowledged to deal best with these factors, and therefore to be the most accurate for measuring the thermal conductivity of fluids, is the transient hot wire technique. We have adapted this method to high-temperature measurements of silicate liquids. Our equipment consists of a thin filament of rhodium wire stretched taught along the axis of a platinum-rhodium cylinder containing the silicate melt. One end of the filament is welded to the base of the cylindrical sample holder, and the other is butt welded to a heavier wire that passes out of the fumace through the upper, open end of the cylinder. At the start of the experiment, these two leads supply a constant, known electrical current through the filament. The filament serves as a line source of heat, increasing in temperature until converging on a steady-state value. Two sense leads attached to the top and bottom of the filament record the potential drop across the filament, which is used in conjunction with the known current passing through the filament to calculate the change of the filament temperature with time. The technique is based on the transient change in temperature of the filament before steady state is reached. The apparatus is designed so that over the time scale of a measurement, the cell wall plays no role during transient heating, and hence the fluid can be treated as being infinite. The slower the temperature change of the filament with time, the higher the thermal conductivity of the liquid surrounding the filament. In 1992 the apparatus was built and tested, and preliminary measurements have been made on diopside liquid. 
GRANTEE:

GRANT:

TITLE:

\section{UNIVERSITY OF CALIFORNIA AT BERKELEY \\ Department of Geology and Geophysics \\ Berkeley, CA 94720}

\section{DE-FG03-85ER 13419}

Advective-Diffusive/Dispersive Transport of Chemically Reacting Species in Hydrothermal Systems

Harold C. Helgeson (510-642-1251; FAX 510-643-9980;

E-mail brogie.garnet.berkeley.edu)
The goal of this project is to achieve a better understanding of chemical mass transport attending fluid flow and water-rock interaction in crustal processes. The overall focus of the research has been on development of comprehensive mass transfer models and calculation of the thermodynamic properties of minerals and aqueous species over a wide range of pressures and temperatures. During the past year research efforts have been concerned primarily with development of speciation models for silicon-and aluminum-bearing supercritical electrolyte solutions in an effort to quantify the influence of bulk composition and solution $\mathrm{pH}$ on mass transfer in hydrothermal processes at high temperatures and pressures.

Activity coefficients of aqueous silica are requisites for accurate calculation of chemical mass transfer among minerals and aqueous solutions at supercritical pressures and temperatures. Critical analyses of the solubilities of quartz and its polymorphs in aqueous electrolyte solutions reported in the literature were carried out using dissociation constants for neutral ion pairs and polyatomic clusters (Oelkers and Helgeson, 1988, 1990, 1992) and Setchénow coefficients $(b \gamma, n)$ for alkali halide ion pairs (Oelkers and Helgeson, 1991; Pokrovskii et al., 1991, 1992) to retrieve corresponding coefficients for $\mathrm{SiO}_{2(\mathrm{aq})}$ at temperatures from 25 to $700^{\circ} \mathrm{C}$ and pressures to 5 kbars. The values of byn for $\mathrm{SiO}_{2(\mathrm{aq})}$ were then used to calculate the relative abundances of $\mathrm{SiO}_{2(\mathrm{aq})}$ and other mononuclear species such as $\mathrm{H}_{3} \mathrm{SiO}_{4}^{-}, \mathrm{NaH}_{3} \mathrm{SiO}_{4}^{0}$, and $\mathrm{KH}_{3} \mathrm{SiO}_{4}^{0}$ in supercritical alkali chloride brines.

Thermodynamic analysis of equilibrium solubility data reported in the literature indicates that aluminum-chloride complexes do not form to an appreciable degree at temperatures below $350^{\circ} \mathrm{C}$ (Pokrovskii and Helgeson, 1989, 1992). However, recent experimental measurements of corundum solubilities in $\mathrm{HCl}, \mathrm{NaCl}$, and $\mathrm{KCl}$ solutions reported in the literature indicates that this may not be the case at supercritical pressures and temperatures.

Regression analysis of the solubility data indicates that increasing corundum solubilities in supercritical alkali chloride solutions can be attributed to the presence of $\mathrm{Al}(\mathrm{OH})^{2+}, \mathrm{Al}(\mathrm{OH})_{2}^{+}$, $\mathrm{Al}(\mathrm{OH})_{4}, \mathrm{NaAl}(\mathrm{OH})_{4}^{0}$, and $\mathrm{KAl}(\mathrm{OH})_{4}^{0}$ and/or formation of a number of chlorine-bearing and mixed polynuclear complexes such as $\mathrm{AlCl}_{2}^{+}, \mathrm{Al}(\mathrm{OH})_{2} \mathrm{Cl}^{\mathbf{0}}$, $\mathrm{Na}_{3}\left[\mathrm{Al}(\mathrm{OH})_{4}\right]_{2}^{+}$, and $\mathrm{Na}_{2}\left[\mathrm{Al}(\mathrm{OH})_{4}\right]_{3}^{-}$.

During FY 1992, a set of bulk composition-pH diagrams for the system $\mathrm{K}_{2} \mathrm{O}-\mathrm{Na}_{2} \mathrm{O}-\mathrm{CaO}-\mathrm{MgO}-\mathrm{FeO}$ $\mathrm{Fe}_{2} \mathrm{O}_{3}-\mathrm{Al}_{2} \mathrm{O}_{3}-\mathrm{SiO}_{2}-\mathrm{H}_{2} \mathrm{O}-\mathrm{CO}_{2}-\mathrm{HCl}$ were generated to describe the consequences of the chemical interaction of granitic rocks and arkosic sediments with interstitial fluids at elevated temperatures and pressures using the approach developed by Pokrovskii and Helgeson (1992). Other research was directed toward thermodynamically characterizing the biogeological evolution of fossil fuels in the Earth's crust. Toward this end, the revised HKF equations of state and correlation algorithms were combined with experimental data taken from the literature to calculate the standard partial molal thermodynamic properties of aqueous sugars, peptides, polypeptides, and other biochemical molecules of geologic interest at elevated temperatures and pressures (Amend and Helgeson, 1991). 
GRANTEE:

GRANT:

TITLE:

PERSONS IN CHARGE:
UNIVERSITY OF CALIFORNIA AT BERKELEY

Department of Materials Science and Mineral Engineering

Berkeley, CA 94720

DE-FG03-92ER14276.000

Multi-station Magnetotellurics

H. F. Morrison (510-642-8109; FAX 510-642-3805) and G. D. Egbert
The magnetotelluric (MT) method for mapping subsurface electrical variations has proven to be a useful geophysical tool both for fundamental studies of continental structure and tectonics and for solving applied problems in exploration for hydrocarbon or geothermal resources. MT uses naturally occurring electromagnetic (EM) field variations. However, the use of passive sources also presents a problem-signal and noise levels can be highly variable and are beyond the control of the experimenter. Success with the MT method thus requires great care in the acquisition and initial reduction of the raw EM time series. The simple single station least squares approach, which was used by early MT practitioners, all too typically produces estimates of apparent resistivities and phases that are heavily biased, wildly oscillatory, and generally useless.

Two developments have improved this situation greatly-the remote reference (RR) method, in which horizontal magnetic fields recorded simultaneously at a second remote site are correlated with the EM fields at the local site, and various sorts of robust data adaptive weighting schemes. However, all too often there are still critical sites and/or frequency ranges where useful results are not obtained, even with the best current practices. In our research, we are developing improved strategies for collecting and processing MT data, particularly in the presence of cultural noise. There are three aspects of our research. First, we conduct a small MT survey, using a three-station array, along a line from an area of significant urban cultural noise to a very isolated quiet area. We use this data to conduct basic studies of the spatial and temporal structure of signal and noise and to evaluate various strategies for collecting RR MT data. Second, we continue work on developing and testing new MT data-processing methods. Third, we will thoroughly test newly developed, as well as previously tried,

processing methods on a collection of wide band MT data sets. 
GRANTEE:
GRANT:

TITLE:

PERSON IN CHARGE:

\author{
UNIVERSITY OF CALIFORNIA AT BERKELEY \\ Department of Physics \\ Berkeley, California 94720
}

\section{DE-FG03-87ER 13667}

Isotopic Studies of Noble Gases in Terrestrial Samples and Natural Nucleosynthesis

J. H. Reynolds (510-642-4863; 642-2260; FAX 510-643-8497; E-mail reynolds@garnet.berkeley.edu)
Our objective is to use noble gases to provide a unique perspective on the many and complex processes influencing compositions, evolution, and transport of crustal fluids. In the Long Valley Caldera, noble gases are demonstrating their potential for assessing geothermal potential and monitoring magmatic activity and transport of magmatic volatiles from depth. Less than 3 months after the onset of seismic swarm activity beneath Mammoth Mountain, the ${ }^{3} \mathrm{He} /{ }^{4} \mathrm{He}$ ratio and helium flux from a previously insignificant fumarole on the north flank of the mountain increased by factors of 2 and 7 , respectively, and have remained high to this day. Rapid response and the need to sustain the high ratio and flux requires injection of fresh basaltic magma into the near surface $(<2 \mathrm{~km})$ and a direct source-surface hydrologic connection. The seismic swarm activity has since moved to beneath the resurgent dome. However, ${ }^{3} \mathrm{He} /{ }^{4} \mathrm{He}$ ratios of springs, fumaroles, and geothermal wells on or in the vicinity of the dome, despite more than a year of almost continuous seismic activity and dome inflation, have not shown any increases or decreases. If magma injection is occurring beneath the resurgent dome, then transport of magmatic volatiles from depth is severely impeded and the geothermal reservoirs can not be in direct communication with the heat source.

Our previous studies of $\mathrm{CH}_{4}$-rich natural gases found that a common feature of reservoirs in sedimentary basins located on the continental side of orogenic belts (e.g., Alberta, Canada, the Pecos Slope, New Mexico, and the Texas PanhandleHugoton field) is an anomalous content of ${ }^{3} \mathrm{He}$ relative to ${ }^{4} \mathrm{He}$ as expected for uranium-thorium radiodecay in typical crustal rocks. Samples of cap, reservoir, and source rocks appear to rule out "exotic" ${ }^{3}$ He sources such as radiogenic production in lithium-enriched environments, cosmogenic production, or cosmic dust. Apparently, the anomalous ${ }^{3} \mathrm{He}$ is of mantle origin, despite a lack of any recent $(<200 \mathrm{Ma}$ ) tectonomagmatic activity. This implies a cause-effect relationship between the injection of fluids, rich with mantle volatiles, deep into the sedimentary basins and the orogenies truncating the basins. A preliminary study of gases from the Michigan Basin, thought to be hydrologically isolated, has found normal radiogenic helium, consistent with the tectonic injection model.

Fluid inclusions (FI) associated with sulphide ores at Hansonburg, New Mexico, contain concentrations of ${ }^{36} \mathrm{Ar}$ and ${ }^{84} \mathrm{Kr}$ equal to $20^{\circ} \mathrm{C}$ air saturated fresh water, $\mathrm{I} / \mathrm{Cl}$ and $\mathrm{Br} / \mathrm{Cl}$ the same as nearby evaporitic salts, and ${ }^{40} \mathrm{Ar} / \mathrm{Pb}$ similar to Paleozoic sediments exposed in this region. FI associated with granitic magmas at Bingham, Utah, and Ascension Island (mid-Atlantic ocean), indicate $\mathrm{I} / \mathrm{Cl}, \mathrm{Br} / \mathrm{Cl}$, and ${ }^{36} \mathrm{Ar} / \mathrm{Cl}$ similar to estimated values for the Earth's mantle, although the latter remains largely uncharacterized for these parameters. Variable FI in Stripa Granite appears to require more than one fluid. Some FI in Stripa contain products of neutron capture reactions, including krypton produced from bromine by epithermal neutrons, which, combined with unusually high $\mathrm{Br} / \mathrm{Cl}$ and $\mathrm{I} / \mathrm{Cl}$, requires that at least one of the fluids must have originated outside of Stripa. 
GRANTEE:

GRANT:

TITLE:

PERSON IN CHARGE:
UNIVERSITY OF CALIFORNIA AT DAVIS

Department of Geology

Davis, California 95616

\section{DE-FG03-92ER14240}

Energetics of Silicate Melts from Thermal Diffusion Studies

C. E. Lesher (916-752-9779; FAX 916-752-0951;

E-mail celesher@ucdavis.edu)

A detailed characterization of silicate liquids is required for a predictive understanding of the evolution of natural magmas within the Earth's crust. A magma's crystallization behavior and interaction with its surroundings determine, among other things, the potential for geothermal energy extraction and the formation of ore deposits. The thermodynamic evolution of magmatic systems depends not only upon the thermochemical details of the solidification products but also on the thermochemical properties of the initial magmatic liquids. These properties are more poorly known for the liquids than for the solids. It is the purpose of this project to aid in the characterization of the thermodynamic properties of silicate liquids by a novel experimental approach, thermal diffusion studies.

Thermal diffusion is the phenomenon of chemical migration in response to a thermal gradient. In a substance with more than one component, chemical heterogeneity can develop in an initially homogeneous substance as a result of a diffusional mass flow consequent on heat flow. The details of this response are conditioned by the thermochemical properties and constitution of the substance. We have experimentally demonstrated that silicate liquids do undergo substantial thermal diffusion differentiation and that observations of this differentiation provide the data necessary to evaluate the form and quantitative values of silicate liquid solution parameters. This information supplements calorimetric and phase equilibrium data on silicate liquids. Techniques have been developed to extract ordinary diffusion coefficients, heats of transport, and energies of mixing from experimental $T-X$ thermal diffusion profiles of multicomponent silicate liquids. Immiscibility relations in the system $\mathrm{Fe}_{2} \mathrm{SiO}_{4}(\mathrm{Fa})-\mathrm{KAlSi}_{2} \mathrm{O}_{6}(\mathrm{Lc})-\mathrm{SiO}_{2}(\mathrm{Qt})$ have been successfully retrieved solely on the basis of thermal diffusion results using a ternary asymmetric regular solution model. A similar approach is being used to quantify solution behavior of naturally occurring silicate, carbonate, and sulfide magmas. Complementary experimental studies of isothermal interdiffusion are providing data on the activation energies for diffusion.

Recent application of thermal diffusion studies to magmatic and aqueous systems involving coexistence of crystals with a multicomponent fluid has shown that there is a substantial potential for inducing chemical migration, even in the absence of convection. Laboratory observations of cumulate maturation under the influence of thermal diffusion have been applied to postcumulus evolution of magma bodies and the formation of cyclic evaporate deposits. 
GRANTEE:

GRANT:

TITLE:

PERSONS IN CHARGE:
UNIVERSITY OF CALIFORNIA AT DAVIS

Department of Chemistry

Davis, CA 95616

DE-FG03-92ER 14307

A New Method for Determining Thermodynamic

Properties of Carbonate Solid-Solution Minerals

P. A. Rock (916-752-0940) and W. H. Casey

(916-752-3211; FAX 916-752-1552)
Incorporation of metals into calcium carbonate minerals is an important pathway for elimination of potentially toxic metals from natural waters. The thermodynamic properties of the resulting solid solutions are, however, poorly known because of difficulties with the solubility measurements. This project uses a new method of measuring these properties that avoids some of these difficulties. The new method involves an electrochemical double cell including carbonate minerals and no liquid junctions. At stoichiometric saturation for magnesian carbonate, the appropriate cell is:

$$
\begin{gathered}
\mathrm{Pb}(\mathrm{Hg}, 2 \text {-phase })\left|\mathrm{PbCO}_{3}(\mathrm{~s}), \mathrm{CaCO}_{3}(\mathrm{~s})\right| \\
\mathrm{CaCl}_{2}(\mathrm{aq})\left|\mathrm{Hg}_{2} \mathrm{Cl}_{2}(\mathrm{~s})\right| \mathrm{Hg}_{(1)}-\mathrm{Hg}_{(1)} \mid \\
\mathrm{Hg}_{2} \mathrm{Cl}_{2}(\mathrm{~s})\left|\left(\mathrm{Ca}_{2} \mathrm{Mg}\right) \mathrm{Cl}_{2}(\mathrm{aq})\right| \mathrm{Ca}_{\mathbf{x}} \mathrm{Mg}_{1-\mathrm{x}} \\
\mathrm{CO}_{3}(\mathrm{~s}), \mathrm{PbCO} \mathrm{CO}_{3}(\mathrm{~s}) \mid \mathrm{Pb}(\mathrm{Hg}, 2 \text {-phase) }
\end{gathered}
$$

The net reaction of this cell is:
$\left(\mathrm{CaCO}_{3}\right)$ calcite $+\mathrm{x} \mathrm{CaCl}(\mathrm{aq})+(1-\mathrm{x}) \mathrm{MgCl}_{2}(\mathrm{aq})=$ $\left(\mathrm{Ca}_{\mathbf{x}} \mathrm{Mg}_{1-\mathrm{x}} \mathrm{CO}_{3}\right) \mathrm{Mg}$-calcite $+\mathrm{CaCl}_{2}(\mathrm{aq})$

The standard Gibbs energy of formation of the binary solid solution $\left(\mathrm{Ca}_{\mathrm{x}} \mathrm{Mg}_{1-\mathrm{x}} \mathrm{CO}_{3}\right)$ is calculated from the cell potential, the known molalities and activity coefficients for $\mathrm{CaCl}_{2}$ and $\mathrm{CaCl}_{2}-\mathrm{MgCl}_{2}$ mixtures in the aqueous phases, and the Gibbs energies of formation of $\left(\mathrm{CaCO}_{3}\right)$ calcite, $\mathrm{Ca}^{+2}(\mathrm{aq})$, and $\mathrm{Mg}^{+2}(\mathrm{aq})$.

This cell is an advance over conventional solubility measurements because: (1) reversibility can be determined quickly, (2) the cell has a higher sensitivity and precision than conventional methods; and (3) it is not sensitive to metal-carbonato speciation. This cell is being used to determine the thermodynamic properties of carbonate solid solutions. Initial work focuses on magnesian- and cadmium-calcites but will be expanded to other carbonate solid solutions via similar cells. 
GRANTEE:

GRANT:

TITLE:

PERSON IN CHARGE:
UNIVERSITY OF CALIFORNIA AT LOS ANGELES

Department of Earth and Space Sciences

Los Angeles, CA 90024

DE-FG-03-89ER 14049

K-feldspar Thermochronology

T. M. Harrison (310-825-7970; FAX 310-825-2779;

E-mail tmh@argon.ess.ucla.edu)
A common ingredient in evaluation of virtually all energy sources is some form of temperature measurement. A complete description of exploitable geological sources, both geothermal and fossil fuel, requires an understanding of the temperature history of the system over extremely long times. Although the natural radioactivity of ${ }^{40} \mathrm{~K}$ continuously produces ${ }^{40} \mathrm{Ar}$ within the lattice of potassium feldspar, this gas is incompletely retained during cooling in the crust causing a record of the temperature-time history to be imprinted into the crystal. The ${ }^{40} \mathrm{Ar} /{ }^{39} \mathrm{Ar}$ method has the potential to furnish information about the internal distribution of the daughter product while simultaneously providing the argon diffusion parameters for that sample. Because virtually all geophysical events involve heat flow discontinuities (e.g., rifting, thrusting, normal faulting, burial, denudation, magmatism), we can use these cooling-related isotopic variations within K-feldspar to reveal past magmatic, hydrothermal, tectonic, or erosional activity. Our objective is to develop and understand this system well enough to apply it to problems of the thermal evolution of sedimentary basins, geothermal prospects, and outstanding questions in continental tectonics.

Our efforts this past year have been directed at testing the various underlying assumptions of our multi-diffusion domain interpretive theory. Although not all model underpinnings have yet been confirmed, tests of several model predictions give us tremendous confidence in the durability of this model. We have shown that diffusion boundaries can be approximated by a simple geometry; that complex, nonmonatonic cooling histories can be accommodated by the theory; and that nonuniform ${ }^{40} \mathrm{~K}$ distributions can lead to a small artifact that we recognize from experiments using natural materials. In addition, we continue to characterize the effect of laboratory heating on low-temperature K-feldspars. TEM, visible light, XRD, and kinetic analyses of MH-10 K-feldspar heated at temperatures up to $1100^{\circ} \mathrm{C}$ show that no changes to the degree of silicon/aluminum ordering, or content, cell dimensions, macroperthite distribution, subgrain boundaries, or defect density have occurred as a result of heating. A small change to argon diffusion coefficients over the first $5 \%$ of gas release appears to correlate with the loss of cryptoperthite exsolution lamellae. We have not been able to detect any significant alteration to the mineral structure or derived diffusion coefficients resulting from laboratory heating that might complicate thermal reconstructions.

This past year we have applied this technique to assessing when motion terminated on the Red River fault zone, a structure postulated to have accommodated a significant fraction of Indo-Asian convergence over the past $50 \mathrm{Ma}$. Our results suggest that ductile strike-slip motion ceased at about $20 \mathrm{Ma}$. This event may be related to a tectonic transition that occurred in Tibet and the Himalaya at the same time. 
GRANTEE:

GRANT:

TITLE:

PERSON IN CHARGE:
UNIVERSITY OF CALIFORNIA AT LOS ANGELES

Department of Earth and Space Sciences

Los Angeles, CA 90024

DE-FG03-91ER14222

Oxygen and Cation Diffusion in Oxide Minerals

K. D. McKeegan (310-825-3580; FAX 310-825-2779;

E-mail kdm@argon.ess.ucla.edu)
This project concerns the experimental determination of diffusion coefficients, under a variety of environmental conditions, for minerals of importance to contemporary petrologic problems. The results of these investigations support efforts to constrain the physical properties of minerals as a function of chemical environment, such as the variation in plastic deformation rate as a function of the oxygen fugacity $\left(\mathrm{fO}_{2}\right)$, by determining relationships between point defect chemistry and diffusive transport. Other applications of the data involve thermochronometry of crustal rocks and meteoritic materials. Work is proceeding in the following areas; (1) the role of $\mathrm{fO}_{2}$ and silica activity on the diffusion of oxygen in olivine; (2) the role of $\mathrm{fO}_{2}$ and silica activity on the diffusion of silicon in olivine; (3) determination of activation volumes for oxygen, silicon, and magnesium diffusion in olivine; (4) oxygen diffusion in diopside, spinel, hibonite, and melilite solid solutions; and (5) lead diffusion in monazite to calibrate a "prograde thermochronometer" to better understand crustal thermal histories.

In the initial year of funding, data have been obtained for oxygen diffusion in anorthite and in melilite. The results have been applied to refining our models of oxygen isotopic exchange with nebular gas during crystallization of calciumaluminum-rich inclusions in carbonaceous meteorites. Analytical procedures for the measurement of lead diffusion in monazite have been developed at the Lawrence Livermore National Laboratory using their CAMECA ims $3 f$ ion microprobe. Ion microscope imaging has revealed that lead-rich regions, likely included during synthesis, complicate diffusion measurement. Nonetheless, a gradient has been measured by depth-profiling of a sample annealed at $1000^{\circ} \mathrm{C}$ indicating that both this material and this approach may be used to determine lead diffusion. 
GRANTEE:

GRANT:

TITLE:

PERSONS IN CHARGE:
UNIVERSITY OF CALIFORNIA AT SAN DIEGO

Scripps Institution of Oceanography

La Jolla, Califomia 92093-0215

DE-FG03-92ER 14245

Deuterium/Hydrogen Ratios and Scanning Electron Microscopy Im aging of Fossil Organic Matter from California's Monterey Formation

A. Schimmelmann and C.E. Reimers (619-534-4605; FAX 619-534-0784)
Bacteria may have contributed substantially to the formation and accumulation of organic matter in the oil-source rocks of California's Monterey Formation. Our objective is to test this hypothesis by determining if a bacterial source is recognizable electron-microscopically as well as geochemically in the deuterium/hydrogen ratios of the sedimentary organic matter. The U.S. Geological Survey supplied two depth-series of samples to us and to other participating laboratories as part of a large-scale research project entitled the "Cooperative Monterey Organic Geochemistry Project." Many kinds of analyses and characterizations are to be compared including $\mathrm{C},-\mathrm{O}-, \mathrm{N}-$, and S-isotopic ratios, GC, GCMS, biomarkers, sedimentology and mineralogy, trace elements, and Rock Eval.

We are using both scanning electron microscopy and light microscope methods to examine remnant microbiological features attributable to bacterial mats, and to describe fine-scale sedimentological clues of paleoenvi- ronment and diagenesis such as varves or authigenic minerals. Thus far, the fossils of filamentous bacteria have been identified in two of eight samples examined systematically. Authigenic m inerals include opal-CT, quartz, pyrite, calcite, dolomite, and carbonate fluorapatite.

Using separations of kerogen, humic acid, and fulvic acid, we are determining the ratio of exchangeable versus nonexchangeable hydrogen and the isotopic composition of nonexchangeable hydrogen by equilibrating exchangeable hydrogen with water vapors of different hydrogen isotopic compositions. Preliminary $\delta D_{\text {sMow }}$ values show indeed a strong depletion with regard to deuterium, confirming an unusual source of organic matter for the Monterey Formation. Organic matter with a large bacterial component may well explain this finding. 
GRANTEE:

GRANT:

TITLE:

PERSON IN CHARGE:
UNIVERSITY OF CALIFORNIA AT SANTA BARBARA

Institute for Crustal Studies

Santa Barbara, California 93106

Physical Modeling of Sedimentary Basins, Magma Mechanics, and Molecular Dynamics of Aqueous Solutions

F. J. Spera (805-893-2260; FAX 805-893-8649;

E-mail spera@magma.geol.ucsb.edu)

This is a collaborative project with D. A. Yuen (University of Minnesota) to conduct modeling of several problems relevant to the geoscience mission of the Department of Energy. The four areas include: (1) thermomechanical modeling of the evolution of sedimentary basins; (2) fundamental investigation of doubly diffusive (thermohaline) convection in low-porosity porous media; (3) molecular dynamics of $\mathrm{H}_{2} \mathrm{O}$ using a potential that includes oxygen polarization and allows for molecular dissociation at elevated temperatures and pressures; and (4) dynamics of magmatic systems including caldera resurgence, withdrawal of magma from crustal reservoirs and rheometric studies of melts in the system $\mathrm{NaAlSiO}_{4}-\mathrm{SiO}_{2}$.

Work in progress includes: (1) the dynamical influences of lithospheric phase transitions on the thermalmechanical evolution of sedimentary basins; (2) the coupling between mantle convection and, in particular, mantle plumes on the thermal regime and subsidence history of rift-related sedimentary basins; (3) numerical modeling of heat and solute transport driven by thermal and salinity gradients in low porosity fractured porous medium as commonly encountered in sedimentary basins undergoing diagenesis and lithification; (4) the thermodynamic and electrostatic properties of water and silicate melts determined by state-of-the-art molecular dynamics methods; (5) the dynamics of magma removal from large crustal reservoirs for magma treated as a rheologically complex fluid; and (6) the dynamics of the resurgence of volcanic calderas in continental regions. 
GRANTEE:

GRANT:

TITLE:

PERSON IN CHARGE:
THE UNIVERSITY OF CHICAGO

Center for Advanced Radiation Sources

5734 S Ellis Ave

Chicago, Illinois 60637

Development of Synchrotron X-Ray Microspectroscopic

Techniques and Application to Problems in Low-Temperature

Geochemistry

J. V. Smith (312-702-8110; FAX 312-702-8110;

E-mail smith@geo1.uchicago.edu)

This proposal defines a research program to develop synchrotron $\mathrm{X}$-ray microprobe techniques and instrumentation for X-ray fluorescence (XRF) and $X$-ray absorption spectroscopy (XAS) applications for low-temperature geochemistry. The project is a collaboration between geoscientists already experienced in the use of synchrotron radiation in earth materials research, geochemists specializing in low-temperature work, and soil and environmental scientists wishing to bring new tools to their field problems. Two coinvestigators, M. L. Rivers and S. R. Sutton, are developing instrumentation, and carrying out pilot studies at beamlines X26-A and X-17 of the National Synchrotron Light Source (NSLS) at Brookhaven National Laboratory in association with Keith W. Jones. Principal collaborators from the national user groups GeoCARS \& Soil/EnviroCARS are J. Bigham (Ohio State University), G. Brown, Jr. (Stanford University), R. Grant (Purdue University), W. Meyers (State University of New York at Stony Brook), D. Schulze (Purdue University), J. Stucki (University of Illinois, Urbana), D. Vanko (Georgia State University), and G. Waychunas (Stanford University). A hands-on user workshop for new users in June 1992 (jointly funded with the National Science Foundation-EAR) attracted 60 new users. New equipment funded by other Department of Energy, National Science Foundation, and National Aeronautics and Space Administration grants has increased the sensitivity for XAS and XRF measurements at NSLS. A workshop in July 1992 will complete the general design for the GeoCARS facility to be built at the Advanced Photon Source (APS) currently under construction at Argonne National Laboratory.

The following geochemical problems are currently being tackled at NSLS: the chemical nature of hydrothermal fluid inclusions (resolution about $10 \mu \mathrm{m}$ with aim of $1 \mu \mathrm{m}$ at APS: sensitivity for trace elements varies but can approach the 10-ppm level); cation fixation mechanisms in phyllosilicates (redox state can be determined by $\mathrm{X}$-ray absorption near-edge structure for certain transition elements at the $0.0 \mathrm{n}$ wt. \% level, and the local atomic bonding by EXAFS at the $n$ to $0 . n$ wt. \% level), iron oxide formation and evolution, diagenetic environments of dolomitization, and aerosol climatology. These intellectually driven research projects are increasing the fundamental knowledge of atomic movements in the outer zone of the earth and are significant for practical applications in management of waste products, migration of salt-bearing fluids, development of petroleum reservoirs, measurement of air pollution from power stations, and so forth. At this time the sensitivity of the equipment at NSLS limits the research to carefully selected projects involving elements at high enough concentrations. The ultimate aims are to push the capabilities as close to the micrometer/micromolar level as possible at APS and to assign research problems to the NSLS and APS experimental stations as befits the needed sensitivities. 
GRANTEE:

GRANT:

TITLE:

PERSONS IN CHARGE:

\section{COLORADO SCHOOL OF MINES}

Golden, Colorado 80401

DE-FG02-89ER 14079

Computational Methods for Improving the Resolution of

Subsurface Seismic Images

K. Larner (303-273-3428; FAX 303-273-3478;

E-mail klarner@Mines.Colorado.edu),

D. Hale, N. Bleistein, and J. Cohen
The quality of subsurface images of the earth requires accurate and efficient representation of seismic wavefields in realistic subsurface media and accurate imaging or inversion of those wavefields. Toward this end, we have been investigating several issues related to accurate imaging of steep interfaces. One area studied is a dip-dependent correction for amplitude loss caused by energy spreading in media for which seismic velocity varies with depth. Results show that the conventional spreading correction, which ignores reflector dip, can yield overcorrection of reflection amplitude by $50 \%$ or more for dips that exceed 60 degrees. Another area studied is documentation of the dip-dependent filtering of seismic signal that occurs in media within which velocity has not only a generally increasing trend with depth but also variation associated with thin layers. Results show that to the stratigraphic filtering familiar for energy that propagates vertically is added "evanescent filtering" that arises for energy that propagates rather parallel to bedding for a good part of the reflection travel path. Modeling of the waves for this study consisted of Korn's two-step process of frequency-wave number finite-difference modeling to determine the Green's function for acoustic waves in a thin-layer medium, followed by computation of reflections via the Born approximation. The results suggest the need for dip-dependent deconvolution in seismic data processing.

The earth's subsurface is known to be anisotropic. For models in which the earth is transversely isotropic, with linear variation of velocity with depth, another component of the study is an investigation of the errors that arise when data are migrated or dip-moveout-corrected with algorithms that ignore the anisotropy (as do all algorithms used routinely for subsurface imaging). This study has involved development of code for ray tracing in such anisotropic, inhomogeneous media. Ongoing research extends this study to pre-stack migration and extends the structural complexity of subsurface models consisting of such anisotropic media. 
GRANTEE:

GRANT:

TITLE:

PERSON IN CHARGE:
UNIVERSTTY OF COLORADO

Department of Geological Sciences

Boulder, Colorado 80309-0250

DE-FR02-92ER14233.000

Crystal Chemistry of Hydroxyl and Water in Silicate Minerals

Joseph R. Smyth (303-492-5521; FAX 303-492-2606;

E-mail JOESMYTH@VAXF.COLORADO)
Hydrogen in the form of hydroxyl and molecular water plays an important role in the chemical and physical properties of silicate minerals. Deuterium/hydrogen and ${ }^{18} \mathrm{O} /{ }^{16} \mathrm{O}$ ratios used as geothermometers to evaluate geothermal and petroleum reservoirs are controlled by hydroxyl stability; the stability of hydroxyl-bearing silicates (such as omphacite, wadsleyite $\left(\beta-\mathrm{Mg}_{2} \mathrm{SiO}_{4}\right)$, rutile, and stishovite) may control melting and magma generation; and the hydration of various cations substituting into the abundant natural zeolite and clinoptilolite may control sorption and migration of cations and radionuclides. This project investigates the crystal chemistry of $\mathrm{OH}$ and $\mathrm{H}_{2} \mathrm{O}$ substitution in silicate minerals by use of $\mathrm{X}$-ray and neutron diffraction methods combined with infrared spectroscopy and interprets and generalizes the results using an electrostatic model for these mineral structures.

The crystal structures of three hydrous and three anhydrous omphacites have been refined. The refinement of the crystal structure of a hydrous omphacite has been completed from neutron data locating the position of the hydrogen atom (located at a position $1.05 \AA$ from the $\mathrm{O}_{2}$ atom along a vector nearly parallel to $a^{*}$ indicating that the hydrogen is stoichiometrically incorporated into the structure compensating for partial $\mathrm{M}_{2}$ site vacancy). The crystal structure of a natural hydrous rutile has been refined from neutron and $X$-ray diffraction data. A 3\%-occupied hydrogen site has been located along the short edge of the titanium octahedron. The apparent effect of this hydrogen is to reduce oxygen-oxygen repulsion along this abnormally short edge of the octahedron as well as to provide charge balance for the $\mathrm{Fe}^{3+}$ substitution in the structure. These findings appear to make it more likely that aluminum-hydrogen coupled substitution may occur in mantle stishovite because the shared edge in stishovite is even shorter than in rutile. A collaborative synthesis of aluminum and hydrogen-bearing stishovite $\left(\mathrm{SiO}_{2}\right)$ and hydrous wadsleyite is under way. The electrostatic site potentials of $\mathrm{OH}$ and oxygen positions in hydroxyl-bearing silicates have been computed, and a rough correlation of hydroxyl site potential (assuming a point charge of -1 ) with the oxygen-hydrogen stretching vibration frequency determined by IR spectra has been observed. These studies should lead to a predictive model for hydrogen and oxygen stable isotope substitution in silicates. In zeolite studies, water ions and exchangeable cations are being located with significantly greater precision using a new $18 \mathrm{~kW}$ rotating-anode diffractometer. Cation exchange experiments have been performed to produce single crystals of $\mathrm{K}, \mathrm{Na}, \mathrm{Rb}, \mathrm{Cs}, \mathrm{Sr}$, and $\mathrm{Ba}$ varieties of the material. Whereas the alkalis exchange readily in these crystals, the alkaline earths do not. 
GRANTEE:

GRANT:

TITLE:

PERSON IN CHARGE:

\section{UNIVERSITY OF COLORADO}

\author{
DE-FG02-87ER 13804
}

Seismic A bsorption in Fluid-Filled Porous Rocks as a

Function of Seismic Frequencies, Pressure, and Temperature

H artmut Spetzler (303-492-6715; FAX 303-492-1149;

E-mail Spetzler_H@CUBLDR.COLORADO.EDU)
An apparatus is being developed for the determination of seismic attenuation $\left(Q^{-1}\right)$ in partially fluid saturated sedimentary rocks. The motivation for this research comes from the desire to better understand the effects of fluid and gas interactions in rocks. Results from this research will enhance the interpretation of seismic data in terms of the fluid saturation of rocks as well as the characteristics of the fluid and thus aid in the monitoring of waste sites and the detection of hydrocarbons.

Based on the experience of earlier investigators and to be able to make measurements under crustal conditions, this new $Q$ apparatus will have the following important features:

1. Longitudinal and shear $Q$ values will be measured on a sample without removing it from the apparatus.

2. Frequencies will be in the seismic range, from 0.01 to $100 \mathrm{~Hz}$.
3. Strain amplitudes will be smaller than $10^{-6}$ to ensure $Q$ values independent of amplitude.

4. The samples will be jacketed and measured under confining pressure to avoid the interaction between the fluid and the sample atmosphere interface (Biot-Gardner effect).

5. Three measurement stations will be used to determine each value of stress and each value of strain. This is necessary to ensure pure mode deformation. Without the knowledge of the purity of the mode of deformation, meaningful $Q$ measurements cannot be made.

6. Control of pure mode deformation is accomplished with two sets of three deformation transducers.

At present the apparatus has achieved design criteria in several areas. Using data from all six stations, phase shifts below $10 \mathrm{mrad}$ can consistently be measured on low loss materials from above $10 \mathrm{~Hz}$ to below $0.1 \mathrm{~Hz}$. These measurements are made at strain levels of $10^{-6}$. 
GRANTEE:

GRANT:

TITLE:

PERSONS IN CHARGE:
COLUMBIA UNIVERSITY

Lamont-Doherty Geological Observatory

Palisades, New York 10964

DE-FG02-88ER 13221

Seismology and Tectonics of the Eastern Aleutian Arc

K. Jacob (914-359-2900; FAX 914-359-5215;

E-mail jacob@lamont.ldgo.columbia.edu) and G. Abers
Physical processes associated with plate convergence and subduction are investigated at the Alaska Aleutian arc-trench system. A digital 15-station seismic network was operated from 1973 to 1981 in the Shumagin Islands. An additional broadband station was added in the late seventies. All seismic operations are now terminated. Only the broadband station is still in place. This segment is a seismic gap with an inferred high probability for a large earthquake during the next few decades. Along the Alaska Peninsula, the Shumagins, Eastern Aleutians, and the adjacent Bering Sea margin, the past network and current teleseismic data are used to study the occurrence and source parameters of earthquakes and to assess their role in active tectonics by combining seismic results with other geological and geophysical information. Research applications concern the seismic, volcanic, and tsunami hazard to potential oil lease sale areas. Detailed studies of the Shumagin region help to understand the plumbing system and geothermal resource potential of the volcanic arc and the tectonic subsidence and thermal histories of basins with hydrocarbon potential. Other topics concern engineering seismology, earthquake prediction, and assessment of seismic/volcanic risk to future energy projects in this active tectonic region. The following topics are investigated: The three-dimensional velocity structure is determined from arrival times of earthquakes in the Shumagin Islands segment of the arc. Hypocenters and velocity structure in the fore-arc and the dipping plate are simultaneously inverted for. At depths less than $100 \mathrm{~km}$ the dipping planes of seismic activity are constrained to very narrow zones, apparently less than $10 \mathrm{~km}$ thick, implying perhaps a thermally or petrologically/ phase-change-controlled locus of seismic activation rather than a purely stress-controlled trigger mechanism for the earthquakes.

Stress indicators at 623 independent points are collected for continental Alaska, the Aleutian Islands, and surrounding areas. The data comprise 551 earthquake focal mechanisms, 32 volcanic indicators, 14 geological fault indicators, and 26 oil well breakouts. Together they display a direction of maximum horizontal compressive stress (MHC) system that is generally consistent with Pacific/ American plate interaction along the southern margin of Alaska.

Body and surface waves of large and great thrust earthquakes between 1923 and 1989 along the Eastern Aleutian arc are analyzed for their implications of tectonics and occurrence of future events. The analysis yields the moments and gross rupture characteristics (focal mechanisms, dimensions, durations, slip, and average stress drops) of the $M_{w}=8.3$ Alaska Peninsula event of 1938, and of six other large earthquakes of $M_{s} 7 \pm 0.5$ in the $500-\mathrm{km}$-long segment of intensive study. Five $M \sim 7$ events in the 1938 rupture zone have similar size, down-dip location, depth, and mechanism and define a shallow dipping (16-19 $)$ plate interface that further flattens to a dip of only $8^{\circ}$ under Kodiak Island. The similar source properties and location allow for the speculative interpretation that the subduction and shearing off of seamounts riding on the descending Pacific plate may be involved in these events. The plate interface dips nearly uniformly between the Shumagin Islands and the 1938 rupture zone, indicating that seismic segmentation, if any is present, is not controlled by the orientation of the plate interface. The next great earthquake may rupture both segments and thus allow for a magnitude in excess of $\mathrm{M}_{\mathrm{w}}=8.5$. 
GRANTEE:

GRANT:

TITLE:

PERSONS IN CHARGE:
COLUMBIA UNIVERSITY

Lamont-Doherty Geological Observatory

Palisades, New York 10964

\section{DE-FG02-86ER 13287}

Energetics of Silicate Melts from Thermal Diffusion Studies

D. Walker and M. C. Johnson

(914-359-2900; FAX 914-365-3183)

A detailed characterization of silicate liquids is required for a predictive understanding of the evolution of natural magmas within the Earth's crust. A magma's crystallization behavior and interaction with its surroundings determine, among other things, the potential for geothermal energy extraction and the formation of ore deposits. The thermodynamic evolution of magmatic systems depends not only upon the thermochemical details of the solidification products but also on the thermochemical properties of the initial magmatic liquids. These properties are more poorly known for the liquids than for the solids. It is the purpose of this project to aid in the characterization of the thermodynamic properties of silicate liquids by a novel experimental approach, thermal diffusion studies. Thermal diffusion is the phenomenon of chemical migration in response to a thermal gradient. In a substance with more than one component, chemical heterogeneity can develop in an initially homogeneous substance as a result of a diffusional mass flow consequent on heat flow. The details of this response are conditioned by the thermochemical properties and constitution of the substance. We have experimentally demonstrated that silicate liquids do undergo substantial thermal diffusion differentiation and that observations of this differentiation provide the data necessary to evaluate the form and quantitative values of silicate liquid solution parameters. This information supplements calorimetric and phase equilibrium data on silicate liquids. Techniques have been developed to extract ordinary diffusion coefficients, heats of transport, and energies of mixing from experimental temperature-composition thermal diffusion profiles of multicomponent silicate liquids. Immiscibility relations in the system $\mathrm{Fe}_{2} \mathrm{SiO}_{4}(\mathrm{Fa})-\mathrm{KA1Si}_{2} \mathrm{O}_{6}(\mathrm{Lc})$ $-\mathrm{SiO}_{2}(\mathrm{Q} t)$ have been successfully retrieved based solely on thermal diffusion results using a ternary asymmetric regular solution model. A similar approach is being used to quantify solution behavior of naturally occurring silicate and sulfide magmas. We have obtained our first results on high-temperature carbonate magmas this year and find that they are also Soret-active.

Recent application of thermal diffusion studies to magmatic and aqueous systems involving coexistence of crystals with a multicomponent fluid has shown that there is a substantial potential for inducing chemical migration, even in the absence of convection. Laboratory observations of cumulate maturation under the influence of thermal diffusion have been applied to postcumulus evolution of magma bodies and the formation of cyclic evaporite deposits.

Much recent effort has been invested on high-pressure technique development. We have succeeded in producing stable multianvil runs in the $100+$ kbar range for time scales of 100 s of hours. This stability has been made possible by advances on pressure media and gasketing configurations. Thermal diffusion experiments in this pressure range are now practicable, a major objective in the establishing of our multianvil lab with Department of Energy/UIG support. Other multianvil labs will benefit from this development work. 
GRANTEE:

GRANT:

TITLE:

PERSON IN CHARGE:
UNIVERSITY OF DELAWARE

Department of Chemistry and Biochemistry

Newark, Delaware 19716

DE-FG02-89ER 14080

Development of an Experimental Data Base and Theories For Prediction of Thermodynamic Properties of Aqueous Electrolytes and Nonelectrolytes of Geochemical Significance at Supercritical Temperatures and Pressures

R. H. Wood (302-831-2941; FAX 302-831-6335;

E-mail CQD00050@UDELVM [Bitnet])
Measurements of the apparent molar heat capacity of aqueous solutions of $\mathrm{H}_{2} \mathrm{~S}, \mathrm{CO}_{2}$, and $\mathrm{CH}_{4}$ have been made at twelve temperatures from 25 to $450^{\circ} \mathrm{C}$ and at pressure near 350 bars. Measurements of the apparent molar volume of aqueous solutions of $\mathrm{H}_{2} \mathrm{~S}, \mathrm{CO}_{2}$, and $\mathrm{CH}_{4}$ are being made at the same twelve temperatures and at two different pressures. These measurements accurately define the equilibrium properties of aqueous solutions of these gases at temperatures up to $450^{\circ} \mathrm{C}$ and pressures to 350 bars. These solutes are crucial reactants or products in (1) the dissolution and precipitation of sulfide minerals, (2) the dissolution and precipitation of carbonate minerals, and (3) the formation of natural gas products. An accurate knowledge of their thermodynamic properties permits a much better understanding of the driving forces for these processes. The measurements double the amount of information available on volumes and heat capacities of aqueous nonelectrolytes at high temperatures.

Theoretical models capable of representing these data and extrapolating them to higher temperatures and pressures are being investigated. We are using molecular dynamics simulations of model methanes in water to estimate the free energy of methane in water at temperatures from 600 to $1200^{\circ} \mathrm{C}$ and densities of 0.3 to $1.0 \mathrm{gm} / \mathrm{cm}^{3}$. Correlations and theoretical models that will allow the estimation of the properties of other nonelectrolytes of geochemical interest are also being investigated. 
GRANTEE:

GRANT:

TITLE:

PERSON IN CHARGE:
INDIANA UNIVERSITY

Department of Chemistry

Bloomington, Indiana 47405

Mechanochemical Self-Organization and Nonlinear

Dynamics in Sedimentary Basins

P. Ortoleva (812-855-2717; FAX 812-855-8300;

E-mail ortoleva@ucs.indiana.edu)

Deep in a sedimentary basin, a strong coupling between reaction, transport, and mechanical (RTM) processes leads to a number of important phenomena for the petroleum industry. These phenomena include diagenetic seals, preserved porosity and permeability, overpressures, episodic fluid release, compaction, and formation collapse. Such phenomena are analyzed via the development of quantitative RTM models to predict their timing and location.

Driven by developed overpressure, upward fluid migration can take on a temporally oscillatory character through the coupling of the overpressuring mechanisms, hydrofracture generation and healing, and fluid transport. The basin disequilibrium provides a necessary condition for the self- organization of features in sedimentary rocks including stylolites, differentiated marl/limestone sequences, and compaction/cementation alternation layering. As the generation of these features may dramatically affect permeability, they in tum affect the large scale spatial distribution of pressure, thereby inducing a multiple scale coupling. Submeter-scale features are affected by local pressure while the location of these features are affected by and affect the distribution of fluid pressure.

A homogenization approach simulated using a highly parallel algorithm has been developed and implemented on an Intel iPSC/860. This is a great step forward in the simulation of basin diagenesis. 
GRANTEE:

GRANT:

TITLE:

PERSONS IN CHARGE:
THE JOHNS HOPKINS UNIVERSITY

Department of Earth and Planetary Sciences

34th and Charles St.

Baltimone, Maryland 21218

\section{DE-FGO2-89ER 14074}

High-Resolution Transmission Electron Microscopy/Analytical Electron Microscopy and Scanning Electron Microscopy Study of Fluid-Rock Interactions: Inter action of Copper-, Silver-, Selenium-, Chromium-, and Cadmium-Bearing Solutions with Geological Materials at Near Surface Conditions, with an Emphasis on Phyllosilicates

D. R. Veblen (410-516-8487; FAX 410-516-7933) and

E. S. Ilton (215-758-5834)

Oxidation-reduction reactions at the mineral-fluid interface can be responsible for the attenuation or mobilization of multivalent elements in the near-surface environment. This project involves the investigation of the interaction of silver-, copper-, selenium $\left(\mathrm{Se}^{4+}\right.$ and $\left.\mathrm{Se}^{6+}\right)-$, and chromium $\left(\mathrm{Cr}^{6+}\right)$-bearing solutions with ferrous phyllosilicates such as biotite, a potential reducing agent, under both oxic and anoxic conditions. Reduced forms of selenium and chromium are less soluble and less toxic than oxidized forms. The reduction of copper and silver during weathering can be an important process in the supergene enrichment of both these elements. Biotite containing ferrous iron was chosen for initial study because it is a ubiquitous, potential reducing agent in rocks and soils; ferrous iron in biotite can be a stronger reducing agent than $\mathrm{Fe}^{2+}$ (aq). Moreover, biotite is capable of simultaneously absorbing and reducing metals (as previously shown for copper). The sorption of cadmium by pnyllosilicates is also being studied. Whereas cadmium is not involved in oxidation-reduction reactions, the sorption of cadmium by phyllosilicates has never been characterized with transmission electron microscopy (TEM).

The emphasis of the experimental work is to examine the surfaces and interior portions of the reacted phyllosilicates with TEM, analytical electron microscopy (AEM), scanning electron microscopy, and $X$-ray photoelectron spectroscopy. The combination of these techniques will help to determine the oxidation state and form of the sorbed species (e.g., inclusions in the interlayer region of the sheet silicate, surface precipitates, absorbed, or adsorbed). This information provides constraints on the physical and chemical conditions that are required for the mobilization or attenuation of these elements from or by phyllosilicates.

One goal is to determine the effect of fluorine in micas on the sorption and potential reduction of multivalent aqueous ions. Fluorine stabilizes potassium in biotite; fluorine in biotite should, therefore, strongly affect the rate and amount of absorption by biotite. Further, because the oxidation of ferrous iron in micas may depend, in part, on the release of potassium (for charge balance) from interlayer sites, it is possible that the rate and extent of reduction of elements by ferrous micas will depend on the fluorine contents of these minerals.

This project continues to use TEM/AEM to study the record of mineral-fluid reactions in the Cyprus Casa Grande porphyry copper deposit. Investigations of naturally occurring copperenriched silicates have been extended to plagioclase and its alteration products and to vein assemblages. 
GRANTEE:

GRANT:

TITLE:

PERSON IN CHARGE:

\section{UNIVERSITY OF HOUSTON}

Houston Petroleum Research Center

Houston, Texas 77204-4231

\title{
DE-FG05-89ER 14058
}

\author{
Cross Hole Geotomography in a Partially Depleted Reservoir
}

\author{
J. A. McDonald (713-743-9150; FAX 713-743-9164;
}

E-mail west76@archie.agl.uh.edu)

Research efforts continue at developing and improving methods to produce high-resolution images using seismic energy. These images are becoming increasingly important in the search for better ways to describe the hydrocarbon reservoir. In addition, these new methods and technologies are furthering our understanding of the basic science of seismology. The principal objectives of this crosshole geotomography project are:

1. Investigating the characteristics of downhole seismic energy sources.

2. Determining which types of energy sources are most suitable for sites with variable lithology, well spacing, diameter, depth, and other parameters.

3. Producing seismic images, in this case tomograms, with resolution up to two orders of magnitude greater than is possible with conventional surface seismic methods.

4. Analyzing crosshole seismic transmission data to understand how various energy modes are propagated and converted.

The Seventy-Six West field is a state-owned field in Duval county, south Texas, and will have only produced an estimated $38 \%$ of oil in place on abandonment. In conjunction with the Bureau of Economic Geology (BEG) of the state of Texas, five cross hole experiments have been completed in this field.

Geotomography using cross hole methods takes advantage of being able to position both the seismic source and receivers below the highly attenuative surface layer. In the Seventy-Six West field, seismic signals with frequencies over $1000 \mathrm{~Hz}$ have been recorded in sediments with an average compressional velocity of $7000 \mathrm{ft} / \mathrm{s}$. In contrast, typical frequencies for surface seismic methods range from 40 to $80 \mathrm{~Hz}$.

Results from the first three experiments showed that a piezoelectric "bender" was effective in producing high frequency cross hole seismic signals. However, the data collected during a fourth experiment with the bender were inadequate for inversion. Early experiments had shown that an air gun produced seismic energy with signal-to-noise ratio suitable for picking arrival times even though its source spectrum had a much lower frequency range than the bender.

It was decided to conduct a fifth experiment using the air gun as a source and hydrophones as receivers. Because wells in the field did not penetrate below the producing horizon, the Cole " $\mathrm{C}$ " sand in the Jackson-Yegua formation, it was decided to target the shallower Frio sand. The Frio has petrophysical properties very similar to those of the Cole "C", namely $30 \%$ porosity, $1100 \mathrm{md}$ permeability, and is also the same thickness. The wells used to generate the ray paths through the Frio sand were separated by 496 - $\mathrm{ft} P$-wave velocity tomograms produced for this interwell region, which successfully imaged the Frio sandstone.

In addition to cross hole data, reversed vertical seismic profile (RVSP) data have been recorded between wells spaced at $1215 \mathrm{ft}$. At this spacing, an air gun was not producing usable cross hole signals; however, usable RVSP data were recorded from which a one-dimensional $P$-wave velocity tomogram has been produced, which directly correlates with a sonic log from a nearby well. 
GRANTEE:

GRANT:

TITLE:

PERSONS IN CHARGE:

\author{
LOUISIANA STATE UNIVERSITY \\ Department of Geology and Geophysics \\ Baton Rouge, Louisiana 70803-4101
}

\author{
Organic/Inorganic Interactions of Nitrogen in Oil Fields- \\ Part II. Mineralogy and Microbiology \\ R. E. Ferrell (504-388-5306; FAX 504-388-2302; \\ E-mail GLFERR@LSUVAX.sncc.lsu.edu) and M. Walsh \\ (504-388-4285)
}

Nitrogen is one of the most ubiquitous elements involved in geological processes. It is the major element in the atmosphere and occurs in minor or trace quantities in water, organic matter, and the minerals of sedimentary, metamorphic, and igneous rocks. Organic activity incorporates nitrogen in cell material; and as it decays during burial, temperatureand time-mitigated reactions release nitrogen with evolving hydrocarbons or directly to the formation fluid. Authigenic minerals, such as feldspars and layer-silicate clays, may incorporate nitrogen as fixed ammonium (fixed $\mathrm{NH}_{4}$ ) in their crystal structure. Recent observations of fixed $\mathrm{NH}_{4}$ anomalies in the clay minerals of petroleum reservoirs has lead to the initiation of research on the origin of the anomalies and the use of fixed $\mathrm{NH}_{4}$ in illite/smectite (I/S) mixed layered minerals as a tracer for hydrocarbon migration. The major objectives of the research are to identify the processes and reactions responsible for the anomalies and to evaluate their use in the identification of the pathways followed by hydrocarbons as they migrate from the source rock to the reservoir.

In the search for hydrocarbons, there are four fundamental questions that must be evaluated: (1) Where are the mature source rocks? (2) Where are the reservoir rocks? (3) Are "traps" present? (4) How are these features related in time and space with regard to hydrocarbon migration? The last of these is the aspect that represents the focal point of this investigation. Nitrogen associated with maturing organic matter and migrating oil and gas $m$ ay have a unique signature that is fixed in diagenetic clay minerals. The results of fixed $\mathrm{NH}_{4}$ studies have revealed correlations among the quantities substituted, the degree of illitization of $I / S$, the presence of hydrocarbons, and the temperature of the diagenetic environment of Fordoche Field and other locations. Migration and clay diagenesis appear to be contemporaneous, so the clays have picked up large quantities of nitrogen from the migrating oil and gas. Preliminary results of microbiological analyses have resulted in the culture of bacteria that may be responsible for the liberation of nitrogen from organic matter. The use of nitrogen isotopes to fingerprint the sources of nitrogen has revealed small differences that cannot be clearly evaluated at this stage of the study. As the coupled inorganic/organic geochemical reactions become better understood, they may provide additional insight on the timing of migration and thereby help to associate the movement of oil and gas with the formation of structural traps. More knowledge of these subsurface associations and their geohistory will improve our knowledge of where and when hydrocarbons are present and thereby improve the overall success of energy exploration programs.

This research is being coordinated with another Department of Energy/Basic Energy Sciences project directed by Lynda Williams of Arizona State University (Organic/1norganic Interactions of Nitrogen in Oilfields-Part I. Geochemistry). 
GRANTEE:

GRANT:

TITLE:

PERSONS IN CHARGE:
MASSACH USETTS INSTITUTE OF TECHNOLOGY

Department of Earth, Atmospheric, and Planetary Sciences

Cambridge, Massachusetts 02139
DE-FG02-86-ER13636

In Situ Permeability Determination Using Borehole and

Seismic Logging Data

M. Nafi Toksoz (617-253-7852; FAX 617-253-6385;

E-mail nafi@erl.mit.edu); and C.H. Arthur Cheng

(617-253-7206; FAX 617-253-6385; E-mail cheng@erl.mit.edu)
The purpose of this work is to study methods of determining in situ permeability or hydraulic conductivity of a fracture or fracture zone using full waveform acoustic logging, vertical seismic profiling, and other downhole and cross hole seismic imaging techniques. The aim is to characterize and image in situ fractures for the purpose of hydrocarbon production from naturally or artificially fractured reservoirs, nuclear waste disposal planning, and geothermal energy recovery.

In the past year we have developed a comprehensive model for fluid flow in porous rocks that is applicable to both fractures and permeable rocks. Using this model we are able to obtain from full waveform acoustic logs an estimate of the hydraulic properties of a permeable fracture by analyzing the transmission and reflection of the Stoneley wave. We have also developed a numerical model that can m odel transient flow in porous media and frequency dependent flow between rough surfaces. Both are important in the interpretation of well test results. In addition, we have developed a new expression for fracture/crack-induced seismic anisotropy based on the Pade approximation. 
GRANTEE:

GRANT:

TITLE:

PERSONS IN CHARGE:
MASSA CH USETTS INSTITUTE OF TECHNOLOGY

Earth Resources Laboratory (ERL)

Department of Earth, Atmospheric, and Planetary Sciences

Cambridge, Massachusetts 02139

\section{DE-FG02-89ER 14084}

Reservoir Characterization by Cross Hole Seismic Imaging

Roger Turpening (617-253-7850; FAX 617-253-6385;

E-mail roger@erl.mit.edu) and M.N. Toksoz (617-253-7852;

FAX 617-253-6385)

The seismic techniques needed for detailed characterization of known hydrocarbon reservoirs are in the early stages of development. To get the needed resolution it is obvious that we must place both the seismic source and receiver in boreholes and these boreholes must straddle the region of interest. To get reasonable coverage the boreholes must be much deeper than the reservoir. To achieve some characterization of the formations, in addition to their image, one must use shear wave sources in addition to compressional (P) wave sources. Furthermore, for the results to be of use, the research must be conducted over typical oil well spacings, not at special test sites.

The ERL, in cooperation with Sandia, is conducting a multiyear research effort at ERL's Reservoir Delineation Research Facility in northern Michigan. There, in a carbonate setting, all of the above requirements are met. Two deep $(6800 \mathrm{ft}$, $2.1 \mathrm{~km})$ boreholes, separated by $2000 \mathrm{ft}(600 \mathrm{~m})$, straddle a 70 -acre, producing reef. The rough shape and position of the reservoir is known from low-frequency three-dimensional reflection data, vertical seismic profiling (VSP) images, and logs. Low resolution characterization of the reservoir has been done with additional nine-component VSPs.

In October 1990 the feasibility of high-frequency $P$-wave propagation over long slant distances $(2,800 \mathrm{ft}, 850 \mathrm{~m})$ was demonstrated at the Michigan test site, and in July 1991 the survey was completed, 40,000 ray paths. The data quality is excellent even though the energy has propagated long distances through a porous reservoir and across several strong impedance contrasts. Preliminary images show features inside the reef that are corroborated by the engineering history of the producing well and the engineering records of MIT's boreholes. These features of the reservoir were not seen by any other geophysical technique.

Recording of the Sandia vertical vibrator data took place in September 1991. Shear (s) wave (dipole) logging took place in the same field session with excellent results in open hole and through casing (through double casing over one interval, corroborated by a previous run in open hole). This interval contains an important gas-producing shale-the Antrim Shale. The cross hole shear-wave velocity data will be compared with the dipole logs, full waveform acoustic logs, televiewer images, and nine-component VSPs in an effort to determine the degree of fracturing at our site.

Complementary theoretical studies are being carried out for the interpretation of the cross hole data. These include: (1) $P$ - and S-wave radiation patterns from piezoelectric sources (cylindrical bender), clamped axial vibrators, and torsional vibrators. These studies are important to interpret observed P- and S-wave amplitudes. (2) Synthetic seismogram calculations for cross hole geometry using both complete elastic wave solutions and high-frequency ray approximations. (3) Putting bounds on the resolution and accuracy of tomographic inversion of $\mathbf{P}$ - and S-wave travel times for a given ray coverage. Unlike the linearized or Backus-Gilbert inversions, the quantification of the resolution or errors does not exist for nonlinear tomographic inversions. (4) Since the Antrim Shale is anisotropic, we are developing forward modeling and inversion for cross hole data in anisotropic media. 
GRANTEE:

UNIVERSTTY OF MIAMI

School of Marine \& Atmospheric Science

Miami, Florida 33149

GRANT:

DE-FG05-92ER 14253

TITLE:

Testing the Correlation Between Sequence Stratigraphy, Seismic Reflectors, and Diagenetic Changes in Carbonates: Implications for the Distribution of Porosity and Permeability

PERSONS IN CHARGE:

G. Eberli (305-361-4678) and P. K. Swart (305-361-4103)

This project will examine (1) two continuous cores through the Neogene-Quaternary margin of Great Bahama Bank (overall $80 \%$ recovery), (2) the full suite of wire line logs, and (3) a vertical seismic profile in order to calibrate seismic and log data of platform carbonates and relate lithologic and diagenetic changes to changes in rock properties. The data set is being used to test the hypothesis that variability in diagenesis is also related to fluctuations in sea level as well as to study several fundamental processes and problems of carbonate platforms, such as (1) the lateral growth of carbonate platforms, (2) the record of sea level fluctuations in prograding carbonates, and (3) the dynamics of burial diagenesis and its relationship to sea level changes. Initial correlation of the cores and seismic reflection patterns suggests that the original composition/texture as well as diagenetic alteration are responsible for the reflectors. This suggests that if the strata pattern is the result of changing sea level, as assumed in sequence stratigraphy, then diagenesis, like facies, is related to sea level fluctuations and would consequently follow a predictable pattern. Such information is essential for the development of better understanding of the properties of oil-bearing carbonates and will lead to enhanced predictive capabilities for the distribution of porosity and permeability in carbonates. 
GRANTEE:

GRANT:

TITLE:

PERSON IN CHARGE:

\section{UNIVERSITY OF MINNESOTA}

Department of Geology and Geophysics

\section{DE-FG03-91ER14212}

Physical Modeling of Sedimentary Basins, Magma Mechanics, and Molecular Dynamics of Aqueous Solutions

D. A. Yuen (612-624-1868; FAX 612-624-6369)
This is a collaborative project with F. J. Spera (University of California at Santa Barbara) to conduct modeling of several problems relevant to the geoscience mission of the Department of Energy. The four areas include: (1) thermo-mechanical modeling of the evolution of sedimentary basins; (2) fundamental investigation of doubly diffusive (thermohaline) convection in low-porosity porous media; (3) molecular dynamics of $\mathrm{H}_{2} \mathrm{O}$ using a potential that includes oxygen polarization and allows for molecular dissociation at elevated temperatures and pressures; and (4) dynamics of magmatic systems including caldera resurgence, withdrawal of magma from crustal reservoirs, and rheometric studies of melts in the system $\mathrm{NaAlSiO}_{4}-\mathrm{SiO}_{2}$. Work currently in progress includes: (1) the dynamical influences of lithospheric phase transitions on the thermalmechanical evolution of sedimentary basins; (2) the coupling between mantle convection and, in particular, mantle plumes on the thermal regime and subsidence history of rift-related sedimentary basins; (3) numerical modeling of heat and solute transport driven by thermal and salinity gradients in low porosity fractured porous medium as commonly encountered in sedimentary basins undergoing diagenesis and lithification; (4) the thermodynamic and electrostatic properties of water and silicate melts determined by state-of-the-art molecular dynamics methods; (5) the dynamics of magma removal from large crustal reservoirs for magma treated as a rheologically complex fluid; and (6) the dynamics of the resurgence of volcanic calderas in continental regions. 
GRANTEE:

GRANT:

TITLE:

PERSON IN CHARGE:

\section{NATIONAL ACADEMY OF SCIENCES \\ NATIONAL RESEARCH COUNCIL \\ Washington, D.C. 20418}

\section{DE-FG05-89ER 14061}

Basic Energy Science Studies

T. Usselman (202-334-2744; FAX 202-334-1377;

E-mail USSELMAN@NAS.BITNET)

A. Board on Earth Sciences and Resources (T. Usselman [202-334-2744; FAX 202-334-1377; E-mail USSELMAN@NAS.BITNET])

The Board on Earth Sciences and Resources, under the Commission on Geosciences, Environment, and Resources of the National Research Council (NRC), coordinates the NRC's advice to the federal government on earth science issues, ranging from basic research to applications. Such advice includes: (1) identification and enunciation of the opportunities for advancing basic earth science research and understanding; (2) analyses of the scientific underpinnings and credibility of earth science information for resource and other earth science applications and decisions; and (3) the science, technology, economics; industrial activity, educational programs, and governmental policies and programs related to hydrocarbon resources, metallic and other energy resources, and nonmetallic mineral resources. The board's actions address the overall health of the earth science disciplines that are vital to the nation in maintaining and increasing its capability to make wise use of the Earth and its resources.

The board has under way a major report, a study on the Status and Research Opportunities in the Solid-Earth Sciences-A Critical Assessment. In addition, the board has begun an assessment of the issues in undergraduate earth science education in light of changing demands on the earth science profession. Several other projects recently have been initiated, with the operational responsibility assigned to either existing or ad hoc committees.

\section{B. U.S. Geodynamics Committee (B. Hanshaw 1202-334-2744; FAX 202-334-1377; E-mail GDUMOUCH@NAS.BITNET])}

The U.S. Geodynamics Committee (USGC) was established in 1969 to foster and encourage studies of the dynamic behavior of the Earth, with appropriate attention to both basic science and applications. The USGC also serves as the U.S. counterpart to the International Lithosphere Program. Major accomplishments have included contributing to the initiation of the Continental Scientific Drilling Program and designing and conducting the North American Continent-Ocean Transects Program. Other topics emphasized by the USGC have been deep seismic reflection profiling, geodynamic data, chemical geodynamics, crustal and mantle dynamics, marine geology and geophysics, fluids in the crust, seismic networks, and sedimentary systems.

Activities during the past year have concentrated on the National Geomagnetic Initiative. A workshop (in Washington, D.C., March 1992) on that topic was attended by about 100 people, and a report is under preparation. Other recent activities have included providing input to the International Decade for Natural Disaster Reduction (two draft working documents-one regarding the adequacy of the knowledge base for understanding various hazards and another regarding volcanic hazards); providing guidelines regarding key topics for the Intemational Lithosphere Program in the 1990s; developing a plan 
toward digitizing present and future transects-this plan, in effect, set the standards for the Global Geoscience Transects Project that is modeled on the successful North American Transect Program. A study to develop a science plan for U.S. volcanoes related to the Decade for Reduction of Natural Disasters is under way.

\section{Studies in Geophysics (T. M. Usselman 1202-334-3349; FAX 202-334-1377; E-mail USSELMAN@NAS.BITNET])}

The Geophysics Study Committee is conducting a series of studies dealing with timely scientific and societal aspects of geophysics and the corresponding demand on geophysical knowledge. The studies include: (1) problem-oriented studies such as demands on geophysical knowledge in connection with climatic variations, fresh water resources, mineral resources, geothermal and other energy resources, natural hazards, and environmental maintenance and (2) science-oriented studies such as fluids in the crust and paleoenvironments. Each study is conducted by a panel selected for the specific purpose. The preliminary findings of each study are presented to the scientific community for comment at a suitable symposium. The committee issued two reports in the past one or two years: (1) Sea-Level Change and (2) The Role of Fluids in Crustal Processes. Two additional studies are in final stages of preparation: (1) "Global Surficial Fluxes" and (2) "The Effects of Past Global Change on Life."

\section{Studies in Seismology (W. E. Benson 1202-334-2744; FAX 202-334-1377; E-mail BBENSON@NAS.BITNETI)}

The objectives of the Committee on Seismology are to influence major trends in seismology and identify related developments in other fields; conduct studies for government agencies; provide advice on U.S. government-supported seismic facilities; maintain cognizance of and provide advice on international seismological activities, including seismic verification of nuclear test ban treaties; and coordinate within the National Research Council activities in engineering seismology, natural disaster mitigation, rock mechanics, geodesy, geodynamics, geology, and seismic verification of nuclear test ban treaties. The committee meets twice a year to discuss current topics of major importance relevant to seismology; review with government agency personnel, in particular, the actions that have resulted from recommendations of the committee and its panels; and to take actions to ensure a healthy science that is in a position to provide maximum benefits to the nation and to society. Panels are established to conduct ad hoc studies on topics specified by the committee.

The report of the panel on real-time earthquake warning was published in 1991 as Real-Time Earthquake Monitoring.

Recently initiated activities include: (1) an assessment of the methodology used in estimating probabilistic sesimic hazards at reactor sites for the Nuclear Regulatory Commission and (2) a workshop and plan for a more mitigative approach to the collection, storage, and use of strong-motion data. In addition, plans are under way for an assessment of the role of seismology in the earth sciences, in societal problems, and as a scientific discipline in its own right.

\section{E. Studies in Geodesy (L. W. Wolf [202-334-2744; FAX 202-334-1377; E-mail LWOLF@NAS.BITNET])}

Activities of the Committee on Geodesy (COG) are aimed at the encouragement of the use of geodetic techniques to solve problems in the physical, oceanic, and atmospheric sciences; fostering the development of improved geodetic technology; assisting government agencies in the solution of their particular problems related to geodetic science and applications; and facilitating the exchange of information on present and future plans between agencies and the scientific community.

The committee is currently examining the following topics: 
- The role of airborne geodesy and geophysics in future research. With the advent of the Global Positioning System (GPS) and the possibility of having very precise navigation, new scientific opportunities have emerged. These include repeated high precision potential field and altimetry surveys and ultraprecise photogrammetry. The COG is currently seeking support for a study to examine the potential scientific contribution of airborne techniques. The study will involve a workshop to explore the limitations of techniques; potential scientific, commercial, and industrial applications; and future instrumentation. A workshop is scheduled for early 1993.

- The issue of declassification of geophysical and geodetic data. The committee is coordinating its efforts on declassification with those of the appropriate liaison agency members and with the NRC Ocean Studies Board, the Navy Panel, the Committee on Geophysical and Environmental Data, and the American Geophysical Union. To date, these combined efforts have contributed to the release of GEOSAT data in both the northern and southern hemispheres.

- The impact of selective availability (SA) and anti-spoofing (AS) on the use of the GPS. The DOD has a stated policy that SA and AS will be implemented. The COG is concerned with the scientific impact of this policy, as the geodetic and surveying communities migrate towards using GPS.

- The role of satellite laser-ranging instruments, such as the GLRS orbital instrument or an airborne version, and the continued use of very long baseline interferometry.

- The status of education in geodesy, which has been substantially impacted by the advent of GPS, and the role of agency extramural activities.

The committee, in conjunction with The International Association of Geodesy, has recently issued a report on the need for an international network of fiducial stations (International Global Network of Fiducial Studies: Scientific and Implementation Issues, 1991). 
GRANTEE:

GRANT:

TITLE:
UNIVERSITY OF NEW MEXICO

Department of Geology

Albuquerque, New Mexico 87131-1116

DE-FG03-92ER 14296.000

Impact Deposits at the Manson Impact Structure: Diagenesis and Postimpact Thermal History

PERSON IN CHARGE:

L. J. Crossey (505-277-5349)

Core materials from the Manson impact site (Manson, Iowa) are being examined in order to evaluate postimpact alteration processes. The research complements ongoing studies of sedimentation and diagenesis of the Creed Formation, Creede, and $\mathrm{CO}$ and integrates with a proposed geochemical investigation of chemical transport in glass-bearing breccias at the Manson impact site. Diagenetic interpretation of postimpact events will be based on petrologic, mineralogic, and geochemical investigation of core materials, including target strata, disturbed and disrupted strata, ejecta, breccias, micorbreccias, and impact melt. The study of multiple cores will permit development of a regional picture of postimpact thermal history. Comparisons with postimpact hydrothermal alteration of other impact sites (e.g., Ries Crater, West Germany) and the diagenesis of moat sediments of the Creed caldera are planned. Results of the study will provide: (1) a detailed description of authigenic and alteration mineralogy from diverse lithologies encountered at the impact site, (2) a model for regional diagenesis from the Cretaceous to the present, (3) mineralogical constraints on the postimpact cooling history for the site, and (4) a better understanding of impact processes associated with large cratering events. 
GRANTEE:

GRANT:

TITLE:

PERSONS IN CHARGE:
UNIVERSITY OF NEW MEXICO

Albuquerque, New Mexico 87131-1126
DE-FG02-90ER 14149

Chemical Transport Through Continental Crust

J. J. Papike (505-277-1644; FAX 505-277-3577;

E-mail JPAPIKE@UNMB) and coinvestigator C. K. Shearer
Caldera-related deposits have been an important facet in our understanding of magma reservoirs, crustal melting events, and hydrothermal systems. The Long Valley Mono-Craters volcanic system is probably one of the best studied of these deposits. It is the most active major silicic system within the continental United States. The last major eruption of the system occurred only $\mathbf{5 5 0}$ years ago, and minor eruptions may have occurred as recently as 100 years ago. Present tectonic activity suggests a rejuvenation of the magmatic system. The main objective of this research is to study the state and evolution of the magmatic-hydrothermal systems in Long Valley. This has application to a fuller understanding of magma evolution and hydrothermal systems worldwide. We have focused upon four aspects of this system:

1. compositional and mineralogical zoning of the intra-caldera Bishop Tuff as a recorder of both eruptive dynamics and magma chamber evolution (SIMS trace element studies of phenocrysts and melt inclusions);

2. intrusive activity under the resurgent dome (analysis of intrusions sampled by drilling);

3. nature and evolution of hydrothermal fluids and their impact on mineral-fluid interaction (sulfur and lead isotope systematics and trace element analysis of sulfides by SIMS; transmission electron microscopy analysis of phenocryst alteration); and

4. development of appropriate techniques that will extract the maximum amount of relevant data from small drill core samples.

Our research has emphasized portions of the system sampled by Phases I and II of the Magma Exploratory Hole LVF51-20, located in the vicinity of the caldera's central magma chamber. The history of this chamber is recorded by surface eruptive activity and by a subsurface array of intrusions and frozen chamber remnants. The first two phases of drilling encountered a swarm of subsurface igneous units (or perhaps intersected segments of the same irregular body), intrusive into welded and devitrified Bishop Tuff. The intrusions are aphyric, microcrystalline rhyolite and exhibit an obsidian border zone at contacts. The chemical signatures of these intrusions closely resemble eruptions of the voluminous Early Rhyolite sequence. Altered samples show depletions in $\mathrm{Na}, \mathrm{Rb}, \mathrm{Sr}$, and $\mathrm{Ba}$ and enrichments in $S, F e, Z n$, and As, presumably reflecting hydrothermal leaching and deposition of pyrite. Preliminary SIMS isotopic analyses of individual pyrite grains indicate that $\delta^{34} S$ may be used to fingerprint episodes of fluid interaction and evolution. 
GRANTEE:

GRANT:

TITLE:

PERSON IN CHARGE:
UNIVERSITY OF NEVA DA, RENO

Mackay School of Mines

Reno, Nevada 89557

DE-FG08-92ER1435.000

Drilling of Washoe Lake, Nevada, for Paleoclimate Studies

R. Karlin (702-784-6050; FAX 702-784-1766)
The research objective of this project is to drill a lacustrine sediment sequence in Washoe Lake in western Nevada for paleoclimatic and paleohydrologic studies. In June 1991, the lake dried completely for the first time since 1937-38 and only the second time in recorded history. This event offers a unique opportunity to obtain a long continuous paleoclimatic and paleohydrologic record from a very sensitive continental region. The lake sediments will be analyzed to evaluate changes in temperature, precipitation, and wind patterns during glacial and interglacial times. Such baseline data provide limits on possible scenarios for climate change as well as tests on the reliability of global circulation models.

Drilling operations have been reasonably successful with two sites drilled to $25 \mathrm{~m}$ with $85 \%$ recovery and excellent undisturbed sections. Two additional sites yielded about $13 \mathrm{~m}$ of section until halted by fluidized sands. The holes have been logged to determine the in situ stratigraphy, and the cores are presently being described and logged. Gravity, magnetics, and electrical surveys of the lake have been conducted to characterize the subsurface structure and to identify additional potential drilling sites.

Initial results suggest that recovered cores have excellent potential for paleoclimatic studies. The sections contain several clay/silt layers with some buried roots horizons indicating that the lake has dried several times in the past. Radiocarbon dating of these zones should allow a determination of the frequency and duration of episodes of drought. Sedimentological, paleontological, and isotopic studies on the recovered material should allow a determination of the lake level, chemistry, and faunal diversity from which a history of climatic and hydrologic change can be constructed. 
GRANTEE:

GRANT:

TITLE:

PERSON IN CHARGE:
CITY UNIVERSITY OF NEW YORK QUEENS COLLEGE

Department of Geology

Flushing, New York 11367-0904

DE-FG02-88ER13961

Evaporites as a Source for Oil

B. C. Schreiber (718-997-3300; FAX 718-997-3349)
Organic matter, present in some sediments, acts as the source for hydrocarbons and has been studied at great length, but organic-rich sediments from hypersaline environments are not yet understood. Many types of organic matter from such restricted environments have been identified; however, their maturation pathways and products are not fully known. By collecting biologically identified organic matter produced within modern evaporative environments from a number of different marine and nonmarine settings and carrying out detailed geochemical examination of samples, we are gradually beginning to understand these materials. The organic-rich samples collected were from evaporative marine, lacustrine, and sabkha deposits and have been subjected to two types of artificial maturation, hydrous and confined pyrolysis, over a fairly wide range of temperatures $\left(200\right.$ to $\left.400^{\circ} \mathrm{C}\right)$. The biomarker products of these treatments are being analyzed and followed through their stages of maturation in great detail. Analyses of saturate and aromatic hydrocarbons as well as sulfur compounds in the original and the matured samples provide a comprehensive view of the biomarker assemblages associated with these different depositional environments at different stages of maturity. Infrared spectroscopy and Rock Eval pyrolysis carried out on the isolated kerogen from both the original and pyrolyzed samples have permitted us to clearly characterize the functional groupings of the organic matter on the one hand and its free hydrocarbons, potential hydrocarbons, and oxgenated compounds on the other hand. We have thus been able to demonstrate the potential of the organic matter associated with the different evaporitic environments to act as a good source for oil generation.

Comparable ancient sediments that are organic-rich, and oils from evaporative systems, have also been sampled, and analyses are being run on the biomarkers present in these samples and in the hydrocarbons that they have produced. By using what we and others are learning of environmental controls on organic production in the modern settings and following the evolution of these compounds during maturation, we are now becoming able to examine ancient rocks and oils to understand the details of the components that went into their formation. 
GRANTEE:

GRANT:

TITLE:

PERSON IN CHARGE:
STATE UNIVERSITY OF NEW YORK (SUNY)

AT STONY BR OOK

Research Foundation of SUNY

Albany, New York 12201

DE-FG02-85ER 13416

Geochemistry and Origin of Regional Dolomites

G. N. Hanson (516-632-8210; FAX 516-632-8240;

E-mail GHANSON@CCMAIL.SUNYSB.EDU)
The goals of this project are to develop geochemical approaches for testing models describing the geochemistry and dynamics of fluid systems responsible for the development of regional dolomites, which are major reservoirs for petroleum. The rocks we initially selected for a very detailed petrographic and geochemical study are the Mississippian (Osagean) Burlington-Keokuk formations of Iowa, Illinois, and Missouri. While the Burlington-Keokuk formations are not a major reservoir for oil, mid-Mississippian shelf dolomites closely akin to the Burlington dolomites in terms of petrography, apparent nature of porosity, and paleogeographic setting, are major reservoirs of oil and gas in many regions of North America. Moreover, similar dolomites with "sucrosic" textures, dominated by intercrystalline and moldic porosity, also are common in shelf-carbonate sequences of other ages and regions.

We are applying a large range of trace elements (REE, Pb, Zn, Ba, B, Li Sr, Mg, Fe, and $\mathrm{Mn}$ ) and isotopic systems ( $\mathrm{Pb}, \mathrm{B}, \mathrm{Sr}, \mathrm{Nd}, \mathrm{S}, \mathrm{C}$, and $\mathrm{O})$ to help discriminate among potential fluids responsible for the diagenesis of sedimentary carbonates. The analytical approaches for the trace element studies include isotope dilution, plasma spectrometry, electron microprobe, and synchrotron $X$-ray microprobe. Our modeling has shown that bivariate plots using a range of trace elements and isotopes can be used to evaluate the type of fluids involved and the water-to-rock ratios necessary for a diagenetic carbonate to reach its present composition.

Our approach has been to apply new geochemical techniques to the Burlington-Keokuk formations. After evaluating their usefulness, the most appropriate techniques are applied to sequences that have quite different tectonic or sedimentary settings. Besides studying the dolomites in the Burlington-Keokuk formations, we are presently also studying dolomites in (1) the Canning Basin, western Australia, formed in Devonian reef complexes and platform carbonates fringing a Precambrian massif landward and a large synsedimentary graben (Fritzroy Trough) basinward and (2) in Neogene carbonates formed in reefal and peri-reefal facies in island settings in the Mediterranean and the Netherland Antilles. 
GRANTEE:

GRANT:

TITLE:

PERSONS IN CHARGE:
STATE UNIVERSITY OF NEW YORK (SUNY)

AT STONY BROOK

Research Foundation of SUNY

Albany, New York 12201-0009

\section{DE-FG02-92ER 14261}

Three-Dimensional Imaging of Drill Core Samples Using

Synchrotron-Computed Microtomography

W. B. Lindquist (516-632-8361; FAX 516-632-8491;

E-mail lindquis@ams.sunysb.edu) and K.W.Jones

Fundamental theories of rock structure are limited by the absence of high-resolution, pore level, three dimensional images that could be used for statistical analysis. The ability to produce such images in a nondestructive manner will then allow for repeated measurements of activity such as fluid motion that could be correlated to the medium properties.

The initial goal of this proposal is to produce cross sectional images of rock drill core samples with $1 \mu \mathrm{m}$ resolution from a set of Berea sandstone drill cores. Using synchrotron $\mathrm{X}$-ray radiation from the Brookhaven National Laboratory National Synchrotron Light Source, initial computed microtomographic scans of $10 \mu \mathrm{m}$ resolution over the complete core cross section $(5-6 \mathrm{~m} \mathrm{~m})$ will allow for calibration for a second scan at $1 \mu \mathrm{m}$ resolution covering the central $1 \mathrm{~mm}$ region of the cross section. Images of this central 1-mm-diam region will be produced for a sequence of slices separated by a width of $2 \mu \mathrm{m}$.

A topological analysis of the pore structures will be performed on the three-dimensional images. Issues addressed will be pore shape; amount, type, and size of disconnected pore volume; connectivity of pores and throats; and two-point correlation structure. This analysis will be performed statistically on the digitized images, aided by visual investigation using three-dimensional imaging software. 
GRANTEE:

GRANT:

TITLE:
THE OHIO STATE UNIVERSITY

Department of Welding Engineering

Columbus, Ohio 43210
PERSON IN CHARGE:
DE-FG02-89ER 13749.A001

Investigation of Ultrasonic Wave Interactions With

Fluid-Saturated Porous Rocks

L. Adler and P. B. Nagy
In this research project we conducted an investigation of ultrasonic wave propagation in fluid-filled porous materials. First, we studied the feasibility of using different surface modes to characterize both synthetic and natural rocks. We introduced a novel experimental technique based on the direct generation of surface waves by edge excitation. We used two low-frequency $(100-500 \mathrm{kHz})$ shear transducers in pitch-catch mode to launch and receive the ultrasonic surface wave. The contact transducers were coupled to the opposite edges of the porous specimens with normal polarization relative to the surface. The same technique was successfully used to generate Rayleigh-type surface modes on the free surface of both dry and water-saturated specimens, as well as Stoneley-type interface modes on the fluid-loaded surfaces of immersed samples. Our main achievement in this area is the realization that, because of surface tension, practically closed-pore boundary conditions can prevail on the free surface of a water-saturated rock for completely open pores. As a result, the velocity of the true surface mode might be much lower than the Rayleigh velocity of the dry skeleton. While the shear velocity drops a meager $2-5 \%$ upon saturating the specimen with water, the corresponding drop in the true surface wave velocity is a disproportional $20-50 \%$ for high-permeability rocks such as sandstones. This behavior is similar to the transformation of a Rayleigh-type surface mode to a much slower Stoneley-type true interface mode on the surface of a submerged solid while the original mode becomes leaky and quickly disappears. To the best of our knowledge, this is the first report on this kind of behavior of the true surface wave on the free surface of water-saturated rocks.

We further developed our experimental technique, which is based on the transmission of airbome ultrasonic waves through air-filled porous plates. This method can be readily used to study the fequency-dependent propagation properties of slow compressional waves in different porous materials, including natural rocks. By simple technical improvements, we extended the measuring range to $1-500 \mathrm{kHz}$ so that we could continously cover both low-frequency (diffuse) and high-frequency (propagating) regimes of the slow wave propagation. In the diffuse region, which is usually below $100 \mathrm{kHz}$, both the velocity and the attenuation coefficient are primarily determined by the static permeability of the material. In the propagating region, the velocity depends on the tortuosity only, while the attenuation coefficient depends also on the pore size and shape. 
GRANTEE:

TITLE:

PERSON IN CHARGE:
THE OHIO STATE UNIVERSITY

Department of Geological Sciences

Columbus, Ohio 43210
Construction of a Calibrated Sea-Level Curve: Mid-Cretaceous Through Mid-Tertiary

D. Sahagian (614-292-3984; FAX 614-292-9640;

E-mail dork@geo2s.mps.ohio-state.edu)
This research is based on the identification and utilization of a stable frame of reference for measurement of sea level. The quantification of sea level variations has historically been hampered by inaccuracy in measurement methods, which are based on depositional and other consequences of sea-level changes as observed in various unstable tectonic environments such as subsiding passive margins. In this study, the tectonically stable Russian platform is being used as a reference frame in the construction of a eustatic sea level curve. In constructing the curve, stratigraphic data from numerous wells distributed across the Russian platform have been backstripped, and then tied to present sea level using the present elevation of various stratigraphic horizons. Most strata observed represent very shallow water deposition $(<25 \mathrm{~m})$, so water depth variations can be determined more reliably than would have been possible in a deep water environment. The stratigraphy of the Russian platform is riddled with unconformities. This is a result of the ability of even minor eustatic fluctuations to cause sea level to drop off of the platform during regressive events. These unconformities are important in accurately fixing sea level ( 0 water depth) at various times throughout the Late Cretaceous-Early Tertiary. The eustatic curve resulting from a related study indicates that sea level rose by $120 \mathrm{~m}$ from the Mid-Jurassic (60 $\mathrm{m}$ above present) to the Mid-Cretaceous (180 m above present). The results of this study indicate that sea level remained high throughout the Late Cretaceous but that significant high-amplitude (up to $80 \mathrm{~m}$ ) and short period (a few million years) eustatic variations took place between the Cenomanian and Maestrichtian. In the Late Maestrichtian, sea level began to drop. This sea level fall continued through the Paleocene and into the Eocene, after which sea level dropped off of the stable Russian platform such that there are no available stratigraphic data beyond the Mid-Tertiary. The eustatic variations throughout the study time interval had magnitudes of tens of meters over time scales of 1 to $5 \mathrm{~m}$.y. The causative mechanism(s) for these variations is not clear. The eustatic curve resulting from this study can be applied to subsiding basins and passive margins in order to quantify subsidence history.

The eustatic curve provided by this study can be applied to passive continental margins for the purpose of quantifying margin thermal subsidence history. This can be accomplished by backstripping passive margin stratigraphy and using sea level as an input parameter. Since water depth and sediment thickness are estimable to within reasonable limits on passive margins, the thermal subsidence can be calculated with greater accuracy than previously possible. This application may shed light on passive margin processes at a level of detail that has previously been unattainable due to the inability to separate eustatic from tectonic influences on stratigraphic sequences. While this application is left for future investigation, preliminary analysis from the adjacent Caspian depression indicates that the northem part of the basin experienced a subsidence rate of $7.8 \mathrm{~m} / \mathrm{m}$.y. during the Mid-Cretaceous. 
GRANTEE:

GRANT:

TITLE:

PERSON IN CHARGE:
UNIVERSITY OF OKLAH OMA

School of Geology and Geophysics

Norman, Oklahoma 73019
DE-FG05-91ER14209

A Study of Hydrocarbon Migration Events: Development and Application of New Methods for Constraining the Time of Migration and an Assessment of Rock-Fluid Interactions

R. D. Elmore (405-325-3253; FAX 405-325-3140;

E-mail AB1635@UOKMVSA)

The objectives of the research are to test and refine a paleomagnetic method for dating hydrocarbon migration and to assess the chemical alteration of crude oils resulting from rock-fluid interactions. Geochemical and paleomagnetic samples have been collected from several units, and laboratory simulation experiments are under way to better understand the mechanisms of magnetite precipitation.

Red samples of Schoolhouse Member (Maroon Fm., Pennsylvanian, northwest Colorado) contain an early magnetization that resides in hematite, whereas hydrocarbon-impregnated samples are remagnetized with weaker magnetizations that reside in magnetite. The Belden Formation (Pennsylvanian), the presumed source for the hydrocarbons in the Schoolhouse, contains a Cretaceous chemical remagnetization in magnetite. Observations with the scanning transmission electron microscope indicate the magnetite has replaced pyrite. The magnetization is related to either organic material or to alteration by radiogenic fluids.

Samples of red sandstones in the Old Red Sandstone in Scotland contain a magnetization in hematite, whereas hydrocarbon-impregnated samples contain a magnetization in magnetite. Lacustrine siltstones in the unit contain a stable late Paleozoic magnetization that resides in magnetite.

Hydrocarbon-impregnated Jurassic limestones in the Hils region in Germany contain a postfolding Cretaceous remagnetization in magnetite. Samples without hydrocarbons have much weaker unstable magnetizations.

The results to date are consistent with the hydrocarbon magnetite connection, although other mechanisms for magnetite authigenesis (e.g., basinal fluids) may apply for some units. 
GRANTEE:

GRANT:

TITLE:
UNIVERSITY OF OKLAHOMA

School of Geology and Geophysics

Norman, Oklahoma 73019

DE-FG05-85ER 13412

A Study of the Source Materials, Depositional Environments, Mechanisms of Generation, and Migration of Oils in the Anadarko and Cherokee Basins

PERSON IN CHARGE:

R. P. Philp (405-325-3253; FAX 405-325-3140)

The major objectives of this research have continued to be directed at studying the nature of source materials and depositional environments for major oil accumulation in the Anadarko Basin, Oklahoma. Despite the fact that it has been extensively explored and large reserves of oil discovered during the last century, the Anadarko Basin provides a natural laboratory in which novel geochemical techniques can be discovered and evaluated for use in the exploration of frontier areas in other parts of the world.

For the past 2 years, less emphasis has been placed on analysis of oils compared to the effort directed at the characterization of potential source formations other than the well-characterized Woodford Shale. Detailed geochemical analysis of carefully screened and selected samples of Springer, Morrow, Viola, Sylvan, and Chester Formations are under way, and this work should be completed in the near future. Of particular note here is data obtained that clearly show the relative abundance of the tricyclic terpanes, a widely used class of compounds, is source/ environment related and less dependent on maturity or extent of biodegradation of the crude oils.
A second important area of this project has developed from the discovery of high molecular weight hydrocarbons ( $>\mathrm{C40}$ ) both in oils from the Anadarko Basin and elsewhere around the world. The discovery of these compounds became possible with the availability of high-temperature gas chromatography columns over the past 2 or 3 years. The discovery of these compounds in the C60-C100 range has lead to the observation that the composition of oils collected at the well head are often different from the composition in the reservoir. Such an observation has extremely important implications for applications to exploration, reservoir characterization, and enhanced oil recovery studies. This work is continuing the examination of a wider more diverse range of samples to try and determine the origin of these compounds.

These are the two major areas of research pursued over the past year. In addition, some effort has been directed at development of novel analytical techniques for biomarker determination from both the soluble and insoluble fractions (kerogens and asphaltenes) of geological samples. 
GRANTEE:

GRANT:

TITLE:

PERSON IN CHARGE:
OREG ON STATE UNIVERSITY

College of Oceanography

Corvallis, Oregon 97331-5503 and the

UNIVERSITY OF CALIFORNIA AT BERKELEY

Engineering Geoscience

DE-06-92ER14277.000

Multi-station Magnetotellurics

G. D. Egbert (503-754-2947; FAX 503-737-2064;

E-mail egbert@oce.orst.edu)
This is a collaborative project with $H$. F. Morrison (University of California, Berkeley) to develop and test improved strategies for collecting and processing remote reference (RR), or more generally multiple station, magnetotelluric (MT) data in areas that are heavily contaminated by sources of cultural noise. The project, which has just been initiated, includes experimental and theoretical components.

Experimental work involves collecting three-station MT array data along a line from an area of significant urban cultural noise to a very isolated quiet area. The general strategy is to occupy a small number of sites for extended periods, with clock synchronized remote sites at varying distances. These data will be used to conduct basic studies of the spatial and temporal structure of signal and noise and to evaluate various strategies for collecting $R R$ MT data.

A second focus of the project is to continue work on developing and testing new MT data processing methods. This research has two general themes. First, RR MT data are highly multivariate (multiple channel time series recorded at multiple stations, often in the presence of cultural noise with complex intercomponent correlation structure), while the statistical methods that have been applied to MT processing are basically univariate. There are a number of procedures from classical multivariate statistics that can be usefully adapted to develop better MT processing methods and to improve understanding of signal and noise characteristics. A second theme is: robustness, again. There is no question that the basic idea of adaptively computed data weights has had a major impact on the quality of MT impedance estimates. However, the best way to use this basic idea in a problem as complex as RR MT processing has hardly been explored. For the most part, methods that have been tried so far were developed for comparatively simple statistical problems (e.g., robust regression, where a single dependent real variable is predicted by several real independent variables). A major goal of this project is to develop and apply more realistic multivariate robust MT processing methods.

A final goal of this project is to assemble a data base that can be used to thoroughly test newly developed, as well as previously tried, MT data processing methods. Test sets will be drawn from the new array data, plus existing data of varying quality, and varying degrees of cultural noise contamination. This test data base will provide a useful standard for validating and comparing the utility of processing procedures developed in this project and in the future. 
GRANTEE:

GRANT:

TITLE:

PERSONS IN CHARGE:
PENNS YLVANIA STATE UNIVERSITY

Department of Geosciences

University Park, Pennsylvania 16802
DE-FG02-92ER14251

Cretaceous Shallow Drilling in the U.S. Western Interior:

Core Research

E-mail OMNET m.arthur or arthur@geosc.psu.edu) and

W. E. Dean (U.S. Geological Survey; 303-236-5760; OMNET w.dean)

This project constitutes a multidisciplinary study of middle to upper Cretaceous marine sedimentary rocks in the Utah-Colorado-Kansas corridor of the Cretaceous seaway that extended from the Gulf Coast to the Arctic during maximum transgressions. The focus is on the Greenhorn and Niobrara cyclothems combining biostratigraphic/ paleoecologic, inorganic, organic and stable isotopic, mineralogical, and high-resolution geophysical logging studies. Ties with seismic reflection profiles, well logs from industry wells, and high-resolution stratigraphy on outcrop will enhance this effort. The major effort has been recovery of continuous cores from three sites in an east-west transect. This strategy provides continuous sampling of strata ranging from pelagic sequences that contain organic-carbon-rich marine source rocks to nearshore coal-bearing units. Continuous core is available from the easternmost site, drilled by Amoco in eastem Kansas (Amoco Rebecca Bounds \#1, Greely County, Kansas), where the Cretaceous strata are largely pelagic and have not experienced deep burial. The westernmost holes were drilled by the U.S. Geological Survey in June 1991, on the Kaiparowitz Plateau in Utah. The main hole in the transect was drilled to the east, in June 1992, near Canion City, Colorado, to obtain cores of offshore, deeper-water (and more deeply buried) pelagic-hemipelagic strata.

Major objectives are: (1) timing and rates of sea-level change and their influence on lithology, sedimentation rate, and sediment geochemistry; (2) rates of subsidence, apparent sea-level change, and facies migration in light of global tectonic-eustatic events; (3) onshore-offshore facies patterns and amount, accumulation rate, type, and degree of preservation of organic matter; (4) variations in faunal and floral components and sedimentary structures to evaluate the extent and intensity of oxygen deficiency during organic-carbon depositional episodes; (5) effects of organic-matter enrichment on geochemical characteristics of the sediments, including cycling of redox sensitive elements; (6) effects of thermal metamorphism and other geochemical characteristics with increasing burial depth; (7) detailed biostratigraphies provided by high-diversity faunal and floral assemblages, together with abundant volcanic ash layers, providing a unique high-resolution time sequence to calibrate possible Milankovitch cyclicity; (8) "absolute" age data allowing calculation of important variables such as rates and timing of sediment supply, organic productivity, and changes in water-mass characteristics that contribute to the sedimentary expression of Milankovitch orbital cycles; (9) elucidate trends in geochemical properties and organic-carbon accumulation rates and in comparison to global trends; $(10)$ providing data for validation of climate models (e.g., GCMS); (11) providing explanations for the significance of bioevents and substantial changes in global biotic diversity during the Cretaceous and document rates and timing of biotic extinction and evolution in detail; and (12) investigating the possibility that such shallow Cretaceous seas were the sources of oxygen-depleted oceanic deep-water masses. 
GRANTEE:

GRANT:

TITLE:

PERSON IN CHARGE:
PRINCETON UNIVERSITY

Department of Geological and Geophysical Sciences

Princeton, New Jersey 08544
DE-FG02-85ER 13437

Thermodynamics of Minerals Stable Near the Earth's Surface

A. Navrotsky (609-258-4674; FAX 609-258-1274;

E-mail alex@wavelet.princeton.edu)
The purpose of this work is to expand our data base and understanding of the thermochemistry of minerals and related materials through a program of high-temperature reaction calorimetric studies. The technique of oxide melt solution calorimetry (in molten $2 \mathrm{PbO} \cdot \mathrm{B}_{2} \mathrm{O}_{3}$ ) has been extended to volatile-bearing phases. Calorimetric conditions under which $\mathrm{H}_{2} \mathrm{O}$ and $\mathrm{CO}_{2}$ reach a well-defined final state upon reaction with molten lead borate have been perfected. These involve calorimetry under a flowing gas atmosphere, which purges all $\mathrm{H}_{2} \mathrm{O}$ and $\mathrm{CO}_{2}$ in the gas phase, leaving essentially none to interact with the solvent (R. Rapp and others).

The calorimetry of carbonates in lead borate has been tested by measuring the enthalpies of three carbonate silicate reactions: $\mathrm{MgCO}_{3}+\mathrm{SiO}_{2}=$ $\mathrm{MgSiO}_{3}+\mathrm{CO}_{2}, \mathrm{CaCO}_{3}+\mathrm{SiO}_{2}=\mathrm{CaSiO}_{3}+\mathrm{CO}_{2}$, and $\mathrm{CaMg}\left(\mathrm{CO}_{3}\right)_{2}+2 \mathrm{SiO}_{2}=\mathrm{CaMgSi}_{2} \mathrm{O}_{6}+2 \mathrm{CO}_{2}$ (L. Chai). Results confirm earlier phase equilibrium and calorimetric studies and also support the enthalpy of the reaction $\mathrm{CaCO}_{3}+\mathrm{MgCO}_{3}=$ $\mathrm{CaMg}\left(\mathrm{CO}_{3}\right)_{2}$ measured by Capobianco using aqueous acid. We are now preparing, characterizing, and starting calorimetry on iron-containing carbonates. The goal is an accurate thermodynamic description of phases in the $\mathrm{CaCO}_{3}-\mathrm{MgCO}_{3}-$ $\mathrm{FeCO}_{3}$ system (L. Chai, Ph.D. thesis).
Work on zeolites (I. Petrovic, Ph.D. thesis) has progressed to the determination of enthalpies of five pure $\mathrm{SiO}_{2}$ zeolites. All are relatively similar in energy and are only $10-15 \mathrm{~kJ} / \mathrm{mol}$ less stable than quartz. Small differences in their enthalpies do not correlate with bulk or framework density but may reflect the destabilizing effect of T-O-T angles of $<135^{\circ}$. The next step is to characterize the energetics of the substitution $\mathrm{Si}=\mathrm{Al}+\mathrm{Na}$ in a series of synthetic faujasites and compare it with the energetics of the same substitution in denser crystalline and glassy aluminosilicates.

Work on amphiboles is progressing (E. Smelik) with synthesis and calorimetry of a suite of phases representing various charge balanced substitutions. Work on tremolite-richterite thermochemistry (A. Pawley) and on phlogopite-eastonite thermochemistry (S. Circone) is submitted for publication.

These studies taken together begin to unravel the simultaneous energetic effects of coupled ionic substitutions, of framework topology, and of water and carbon dioxide content in complex chain, sheet, and framework silicates and in carbonates. The thermodynamic properties of such phases are important in diagenesis, metamorphism, rock-water and rock- $\mathrm{CO}_{2}$ interactions, and nuclear waste disposal. 
GRANTEE:

GRANT:

TITLE:

PERSON IN CHARGE:
PRINCETON UNIVERSITY

Department of Geological and Geophysical Sciences

Princeton, New Jersey 08544

The Effects of Natural and Induced Defects on Noble-Gas

Transport in Silicates: a Study of Argon Using Laser, X-Ray, and Electron Microprobes.

T. C. Onstott (609-258-5706; FAX 609-258-1274;

E-mail tullis@warbler.princeton.edu)

${ }^{40} \mathrm{Ar} /{ }^{39} \mathrm{Ar}$ laser microprobe analyses indicate that for hydrous silicates, such as biotite and homblende, that possess a small concentration of defects, the radius of diffusion is on the order of the grain size. Similar analyses recently performed on samples of mylonitic hornblende containing a high concentration of defects revealed that the apparent radius of diffusion is much smaller. Numerical models of short-circuit diffusion (i.e., pipe diffusion along extended defects) using parameters determined by isothermal heating experiments at low temperatures for homblende, biotite, and muscovite suggest that, for defect densities typical of highly deformed rocks, the blocking temperature increases with grain size until approximately 30 to $60 \mu$. Above this radius, the blocking temperature quickly approaches an asymptotic value. Such a mechanism may play an important role in these minerals but also in complexly exsolved and altered potassium feldspars.

To test this hypothesis, an etching technique was developed to image defects, submicron to tens of microns in size, on the surface of laser microprobe thick sections. Transmission electron microscopy (TEM) of the same samples was used to calibrate etching times and to correlate etching morphologies with different defect structure types. This approach has two advantages over methods currently employed: (1) we can confidently identify defect structure type and density of the laser target prior to ablation; and (2) it eliminates the enormous tedium and expense of TEM mosaics of sample splits.

Extended defects are not only paths of rapid diffusion, but micropores ( $0.5 \mu$ in size) present at intersections of extended defects act as traps for argon. When this argon is radiogenically enriched it perturbs the potassium-argon system producing anomalously old ages. Laser microprobe analyses reveal that chlorine, dislocations as determined from ${ }^{38} \mathrm{Ar}$, is also present in the micropores and can be used to correct for the excess argon. This correction is achieved by using least squares fitting of four-dimensional hyperplanes to the data. 
GRANTEE:

GRANT:

TITLE:

PERSON IN CHARGE:
PURDUE UNIVERSTTY

Department of Earth and Atmospheric Sciences

West Lafayette, Indiana 47907

DE-FG02-90ER14113

Hyperfiltration-Induced Fractionation of Lithium Isotopes in Geologic Systems

S. J. Fritz (317-494-3276; FAX 317-496-1210)
Hyperfiltration through clay membranes induces isotopic fractionation in which a solute's heavy isotope is depleted on the clay membrane's high-pressure side. It should thus be possible to delineate regions of high- and low-hydrostatic heads in the subsurface by plotting distributions of isotopic ratios obtained through analyses of samples collected from opposing sides of aquitards.

High degrees of hyperfiltration-induced fractionation should result when ions of a low atomic-weight element are hydraulically forced through a highly ideal clay membrane. This study gauges the magnitude of ${ }^{6} \mathrm{Li} /{ }^{7} \mathrm{Li}$ fractionation during hyperfiltration through clay membranes. The results will yield baseline data against which hyperfiltration-induced isotopic fractionation of higher atomic-weight elements should be compared in future hydrogeochemical investigations.

A long-term hyperfiltration run was performed in which a $9.68 \mathrm{mN} \mathrm{LiCl}$ solution was hyperfiltrated through a membrane having a thickness of $0.005 \mathrm{~cm}$ and a hydraulic conductivity of $2 \times 10^{-11} \mathrm{~cm} / \mathrm{sec}$. The stock solution and effluents were analyzed for ${ }^{6} \mathrm{Li} /{ }^{7} \mathrm{Li}$ ratios by the Analytical Chemistry Division of Argonne National Laboratory. The stock solution had a $\delta^{7} \mathbf{L i}$ value of -3.01 per mil relative to SVEC. Effluents were collected up until the time that steady state was achieved. The results, listed here as $\delta^{\mathbf{7}} \mathbf{L i}$ relative to the input stock solution, showed an oscillation of the ${ }^{6} \mathrm{Li} /{ }^{7} \mathrm{Li}$ ratios of the effluent solutions. Twelve effluents were collected. Their $\delta^{7} \mathrm{Li}$ per mil values (in chronological order from first to last effluent collection) were: $+0.49,-0.34,+1.41$, $+1.08,-1.67,+2.08,+1.41,-4.49,-0.09$, +0.91, +3.49 , and -3.24 . Although hydraulic and chemical steady state were nearly achieved at the termination of the run, the oscillatory behavior of the ${ }^{6} \mathrm{Li} /{ }^{7} \mathrm{Li}$ ratios shows that isotopic equilibrium was far from being realized. Postulated is that there is a continual adjustment of the isotopic ratio within the concentration polarization layer developed on the high-pressure side of the membrane. 
GRANTEE:

GRANT:

TITLE:

PERSON IN CHARGE:
RICE UNIVERSITY

Geology and Geophysics

Houston, Texas 77251-1892

DE-FG03-92ER 14295.000

Transition Metal Catalysis in the Generation of Petroleum and Natural Gas

F. Mango (713-527-4880; FAX 713-285-5214)
The light hydrocarbons in petroleum $\left(\mathrm{C}_{5}-\mathrm{C}_{9}\right)$ and natural gas $\left(C_{1}-C_{4}\right)$ are conventionally viewed as thermolytic products formed in the Earth from the progressive thermal breakdown of kerogen and oil. Two recent observations contradict this view, however. First, a comprehensive analysis of oil and gas deposits could find no evidence of oil decomposing to gas. Second, certain ratios of light hydrocarbons, the presumed products of thermal decomposition, remain virtually invariant over the course of petroleum generation. A new hypothesis is introduced for the generation of petroleum and natural gas. The transition metals, activated under the reducing conditions of diagenesis, are proposed as catalysts in the generation of light hydrocarbons. The objective of this proposal is to test that hypothesis. Transition metals (Ni, V, Ti, Co, Fe), in kerogenous sedimentary rocks, petroporphyrins, and as pure compounds, will be reduced under diagenetic conditions and analyzed for catalytic activity. If the hypothesis is correct, kerogenous transition metals should become catalytically active under the reducing conditions of diagenesis and catalyze the conversion of paraffins into the light hydrocarbons seen in petroleum. Moreover, the $C_{1}-C_{4}$ hydrocarbons generated catalytically should be similar in molecular and isotopic compositions to natural gas. 
GRANTEE:

GRANT:

TITLE:

PERSON IN CHARGE:
SAN DIEGO STATE UNIVERSITY

Department of Geological Sciences

San Diego, California 92041

DE-FG03-92ER14292.000

Eleventh Workshop on Electromagnetic Induction in the Earth

G. R. Jiracek (619-594-5586; FAX 619-594-4372)
Electrical conductivity measurements provide a unique view of Earth's interior because of the high sensitivity of conductivity to temperature differences and to fluids, ore minerals, and elemental carbon. These measurements represent an important set of geophysical data that are used to generate models of subsurface features. Conductivity measurements are important in monitoring environmental problems, exploring for energy and mineral occurrences, investigating regions of potential natural hazards (seismic and volcanic zones), and studying the internal structure of the Earth. The workshops on electromagnetic induction have provided a forum for leading international experts to present their research results, to exchange ideas, and to apprise young investigators and graduate students of the latest developments in this subject. This conference, the 11 th in the series, is one of great interest as geophysical imaging of rock-water systems represents a key theme of the Basic Energy Sciences/Geosciences Program. 
GRANTEE:

GRANT:

TITLE:

PERSON IN CHARGE:
UNIVERSITY OF SOUTHERN CALIFORNIA

Department of Geological Sciences

Los Angeles, California 90089-0740

\section{DE-FG03-87ER 13807}

Continental Scientific Drilling Program: The Seismology of Continental Thermal Regimes

K. Aki (213-740-5830; FAX 213-740-0011;

E-mail Aki\%sei@gamera.usc.edu)
This program was started as an involvement in two $m$ ajor geothermal projects, namely, the Hot Dry Rock Geothermal Energy Project of Los Alamos National Laboratory and the Magma Energy Project of Sandia National Laboratories. The theory and methods developed for interpretation of various seismic experiments conducted at Fenton Hill, New Mexico, and Kilauea Iki, Hawaii, however, found a variety of applications to other geothermal areas and volcanoes, and our research has been evolving into what might be called volcanic seismology.

In this program we are developing and applying the interpretation methods of passive seismology using natural seismic sources occurring in geothermal areas, as well as active seismology using artificial sources to the candidate sites for the Continental Scientific Drilling Program in order to delineate the geothermal and mechanical properties as well as the mass and energy transport mechanism of the geothermal system.

For example, recently we developed a new reliable method to separate scattering and absorption effects on high-frequency seismic waves and applied it to several geothermal sites including Long Valley, California, and the Island of Hawaii. Another example is the development of seismic tomography based on the waveform data. We applied the method to the Valles Caldera, New Mexico and found low-velocity and high-absorptive bodies under the caldera. 
GRANTEE:

GRANT:

TITLE:

PERSONS IN CHARGE:
UNIVERSITY OF SOUTH FLORIDA

Department of Marine Science

St. Petersburg, Florida 33701-5016

DE-FG05-92ER14300

Clay Mineral Diagenesis in the Monterey Formation

J. S. Compton (813-893-9158) and W. M. Sackett

(813-893-9130; FAX 813-893-8189)
The Miocene Monterey Formation contains a significant constituent of clay minerals that are known to be an important factor in silica, carbonate, and organic matter diagenesis. Results from offshore and onshore sequences of the Monterey in the Santa Maria basin area show a diverse clay mineral assemblage that includes smectite, mixed-layered illite/smectite, kaolinite, chlorite, corrensite, and illite. Many of these clay m inerals formed as a result of progressive burial diagenesis and overlap with the burial depths associated with oil generation and migration. This project examines the clay mineral reactions in the Monterey Formation by determining the detailed mineral, elemental, and isotopic composition of Monterey rocks. The study will quantify for the first time the complete mineral associations of the Monterey Formation and provide detailed analysis of the significance of clay minerals in the complex diagenesis of these hydrocarbon source and reservoir rocks. The project will (1) quantify the clay mineral reactions that occur in individual vitreous volcanic ash layers as they undergo increasing burial diagenesis (glass to bentonite to metabentonite), (2) compare clay mineral reactions in the ash layers to those in adjacent siliceous shales and test the hypothesis that the illitization of smectite is limited by the availability of $K$, (3) determine the relation between progressive illitization and the thermal maturation of organic matter, and (4) evaluate the use of fixed- $\mathrm{NH}_{4}$ contents as proxies for hydrocarbon fluids. 
GRANTEE:

GRANT:

TITLE:
STANFORD UNIVERSITY

Department of Geology

Stanford, California 94305-2115

DE-FG03-90ER14154

Fluid Flow, Element Migration, and Petrotectonic Evolution

of the Early Mesozoic Central Klamath Island Arc, Northwesternmost California

W. G. Ernst (415-723-2750; FAX 415-725-6566)

Geologic and geochemical investigations in the central Klamath Mountains have documented the presence of a polymetamorphosed suite of highly magnesian basaltic rocks, the early Mesozoic Yellow Dog greenstones, in the Sawyers Bar terrane of the western Triassic and Paleozoic belt. The Yellow Dog metavolcanics display apparent komatiitic chemical affinities; bulk-rock analyses of fourteen of the highly magnesian suite average nearly $15 \mathrm{wt} \%$ MgO. In actuality, these compositions reflect the concentration of cumulate hornblende during igneous differentiation and both submarine and regional + contact metamorphic element transfer. Protoliths were mildly alkalic, $\mathrm{Fe}+\mathrm{Ti}+\mathrm{P}$-rich oceanic island lavas (OIBs) and surmounting immature island-arc basalts (IATs). The mafic extrusives are interlayered with, and largely overlie distal turbidites. Associated dikes/sills represent two chemically distinct series: (1) $\mathrm{Cr}+\mathrm{Ni}$-rich Yellow Dog metadiabases and (2) altered $\mathrm{Si}+\mathrm{K}+\mathrm{Rb}+\mathrm{Sr}$ $+\mathrm{Zr}+$ LREE-rich mafic diorites genetically associated with mid-Jurassic calc-alkaline plutons. The latter are granitoid stocks that intrude the metalavas and metaclastics. The supracrustal assemblage was laid down, altered, and metasomatized during the collapse of a marginal basin that brought the westerly, outboard Sawyers Bar oceanic-arc terrane into juxtaposition with the inboard, preexisting Stuart Fork subduction complex. Granitoids immediately invade the amalgamated terrane complex. Tectonic events reflect the addition of substantial amounts of magmatic heat to the Klamath arc superstructure over the relatively brief period $160-225$ m.y.b.p.
Research supported by the current Department of Energy grant has clarified the areal extent, geochemical evolution, and structural/stratigraphic relations of these mafic/ultramafic Yellow Dog metavolcanic units, and has documented very minor crustal contamination of the melts by associated terrigeneous metasediments (employing neodymium-samarium data). Following very low-pressure ( $<1 \mathrm{kbar}$ ) submarine alteration, the physical conditions of metamorphism and of water-rock interaction accompanying island-arc accretion have been determined as follows: Early-Middle Jurassic regional metamorphism of the Sawyers Bar/Stuart Fork amalgamated terrane took place at 350 to $500^{\circ} \mathrm{C}$ and 2.5 to $4.0 \mathrm{kbar}$; contact aureoles peripheral to the mid-Jurassic calc-alkaline plutons reached maximum physical conditions of 500 to $600^{\circ} \mathrm{C}$ at 2.0 to $3.0 \mathrm{kbar}$. The post-collisional granitoids mobilized alkalis, silica, and oxygen isotopes in the sedimentary strata intimately interlayered with the Yellow Dog greenstones, overprinting effects of an earlier oceanic alteration in the mafic volcanics (bulk-rock $\delta^{18} \mathrm{O}$ went from $\sim 6$ to $12 \pm 3$ ). The thermal structure and its evolution in the central Klamath Mountains reflects surfaceward advective transport of magmatic energy derived from partly fused downgoing oceanic lithosphere, as well as upper crustal hydrothermal fluid circulation. Elucidation and documentation of the element migration, volatile pathways, and thermal evolution of this upper crust-constructional event in an immature arc are the goals of the ongoing research. The author is joined in this research by postdoctoral fellow B. R. Hacker and doctoral student D. E. Miller. 
GRANTEE:

GRANT:

TITLE:

PERSON IN CHARGE:
STANFORD UNIVERSITY

Geophysics Department

Stanford, California 94305-2215

DE-FG03-86ER 13601-A004

Porous Reservoir Rocks with Fluids: Acoustic and Reservoir and Transport Properties

A. M. Nur (415-723-9526; Fax 415-723-1188;

E-mail Nur@Pangea.Stanford.Edu)
Our studies are focused on five important problems in rock physics: seismic properties of source-rocks and their relation to hydrocarbon generation; critical porosity of porous and cracked rocks and its relation to mechanical and acoustic properties; laboratory measurements of acoustic velocity and attenuation anisotropy in rocks; quantitative analytical relationships among permeability anisotropy and attenuation; and the effect of the local flow mechanism on velocity dispersion and attenuation.

Seismic properties of hydrocarbon source rocks. An experimental study of the physical properties of black, kerogen-rich shales revealed that both compressional (P) and shear (S) velocities normal to bedding are extremely low, whereas they are much higher parallel to bedding, giving rise to a strong anisotropy even at high confining pressure. These parameters primarily reflect kerogen content, microstructure, and maturation level of these rocks. Microcracks inferred from ultrasonic velocity measurements occur only in mature shales. Therefore, velocity anisotropy reflects the degree of maturation of organic matter in the black shales.

Critical porosity. The critical porosity is the transition porosity between solid matrix-supported and fluid matrix-supported mechanisms in rocks. The critical porosity concept allows for the quantitative formalization of experimental relationships among velocities, porosity, and clay content. This approach has been successfully extended to describe not only velocity-porosity-clay content relations but also effective stress laws and strength criteria of rocks.
Measurements of acoustic velocity and attenuation anisotropy. Compressional and shear wave velocity anisotropy has been studied in Freeman Jewett Shale samples both under dry and saturated conditions. The results show that the magnitude of anisotropy decreases with increasing confining pressure. The anisotropy effect may be attributed to the grain preferential orientation. Stress-induced velocity and attenuation anisotropy have been investigated in granite, dolomite, sandstone, shale, and sand samples for $P$ and $S$ waves. The orthorhombic anisotropy model can closely mimic these experimental results.

Permeability anisotropy. The attenuation of a $\mathbf{P}$ wave has been related to permeability anisotropy by examining a theoretical model of a cylindrical pore filled with viscous liquid. It was found that attenuation is maximum when a high-frequency wave propagates perpendicular to the direction of maximum permeability. This result is consistent with experimental data obtained on an andesite sample.

The effect of the local flow mechanism. A simple technique has been developed for relating dry and saturated $P$ and $S$ velocities in anisotropic rocks. The model is based on the local-flow mechanism in thin cracks. A unified dynamic poroelasticity theory has been developed for the propagation of $P$ waves in a rock containing compressible viscous fluid. The theory systematically takes into account both the Biot and the local flow mechanisms. It allows for estimating fluid properties and permeability from seismic measurements. 
GRANTEE:

GRANT:

TITLE:

PERSON IN CHARGE:
STANFORD UNIVERSITY

Department of Applied Earth Sciences

Stanford, California 94305-2115

Models of Natural Fracture Connectivity:

Implications for Reservoir Permeability

D. D. Pollard (415-723-4679; FAX 415-725-0979;

E-mail dpollard@pangea.stanford.edu)

The goals of this project are to characterize the geometry of natural fracture systems in reservoirs and aquifers, to elucidate the mechanical aspects of their evolution and behavior, and to understand the factors that influence the flow of hydrocarbons and groundwater in fractured rock. This research has important implications both for the energy industry and for environmental problems. This grantsupported research, carried out by one post-doctoral student and two graduate students, is summarized in the following paragraphs.

Model experiments have been conducted for one and two sets of opening mode fractures in layered brittle materials using brittle coating techniques. Major results include determination of: (1) the effect of strain rate, ranging from $10^{-8} / \mathrm{sec}$ to $10^{-1} / \mathrm{sec}$, on fracture patterns; (2) the relationship between fracture spacing and layer thickness; (3) the interaction between two fracture sets caused by changing of remote stress orientation with angles from 0 to 90 degrees; and (4) fracture patterns along the boundary between two fracture domains. We have designed experiments for pure bending to study the development of multiple fracture sets in folded sedimentary sequences. These experiments will help us to understand the relative ages and interconnection of multiple fracture sets.

A change in the stress state at the tip of a propagating fracture can cause breakdown into multiple echelon segments. To understand this common phenomenon we have conducted laboratory experiments on PMMA blocks subject to mixed mode I-III loading and observed breakdown as a function of loading history. Linear elastic fracture mechanics suggests that the propagation angle of the echelon fractures relative to the parent fracture depends on the ratio of stress intensity factors. Our preliminary experimental results support this theoretical prediction and provide important relationships between the fracture geometry and loading that can be used to interpret natural fracture geometry.

As fluid flow in fractured formations is largely controlled by the geometry of the fracture network, we are exploring limiting factors of crack growth and their influence on network flow properties. For example, laboratory and theoretical modeling have identified the conditions under which a crack will terminate at a material interface such as a bedding plane. Numerical modeling of fracture growth has been used to determine the maximum rate at which a fracture can grow in a saturated formation and how the growth rate of fractures in an unsaturated formation is related to propagation energy. By understanding these controls on fracture network development, we can quantify the relationship between the conditions for fracture network formation and the resulting flow properties of the network. 
GRANTEE:

GRANT:

TITLE:

PERSON IN CHARGE:
STANFORD UNIVERSITY

Department of Geophysics

Stanford, California 94305-2215

DE-FG03-90ER 14152

Seismicity Induced By Hydrocarbon Production

P. Segall (415-725-7241; FAX 415-725-7344;

E-mail segall@kilauea.stanford.edu)

A number of active oil and gas fields, where pore pressures have declined by several 10 s of $\mathrm{MPa}$, exhibit clear seismic activity. These observations cannot be explained by changes in effective stress alone, which predict that decreasing pore-fluid pressures tend to stabilize faults. Poroelastic stress, associated with volumetric contraction of the reservoir rocks, is likely responsible for induced seismicity associated with fluid extraction and declining pore pressures. The goal of this project is to develop a fundamental understanding of the coupling among induced seismicity, pore fluid flow, and rock deformation.

Efforts are concentrated on the Lacq gas field in southwestern France. This area has been the site of hundreds of shallow, small to moderate earthquakes over the last 20+ years. Earthquakes were initially concentrated above the field; however, seismicity below the field began in 1982. The reservoir pressure had declined by $30 \mathrm{MPa}$ at the onset of seismicity and by $55 \mathrm{MPa}$ at the onset of deep seismicity.
Composite focal mechanisms are heterogeneous, with a tendency for $P$ axes to be radially distributed. Repeated leveling shows subsidence localized above the gas reservoir reaching a maximum of $60 \mathrm{~mm}$ in 1989.

The relationship between average reservoir pressure decline and subsidence is remarkably linear, lending support to the linear poroelastic model. Using available field and laboratory data, it is possible to predict the poroelastic fields without any free parameters. The computed vertical displacements are in good agreement with the observed subsidence. Given these same parameters, poroelastic stress changes at the onset of seismicity (both above and below the reservoir) are computed to be only a few bars. There is evidence that the seismicity at Lacq is concentrated in the stiffer carbonate units rather than in the more compliant marls. Finite element calculations are being conducted to investigate the importance of material heterogeneity on the computed stress state. 
GRANTEE:
TEXAS A\&M UNIVERSITY

Center for Tectonophysics

College Station, Texas 77843-3113
GRANT:

TITLE:

PERSONS IN CHARGE:

\section{DE-FG05-87ER 13711}

Mechanical Properties and Modeling of Seal-Forming Lithologies

A. K. Kronenberg, J. E. Russell, and N. L. Carter (409-845-0132; FAX 409-845-6780;

E-mail akk8153@geopsun.tamu.edu)

Both rocksalt and shale lithologies are actively deformed in response to gravitational loads associated with deposition, and both form effective seals to petroleum and natural gas. The goal of this research is to evaluate the roles of deformation and occurrence of these weak sedimentary lithologies subjected to gravitational loads in shaping conventional and unconventional oil and gas reservoirs. The fracture and flow properties of shales are not well constrained, and investigations include an experimental program on shale deformation. The rheology of rock salt, on the other hand, is well known, and numerical flow models for the growth of salt diapirs and large scale nappe structures are under development.

Over the last year, progress has been made in the experimental study of an illite-bearing shale from Louisiana with 1.8 weight $\% \mathrm{H}_{2} \mathrm{O}$ within clay interlayers. Triaxial compression experiments on samples cored parallel, perpendicular, and at $45^{\circ}$ to bedding reveal anisotropy in the strength of this shale that can be attributed to compositional layering and the preferred orientation of illite (001) planes, as determined by $\mathrm{X}$-ray goniometry. The highest differential stresses are measured for samples shortened parallel to bedding, with somewhat lower stresses measured perpendicular to bedding, while samples shortened at $45^{\circ}$ to bedding are weakest. Deformation is brittle at low pressures, while transitional brittle-ductile behavior is observed at the higher pressures. Mohr envelopes for samples of all three orientations are nonlinear, and samples shortened at $45^{\circ}$ to bedding exhibit the weakest pressure dependence with values of $\mu$ that drop to $\sim 0.18$ ( $\sigma \mathrm{n}=250 \mathrm{MPa}$ ). Strengths measured at $\mathrm{Pc}=250 \mathrm{MPa}$ are weakly dependent on $\varepsilon$ and $\mathrm{T}$.
Assuming a relationship $\varepsilon=A \exp \{\alpha(\sigma 1-\sigma 3)\}$ $\exp (-Q / R T)$ at a constant pressure, results of temperature- and strain rate-stepping experiments give values of $Q=69( \pm 10) \mathrm{kJ} \mathrm{mol}^{-1}$ and $\alpha$ ranging from $0.29( \pm 0.04) \mathrm{MPa}^{-1}$ to $0.52( \pm 0.07) \mathrm{MPa}^{-1}$ depending upon orientation. While pressure dependent, presumably brittle processes continue to be important at this pressure, values of $Q$ and $\alpha$ for shales are comparable to those associated with glide and kinking in mica-bearing schists investigated earlier.

In order to model the development of salt structures under gravitational loads, a numerical finite difference code has been developed to solve the incompressible Navier-Stokes equations, and it has been validated using a two-layer linear viscous model for which analytic solutions are available. Comparison of the numerical results with analytic solutions of Chandrasakhar for two infinite half-spaces and solutions of Ramberg for two finite layers with fixed top and bottom boundaries indicate that errors are of the order of $2 \%$ for low-viscosity cases $\left(10^{-5}\right.$ to $\left.10^{2} \mathrm{~Pa}-\mathrm{s}\right)$. Departures from the analytic solutions of $25-30 \%$ have been observed for high-viscosity cases $\left(10^{15}-10^{22} \mathrm{~Pa}-\mathrm{s}\right)$; however, and improvements in the code are currently being developed. Although the code has only been validated for the linear viscous case, it is capable of solving for highly nonlinear constitutive laws as well as solving for arbitrary interfaces between the salt and overburden. Once validation is complete, the code will be applied to examine the development of salt structures, as are present in the Gulf of Mexico, using power law rheologies determined at low experimental strain rates (to $10^{-9} \mathrm{~s}^{-1}$ ). 
GRANTEE:

GRANT:

TITLE:

PERSONS IN CHARGE:
THE UNIVERSITY OF TEXAS AT AUSTIN

Department of Geological Sciences

Austin, Texas 78713-7909

DE-FG05-92ER 14249

The Role of Mud Rocks in Burial Diagenesis

L. S. Land (512-471-3534; FAX 512-471-9425),

K. L. Milliken, and L. E. Mack
Terrigenous mud rocks (lithified rocks consisting of a mixture of silt- and clay-sized material) comprise approximately 80 percent volume of sediments in the Gulf of Mexico sedimentary basin and are commonly cited as the source of material $\left(\mathrm{CaCO}_{3}, \mathrm{SiO}_{2}\right.$, etc.) for porosity-occluding cements in sandstones, and for liquid and gaseous hydrocarbons. Systematic sampling of cuttings across a broad range of depths $(\sim 1-6 \mathrm{~km})$ is under way in Eocene and Oligocene units (Wilcox and Frio Formations) that underlie the Texas Gulf Coastal Plain.

Several lines of evidence suggest that burial diagenesis in the Gulf basin takes place in an open chemical system characterized by fluid and elemental transport in both directions between sands and mud rocks. Many wells in the Texas Gulf Coast display a systematic increase in $\mathrm{K}_{2} \mathrm{O}$ in mud rocks with increasing depth, suggesting that potassium from $\mathrm{K}$-feldspar dissolution in sands (documented by previous studies) is transferred from sandstones into mud rocks where it is sequestered by illitization. Differential transport of samarium and neodymium between sands and mud rocks has also been demonstrated, despite the relative insolubility of these elements. Back-scattered electron imaging documents the role of pressure solution in the volume loss of silt-sized carbonate from the mud rocks. In general, textural evidence from back-scattered electron imaging supports the idea that transport of materials is not a limiting parameter in the volumetrically significant reactions affecting metastable detrita feldspars and carbonates in either sandstones or mud rocks.

The proportional roles of provenance versus diagenetic change as causes of depth-related chemical variation is addressed by examining units of similar burial history but different provenance. Eocene sediments have greater mineralogical maturity than do Oligocene sediments, and Oligocene sediments from south Texas are very volcanogenic. Careful assessment of various "immobile" elements (Al, Ti, REE, Zr, Hf, Th) are also central to determining the relative roles of: provenance variations, sorting effects, volume loss, and/or differential gain/loss in accounting for chemical changes with depth. Isotopic analyses $\left(\delta^{18} \mathrm{O},{ }^{87} \mathrm{Sr} /{ }^{86} \mathrm{Sr}, \mathrm{Sm} / \mathrm{Nd}, \mathrm{U} / \mathrm{Pb}\right)$ of whole-rocks and various size fractions will further constrain material transport when integrated with existing data from sandstones and formation waters.

A suite of samples from conventional cores will be compared to cuttings from nearby wells in order to ensure that conclusions based on study of cuttings are valid. Analyses of the oxidation state of iron will also be conducted on the core samples. 
GRANTEE:

GRANT:

TITLE:
THE UNIVERSITY OF TEXAS AT AUSTIN Department of Geological Sciences

Austin, TX 78713-7909

DE-FG05-92ER14278.000

Energy Flux and Hydrogeology of Thermal Anomalies in the Gulf of Mexico Sedimentary Basin—South Texas Example

PERSON IN CHARGE:

J. M. Sharp (512-471-5172; FAX 512-471-9425)

The Gulf of Mexico sedimentary basin hosts vast reserves of natural gas, oil, lignite, and uranium, as well as hot, geopressured fluids that have been considered as a supplementary energy resource. Despite the intense drilling for and exploitation of these resources, the basic thermal, hydrological, and geologic processes are poorly understood, data are sparse, and the capabilities of numerical models of fluid and energy flow in the basin have surpassed the resolution of ground-truth data.

This research will produce fundamental thermophysical data and integrate them with a large temperature/fluid-pressure data base and numerical mocieling to bridge the gap between modeling and data. The fluid and energy fluxes responsible for a geothermal anomaly surrounding vast reserves of oil, natural gas, and uranium in south Texas will be quantified. Thermal conductivity and radiogenic heat-production measurements on rock cores will be the first reported for south Texas and will augment very sparse data on thermal rock properties in the Gulf of Mexico Basin. A large temperature/ fluid-pressure data base will be used for the first time to map a hydrothermal system in a passive margin setting. By constraining numerical models with new data, the research will test the hypothesis that the observed thermal anomaly is caused by the upwelling of deep basinal fluids in the vicinity of growth faults. 
GRANTEE:

GRANT:

TITLE:

PERSON IN CHARGE:
UNIVERSITY OF TULSA

Department of Geosciences

Tulsa, Oklahoma 74104

DE-FG05-88ER 13417

Stability of Natural Gas in the Deep Subsurface

C. Barker (918-631-3014; FAX 918-631-2286)
Depth limitations on the occurrence of oil are fairly well understood, but the factors controlling deep gas composition and distribution are poorly known. It is important to establish which factors are important in order to predict the possibility of significant gas reserves in the deepest (and undrilled) parts of many basins, and in once deeply buried basins that have been uplifted to drillable depths. We have continued to use a combined theoretical and experimental approach to develop an understanding of deep gas composition and the factors that control it.

Fluid inclusions in minerals that formed in the deep subsurface (such as quartz overgrowths and fracture-filling cements) provide samples of the volatiles present in that environment. We have continued to develop our computer-driven, dual mass spectrometer system for analyzing the bursts of gas released as individual inclusions rupture on heating in vacuum. Recent installation of additional amplifiers has improved the ability to analyze small inclusions, and software development has extended the ability to monitor gas release over the full temperature range (up to $1200^{\circ} \mathrm{C}$ ). These analytical methods, together with thermodynamic calculations, are being applied to the Arkoma basin since this was buried much deeper in the past. Cores from the Bonanza, Wilburton, and Red Oak fields have been obtained and thin sections cut from the Arbuckle formation. Fluid inclusion filling temperatures have been determined and fluid inclusion gas compositions measured for different generations. Some inclusions show a graphitic residue. Bulk composition has been used to calculate equilibrium gas composition thermodynamically. Carbonate overgrowths on silica grains in and near the Raven Creek field, Powder River Basin, are being studied optically and by mass spectrometry to evaluate the possibility of establishing paleomigration routes for oil. A wide range of samples has been run in cooperation with other research groups, and preliminary attempts have been made to monitor ammonia and nitrogen release from ammoniumbearing clays.

Deep gas composition has been calculated thermodynamically using a free energy minimization program that can handle up to 70 components in up to 25 phases. We have completed a detailed study of clastic reservoirs including those with feldspars, clays, iron oxides, carbonate cements, and anhydrite. Reservoirs initially containing oil that was subsequently cracked to methane will also contain a graphitic residue, and we have modeled reservoirs both with and without graphite. In general, the presence of graphite enhances methane stability, and with increasing temperature the carbon reacts with water to generate some methane. When graphite is eliminated methane reacts with water to generate carbon dioxide and hydrogen. Large quantities of carbon dioxide are also formed by the thermal breakdown of carbonate cements and this can dilute other components and reduce them to trace levels. In shallow reservoirs that were once deeply buried, gas composition is not controlled by the greatest depth of burial, but rather by the shallowest depth at which gas composition was in thermodynamic equilibrium with the local mineral assemblage. 
GRANTEE:

\author{
U.S. GEOLOGICAL SURVEY \\ Branch of Sedimentary Processes \\ Department of the Interior \\ Denver Federal Center \\ Denver, Colorado 80225
}

GRANT:

DE-FG05-92ER 14250.000

TITLE:

Cretaceous Shallow Drilling in the U.S. Western Interior

PERSONS IN CHARGE:
Walter E. Dean (303-236-1644; OMNET w.dean) and M. A. Arthur
This project drilled and continuously cored a hole in the Florence-Cañon City, Colorado, area to recover a continuous unweathered sequence of Cretaceous strata. This project constitutes a multidisciplinary study of middle to upper Cretaceous marine sedimentary rocks in the Utah-Colorado-Kansas corridor of the Cretaceous seaway that extended from the Gulf Coast to the Arctic during maximum transgressions. The focus is on the Greenhorn and Niobrara cyclothems combining biostratigraphic/paleoecologic, inorganic, organic and stable isotopic, mineralogical, and high-resolution geophysical logging studies. The major effort has been recovery of continuous cores from three sites in an east-west transect. The westernmost holes were drilled by the U.S. Geological Survey in June 1991, on the Kaiparowitz Plateau in Utah. The main hole in the transect was drilled to the east, in June 1992, near Cañon City, Colorado, to obtain cores of offshore, deeper-water (and more deeply buried) pelagic-hemipelagic strata. Ties with seismic reflection profiles, high-resolution stratigraphy on outcrop well logs from industry wells, and continuous core from the easternmost site (Amoco Rebecca Bounds \#1, Greely County, Kansas) will enhance this effort.

Major objectives are: (1) timing and rates of sea-level change and their influence on lithology, sedimentation rate, and sediment geochemistry; (2) rates of subsidence, apparent sea-level change, and facies migration in light of global tectonic-eustatic events; (3) onshore-offshore facies patterns and amount, accumulation rate, type, and degree of preservation of organic matter; (4) variations in faunal and floral components and sedimentary structures to evaluate the extent and intensity of oxygen deficiency during organiccarbon depositional episodes; (5) effects of organic-matter enrichment on geochemical characteristics of the sediments, including cycling of redox sensitive elements; and (6) effects of thermal metamorphism and other geochemical characteristics with increasing burial depth; (7) detailed biostratigraphies provided by high-diversity faunal and floral assemblages, together with abundant volcanic ash layers, providing a unique highresolution time sequence to calibrate possible Milankovitch cyclicity; (8) "absolute" age data allowing calculation of important variables such as rates and timing of sediment supply, organic productivity, and changes in water-mass characteristics that contribute to the sedimentary expression of Milankovitch orbital cycles; (9) elucidate trends in geochemical properties and organic-carbon accumulation rates and in comparison to global trends; (10) providing data for validation of climate models (e.g., GCMs); (11) providing explanations for the significance of bioevents and substantial changes in global biotic diversity during the Cretaceous and document rates and timing of biotic extinction and evolution in detail; and (12) investigating the possibility that such shallow Cretaceous seas were the sources of oxygen-depleted oceanic deep-water masses. 
GRANTEE:

TITLE:
UNIVERSITY OF UTAH RESEARCH INSTITUTE

Earth Science Laboratory

391-C Chipeta Way

Salt Lake City, Utah 84108-1295

\section{GRANT: $\quad$ DE-FG02-91ER14207}

Participation in the Creede Scientific Project as On-Site Principal Investigator

The drilling phase of the U.S. Geological Survey's (USGS's) Creede Scientific Drilling Project commenced in October and November 1991 with successful completion (99\% + core recovery) of two continuously cored holes through the lacustrine moat-filling sequence of the 26 m.y.-old Creede caldera in the central San Juan caldera cluster of southern Colorado. The drilling was undertaken as part of the U.S. Base Program of Continental Scientific Drilling under guidance by the Interagency Coordinating Group.

The project's principal objective is a definitive test of the hypothesis that the Creede caldera's moatfilling lacustrine sedimentary and volcanic sequence furmished the moderate-salinity fluids which would ultimately deposit, at about $25 \mathrm{Ma}$, the rich silver/ base-metal ores of the Creede mining district a few kilometers north of the moat. The two coreholes drilled in support of this objective also provide an excellent opportunity to investigate other aspects of the caldera's volcanotectonic, sedimentary/ diagenetic, hydrogeochemical, and thermal evolution, by characterizing: (1) the primary compositions, textures, bedding characteristics, and primary structures of the moat rocks; (2) diagenetic and hydrothermal modifications of these deposits, both laterally and vertically; (3) paleomagnetic and rock magnetic properties; (4) vein- and pore-filling phases-their mineralogy, paragenesis, chemical compositions, isotopic signatures, and fluidinclusion systematics; (5) the moat's contemporary thermal regime-through detailed temperature logging and heat-flow studies; (6) hydrologic transport properties of the moat rocks-by direct measurement of representative core samples; (7) the ages of the moat rocks- through accurate ${ }^{40} \mathrm{Ar}{ }^{39} \mathrm{Ar}$ geochronology; (8) organic constituents of the moat rocks and the changes these organics have undergone since initial deposition; (9) the chemical and isotopic compositions of modem formation waters.

The shallower of the two Creede coreholes (CCM-1, $430 \mathrm{~m}$ ) was completed first, several kilometers west of the inferred moat-sequence ore-fluid source for the Creede hydrothermal system (active at about $25 \mathrm{Ma}$ ). This hole penetrated $367 \mathrm{~m}$ of the lacustrine (and, deeper, possibly fluvial) facies of the Creede Formation, then another $51 \mathrm{~m}$ of Creede caldera- collapse and other breccias to total depth at $418 \mathrm{~m}$. The lacustrine rocks were dominantly laminated to thinly-bedded, argillized and/or zeolitized tuffaceous turbiditic sandstones, but also included reworked, fine-ash (phreatomagmatic?) silicic fallout tuffs, local debris-flow deposits, and, in the upper half of the hole, thin calcium carbonate laminae. Organic material was common throughout the lacustrine sequence, and spectacular fossils such as fir cones and currant leaves were discovered in some cores.

Corehole CCM-2, sited about $8 \mathrm{~km}$ east of CCM-1, penetrated in downward succession: $37 \mathrm{~m}$ of river gravels and sands; $453 \mathrm{~m}$ of lacustrine-facies Creede Formation similar to that intersected in CCM-1; $197 \mathrm{~m}$ of caldera-collapse and other breccias of unknown origin interbedded with thin fluvial sequences; and $58 \mathrm{~m}$ of mostly densely welded, intermediate- to felsic-composition ignimbrite to total depth at $708 \mathrm{~m}$.

Detailed preliminary geologic logs were prepared for both moat coreholes by the on-site science team, and a full suite of geophysical logs obtained by the USGS. 
GRANTEE:
GRANT:

TITLE:
UNIVERSITY OF UTAH RESEARCH INSTITUTE

Earth Science Laboratory

391-C Chipeta Way

Salt Lake City, Utah 84108-1295
DE-FG02-90ER 14133

Investigation of High-Temperature, Igneous-Related

Hydraulic Fracturing as a Reservoir Control in the Blackburn and Grant Canyon Oil Fields, Nevada
The Grant Canyon and Blackburn oil fields, in the eastern Basin and Range province of Nevada, are both hosted by brecciated Devonian dolomites in structural highs (horsts) beneath Cenozoic valley fill at the margins of extensional fault-bounded basins. The breccias hosting oil at these unusual fields are remarkably similar in texture to the hydrothermal breccias accompanying many epigenetic ore deposits. These textures, and the fact that both oil fields occur in close proximity to granitic stocks, prompted our initial investigation of the breccias as having formed through natural hydraulic fracturing - that is, rock rupture induced by overpressured, magmatically heated hydrothermal fluids. Secondary porosity created by this process is known to focus ore mineralization, and would provide equally effective storage for liquid hydrocarbons.

Our fluid-inclusion, vein mineralization, and hydrothermal alteration studies at the Blackburn field have shown that the high temperatures $\left(>350^{\circ} \mathrm{C}\right)$ conducive to violent hydrothermal brecciation once prevailed there in the dolomite reservoir rock. Coupled with the breccia's distinctive texture and the nearby (possibly subjacent) presence of an igneous intrusion, these paleotemperatures strongly support natural hydraulic fracturing as a porosity-inducing process at Blackburn; other fields both in production and remaining to be discovered may also owe their existence in part to hydrothermal brecciation.

However, even though breccias at the Grant Canyon field are texturally indistinguishable from their counterparts at Blackburn, they may have formed by other means. Detailed fluid-inclusion studies of the Grant Canyon breccias show no apparent paleotemperatures in excess of about $165^{\circ} \mathrm{C}$, and even this temperature corresponds to a pre-breccia period of vein mineralization. This does not rule out hydrothermal brecciation as a porosity-inducing mechanism at Grant Canyon (also, like Blackburn, in proximity to a granitic stock), but makes such an origin there somewhat less likely.

Fluid inclusion and alteration studies at Grant Canyon, however, have pointed to a direct and possibly more important geothermal influence in oil-reservoir evolution in the eastern Basin and Range. Breccia-cementing quartz at Grant Canyon hosts oil and coexisting aqueous inclusions that suggest transport of the oil to the trap in a convecting. moderate-temperature $\left(100-150^{\circ} \mathrm{C}\right)$ geothermal system. This system may still be active and circulating, since the current reservoir temperature at this field is $120^{\circ} \mathrm{C}$ at only $1.2 \mathrm{~km}$ deep. We have also documented, in preliminary fashion, possible fossil analogues for the Grant Canyon field in the Alligator Ridge mining district, about $90 \mathrm{~km}$ to the north. At the Yankee and Casino mines in this district of Carlin-type, low-grade disseminated gold deposits, "live" (theoretically producible) oil occurs in direct spatial and probably genetic association with mineralization. At Yankee, aqueous and oil fluid inclusions show homogenization (here probable entrapment) temperatures very similar to both contemporary and fluid-inclusion temperatures at Grant Canyon. 
GRANTEE:

GRANT:

TITLE:
UNIVERSITY OF UTAH RESEARCH INSTITUTE

Earth Science Laboratory

391-C Chipeta Way

Salt Lake City, Utah 84108-1295

\section{DE-FG02-89ER 14083}

Tensor, Controlled-Source Audiomagnetotelluric Survey Over the Sulphur Springs Thermal Area, Valles Caldera (Including Phase 2-Analysis of the Tensor Controlled-Source Audiomagnetotelluric Method in an Inhomogeneous Environment)

PERSON IN CHARGE:

Philip E. Wannamaker (801-524-3445; FAX 801-524-3453)

Forty-five tensor, controlled-source audiomagnetotelluric (CSAMT) soundings were obtained with our own equipment at the Sulphur Springs thermal area of the Valles caldera, New Mexico, by early July 1991 . This survey is in support of scientific interpretation of Continental Scientific Drilling Program drillholes VC-2A and VC-2B. Purposes of the CSAMT survey include establishing basement relief, mapping stratigraphy, estimating relative fluid content or alteration, inferring relative permeability, delineating possible vapor regimes, and establishing geometric controls on the hydrothermal system. The tensor approach has the advantage of independence of source field polarization and a complete estimation of the resistivity response regardless of dimensionality. The electric field component across strike was acquired with contiguous dipoles to ensure against undersampling the lateral response variation. This data set furthermore should be highly valuable in testing two- and three-dimensional magnetotelluric inversion algorithms currently under development.

However, in addition to addressing the geological goals summarized above, this unique data set is interesting in terms of the CSAMT method itself. This is the purpose of the phase 2 study, which has just commenced. Issues here include stability and accuracy of scalar versus tensor estimates, theoretical versus observed survey field patterns, and controls on near-field effects. For example, scalar results have been observed to straddle tensor quantities and bracket a range of up to $0.5 \mathrm{log}$ unit. Such discrepancies can be shown to arise because of both inhomogeneity and oblique orientation of the source fields. Also, near-field effects have been observed starting at $2 \mathrm{~Hz}$ in the Sulphur Springs area, which is unexpectedly high given the local apparent resistivities. Lithologies exterior to the caldera, where we also have data, are substantially more resistive than within, suggesting it is both local and host structure which determines the plane-wave assumption. Current efforts include comparison of observed and theoretical electromagnetic field patterns over the survey area, construction of a simple three-dimensional model of the caldera, assessment of its controls on field geometries and near-field effects using our own three-dimensional electromagnetic simulation algorithms. Our efforts are aided greatly by the recent donation of 31 high-quality MT stations by Unocal Geothermal Co. 
GRANTEE:

GRANT:

TITLE:

PERSON IN CHARGE:
VIRGINIA POLYTECHNIC INSTITUTE AND

STATE UNIVERSITY

Fluids Research Laboratory

Department of Geological Sciences

Blacksburg, Virginia 24061

\section{DE-FG05-89ER 14065}

PVTX Properties of Fluid Systems: $\mathrm{H}_{2} \mathrm{O}-\mathrm{CO}_{2}-\mathrm{NaCl}$

R. J. Bodnar (703-231-7455; FAX 703-231-3386;

E-mail RJB@VTVM2.cc.vt.edu)

Most fluids associated with crustal geologic processes are aqueous solutions containing varying amounts of salts and volatile components. In most cases, the salt component is dominated by $\mathrm{NaCl}$, and the volatile component is often $\mathrm{CO}_{2}$ rich. Thus, the system $\mathrm{H}_{2} \mathrm{O}-\mathrm{CO}_{2}-\mathrm{NaCl}$ represents one of the most important fluid systems for predicting the properties and behavior of fluids in crustal environments. Our research objective is to determine the pressurevolume-temperature-composition (PVTX) properties of the $\mathrm{H}_{2} \mathrm{O}-\mathrm{NaCl}$ and $\mathrm{H}_{2} \mathrm{O}-\mathrm{CO}_{2}$ binaries over the complete range of crustal P-T conditions, and to initiate studies within the temary at PTX conditions applicable to fluids in crustal environments. These data are needed to interpret microthermometric data obtained from natural fluid inclusions and to develop and test empirical and theoretical models describing the thermodynamic properties of aqueous fluids at high temperatures and pressures.

During the past several years, research in our laboratory has focussed on determination of the PVTX properties of the $\mathrm{H}_{2} \mathrm{O} \pm \mathrm{CO}_{2} \pm \mathrm{NaCl}$ system using the synthetic fluid inclusion technique developed by Bodnar and coworkers. These previous studies have provided a thorough understanding of
(1) phase equilibria in the $\mathrm{H} 2 \mathrm{O}-\mathrm{NaCl}$ binary under vapor-saturated conditions and (2) phase equilibria and volumetric properties of the $\mathrm{H}_{2} \mathrm{O}-\mathrm{CO}_{2}$ binary at elevated temperatures and pressures. During the past year, the PVTX properties of concentrated $\mathrm{H}_{2} \mathrm{O}$ $\mathrm{NaCl}$ fluids have been determined. This research has produced the first and only experimental data on the volumetric properties of high salinity (40 wt. \% $\mathrm{NaCl}) \mathrm{H}_{2} \mathrm{O}-\mathrm{NaCl}$ fluids within both the two-phase (liquid + halite) and the single-phase (liquid) fields. These data indicate that the slopes of the isochores within the halite +liquid field are m uch steeper than the isochoric slopes within the liquid field. This behavior is the opposite of that commonly assumed during the interpretation of halite-bearing fluid inclusions from hydrothermal systems. The implication of these results is that if fluid inclusions from hydrothermal systems exhibit halite dissolution temperatures higher than the vapor-disappearance temperature, the inclusions must have been trapped at high pressures. These data provide an independent geobarometer for inclusions which homogenize by halite dissolution, and the exact pressure may be obtained from the difference between the halite and vapor disappearance temperatures using data obtained in this study. 
GRANTEE:

GRANT:

TITLE:

PERSON IN CHARGE:
VIRGINIA POLYTECHNIC INSTITUTE AND STATE UNIVERSITY

Department of Geological Sciences

Blacksburg, Virginia 24061

DE-FG05-88ER 13951

Zircons and Fluids: An Experimental Investigation with

Applications for Radioactive Waste Storage

A. K. Sinha (703-231-5580; FAX 703-231-3386;

E-mail GEOLSCI@VTVM)

Our current research is aimed at providing a comprehensive physical and chemical data base for $\mathrm{ZrSiO}_{4}$ (zircon) that integrates measurements of solubility, alpha damage, and development of fractures induced because of both radiation and temperature-enhanced stresses. We have gathered new analytical data that bear on the chemical stability of $\mathrm{ZrSiO}_{4}$ in varying fluid compositions.

Solubility studies include both batch and mixed-flow reactor experiments. The starting material (20 m.y. old zircon from Tanzania) is compositionally homogeneous and non-metamict. Experimental charges were treated with $2 \mathrm{~m} \mathrm{NaCl}$ and $2 \% \mathrm{HNO}_{3}$ solutions at $1000 \mathrm{psi}$ and $210^{\circ} \mathrm{C}$ at a flow rate of $0.01 \mathrm{~mL} / \mathrm{min}$. In flow reactor experiments, zircon concentrations were below the detection limit $(<0.1 \mathrm{ppm})$. Measured concentrations of silicon over time indicate a steady-state saturation value of $0.3 \mathrm{ppm}$ and, based on congruent dissolution models, $\mathbf{Z r}$ steady-state values could be as high as $0.97 \mathrm{ppm}$. Using $3 \mathrm{~N} \mathrm{HCl}(-0.5 \mathrm{pH})$ solution in batch reaction experiments, both silicon and zircon measured in solution yielded $\mathrm{Zr}$ :Si atomic ratios of $2: 1$ at $220^{\circ} \mathrm{C}$ and $5: 1$ at $102^{\circ} \mathrm{C}$. The calculated value of dissolution activation energy $\left(\Delta \mathrm{E}_{\mathrm{a}}\right)$ of $\sim 30 \mathrm{Kcal}$ suggests surface detachment reactions as the rate limiting process.

Current research efforts also include development of techniques for measurement of zircon by isotope dilution methods to permit measurement of zircon concentrations in solutions at parts per billion levels. The continued integration of physical and chemical data will provide a comprehensive model for the stability of $\mathrm{ZrSiO}_{4}$ as a host for radioactive waste. 
GRANTEE:

GRANT:

TITLE:

PERSON IN CHARGE:
UNIVERSITY OF WASHINGTON

Geophysics Program

Seattle, Washington 98195

DE-FG06-92ER 14231

Two- and Three-Dimensional Magnetotelluric Inversion

J. R. Booker (206-543-9492; Fax 206-543-0489;

E-mail booker@geophys.washington.edu)

With prior support, we developed an iterative algorithm to invert large magnetotelluric (MT) data sets for multidimensional structure, which is at least two orders of magnitude faster than competing codes and is very memory efficient. We call the method the Rapid Relaxation Inverse (RRI). The basic two-dimensional (2D) code (in color or gray-levels) has now been made widely available. It is known to run on Sun or Hewlett-Packard workstations but should be relatively easy to use in most computing environments with at least $4 \mathrm{MB}(8-16 \mathrm{MB}$ recommended) of memory. Copies for academic or government research can be obtained from the above address.

This past year we have incorporated a series of improvements to the $2 \mathrm{D}$ code. These include provision for surface topography, a priori constraints at any node within the model, a more accurate finite difference approximation, and data collected at the interface between the ocean and the sea floor. These improvements were dictated both by real data sets that we have examined and by expected complications in data we are collecting with separate funding. Together with improved strategies for calculating so-called static shifts in the logarithm of apparent resistivity associated with small scale three-dimensional structure, we appear to have largely overcome earlier difficulties in finding models that can simultaneously satisfy the two independent polarizations with the electric field parallel to (TE) and perpendicular to (TM) structural strike. In particular, we have demonstrated that when the data show no TM response to structure that has a strong TE response, inclusion of the TM data in a joint inversion with TE can substantially sharpen the focus or resolution over an inversion of TE data alone. The improved code should be publicly available in the near future.

RRI can be generalized to $3 D$ and has the potential of making true 3D inversion practical with existing computer hardware. In the past year we have completed work on the most important element in a practical code: a fast, accurate forward algorithm for arbitrary 3D structure. We use a staggered finite difference grid that explicitly enforces electric current conservation. We use an incomplete Cholesky decomposition to precondition iterative solution of the sparse linear system by a biconjugate gradient technique. A special "static correction" that removes the erroneous electric field because of residual failure of current conservation is made every few iterations. This correction permits the algorithm to rapidly reduce residuals to machine precision even at long periods. We have demonstrated $1 \%$ agreement with 2D analytic solutions in which structure runs diagonally across the grid to simulate 3D models. We have demonstrated the accuracy of an error estimation technique that uses the spatial spectrum of the fields within the model. We have found that fully 3D calculations with a predicted accuracy of $1 \%$ in a $20 \times 20 \times 20$ grid take about 2 min per frequency on a Sparc 2 workstation, and finally, we have successfully solved 3D problems with more than four orders of magnitude conductivity variation on a $40 \times 40 \times \mathbf{4 0}$ grid with same machine. 
GRANTEE:

GRANT:

TITLE:
PERSON IN CHARGE:

\section{TILE.}

PERSON IN CHARGE:
WASHINGTON STATE UNIVERSITY

Department of Geology

Pullman, Washington 99164

\section{DE-FG06-91ER 14172}

Origin of Flood-Basalt Volcanism on the Columbia Plateau: an Integrated Approach Using Geology, Geophysics, and Petrology

S. P. Reidel (509-335-3009, 509-376-9932;

FAX 509-376-7893)
The objectives of this research are to understand the nature of flood-basalt volcanism and tectonism on the Columbia Plateau and its impact on the hydrocarbon potential of this area, one of the largest frontier petroleum provinces in the United States. The approach is to interpret a large unpublished geologic and geophysical data base supplemented with new work.

Status:

1. A study of the Teepee Butte Member $\left(2500 \mathrm{~km}^{3}\right)$ provides insight into the eruption and emplacement history of large volume basalt flows (accepted by Geological Society of America Bulletin).

2. A study of dissolved methane in Columbia River Basalt Group (CRBG) aquifers found shallow biogenic and deep thermogenic components. Methane occurrences are structurally controlled. This study provides a new, inexpensive method for determining the extent of thermogenic methane and assessing the hydrocarbon potential of the area (accepted by American Association of Petroleum Geologists Bulletin).

3. A map of the main CRBG dike-swarm area and unpublished geologic mapping $\left(7000 \mathrm{~km}^{2}\right)$ compiled onto four 1:100,000 maps, were published by the Washington Division of Geology and Earth Resources.

4. A manuscript, in review, discusses the post-CRBG tectonic development of the Columbia Plateau (invited for symposium volume on Geology of Washington). 
GRANTEE:

GRANT:

TITLE:

PERSON IN CHARGE:
WASHINGTON STATE UNIVERSITY TRI-CITIES

Environmental Sciences Program

Richland, Washington 99352

DE-FG06-91ER14217

Transport in Porous and Fractured Media of the Creede

Formation

J. L. Conca (509-375-3268/4787; FAX 509-375-4838)
The objective of this investigation is to determine the hydrologic parameters of Creede formation rocks for use in transport model development and for image analysis of transport pathways to produce a porosity/permeability evolution curve to support geochemical and isotopic water/rock interaction models. The ultimate goal of research drilling in the Creede mining district is characterization of the paleohydrologic cycle and mass transfer environment in the Creede hydrothermal system. This goal requires knowledge of the transport parameters of the media with respect to the fluids, species, and conditions of interest. The hydraulic conductivity, $K$, and diffusion coefficient, $D$, are key input parameters to existing and developing models of mass transport that have traditionally been difficult to measure directly in fractured and porous media, and have generally been inferred from porosity information. In addition, the actual transport pathways in the fractured media are also inferred from hand specimen and thin section analysis and are not directly determined. This study proposes to directly measure the hydraulic conductivity, the diffusion coefficient, and the actual fluid flow paths in rocks of the Creede area for use in transport model development and for image analysis of transport pathways. Samples will include host rocks of varying degrees of mineralization to establish changes in transport properties as a function of time and position in the hydrothermal system. Results of this study will also be applicable to remediation and site restoration of mining areas where predictive models of mass transport and contaminant release require transport parameters for these materials and where development of remediation technologies and strategies require material properties. Results will contribute to general theories for porosity-controlled hydrothermal ore deposition in caldera complexes. 
GRANTEE:

GRANT:

TITLE:
WASHING TON UNIVERSITY

Department of Earth \& Planetary Sciences

St. Louis, Missouri 63130

\section{DE-FG02-92ER 14297}

Development of an Experimental Data Base and Theories for Prediction of Thermodynamic Properties of Aqueous Electrolytes and Nonelectrolytes of Geochemical Significance at Supercritical Temperatures and Pressures

PERSONS IN CHARGE:

E. L. Shock (314-935-4258) and R. H. Wood (302-451-2941)

Evaluating the consequences of reactions among minerals, organic compounds, and aqueous solutions is central to understanding the geochemical processes involved in the generation, transport, and accumulation of petroleum resources. In addition, the efficient development of energy resources, the energy-efficient design of industrial processes, and the cleanup of industrial wastes require methods for predicting chemical equilibria under a wide variety of conditions. These advances require the modification and/or replacement of the best available predictive methods. This project is measuring the heat capacities and volumes of aqueous solutions of $\mathrm{SO}_{2}, \mathrm{H}_{3} \mathrm{PO}_{4}, \mathrm{Mg}$-acetate, $\mathrm{Na}$-propanoate, $\mathrm{Na}$-benzenesulfonate, propanoic acid, hexanoic acid, propanamide, propanammonium- $\mathrm{Cl}$, propanol, benzoic acid, phenol, and pyridine, at temperatures near $25,100,175,250$, and $325^{\circ}$ at 180 bars. Taken together with (1) existing data on heat capacities and volumes of aqueous $\mathrm{CH}_{4}$, $\mathrm{H}_{2} \mathrm{~S}, \mathrm{CO}_{2}, \mathrm{NH}_{3}$, and $\mathrm{B}(\mathrm{OH})_{3}$, and (2) data on volumes and heat capacities of $1: 1$ electrolytes, this project is developing and testing the correlation equations and predictive schemes for both electrolytes and nonelectrolytes. Existing data on ion-pair association constants and modern statistical mechanical approaches are combined to estimate the activities of ions in concentrated electrolyte solutions at high temperatures. Using group additivity, the results for the organic solutes are being used to predict the equilibrium properties of aqueous species containing the functional groups in the above compounds. These advances will greatly extend our ability to model the interactions among aqueous solutions, minerals, and organic compounds throughout sedimentary basins, and to employ energy resources in an efficient manner. 
GRANTEE:

GRANT:

TITLE:

PERSON IN CHARGE:
UNIVERSITY OF WISCONSIN

Department of Geology and Geophysics

Madison, Wisconsin 53706

DE-FG-02-91-ER 14194

Poroelasticity of Rock

H. F. WANG (608-262-5932; FAX 608-262-0693;

E-mail wang@geology.wisc.edu)
The coupled response of rock masses to stress and fluid flow is important in many geologic processes and energy technologies. This research program is an experimental study of static and dynamic poroelastic behavior of rocks. Measurements of Skempton's coefficient and undrained Poisson's ratio together with drained bulk modulus and shear modulus will provide a complete set of the four poroelastic moduli. Wave velocity and attenuation measurements from seismic to ultrasonic frequencies establish a phenomenological model of the effects of permeability, porosity, and saturation for seismic exploration.

Stress coupling to fluid flow in fractured rock can occur also through changes of fracture permeability because of fracture compressibility. A set of governing equations has been derived for the situation in which pressure lowering in the fracture of a double porosity reservoir will produce significant reduction in fracture permeability through increased effective vertical stress.

A new technique has been developed for measuring hydraulic diffusivities in sandstones that have permeability in the millidarcy range. The hydraulic diffusivity is obtained from either the phase shift or amplitude of the pressure signal recorded in a no-flow end plug for an input sinusoidal pressure variation. A rigorous inversion method has been developed to obtain both permeability and diffusivity in an apparatus that includes fixed volume fluid reservoirs at the inlet and outlet ends of the sample. For an apparatus in which applied pore pressures generate an equal vertical load, poroelastic theory shows that permeability can be obtained independently of storage.

The concept of a double porosity medium used for fluid flow in fractured rock has been applied to diffusion in rock containing a small, continuous fluid phase. The model was applied to laboratory iron diffusion data in olivine and to field oxygen isotope data at marble-metagranite contacts. The model quantifies the relative role of diffusion in the fluid and solid phases of the rock. The fluid is the fast diffusion path, but the solid contains the volumetrically significant amount of the diffusing species. The double medium results approach a local, grain-scale equilibrium model for times large relative to the time constant for solid diffusion. 
GRANTEE:

GRANT:

TITLE:
WOODS HOLE OCEANOGRAPHIC INSTITUTION

Department of Marine Chemistry and Geochemistry

Woods Hole, Massachusetts 02543

DE-FG02-92ER14232

Geochemical Incorporation of Sulfur Into Organic Matter: Role of Sulfur in the Formation and Diagenesis of Macromolecular Organic Matter in Sediments
The overall objective of this program is to develop a fuller understanding of the role of sulfur in the preservation and diagenesis of organic matter in sediments. It has been proposed that reaction of sulfur with organic matter during early diagenesis promotes preservation of biological molecules through the formation of sulfur cross-linked macromolecules. Specific aims of the project include: (1) to test validity and importance of the models proposed to describe macromolecularly bound sulfur; (2) to provide an inventory quantitatively describing the major forms of organically bound sulfur in sediments; (3) to determine the compositional relationships between sulfur associated with different organic matter fractions (kerogens, asphaltenes, resins, etc.) and to evaluate the role of sulfur in controlling the molecular weight distribution of organic matter; (4) to assess the timing and quantitative significance of abiotic sulfur incorporation as an organic matter preservation mechanism and as a sedimentary sink for sulfur; and (5) to evaluate the proposed diagenetic pathways of organically bound sulfur including transformation of cyclic sulfides (thiolanes, thianes) to aromatized forms (thiophenes) and preferential cleavage of sulfur-containing linkages during maturation ("early petroleum generation").

The analytical strategy involves isolation of fractions from sedimentary organic matter representing a number of different molecular size ranges, followed by detailed characterization using a variety of complementary techniques including elemental analysis, sulfur-selective chemical degradation, analytical pyrolysis, and XAS. In this way, information will be derived for each molecular size range, concerning the amount of organic sulfur, the type of organic molecules involved (chain-length, carbon skeleton), the type of sulfur linkages (acyclic, vs cyclic, mono vs di, or polysulfide, etc.) and number of S-bridges per organic molecule. An integral part of this project is the utilization of the National Synchrotron Light Source at Brookhaven National Laboratory for XAS studies of sulfur speciation.

Initial focus has been placed upon sediment samples from the Peru upwelling region. This area is of interest because it is percieved as a modern analogue of sulfur-rich source rocks such as those of the Monterey Formation. The initial phase of the project has been devoted to an assessment of the gross compositional characteristics of Peru margin sediments. Preliminary results from elemental analysis and XAS of cores spanning a 100-m depth interval indicate that organically bound sulfur increases over the first $10 \mathrm{~m}$, below which $\mathrm{S} / \mathrm{C}$ ratios remain relatively constant. The major iype of organically bound sulfur detected was organic sulfide with minor amounts of thiophenic and sulfate sulfur. Comparison of Peru XAS data with analyses of organic matter in consolidated sulfur-rich sediments from other locations revealed distinct differences in the thiophene/sulfide ratio, the latter exhibiting higher values. The thiophene/sulfide ratio also varied between corresponding asphaltene/ kerogen pairs, in each case suggesting that kerogens contain higher relative abundances of organically bound sulfides relative to thiophenes. This observation is consistent with the hypothesis that kerogens contain more inter-molecular sulfide bridges and are consequently more cross-linked and less soluble, than asphaltenes. 
GRANTEE:

GRANT:

TITLE:

PERSON IN CHARGE:
WOODS HOLE OCEANOGRAPHIC INSTITUTION

Department of Marine Chemistry and Geochemistry

Woods Hole Oceanographic Institution

Woods Hole, Massachusetts 02543

DE-FG02-89ER 13466

Organic Geochemistry of Outer Continental Margins and

Deep-Water Sediments

J. K. Whelan (508-457-2000, Ext. 2819; FAX 508-457-2164;

E-mail jwhelan@red.whoi.edu)
The objective of this program is to develop a better understanding of processes regulating hydrocarbon generation and migration in coastal and offshore sedimentary basins as an aid in predicting favorable exploration areas for oil and gas. We are the principal organic geochemical arm of a recently formed Global Basin Research Network (GBRN), an ambitious attempt to create a distributed network of scientists working to understand the coupled physical and chemical processes that control fluid movement in sedimentary basins. These processes, which are currently poorly understood, are fundamental to oil and gas formation and migration, metal ore deposit formation, and hydrology and associated pollutant movements around basins.

The Woods Hole organic geochemical research has focused on two specific tasks within the GBRN over the last year:

1. Hydrous pyrolysis experiments to define kinetic parameters, compositions, and amounts of gases which can be generated from various types of kerogen at various depths. Almost no reliable data of this type, which is critically important to estimating depths and amounts of natural gas potentially available in various basins, is currently available. Initial experiments have demonstrated the importance of redox and the presence of water in affecting the amounts and relative distribution of individual hydrocarbons. For example, under reducing conditions, disproportionation of water provides a direct source of hydrogen available to react with kerogen alteration products to form saturated hydrocarbons. The results of these experiments are being incorporated into the GBRN models being developed at Cornell.

2. Insertion of an extensive data base of Gulf Coast gas and oil compositions gathered by the Texas A \& $M$ University's Geochemical and Environmental Research Group (GERG) into the GBRN's first "data cube" covering $20 \times 40 \mathrm{~km}$ of the Eugene Island-S. Marsh Island area in the offshore Louisiana Gulf Coast. Initial results comparing gas and oil compositions and maturities to three-dimensional profiles of temperature, pressure, salt topography, sediment depocenters, and faults present a remarkable picture of active oil and gas injection into Eugene Island reservoirs at the present time. While individual parameters can be explained in other ways, the combined evidence, including a variety of hydrocarbon indicators (e.g., gas coexisting with biodegraded oil, $\mathrm{C}_{7}$ hydrocarbon ratios consistent with recently depressurized and migrated condensate, and water column profiles of $\mathrm{C}_{1}-\mathrm{C}_{3}$ that correlate with underlying active faults) present a compelling case for "dynamic injection" at the present time. The nearby South Marsh Island area provides a good "normal" Gulf Coast reference area where reservoirs contain less sulfur-rich and more mature oils and do not show evidence for dynamic injection. 
GRANTEE:

GRANT:

TITLE:

PERSONS IN CHARGE:
W RI-7 Organizing Committee

3385 St. Michael Drive

Palo Alto, Califomia 94306

DE-FG03-92ER14256

Seventh International Symposium on Water-Rock Interaction (WRI-7)

T. Wolery (510-422-5789) and Y. Kharaka (415-329-4535)
This project was for partial support of the 7th International Symposium on Water-Rock Interaction (WRI-7). Water-rock interactions are an important component of almost all geological processes operating in the Earth's crust. Continuing investigations into these interactions are relevant to environmental concerns, energy and mineral occurrences, global change, and natural hazards. The International Water-Rock Symposia series provides a forum for leading intemational hydrogeochemists to present their research results, exchange ideas, and appraise other investigators of the latest developments in this interdisciplinary field.

The WRI-7 Symposium was held in Park City, Utah, July 13-18, 1992. It consisted of four days of oral and poster sessions and attracted about 500 scientists from about 40 countries. The meeting included pre-session and post-session field trips to Yellowstone National Park, which were completely filled with about 100 participants each. A two- volume proceedings set has been produced (Water-Rock Interaction, Yousif K. Kharaka and Ann S. Maest, eds., A. A. Balkema Publishers, Brookfield, Vermont; Volume 1, pages 1-860, ISBN 9054100761 ; Volume 2, pages 861-1686,ISBN 90 $5410077 \mathrm{X}$ ) which includes 368 papers covering the major themes of: (1) Mineral-Fluid Interface Geochemistry, (2) Geochemical Modelling, (3) Organic Geochemistry, (4) Natural Hazards and Environmental Contamination, (5) Global Processes, (6) Oxidation-Reduction Reactions in Surface and Groundwaters, (7) Weathering Processes and Surface Water Environments, (8) Saline Lakes and Evaporite Deposits, (9) Unsaturated Zone Environments, (10) Groundwater Environments, (11) Stable and Radioactive Isotopes, (12) Sedimentary Basins, (13) Geothermal Systems, (14) Metamorphic Environments, (15) Hydrothermal Ore Deposits, and (16) Sea- water-Rock Interactions. 
GRANTEE:

TITLE:

\section{GRANT:}

YALE UNIVERSITY

Department of Geology and Geophysics

New Haven, Connecticut 06511
PERSONS IN CHARGE:

\section{DE-FG02-9OER 14153}

Reactive Fluid Flow and Applications to Diagenesis, Mineral Deposits, and Crustal Rocks

A. C. Lasaga (203 432-3114; FAX 203-432-3134)

and D. M. Rye

This project is obtaining new results and developing new techniques along three directions: (1) experimental studies of water-rock reactions, (2) theoretical modeling of coupled fluid-flow chemical reactions, and (3) isotopic measurements of both regional isotopic compositions as well as isotopic zoning within individual mineral grains. An important part of the project is the integration of all three approaches into a concerted effort aimed at new understanding of the behavior of fluids and their chemical reactions with minerals in the crust.

The main thrust of the theoretical modeling has been to develop further the differences between equilibrium, steady-state, and nonsteady-state behavior of the chemical evolution of open fluid-rock systems. These differences have not been fully appreciated in previous models. We have found that the mixing of fluids in two-dimensional models (from processes such as dispersion) has profoundly different chemical patterns from those found in the one-dimensional models.

The experimental work pioneered in our laboratories has produced several startling results on the kinetic rate laws of silicate-water reactions. The approach to equilibrium has been shown to follow a nonlinear path in rate constant-free energy space. The work to date has involved albite, kaolinite, and gibbsite, which together with silica would comprise a kinetic "granite system prototype." These new data can now be used in our two-dimensional code, "2DREACT," previously developed to study reactive flow in hydrothermal systems.

In addition, to apply the previously developed models to field data, we have developed techniques to measure isotopic zonation within individual mineral grains. These techniques include: (1) micro-drilling of samples with a fine dental drill coupled with a micro volume inlet system on the mass spectrometer and (2) separation of minerals from fine grain rocks by a series of dissolution steps. These techniques are superior to the laser techniques because they avoid the problem of isotopic fractionation during the sampling process, and they allow us to analyze more than one mineral phase in the rock.

As a first step in using isotopic data in metamorphic systems, we have developed one-dimensional isothermal steady-state flow path isotopic exchange models for both veins and wall rocks. These models incorporate diffusion, advection, and isotopic exchange (assuming first order kinetics). We find that even for relatively rapid isotopic exchange rates and small fluid fluxes, significant oxygen isotope disequilibrium between fluid and wall rock can be maintained for long distances for long periods of time along the flow path.

We have used the transport-exchange model to interpret a set of oxygen isotope data from veins and wall rocks from the Wepawaug Schist of South-central Connecticut. The transport-exchange model can successfully reproduce the field data for fracture-controlled flow with a time integrated flux of $10^{2}$ to $10^{3.5} \mathrm{~m}^{3}$ fluid $/ \mathrm{m}^{2}$ and a distance along the steady-state gradient, at which one-half of isotopic equilibrium with wall rocks was achieved, of $1100 \mathrm{~m}$. 
TABLE 1

DOE/OBES GEOSCIENCES RESEARCH

HISTORICAL SUMMARY

(OPERATING FUIDS - THOUSANDS)

$\stackrel{\varpi}{\varpi}$

\begin{tabular}{|c|c|c|c|c|c|c|c|c|c|c|}
\hline OAS-SITE & FY 1983 & FY 1984 & FY 1985 & FY 1986 & FY 1987 & FY 1988 & EY 1989 & EY 1990 & FX 1991 & FY 1992 \\
\hline ANL & $\$ 330$ & $\$ 360$ & $\$ 360$ & $\$ 355$ & +340 & \& 335 & $\$ 440$ & $\$ 454$ & $\$ 385$ & $\$ 440$ \\
\hline BNL & - & - & - & - & - & 50 & 90 & 49 & - & 213 \\
\hline INEI & - & - & - & - & - & - & - & - & - & 35 \\
\hline LANI & 1,684 & 2,343 & 2,289 & 2,263 & 2,603 & 2,868 & 2,638 & 2,613 & 2,518 & 2,730 \\
\hline LBL & 1,405 & 1,485 & 1,596 & 1,632 & 2,162 & 2,100 & 2,265 & 2,372 & 2,109 & 2,225 \\
\hline LLKL & 1,280 & 1,815 & 1,898 & 1,521 & 1,837 & 1,732 & 2,121 & 2,169 & 2,103 & 2,288 \\
\hline ORNL & 430 & 470 & 480 & 492 & 690 & 785 & 944 & 1,226 & 1,097 & 1,209 \\
\hline PRI & 520 & 578 & 595 & 605 & 725 & 850 & 848 & 819 & 735 & 780 \\
\hline skL/A & 1,682 & 2,087 & 1,861 & $2 ; 256$ & 2,462 & 2,711 & 2,213 & 1,828 & 2,167 & 2,098 \\
\hline \multirow[t]{2}{*}{ WhI } & - & - & - & - & - & - & - & - & .44 & 46 \\
\hline & 7,331 & 9,138 & 9,079 & 9,124 & 10,819 & 11,431 & 11,559 & 11,530 & 11,158 & 12.064 \\
\hline \multirow[t]{2}{*}{ TOTAI OFF-SITE } & 4,523 & 3,308 & 4,260 & 3,500 & 4,453 & 4,868 & 5,755 & 5,685 & 5,987 & 7,123 \\
\hline & ------ & $-\cdots--$ & ----- & $\cdots-$ & --..-- & -....- & - & & & -....-- \\
\hline TOTAL OPERATIKO & 11,854 & 12,446 & 13,339 & 12,632 & 15,272 & 16,299 & 17,314 & 17,215 & 17,145 & 19,187 \\
\hline \multirow[t]{2}{*}{ TOTAL EQUIPAETT } & 890 & 960 & 1,100 & 1,094 & 1,150 & 1,150 & 1,150 & 1,150 & 1,110 & 1,302 \\
\hline & $\cdots--$ & ------ & -....- & $\cdots-\cdots$ & & & & & & \\
\hline TOTAL GEOSCIEWCES & $\$ 12,744$ & $\$ 13,406$ & $\$ 14,439$ & $\$ 13,726$ & $\$ 16,422$ & $\$ 17,449$ & $\$ 18,464$ & $\$ 18,365$ & $\$ 18,255$ & $\$ 20,489$ \\
\hline
\end{tabular}


TABLE 2

DOE/OBES GEOSCIENCES RESEARCH

HISTORICAL SUMMARY/OFF-SITE

(OPERATING FUNDS - THOUSANDS)

\section{DEeriturios (PI)}

U/Alaska (Lee)

U/Alakka (Blchelberger)

Aa. Geophys. Unton (Sp1lhaus)

Ain. Mus. NY (Mathez)

u/Arizona (Anovitz)

U/Arizona (Bill)

U/Ar1zona (Norton)

Arizona st. (FInk)*

Arizona st. (Navrotsky)

Arizona st. (willams)

Bechtel (Harper)

Browi U (Bermance) *

Brown U (Yund)

Cal Tech (Ahrene)*

Cal Tech (Btolper)

Cal Tech (Wasserburg)

vj/Callfornia-B (Carmichael)

U/California-B (Belgeson)

U/California (Morr1son)

U/Callfornta-B (Reynolds)

U/Callfornia-d (Lesher)

U/California-D (Rock)

U/California-ra (Anderson)

U/California-IA (Boehler)

U/California-ra (Brnst)

U/Callfornia-la (Harrison)

U/Cal1fornia-LA (McKeogan)

U/Callfornia-R (MoKibben)*

U/Cal1forn1a-8B (Spera)

v/California-sp (Chave)

\begin{tabular}{|c|c|c|c|c|c|c|c|c|c|}
\hline$\frac{\text { F } 1983}{\$ 117}$ & $\frac{\text { FY 1984 }}{1120}$ & $\frac{\text { FI } 1985}{\$ 226}$ & $\frac{F I 1986}{\$ 126}$ & $\frac{F 1987}{\$ 128}$ & $\frac{F Y 1980}{\$ 140}$ & $\frac{F Y 1989}{\$ 143}$ & $\frac{F 1990}{\$ 140}$ & $\frac{F Y 1991}{\$ 145}$ & $\frac{\text { FI } 1992}{\$ 125}$ \\
\hline - & - & - & - & - & - & - & - & - & 149 \\
\hline- & - & - & - & - & - & 5 & - & - & - \\
\hline - & - & - & - & - & - & - & - & - & 49 \\
\hline- & - & - & - & - & - & - & 60 & 47 & - \\
\hline 101 & 90 & 121 & - & 101 & 103 & 121 & 120 & 126 & 130 \\
\hline 48 & - & - & - & - & - & - & - & - & - \\
\hline- & - & 22 & 23 & 11 & - & - & - & - & - \\
\hline 123 & - & - & - & - & - & - & - & - & - \\
\hline- & - & + & - & - & - & - & - & 108 & - \\
\hline- & - & - & 25 & - & - & - & - & - & - \\
\hline 333 & - & 166 & - & 150 & 150 & - & - & - & - \\
\hline- & - & - & - & - & - & - & 70 & 71 & 141 \\
\hline 72 & 81 & 160 & - & 150 & 100 & - & - & - & - \\
\hline- & - & 50 & 98 & - & 78 & 82 & 85 & 87 & 90 \\
\hline - & - & - & - & - & 200 & 250 & 250 & 300 & 345 \\
\hline- & - & - & - & - & - & - & - & 117 & 109 \\
\hline 204 & - & 120 & 120 & 135 & 116 & 121 & 120 & 135 & 140 \\
\hline- & - & - & - & - & - & - & - & - & 68 \\
\hline 165 & 196 & 233 & 200 & 200 & 210 & 236 & 245 & 245 & 264 \\
\hline- & 2 & - & - & - & - & - & - & - & 65 \\
\hline- & - & - & - & - & - & - & - & - & 83 \\
\hline- & 60 & 74 & - & 23 & - & - & - & - & - \\
\hline 60 & 66 & 75 & - & - & - & - & - & - & - \\
\hline- & - & - & - & 64 & 69 & - & - & - & - \\
\hline- & - & - & - & - & - & 54 & 54 & 54 & 57 \\
\hline- & - & - & - & - & - & - & - & 64 & - \\
\hline- & - & 30 & - & 40 & - & 77 & 49 & - & - \\
\hline- & - & - & - & - & - & 64 & 47 & 101 & - \\
\hline- & - & - & - & 120 & - & - & - & - & - \\
\hline
\end{tabular}




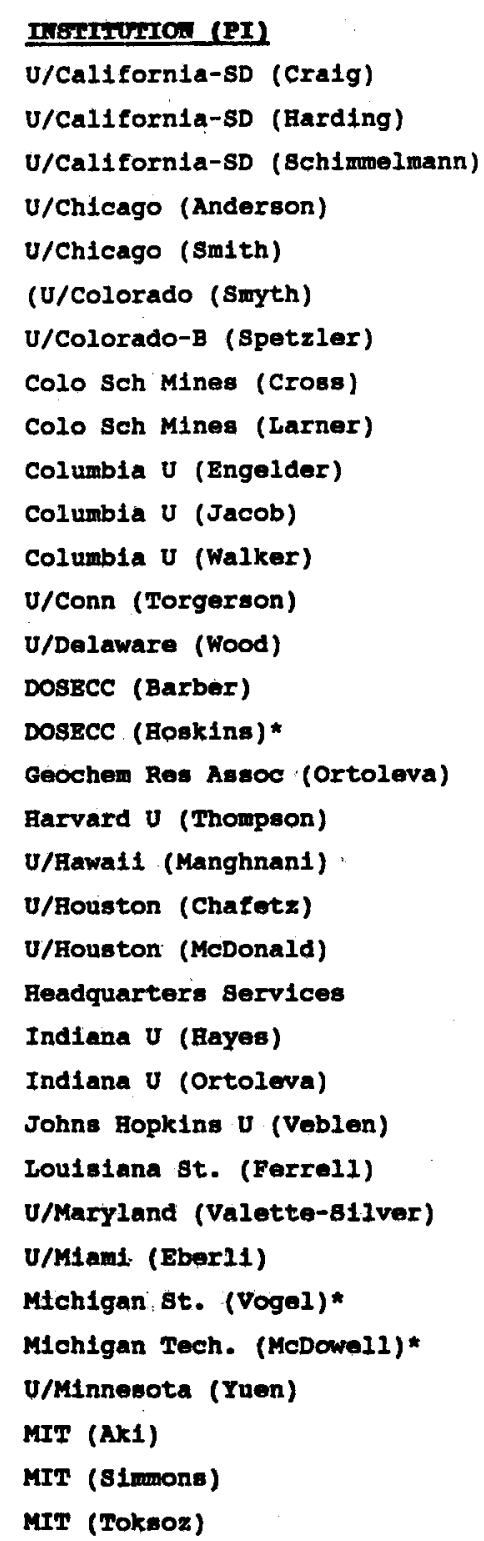

\begin{tabular}{|c|c|c|c|c|c|c|c|c|c|}
\hline FI 1983 & EI 1984 & FI 1985 & FI 1986 & FI 1987 & FI 1988 & FI 1989 & FI 1990 & FX 1991 & FI 1992 \\
\hline- & 35 & 41 & 41 & 42 & 35 & - & - & - & - \\
\hline - & - & - & - & - & - & 63 & - & - & - \\
\hline - & - & - & - & - & - & - & - & - & 110 \\
\hline 98 & - & 46 & - & - & - & - & - & - & - \\
\hline - & - & - & - & - & - & - & - & - & 105 \\
\hline - & - & - & - & - & - & - & - & - & 93 \\
\hline - & - & - & - & 95 & 87 & 91 & - & 50 & 65 \\
\hline - & - & - & - & - & 10 & - & - & - & - \\
\hline - & - & - & - & - & - & 192 & 195 & 200 & - \\
\hline 289 & - & 150 & 75 & - & - & - & - & - & - \\
\hline 337 & 359 & 360 & 360 & 360 & 360 & 290 & 203 & - & 25 \\
\hline- & 73 & 79 & 106 & - & 85 & 90 & 127 & 127 & 77 \\
\hline - & - & - & - & - & - & - & 4 & - & 110 \\
\hline - & - & - & - & - & - & 62 & 56 & 67 & 176 \\
\hline - & - & 6 & - & - & 66 & - & - & - & - \\
\hline - & - & - & - & - & - & - & 65 & 70 & 71 \\
\hline- & - & - & - & 50 & 100 & - & - & - & - \\
\hline 372 & - & 115 & - & 18 & - & - & - & - & - \\
\hline 96 & 99 & 200 & - & 100 & 100 & - & - & - & - \\
\hline - & - & - & - & 69 & - & - & - & - & - \\
\hline- & - & - & - & - & - & 273 & 295 & 221 & - \\
\hline 1 & 3 & 15 & 5 & 3 & 3 & 3 & 5 & 2 & 5 \\
\hline - & - & - & - & - & 186 & 162 & 150 & - & - \\
\hline- & - & - & - & - & - & - & - & 80 & 85 \\
\hline- & - & - & - & - & - & 63 & 66 & 135 & 134 \\
\hline - & - & - & - & 60 & 59 & 64 & - & 127 & - \\
\hline- & - & 43 & - & - & - & - & - & - & - \\
\hline - & - & - & - & - & - & - & - & - & 127 \\
\hline - & - & 31 & 31 & 34 & - & - & - & $=$ & $\therefore$ \\
\hline- & - & 50 & - & - & - & - & - & - & - \\
\hline - & - & - & - & - & - & 48 & 42 & 102 & - \\
\hline 158 & 147 & - & - & - & - & - & - & - & - \\
\hline 106 & 110 & 80 & 80 & - & - & - & - & - & - \\
\hline - & - & - & 142 & - & 113 & 370 & 498 & 485 & 372 \\
\hline
\end{tabular}




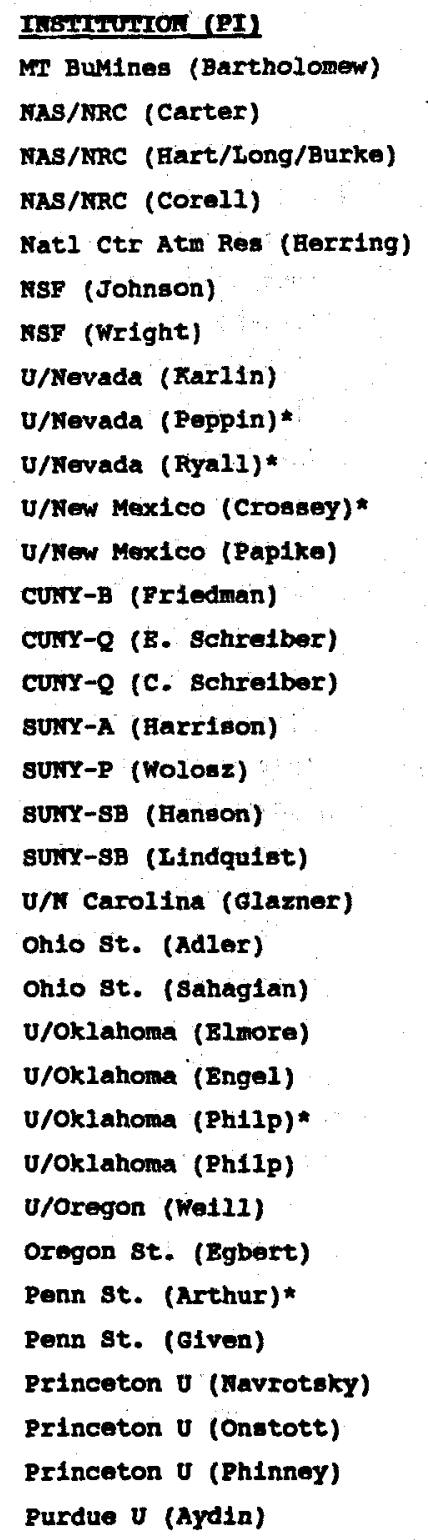

\begin{tabular}{|c|c|c|c|c|c|c|c|c|c|}
\hline EY 1983 & FI 1984 & FI 1985 & FI 1986 & FI 1987 & FI 1988 & 1989 & FI 1990 & FI 1991 & FI 1992 \\
\hline- & - & - & - & - & 8 & - & - & 9 & - \\
\hline - & - & - & - & - & - & 3 & 3 & - & - \\
\hline- & 200 & 187 & 124 & 202 & 132 & 100 & 105 & 200 & 5 \\
\hline - & - & - & - & - & 5 & - & - & - & - \\
\hline - & - & - & - & 10 & - & - & - & - & - \\
\hline - & - & - & - & - & - & 30 & - & - & - \\
\hline - & - & - & - & 200 & - & - & - & - & - \\
\hline - & - & - & - & - & - & - & - & - & 48 \\
\hline - & - & - & 143 & - & - & - & - & - & - \\
\hline 87 & 95 & - & - & - & - & - & - & - & - \\
\hline- & - & - & - & - & - & - & - & - & 43 \\
\hline - & - & - & - & - & - & - & 200 & - & - \\
\hline- & - & 95 & 86 & 100 & 50 & - & - & - & - \\
\hline 49 & - & 116 & - & $\ldots-$ & - & - & - & - & - \\
\hline - & - & - & - & - & 101 & 105 & - & 119 & 126 \\
\hline 136 & - & 58 & 60 & 54 & 52 & - & - & - & - \\
\hline- & - & - & - & 72 & - & 56 & 42 & - & - \\
\hline 112 & 118 & 120 & 120 & 128 & 128 & 120 & 119 & 124 & 128 \\
\hline$\therefore-$ & $\therefore-$ & - & - & - & - & - & - & - & 21 \\
\hline$\therefore-$ & - & 38 & 39 & - & 35 & - & - & - & - \\
\hline- & - & - & - & 50 & 52 & 55 & 54 & 56 & 59 \\
\hline- & - & - & - & - & - & - & - & 40 & - \\
\hline- & - & - & - & - & - & - & - & 109 & 112 \\
\hline- & - & - & - & - & - & 112 & 106 & - & - \\
\hline- & - & - & 28 & - & - & - & - & - & - \\
\hline - & - & 84 & 88 & 106 & 110 & 124 & 121 & 143 & - \\
\hline 103 & 94 & - & - & - & - & - & - & - & - \\
\hline- & - & - & - & - & - & 43 & 41 & - & 211 \\
\hline - & - & - & - & - & - & - & - & - & 129 \\
\hline- & 100 & - & - & - & - & - & - & - & - \\
\hline- & - & 100 & - & 85 & 120 & 125 & 123 & 125 & 130 \\
\hline$\therefore$ & - & - & - & - & - & - & - & 103 & - \\
\hline- & - & - & - & - & - & 97 & - & - & - \\
\hline- & - & - & - & - & - & 56 & 56 & - & - \\
\hline
\end{tabular}




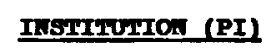

Purdue U (Fritz)

Purdue U (Hinze)

RPI (Friedman)

Rice U (Ave Lallement)

Rice $U$ (Mango)

San Dlego St. (J1racek)

S Dakota Sch MaT (Papike)

U/S Florida (Compton)

U/s California (Ak1)*

stanford U (Ernst)

stanford U (LiOu)

stanford $U$ (Nur)

stanford U (Parks)

stanford U (Pollard)*

stanford U (Pollard)

Stanford U (Segall)

U/wRochester (Gove)

U/Texas-Arl (Self)*

U/Texas-Aus (Barker)

U/Texas-Aus (Land)

U/Texas-Aus (Sharp)

U/Texas-D (M1tterer)

Texas AGM (Carlson)

Texas AAM (Carter)

Texas ACM (Dorobek)

Texas ACM (Frledman)

Texas AGM (G1lbert)

Texas AkM (Kronenberg)

U/Tulsa (Barker)

USGS (Dean)*

USGS (Kharaka)

usGs (Morgan)

USGS (Rusa)*

USGS (Wesson)

\begin{tabular}{|c|c|c|c|c|c|c|c|c|c|}
\hline FY 1983 & FY 1984 & FI 1985 & FI 1986 & FI 1987 & FY 1988 & FY 1989 & FT 1990 & Ex 1991 & FI 1992 \\
\hline - & - & - & - & - & - & - & 71 & 44 & 47 \\
\hline- & - & - & - & 8 & - & - & - & - & - \\
\hline 150 & - & - & - & - & - & - & - & - & - \\
\hline 120 & 121 & - & - & - & - & - & - & - & - \\
\hline - & - & - & - & - & - & - & - & - & 127 \\
\hline- & - & - & - & - & - & - & 5 & - & 10 \\
\hline 100 & 130 & 150 & 99 & 100 & 105 & 115 & - & - & - \\
\hline- & - & - & - & - & - & - & - & - & 122 \\
\hline- & - & 150 & 150 & 155 & 159 & 164 & 147 & 160 & 160 \\
\hline - & - & - & - & - & - & - & 100 & 101 & 158 \\
\hline 45 & - & - & - & - & - & - & - & - & - \\
\hline 160 & 172 & 172 & 165 & 165 & 170 & 175 & 328 & - & 176 \\
\hline 56 & 56 & - & - & - & - & - & - & - & - \\
\hline - & - & 39 & 42 & 44 & 70 & 73 & 30 & - & - \\
\hline- & - & - & - & - & - & 79 & 75 & 183 & 159 \\
\hline - & - & - & - & - & - & - & 80 & - & 70 \\
\hline- & - & - & - & 8 & - & - & - & - & - \\
\hline - & - & 43 & - & 80 & - & - & - & - & - \\
\hline 54 & - & - & - & - & - & - & - & - & - \\
\hline - & - & - & - & - & - & - & - & - & 100 \\
\hline- & - & - & - & - & - & - & - & - & 98 \\
\hline- & - & - & - & - & - & - & 119 & 112 & 114 \\
\hline- & - & - & 98 & - & - & - & - & - & - \\
\hline- & 70 & - & - & - & - & - & - & - & - \\
\hline- & - & - & - & 52 & 55 & 57 & - & - & - \\
\hline 201 & 93 & 100 & 194 & - & - & - & - & - & - \\
\hline- & - & - & 98 & 88 & 101 & 10 & - & - & - \\
\hline - & - & - & - & 117 & 156 & 197 & 149 & 143 & 149 \\
\hline 75 & 80 & 80 & 81 & 133 & - & 76 & 71 & 84 & 205 \\
\hline- & - & - & - & - & - & - & - & - & 99 \\
\hline- & - & - & - & - & - & - & - & - & 18 \\
\hline - & - & - & - & 35 & - & - & - & - & - \\
\hline- & - & - & - & - & - & 12 & - & 137 & 56 \\
\hline- & - & - & - & - & 6 & - & - & - & - \\
\hline
\end{tabular}




\begin{tabular}{|c|c|c|c|c|c|c|c|c|c|c|}
\hline IMBITIUIMTON (RI) & FI 1983 & II 1984 & $\underline{M} 1985$ & F 1986 & FI 1987 & FI 1988 & FI 1989 & FI 1990 & FI 1991 & FI 1992 \\
\hline U/Utah (Neilson)* & - & - & - & 114 & - & - & - & - & - & - \\
\hline U/Utah (Bulen)* & - & - & - & - & - & 125 & - & 85 & 126 & - \\
\hline U/Utah (Wannamaker) & - & - & - & - & - & - & 91 & - & - & 75 \\
\hline VPI \& SU (Bodnar) & - & - & - & - & - & - & 114 & 78 & - & 127 \\
\hline VPI SU (SInha) & - & - & - & - & - & 82 & 60 & 87 & 74 & 63 \\
\hline U/Washington (Booker) & - & - & - & 27 & 30 & - & 78 & 81 & - & 101 \\
\hline U/Washington (Malone) & - & - & - & - & - & 32 & 32 & - & - & - \\
\hline Wash. St.-P (Th1essen) & - & - & - & - & 103 & - & - & - & - & - \\
\hline Wash. St. Tri-cities (Conca)* & - & - & - & - & - & - & - & - & 95 & - \\
\hline Washington U (Shock) & - & - & - & - & - & - & - & - & - & 46 \\
\hline U/W1sconsin (Wang) & - & 48 & 52 & 97 & 84 & 87 & 92 & - & 97 & 99 \\
\hline Woode Bole 0.I. (Eglinton) & - & - & - & - & - & - & - & - & - & 99 \\
\hline Woods Hole 0.I. (Hunt) & 190 & 208 & - & - & - & - & - & - & - & - \\
\hline Woods Hole O.I. (Mhelan) & - & - & 223 & 223 & 226 & 238 & 220 & 208 & 197 & 199 \\
\hline U/Wyoming (surdam) & - & - & - & - & 65 & 63 & - & - & - & - \\
\hline Xdata (DInes) & 66 & - & - & - & - & - & - & - & - & - \\
\hline Yale U (Gordon) & 39 & 184 & - & 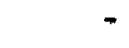 & - & - & - & - & - & - \\
\hline Yale U (Lasaga) & - & - & - & - & - & - & - & 50 & 91 & 113 \\
\hline Other & - & - & - & - & - & 254 & 160 & 5 & 4 & 3 \\
\hline - & ----- & $-\cdots-$ & ---- & ---- & $\cdots-$ & $-\cdots$ & $\cdots+-$ & $-\cdots$ & ----- & $-\cdots-$ \\
\hline OFF-SITE TOTALS & $\$ 4523$ & $\$ 3308$ & $\$ 4260$ & $\$ 3508$ & $\$ 4453$ & $\$ 4868$ & $\$ 5755$ & $\$ 5685$ & $\$ 5987$ & $\$ 7123$ \\
\hline
\end{tabular}

*Continental scientific Drilling Activity 



\section{GEOPHYSICS AND EARTH DYNAMICS}

Large-Scale Earth Dynamics . . . . . . . . . . . . . . . . . . . . . . 9, 45, 82, 93, 103, 123

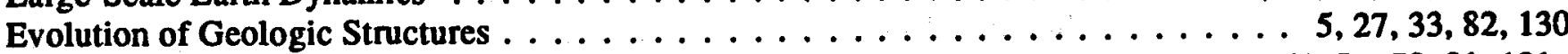

Properties of Earth Materials . . . . . . 8, 16, 18, 19, 24, 25, 26, 37, 49, 52, 53, 61, 77, 78, 81, 101,

$102,112,116,119,133$

Rock Mechanics, Fracture, and Fluid Flow . . . . . . 9, 10, 11, 17, 18, 20, 49, 51, 54, 81, 89, 90, 116,

$117,118,119,121,131,133$

Underground Imaging $\ldots \ldots \ldots \ldots \ldots$. . . . . . 17, 18, 23, 24, 25, 26, 27, 37, 45, 46, 50, 70, 79, 87,

$90,91,106,112,113,118,126,129$.

\section{GEOCHEMISTRY}

Thermochemical Properties of Geologic Materials . . . . 12, 21, 22, 28, 31, 32, 38, 40, 42, 43, 53, 62, $66,68,69,72,73,74,75,78,80,83,84,108,127,128,132$ Rock-Fluid Interactions . . . . . . . . 3, 4, 28, 30, 32, 38, 42, 43, 49, 64, 65, 85, 86, 88, 92, 96, 99, $114,115,120,124,125,127,128,136,137$ Organic Geochemistry . . . . . . . . . . 4, 5, 12, 21, 38, 40, 64, 76, 88, 111, 104, 105, 132, 134, 135 Geochemical Transport . . . . . . 13, 21, 28, 29, 30,31, 32, 35, 38, 42, 43, 49, 50, 52, 53, 65, 66, $67,69,71,74,75,86,100,109,110,115,120,122,124,125,127,128,137$

\section{ENERGY RESOURCE RECOGNITION, EVALUATION, AND UTILIZATION}

Resource Definition and Utilization $\ldots \ldots \ldots . \ldots, 15,45,46,49,111,114,115,125,126,130,135$ Reservoir Dynamics and Modeling . . . . . . 14, 32, 50, 51, 54, 85, 87, 117, 118, 121, 122, 125, 129,135

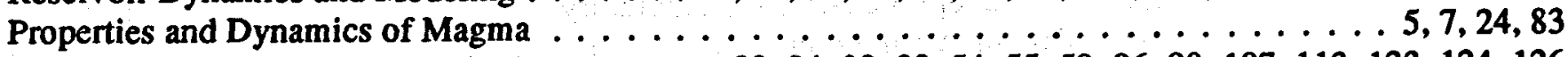
Continental Scientific Drilling . . ......22, 24, 32, 33, 54, 55, 59, 96, 98, 107, 113, 123, 124,126

\section{HYDROGEOLOGY AND EXOGEOCHEMISTRY}

Fluid Transport Dynamics and Modeling $\ldots \ldots \ldots \ldots \ldots \ldots, 5 \ldots \ldots \ldots, 85,89,121,133,136,137$ Thermochemical Properties of Energy Materials . . . . . . . . . . . . . . . . . . . . 77, 88

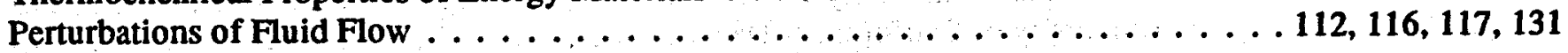

\section{SOLAR-TERRESTRIAL INTERACTIONS}

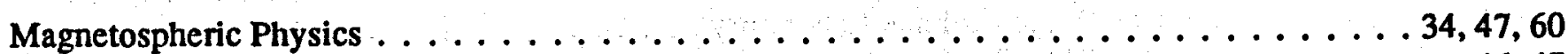

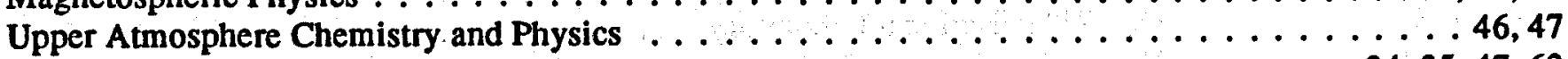

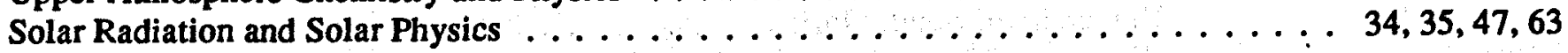




\section{INDEX OF TECHNICAL CONTRIBUTORS}

CONTRIBUTOR

Abers, $\mathbf{G}$.

Adler, $\mathbf{L}$.

Akasofu, S.-I.

Aki, $K$.

Albright, J. N.

Anovitz, L. M.

Arehart, G. B.

Arthur, M. A.

Attrep, M., Jr.

Bakel, A. J.

Baldridge, W. S.

Barker, $\mathrm{C}$.

Becker, A.

Beeman, M. L.

Bell, J. L. S.

Benson, W. E.

Berryman, J. G.

Bim, J.

Bish, D. L.

Blair, S. C.

Blankenship, D.

Blencoe, J. G.

Bodnar, R. J.

Bonner, B. P.

Booker, J. R.

Braun, R. L.

Brown, $\mathbf{S}$. R.

Burnham, A. K.

Carmichael, I. S. E.

Carnahan, C. L.

Carter, N. L.

Casey, W. H.

Charles, R. W.

Cheng, C. H. A.

Chiarello, R. P.

Christie, W. H.

Cole, D. R.

Compton, J. S.

Conca, J. L.

Cook, N. G. W.

Crossey, L. J.

Curtis, D. B.

Cygan, R. T.

Daily, W. D.

Dayvault R.

Dean, W. E.
INSTITUTION

PAGES

Columbia University . . . . . . . . . . . . . . . . . 82

The Ohio State University . . . . . . . . . . . . . . . . . . 102

University of Alaska . . . . . . . . . . . . . . . 60

University of Southern California . . . . . . . . . . . . . . 113

Los Alamos National Laboratory . . . . . . . . . . . . . . . . 25

University of Arizona ..................... . . 62

Argonne National Laboratory . . . . . . . . . . . . . . . 3

Pennsylvania State University . . . . . . . . . . . . . . . 107, 123

Los Alamos National Laboratory . . . . . . . . . . . . . . . . . . 31

Argonne National Laboratory . . . . . . . . . . . . . . . . . . . 4

Los Alamos National Laboratory . . . . . . . . . . . . . . . . . . 27

University of Tulsa . . . . . . . . . . . . . . . . . . . 122

Lawrence Berkeley Laboratory . . . . . . . . . . . . . . . . 8

Lawrence Livermore National Laboratory . . . . . . . . . . . . . . . . 16

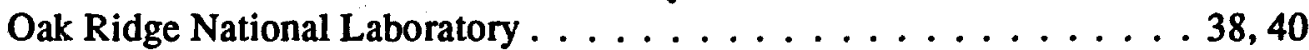

National Academy of Sciences . . . . . . . . . . . . . . . . . . 94

Lawrence Livermore National Laboratory . . . . . . . . . . . . . . . 18, 23

Los Alamos National Laboratory . . . . . . . . . . . . . . . . . 34

Los Alamos National Laboratory . . . . . . . . . . . . . . . . . . 29

Lawrence Livermore National Laboratory . . . . . . . . . . . . . . 18

Sandia National Laboratories . . . . . . . . . . . . . . . . . 54

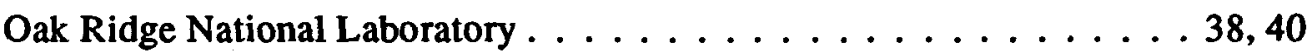

Virginia Polytechnic Institute and State University . . . . . . . . . . . . 127

Lawrence Livermore National Laboratory . . . . . . . . . . . . . 17, 18, 19, 26

University of Washington . . . . . . . . . . . . . . . . . . . 129

Lawrence Livermore National Laboratory . . . . . . . . . . . . . . . 21

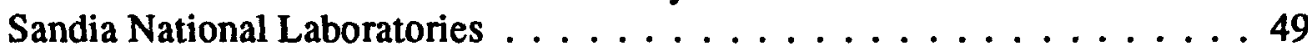

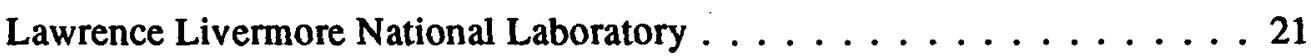

University of California . . . . . . . . . . . . . . . 68

Lawrence Berkeley Laboratory . . . . . . . . . . . . . . . . . 13

Texas A\&M University . . . . . . . . . . . . . . . . . . . . . 119

University of California at Davis . . . . . . . . . . . . . . 73

Los Alamos National Laboratory . . . . . . . . . . . . . . . . 30, 35

Massachusetts Institute of Technology . . . . . . . . . . . . . . . 89

Argonne National Laboratory . . . . . . . . . . . . . . . . . . 4

Oak Ridge National Laboratory . . . . . . . . . . . . . . . . . . . . 43

Oak Ridge National Laboratory . . . . . . . . . . . . . . . 38,42,43

University of South Florida . . . . . . . . . . . . . . . . . 114

Washington State University Tri-Cities . . . . . . . . . . . . . 131

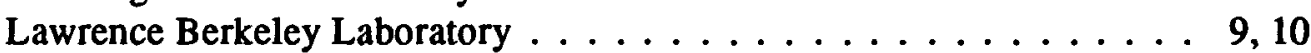

University of New Mexico . . . . . . . . . . . . . . . . . . . . . . . . . . . . . . . . .

Los Alamos National Laboratory . . . . . . . . . . . . . . . . . . 29

Sandia National Laboratories . . . . . . . . . . . . . . . . 52,53

Lawrence Livermore National Laboratory . . . . . . . . . . . . . . . . . . . . . . . . . . . . . . . . . . . . . . .

University of North Carolina . . . . . . . . . . . . . . . 33

U. S. Geological Survey . . . . . . . . . . . . . . . . . . . . 107, 123 
DePaolo, D. J.

Dixon, P. R.

Duba, A. G.

Durham, W. B.

Eberli, G.

Egbert, G. D.

Eglinton, T. I.

Eichelberger, J. C.

Elbring, G. J.

Elmore, R. D.

Epstein, S

Ernst, W. G.

Fabryka-Martin, J. T.

Farver, J. R.

Fearey, B. L.

Fehler, $M$.

Ferrell, R. E.

Foley, M. G.

Foote, H. P.

Fritz, S. J.

Gardner, J. N.

Gary, S. P.

Gisler, G. R.

Goff, F. E.

Goff, S. J.

Goldstein, N. E.

Goldstein, S. J.

Guthrie, G. D., Jr.

Hackett, W. R.

Hair, L. H.

Hanshaw, B.

Hanson, G. N.

Harrison, T. M.

Heasler, P. G.

Heiken, G.

Helgeson, C.

Hill, H. A.

Hirsch, L. M.

Holcomb, D. J.

Holt, B. D.

Hones, E. W., Jr.

Hoover, K. A.

Horita, J.

House, $L$.

Hulen, J. B.

Ilton, E. S.

Jacob, $\mathbf{K}$.

Jacobson, R.

Janecky, D. R.

Jiracek, G. R.

Johnson, P. A.
Lawrence Berkeley Laboratory . . . . . . . . . . . . . . . . . . 13

Los Alamos National Laboratory . . . . . . . . . . . . . . . . . . . 30

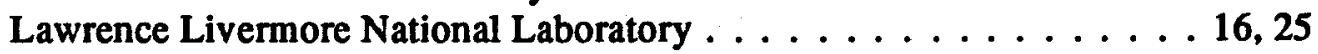

Lawrence Livermore National Laboratory . . . . . . . . . . . . . . . . . 17

University of Miami . . . . . . . . . . . . . . . . . 91

Oregon State University . . . . . . . . . . . . . . . . . . 106

Woods Hole Oceanographic Institution . . . . . . . . . . . . . . 134

University of Alaska . . . . . . . . . . . . . . . . . . 59

Sandia National Laboratories . . . . . . . . . . . . . . . 50

University of Oklahoma . . . . . . . . . . . . . . . . . . . . 104

California Institute of Technology . . . . . . . . . . . . . . 66

Standford University . . . . . . . . . . . . . . . . . . . . . 115

Los Alamos National Laboratory . . . . . . . . . . . . . . . . . 29

Brown University . . . . . . . . . . . . . . . . . 65

Los Alamos National Laboratory . . . . . . . . . . . . . . . . . 28

Los Alamos National Laboratory . . . . . . . . . . . . . . . . . 26, 27

Louisiana State University .................... 88

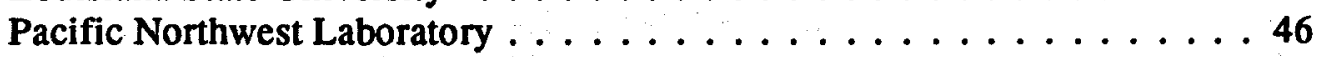

Pacific Northwest Laboratory . . . . . . . . . . . . . . . . 45,46

Purdue University . . . . . . . . . . . . . . . . . . . 110

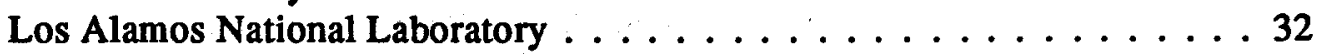

Los Alamos National Laboratory . . . . . . . . . . . . . . . . . 34

Los Alamos National Laboratory . . . . . . . . . . . . . . . . 35

Los Alamos National Laboratory . . . . . . . . . . . . . . . . . 33

Los Alamos National Laboratory . . . . . . . . . . . . . . . . . 32

Lawrence Berkeley Laboratory . . . . . . . . . . . . . . . . . 8

Los Alamos National Laboratory . . . . . . . . . . . . . . . . . 28

Los Alamos National Laboratory . . . . . . . . . . . . . . . . . . 29

Idaho National Engineering Labortory . . . . . . . . . . . . . . . 7

Lawrence Livermore National Laboratory . . . . . . . . . . . . . . . . 21

National Academy of Sciences . . . . . . . . . . . . . . . 93,94

State University of New York at Stony Brook . . . . . . . . . . . . 100

University of California at Los Angeles . . . . . . . . . . . . . 74

Pacific Northwest Laboratory . . . . . . . . . . . . . . . . . 46

Los Alamos National Laboratory . . . . . . . . . . . . . . . . . 33

University of California at Berkeley . . . . . . . . . . . . . . 69

University of Arizona ....................... 63

Lawrence Livermore National Laboratory . . . . . . . . . . . . . . 25

Sandia National Laboratories . . . . . . . . . . . . . 24,49,55

Argonne National Laboratory . . . . . . . . . . . . . . . . . 3,4

Los Alamos National Laboratory . . . . . . . . . . . . . . . . 34

Pacific Northwest Laboratory . . . . . . . . . . . . . . . . . 46

Oak Ridge National Laboratory . . . . . . . . . . . . . . . . 42

Los Alamos National Laboratory . . . . . . . . . . . . . . . 32

University of Utah Research Institute . . . . . . . . . . . 124, 125

The Johns Hopkins University . . . . . . . . . . . . . . . . 86

Columbia University . . . . . . . . . . . . . . . 82

Sandia National Laboratories . . . . . . . . . . . . . . . . 54

Los Alamos National Laboratory . . . . . . . . . . . . . . . . 30, 31

San Diego State University . . . . . . . . . . . . . . . . . . . 112

Lawrence Livermore National Laboratory . . . . . . . . . . . . 18, 25, 26 
Johnson, M. C. Jones, K. W. Joyce, D. B. Karlin, R.

Kasameyer, P. W.

Kharaka, Y.

Kleckner, E. W.

Krier, D.

Kronenberg, A. K.

Lambert, S. J.

Land, L. S.

Lamer, $\mathbf{K}$.

Larson, N. R.

Lasaga, A. C.

Lee, L. C.

Lee, $K$. H.

Lesher, C. E.

Lewis, C. H.

Lindquist, W. B.

Long, J. C. S.

Lysne, $P$.

Majer, E. L.

Mango, F.

Manowitz, B.

Mathez, E. A.

McDonald, J. A.

McEvilly, T. V.

McKeenan, K. D.

McTigue, D. F.

Mesmer, R. E.

Miller, D. G.

Morgan, D.

Morrison, H. F.

Morrison, H. F.

Murrell, M. T.

Musgrave, J.

Myer, L. R.

Myers, C.

Myers, W. P.

Nagy, P. B.

Navrotsky, A.

Noorishad, J.

Nur, A. M.

O'Connell, R. J.

Onstott, T. C.

Ortoleva, $\mathbf{P}$.

Palmer, D. A.

Papike, J. J.

Perry, D. L.

Philp, R. P.

Pickett, D. A.
Columbia University . . . . . . . . . . . . . . . 83

Brookhaven National Laboratory . . . . . . . . . . . . . . 6

Oak Ridge National Laboratory . . . . . . . . . . . . . . . . . . 40

University of Nevada, Reno . . . . . . . . . . . . . . . . . 98

Lawrence Livermore National Laboratory . . . . . . . . . . . . . . . . . . . . . . . . . . .

WRI-7 Organizing Committee . . . . . . . . . . . . . . . 136

Pacific Northwest Laboratory . . . . . . . . . . . . . . . . 45,46, 47

Los Alamos National Laboratory . . . . . . . . . . . . . . . 33

Texas A\&M University . . . . . . . . . . . . . . . . . . . 119

Sandia National Laboratories . . . . . . . . . . . . . . . 53

The University of Texas at Austin . . . . . . . . . . . . . . 120

Colorado School of Mines . . . . . . . . . . . . . . . . . . . 79

Pacific Northwest Laboratory . . . . . . . . . . . . . . . . . . 47

Yale University . . . . . . . . . . . . . . . . . . . . 137

University of Alaska . . . . . . . . . . . . . . . . . 60

Lawrence Berkeley Laboratory . . . . . . . . . . . . . . . . . 8

University of California at Davis ................ . . 72

Argonne National Laboratory . . . . . . . . . . . . . . . . 3

State University of New York at Stony Brook . . . . . . . . . . . 6, 101

Lawrence Berkeley Laboratory . . . . . . . . . . . . . . . . 10

Sandia National Laboratories . . . . . . . . . . . . . . . . 54

Lawrence Berkeley Laboratory . . . . . . . . . . . . . . . . . . . . . . . . . . . . . . . . . . . . .

Rice University . . . . . . . . . . . . . . . . . . . 111

Brookhaven National Laboratory . . . . . . . . . . . . . . . 5

American Museum of Natural History . . . . . . . . . . . 66 61

University of Houston . . . . . . . . . . . . . . . . 87

Lawrence Berkeley Laboratory . . . . . . . . . . . . . . . . 9, 10, 11, 15

University of California at Los Angeles . . . . . . . . . . . . 19,75

Sandia National Laboratories . . . . . . . . . . . . . . . . 54

Oak Ridge National Laboratory . . . . . . . . . . . . . . . . . . 38

Lawrence Livermore National Laboratory . . . . . . . . . . . . . . . 21

Transylvania University . . . . . . . . . . . . . . . . . . . . . . . . . . . . . . . . . . . . . . .

Lawrence Berkeley Laboratory . . . . . . . . . . . . . . . . . . . . . . . . . . . . . . . . . . . . . . .

University of California at Berkeley . . . . . . . . . . . . 70

Los Alamos National Laboratory . . . . . . . . . . . . . . . . . . . 28

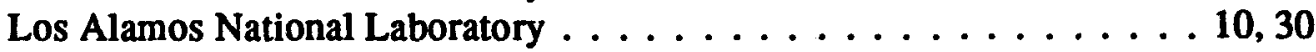

Lawrence Berkeley Laboratory . . . . . . . . . . . . . . . . . 9

Los Alamos National Laboratory . . . . . . . . . . . . . . . . . 35

Los Alamos National Laboratory . . . . . . . . . . . . . . . . . . 30

The Ohio State University . . . . . . . . . . . . . . . . . . . . . . 102

Princeton University . . . . . . . . . . . . . . . . . . . 108

Lawrence Berkeley Laboratory . . . . . . . . . . . . . . . . 11

Standford University . . . . . . . . . . . . . . . . . . . . . 116

Harvard University . . . . . . . . . . . . . . . . . 18, 26

Princeton University . . . . . . . . . . . . . . . . . . . . 109

Indiana University . . . . . . . . . . . . . . . . 85

Oak Ridge National Laboratory . . . . . . . . . . . . . . . . 38

University of New Mexico . . . . . . . . . . . . . . . . . . 97

Lawrence Berkeley Laboratory . . . . . . . . . . . . . . . . . 12

University of Oklahoma . . . . . . . . . . . . . . . . . 105

Los Alamos National Laboratory . . . . . . . . . . . . . . . 28 
Pitzer, K. S. Pollard, D. D. Rard, J. A. Raymond, R., Jr. Reeves, G. D. Reidel, S. P. Reimers, C. E. Reneau, S. L. Reynolds, J. G. Reynolds, J. H. Riciputi, L. Rock, P. A. Rogers, P. S. Z. Rokop, D. J. Rundle, J. B. Russell, J. E. Rye, D. M. Ryerson, F. J. Sackett, W. M. Sahagian, D. Sattler, A. Schimmelmann, A. Schreiber, B. C. Schroeder, N. C. Schwandt, C. S. Segall, P. Seitz, J. C. Shankland, T. J. Sharp, J. M. Shaw, H. F. Shearer, C. K. Shock, E. L. Sinha, A. K. Slater, D. W. Smith, J. V. Smyth, J. R. Spera, F. J. Spetzler, H. Stockman, H. W. Stopler, E. Sturchio, N. C. Swanson, S. E. Swart, P. K. Sweeney, J. J. Tait, C. D. Teufel, L. M Tissue, B. M. Toksoz, M. N. Tsang C.-F. Turpening, $\mathbf{R}$. Usselman, $T$.
Lawrence Berkeley Laboratory . . . . . . . . . . . . . . . . . 12

Stanford University . . . . . . . . . . . . . . . . . . 117

Lawrence Livermore National Laboratory . . . . . . . . . . . . . . . 21

Los Alamos National Laboratory . . . . . . . . . . . . . . . . . 29

Los Alamos National Laboratory . . . . . . . . . . . . . . . . . 34

Washington State University . . . . . . . . . . . . . . . . 130

University of California at San Diego . . . . . . . . . . . . . 76

Los Alamos National Laboratory . . . . . . . . . . . . . . . . . 29

Lawrence Livermore National Laboratory . . . . . . . . . . . . . . 21

University of California at Berkeley .............. 71

Oak Ridge National Laboratory . . . . . . . . . . . . . . . 43

University of California at Davis . . . . . . . . . . . . 73

Los Alamos National Laboratory . . . . . . . . . . . . . 28

Los Alamos National Laboratory . . . . . . . . . . . . . . . . . . . . . . . . . . . . . . . . . . . .

Lawrence Livermore National Laboratory . . . . . . . . . . . . . 20, 24, 25

Texas A\&M University . . . . . . . . . . . . . . . . . . 119

Yale University . . . . . . . . . . . . . . . . . . . . . . 137

Lawrence Livermore National Laboratory . . . . . . . . . . . 16, 19, 20, 22

University of South Florida . . . . . . . . . . . . . . . . 114

Ohio State University . . . . . . . . . . . . . . . 103

Sandia National Laboratories . . . . . . . . . . . . . . . . . 54

University of California at San Diego . . . . . . . . . . . . 76

City University of New York, Queens College . . . . . . . . . . . . . . 99

Los Alamos National Laboratory . . . . . . . . . . . . . . . . . 29

Sandia National Laboratories . . . . . . . . . . . . . . . 52

Stanford University . . . . . . . . . . . . . . . . . . . 54118

Oak Ridge National Laboratory . . . . . . . . . . . . . . . . . . . . 40

Los Alamos National Laboratory . . . . . . . . . . . . . . . 16, 18, 25, 26

University of Texas, Austin . . . . . . . . . . . . . . . 121

Lawrence Livermore National Laboratory . . . . . . . . . . . . . . . . 22

University of New Mexico . . . . . . . . . . . . . . . . . . 97

Washington University . . . . . . . . . . . . . . . . 132

Virginia Polytechnic Institute \& State Univer. . . . . . . . . . . . . . 128

Pacific Northwest Laboratory . . . . . . . . . . . . . . . . . . . . 47

The University of Chicago ... . . . . . . . . . . . 78

University of Colorado ... . . . . . . . . . . . . . 80

University of California at Santa Barbara . . . . . . . . . . . . . 77

University of Colorado ...................81

Sandia National Laboratories . . . . . . . . . . . . . . . . 50

California Institute of Technology . . . . . . . . . . . . 66

Argonne National Laboratory . . . . . . . . . . . . . . . . 3,4

University of Alaska . . . . . . . . . . . . . . . . . 59

University of Miami . . . . . . . . . . . . . . . 91

Lawrence Livermore National Laboratory . . . . . . . . . . . . . 21

Los Alamos National Laboratory . . . . . . . . . . . . . . . . 31

Sandia National Laboratories . . . . . . . . . . . . . . 24,51,55

Los Alamos National Laboratory . . . . . . . . . . . . . . . . . . 28

Massachusetts Institute of Technology . . . . . . . . . . . . . . 89,90

Lawrence Berkeley Laboratory . . . . . . . . . . . . . . . . . . . . 11

Massachusetts Institute of Technology . . . . . . . . . . . . . 50,90

National Academy of Sciences . . . . . . . . . . . . . . . 93 
Vairavamurthy, A. Veblen, D. R.

Volpe, A. M.

Walck, M. C.

Walker, D

Walsh, $\mathbf{M}$.

Wang, H. F.

Wannamaker, P. E.

Wasserberg, G. J.

Wawersik, W. R.

Wesolowski, D. J.

Westrich, H. R.

Whelan, J. K.

Williams, L. B.

Williams, R. T.

Wilt, $M$.

Wogelius, R. A.

Wolery, $T$.

Wolf, L: W.

Wollenberg, H. A.

Wood, K. H.

Wukelic, G. E.

Yuen, D. A.

Yund, R. A.

Zandt, G.
Brookhaven National Laboratory . . . . . . . . . . . . . . . . 5

The Johns Hopkins University . . . . . . . . . . . . . . . . 86

Los Alamos National Laboratory . . . . . . . . . . . . . . . . . 28

Sandia National Laboratories . . . . . . . . . . . . . . 49,52,54

Columbia University . . . . . . . . . . . . . . . . . 83

Louisiana State University $\ldots \ldots \ldots$. . . . . . . . . . 88

University of Wisconsin . . . . . . . . . . . . . . 133

University of Utah Research Institute . . . . . . . . . . . . . . . 126

California Institute of Technology . . . . . . . . . . . . . 67

Sandia National Laboratories . . . . . . . . . . . . . . 24,51,55

Oak Ridge National Laboratory . . . . . . . . . . . . . . . 38,42,43

Sandia National Laboratories . . . . . . . . . . . . . . . . 52,53

Woods Hole Oceanographic Institution . . . . . . . . . . . . 135

Arizona State University . . . . . . . . . . . . . . . . . 64

Oak Ridge National Laboratory . . . . . . . . . . . . . . . . 37

Lawrence Livermore National Laboratory . . . . . . . . . . . . . . . . 22

Argonne National Laboratory . . . . . . . . . . . . . . . . . 4

WRI-7 Organizing Committee . . . . . . . . . . . . . . . 136

National Academy of Sciences . . . . . . . . . . . . . . . . . . 94

Lawrence Berkeley Laboratory . . . . . . . . . . . . . . . . . . . 14

University of Delaware . . . . . . . . . . . . . . . . . . 84,132

Pacific Northwest Laboratory . . . . . . . . . . . . . . . . . . 45

University of Minnesota . . . . . . . . . . . . . . . . 92

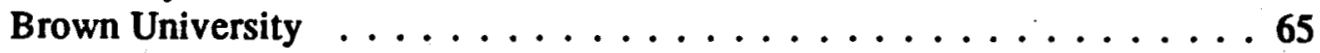

Lawrence Livermore National Laboratory . . . . . . . . . . . . . 17 